\title{
La infodiversidad y el uso ético del conocimiento individual y colectivo
}

Estela Morales Campos

(Coordinadora)

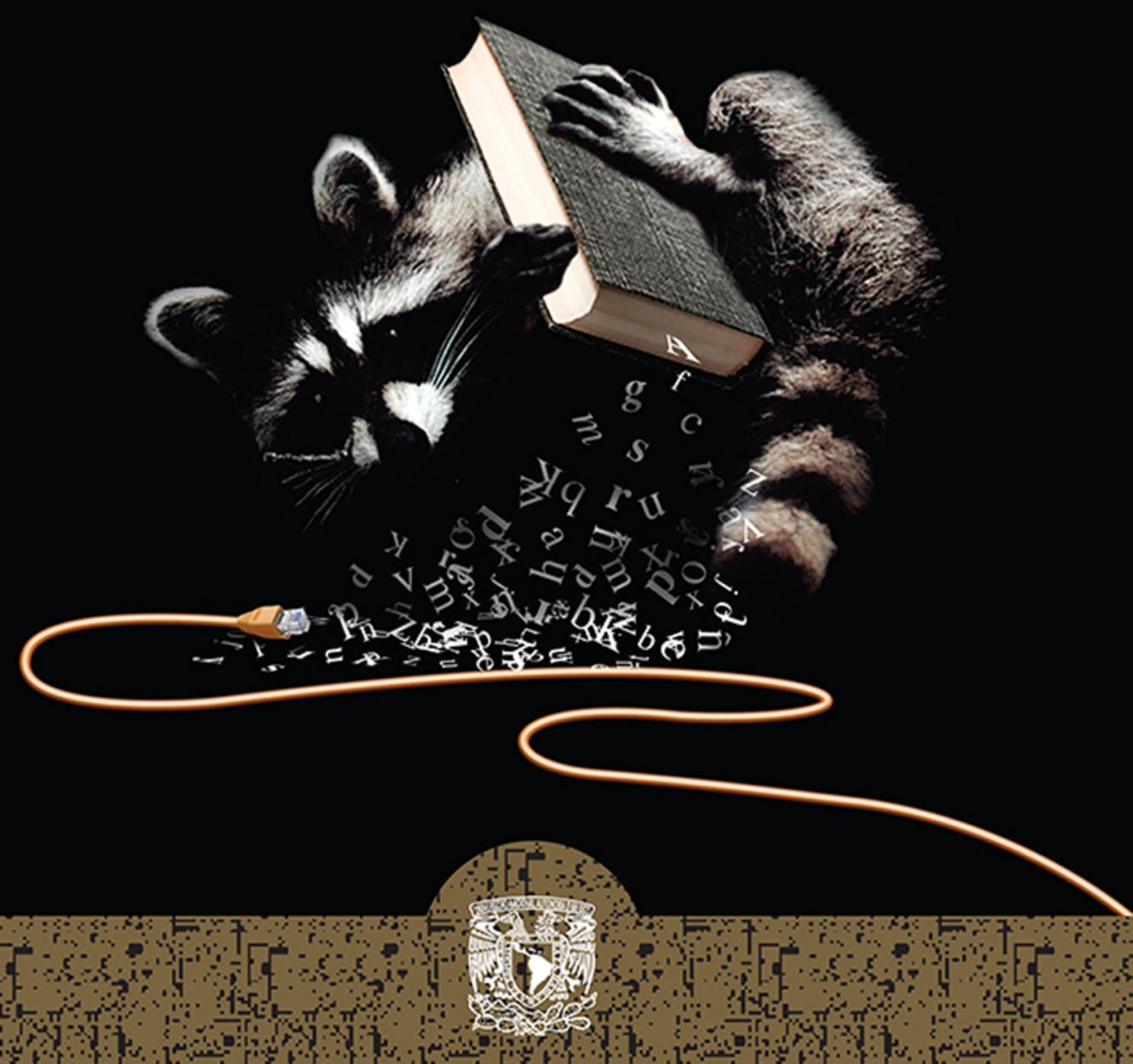




\section{La presente obra está bajo una licencia de:}

\section{http://creativecommons.org/licenses/by-nc-sa/3.0/deed.es MX}

\section{Atribución-No Comercial-Licenciamiento Reciproco 3.0 Unported}

Eres libre de:

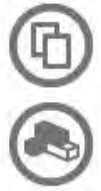

copiar, distribuir y comunicar públicamente la obra

hacer obras derivadas

Bajo las condiciones siguientes:

Atribución - Debes reconocer la autoría de la obra en los términos

especificados por el propio autor o licenciante.

No comercial - No puedes utilizar esta obra para fines comerciales.

Licenciamiento Recíproco - Si alteras, transformas o creas una obra a

partir de esta obra, solo podrás distribuir la obra resultante bajo una licencia

igual a ésta.

\section{Esto es un resumen fácilmente legible del: texto legal (de la licencia completa)}

En los casos que sea usada la presente obra, deben respetarse los términos especificados en esta licencia.
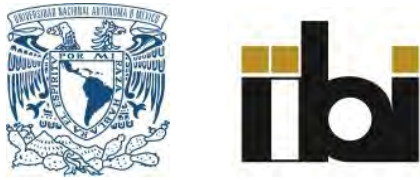
La Infodiversidad y el uso ético del conocimiento individual y colectivo 


\section{COLECCIÓN}

BIBLIOTECOLOGÍA, INFORMACIÓN Y SOCIEDAD

Instituto de Investigaciones Bibliotecológicas y de la Información 


\title{
La Infodiversidad y el uso ético del conocimiento individual y colectivo
}

\author{
Coordinadora \\ Estela Morales Campos
}

Universidad Nacional Autónoma de México 2017 


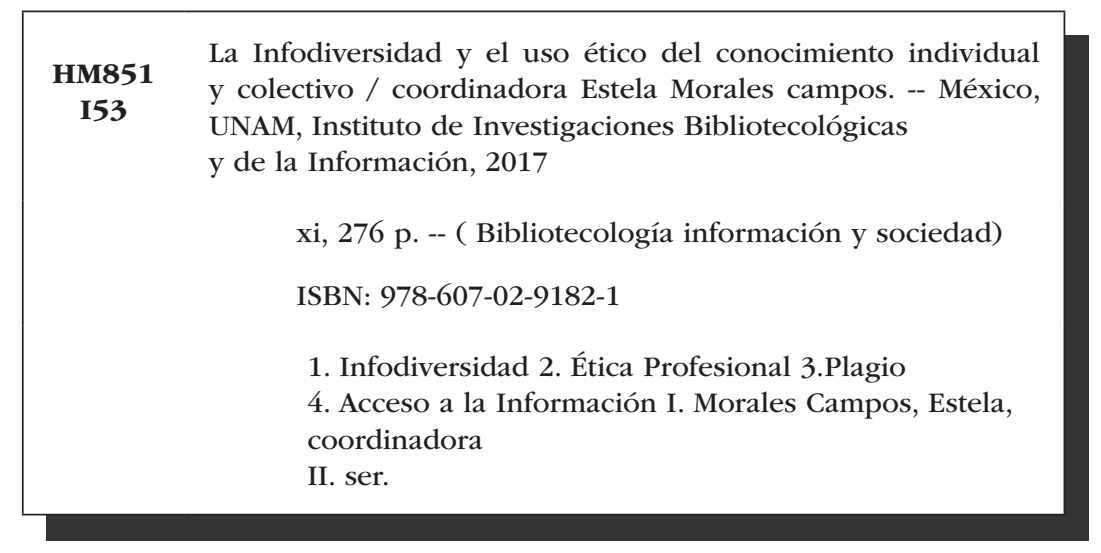

Diseño de portada: Mario Ocampo Chávez

Primera Edición 2017

DR (C) Universidad NaCiOnal AuTónOma de MéXICO

Ciudad Universitaria, 04510, Ciudad de México

Impreso y hecho en México

ISBN: 978-607-02-9182-1

Publicación dictaminada 


\title{
Tabla de contenido
}

Presentación ..........................

Estela Morales Campos

\author{
ÉTICA E INFORMACIÓN
}

UN PAPEL PARA LA ÉTICA EN LA COMUNICACIÓN ACADÉMICA

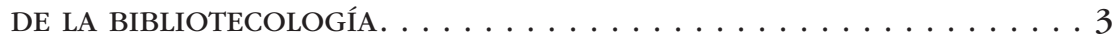

Jaime Ríos Ortega

EL USO ÉTICO DE LA INFORMACIÓN ANTE LAS FACILIDADES

SOCIALES DE SU LIBRE ACCESO. . . . . . . . . . . . . . . . . . . . . 29

Estela Morales Campos

LA ÉTICA CIUDADANA FRENTE AL RESPETO DE LOS SABERES

INDIVIDUALES Y COLECTIVOS . . . . . . . . . . . . . . . . . 55

Alejandro Ramos Chávez

LA ESCRITURA ACADÉMICA Y LOS CÓDIGOS DE ÉTICA EN EL AULA: EL PAPEL DEL DOCENTE FRENTE AL PLAGIO ACADÉMICO . . . . . 75

José Alfredo Verdugo Sánchez

\section{DERECHO A LA INFORMACIÓN Y ACCESO A LA INFORMACIÓN}

EL DERECHO DE AUTOR Y EL DERECHO DE ACCESO A LA INFODIVERSIDAD . . . . . . . . . . . . . . . . . . . . . . . 89

Rosa María Martínez Rider, Adriana Mata Puente, Eduardo Oliva Cruz

¿HASTA DÓNDE LA CREATIVIDAD INTELECTUAL Y EL ACCESO ABIERTO A LA INFORMACIÓN ATENTAN CONTRA EL DERECHO DE AUTOR? . . . . . . . . . . . . . . . . . . . . . . . . 105

Jesús Francisco García Pérez 
LA MÁQUINA DE LA CREATIVIDAD Y LA COPIA: INTERNET Y EL

DILEMA DE LOS DERECHOS DE AUTOR. . . . . . . . . . . . . . . . . 125

Jonathan Hernández Pérez

EN BUSCA DEL EQUILIBRIO ENTRE PROPIEDAD INTELECTUAL

Y ACCESO A LA INFORMACIÓN Y AL CONOCIMIENTO . . . . . . . . . . . . 141

Hugo Alberto Figueroa Alcántara

LOS DERECHOS DE AUTOR DE LOS ARCHIVOS SONOROS EN LA

ERA DE LA INFORMACIÓN $\ldots \ldots \ldots \ldots \ldots \ldots \ldots$

Perla Olivia Rodríguez Reséndiz

\section{LA ACADEMIA Y EL USO DE LA INFORMACIÓN}

EL PLAGIO, UN ACTO DE DESHONESTIDAD INTELECTUAL

Y UNA FALTA DE RESPETO AL TRABAJO DEL OTRO . . . . . . . . . . 193

Beatriz Casa Tirao

LA EDUCACIÓN BIBLIOTECOLÓGICA EN MÉXICO ANTE EL PLAGIO . . . . 209 María Graciela Martha Técuatl Quechol

ALFABETIZACIÓN INFORMATIVA COMO APOYO PARA EVITAR

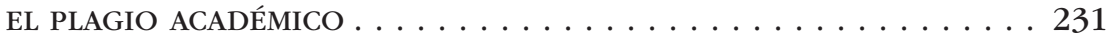

Celia Mireles Cárdenas

ESTRATEGIAS Y HERRAMIENTAS TECNOLÓGICAS PARA EVITAR

EL PLAGIO ACADÉMICO . . . . . . . . . . . . . . . . . . . . . . 253

Andrés Fernández Ramos 


\section{Presentación}

$7 \mathrm{n}$ años recientes hemos leído en medios tanto impresos como digitales, con mucha frecuencia, notas que denuncian que se ha descubierto que algún escritor, profesor, investigador o estudiante han usado algunas ideas, párrafos y hasta páginas de otro autor y que, lamentablemente, el escritor objeto de la denuncia no le dio crédito al autor original con la cita correspondiente.

La reiterada situación de uso indebido de textos o ideas -que puede configurar un hecho de fraude o de plagio, o de una mala conducta en el trabajo académico, en un proceso de creación de conocimiento que se ofrece como nuevo aporte a la ciencia- genera una circunstancia difícil. Lo anterior cuestiona la honestidad con la que se desarrolla el trabajo académico y la integridad del autor respecto a su poca responsabilidad ética ante el proceso investigativo, así como ante la formación de jóvenes al darles un mal ejemplo consumando esos fraudes académicos de forma muy ligera, 
La Infodiversidad y el uso ético del conocimiento...

además de no revisarles sus textos de clase, sus publicaciones o sus tesis.

El fenómeno de un mal uso de la información - esa falta de valores éticos en el uso de la información, en la historia de los pueblos, sobre todo en la historia de los pueblos letrados- no es nuevo, ni es una característica de este siglo. Podríamos encontrar fraudes, plagios, versiones apócrifas, textos adulterados de los cuales hay registros bien documentados que dan fe del mal uso de los textos originales, desde que los pueblos hicieron uso del alfabeto para dejar huella de su pensamiento, de sus sentimientos, de sus conocimientos y de hechos relevantes.

¿Por qué en nuestros días parece que el problema del mal uso de información ajena o la apropiación de información de otro autor crece, se hace pública y lo vemos de manera cotidiana? Podríamos citar varias causas porque, en efecto, puede tratarse de un problema multicausal; mencionaremos algunos motivos, como:

a) El crecimiento de la nómina de profesores-investigadores, y la inscripción de estudiantes universitarios que son generadores en potencia de nuevo conocimiento y de textos académicos que se hacen públicos.

b) El empleo masivo de las Tecnologías de la Información y la Comunicación (TIC) como apoyo al registro de información, y como el gran facilitador para su uso en diferentes formatos, así como diferentes posibilidades de jugar con el texto requerido, ya sea para modificarlo, trasmitirlo o presentarlo en diferentes formatos.

c) La exigencia académica de presentar periódicamente textos (artículos, reportes, libros) que prueben la 
productividad de profesores-investigadores y, en su caso, de los estudiantes.

d) El sistema de evaluación académica asociado a una contraprestación económica, que se traduciría en una ecuación "perversa" donde, a mayor producción en cuanto a cantidad y calidad, se recibiría un mayor estímulo económico, además de otras distinciones y halagos importantes en el medio académico (situación que ocurre en México y otros países del mundo).

e) En la evaluación de alumnos, el "premio" es una calificación y la formación de un prestigio y la posibilidad de participar en otras publicaciones y/o proyectos de investigación al abrigo de sus profesores.

f) Construir un curriculum académico "abultado" de manera muy rápida con poco esfuerzo.

Si todos estos elementos se combinan con malas prácticas académicas, con una deficiente formación educativa, con ausencia de valores éticos en el uso de la información, así como falta de respeto al otro y al trabajo del otro, los resultados serán catastróficos respecto a las conductas sociales y éticas que permitirían la conciencia en una sociedad con normas y principios, como supuestamente son los actuales grupos humanos que conviven en un colectivo de investigación, en una universidad, en una comunidad, en un pueblo, en una ciudad, o en un país.

La proliferación del uso inadecuado de la información que propicia fraudes y plagios* de textos, en la actualidad, es una gran preocupación de las universidades que forman a las jóvenes generaciones y que, asimismo, producen un alto porcentaje de la investigación y la creación de nuevo

* La ley de derechos de autor no usa este término. 
La Infodiversidad y el uso ético del conocimiento...

conocimiento, así como también de los centros de investigación, los consejos de ciencia y las asociaciones disciplinarias. Por tal razón, especialistas de varios campos han puesto interés en estudiar el fenómeno, buscar sus causas y proponer medidas que inhiban la tentación de usar indebidamente información ajena sin el respeto y la citación correspondiente. Entre estos profesionales podemos mencionar a los filósofos, los abogados, los pedagogos, los comunicólogos y, por supuesto, los bibliotecólogos.

Los bibliotecólogos, entre sus más importantes tareas, tienen la de formar usuarios de información, educarlos para moldear actitudes, habilidades y criterios; enseñan no sólo cómo encontrar la información adecuada, sino cómo usarla y para qué usarla. Siendo una de las más importantes responsabilidades del bibliotecólogo la relación con el usuario y su interacción con la información, el seminario de Bibliotecología, Información y Sociedad, durante 2016, abordó como tema de trabajó "El uso ético de la información".

El Seminario convocó a cuatro sesiones de trabajo interno a fin de discutir los alcances de los aspectos y temas a tratar durante las diferentes reuniones del año. Se estudiaron dos grandes temas: a) "La Infodiversidad y el uso ético del conocimiento individual y colectivo" y b) El uso ético de la información y la práctica del libre acceso”. Las discusiones generales se dieron en las reuniones cerradas, donde se seleccionaron los temas específicos que desarrollaría cada uno de los miembros del grupo de investigación. Al tener dos grandes temas a estudiar, se contó con las sedes correspondientes para presentar los avances de cada uno de los trabajos individuales, una de cuales fue la Facultad de Ciencias de la Información de la Universidad Autónoma de San Luis Potosí. 
En esta obra colectiva presentamos los capítulos que se trabajaron durante el primer semestre y que tuvieron su primera discusión abierta entre especialistas invitados y público interesado los días 2 y 3 de marzo de 2016 en las instalaciones de la propia Facultad de Ciencias de la Información. Se presentan 13 contribuciones sobre el uso ético de la información, las cuales se agruparon en tres grandes capítulos: a) Ética e Información; b) Derecho de autor y acceso a la información, y c) La academia y el uso de la Información.

Esta obra es una invitación a conocer diferentes puntos de vista sobre un tema de actualidad que está demandando nuestra atención, a fin de tener más ideas que nos permitan influir en la actitud de nuestros usuarios respecto al empleo responsable de la información, el respeto a los otros autores y el conocimiento de las normas éticas y legales.

Estela Morales Campos 
Ética e información 


\title{
Un papel para la ética en la comunicación académica de la bibliotecología
}

\author{
JAIME RÍOS ORTEGA \\ Universidad Nacional Autónoma de México
}

\begin{abstract}
$7 \mathrm{n}$ este trabajo me propongo mostrar que es fundamental para los bibliotecólogos, en ejercicio y en formación, analizar a fondo los siguientes conceptos: normas éticas, comunicación científica, ethos académico, responsabilidad y prácticas académicas responsables. Este análisis es crucial debido a las repercusiones negativas que se constatan en la formación de los estudiantes de pregrado y posgrado, así como en la práctica profesional de la disciplina. Por otra parte, se sostiene que debido a la naturaleza del dominio cognoscitivo de los bibliotecólogos sobre el registro bibliográfico se matiza la importancia de la disciplina bibliotecológica para la sociedad y, en particular, la academia. El trabajo se divide en dos partes; en la primera hablo sobre las normas éticas del trabajo científico y en la segunda trato aspectos sobre la bibliotecología, el ethos y los retos.
\end{abstract}

NORMAS ÉTICAS DEL TRABAJO CIENTÍFICO

Comienzo por citar a Christine Korsgaard, quien señala: "Nietzsche tenía razón cuando les advirtió a los enemigos 
La Infodiversidad y el uso ético del conocimiento...

de la obligación que se guardaran de tenerla en poco por el hecho de ser fea y dolorosa, pues la obligación es lo que nos hace humanos". (Korsgaard, 2000: 17)

Podemos observar y comprobar a cada momento que prácticamente la normatividad, entendida como las obligaciones a las cuales estamos sujetos, regula nuestros modos de ser y de actuar en nuestras vidas; escapar de la obligación a través de los medios de que disponga el individuo socava las formas de convivencia. Por lo anterior, resulta necesario dedicar tiempo y esfuerzo racional para comprender de dónde provienen los valores que guían o exigen el actuar de los seres humanos que conviven en sociedad.

Para el caso de la comunicación científica o académica, las normas que regulan la acción de los sujetos inmersos en dicha comunicación han sido estudiadas y explicitadas. Sin embargo, particularmente me interesa referirme a un artículo de investigación que el sociólogo Robert K. Merton publicó en 1942, con el título Science and Democratic Social Structure, traducido de modo afortunado - para el propósito de esta exposición- como La estructura normativa de la ciencia.

Merton propone que para los hombres dedicados a la ciencia existe un ethos, el cual es "[...] ese complejo, con resonancias afectivas, de valores y normas que se consideran obligatorias". (Merton, 1977: 357) Como complemento de tal explicación, conviene recurrir al significado de esta palabra que propone la Real Academia Española: "Conjunto de rasgos y modos de comportamiento que conforman el carácter o la identidad de una persona o una comunidad". De acuerdo con las dos definiciones anteriores, destacan los términos valor, norma, obligación, comportamiento e identidad; con excepción de este último, estamos refiriéndonos a reglas éticas que son normativas. 
Antes de centrarme en el ethos que expone Merton, y para efecto de clarificar cuanto me sea posible la relevancia de las reglas normativas, de nueva cuenta cito a Christine Korsgaard, quien destaca la naturaleza de las mismas y las explica del siguiente modo:

No simplemente describen la manera como de hecho regulamos nuestra conducta, sino que nos hacen exigencias: ordenan, obligan, recomiendan o guían; al menos, cuando las invocamos, nos exigimos unas cosas los unos a los otros. Cuando digo que una acción es correcta estoy diciendo que deberías hacerla; cuando digo que algo es bueno lo estoy recomendando como digno de tu elección. (Korsgaard, 2000: 21)

Esta autora también indica que "[...] conceptos como conocimiento, belleza y significado, así como virtud y justicia, tienen una dimensión normativa, pues nos indican qué pensar, de qué gustar, qué hacer y qué ser". (Korsgaard, 2000: 21) Hecha esta aclaración, ahora sí, es preciso referir los cuatro conjuntos de imperativos institucionales que según Merton componen el ethos de la ciencia moderna: 1. Universalismo, 2. Comunismo, 3. Desinterés y 4. Escepticismo organizado. El primero de ellos se refiere a que todas las pretensiones de verdad, cualquiera que sea su fuente, deben ser sometidas a criterios impersonales preestablecidos; en este sentido, universalismo significa objetividad. El segundo considera que los hallazgos de la ciencia "[...] son un producto de la colaboración social y son asignados a la comunidad." (Merton, 1977: 362) En consecuencia, de este comunismo se desprende el imperativo de la comunicación de los hallazgos. Así pues, dice Merton:

El secreto es la antítesis de esta norma; la comunicación plena y abierta es su cumplimiento. La presión para la difusión de los resultados es reforzada por el objetivo institucional de dilatar los 
La Infodiversidad y el uso ético del conocimiento...

límites del conocimiento y por el incentivo del reconocimiento que, claro está, depende de la publicación. (Merton, 1977: 364)

En cuanto al "desinterés", el autor citado expresa que debe entenderse como un elemento institucional básico y circunscrito al carácter público de la ciencia que obliga a los científicos a rendir cuentas ante sus iguales. Es decir, al ser verificables los resultados siempre se está bajo el examen riguroso de otros colegas. El cumplimiento de esta norma proporciona en gran medida estabilidad institucional a la ciencia. Por último, el escepticismo organizado describe una conducta personal e institucional, orientada a no preservar el abismo entre lo sagrado y lo profano, "[...] entre lo que exige respeto acrítico y lo que puede ser analizado objetivamente." (Merton 1977, 368)

Del año 1942 a la fecha han transcurrido 75 años y el progreso de las ciencias, las ciencias aplicadas y sus productos tecnocientíficos son inconmensurables. Sin embargo, y aunque es un hecho que las formas de producción científica también se han transformado considerablemente, no creo que sea suficiente para afirmar que este ethos haya perdido su valor explicativo para comprender a la ciencia como una institución pública. Antes bien, deberá profundizarse en ellos y, si fuera el caso, fortalecer el sentido imperativo con el cual lo expuso Merton.

\section{LA BIBLIOTECOLOGÍA, EL ETHOS Y LOS RETOS}

La bibliotecología es parte de la ciencia mundial y es un contrasentido pensar que ha progresado al margen de las normas éticas que exige la construcción del conocimiento avanzado. Por lo anterior, el título de esta exposición es totalmente retórico y provocador, ya que simplemente no 
existiría la bibliotecología como una disciplina certificada en la ciencia moderna si no se hubiera desarrollado sobre la base de las normas éticas intrínsecas al conocimiento científico. Los argumentos esgrimidos por los autores citados con antelación nos permiten deducirlo fácilmente.

Sin embargo, me interesa argüir en mi defensa respecto al título de este trabajo que la razón de redactarlo de ese modo también me daba la ventaja de llamar la atención sobre conceptos que son comunes en nuestro lenguaje académico, pero totalmente descuidados en su enseñanza y en su práctica profesional. Por ello, tal vez sea momento de integrar en la formación de los alumnos contenidos de clara orientación ética cuya apropiación los ayude a conducirse con normas de valor universal y los integre en pensamiento y acción a identidades prácticas propias de la bibliotecología, con base en la comprensión y estudio de la genealogía de las normas éticas de la ciencia y de la bibliotecología, incluidas las de la academia.

Dicho de otro modo: idealmente me interesa proponer que nuestros estudiantes y egresados sean capaces de identificar y comprender los valores en que se sustenta la bibliotecología, en cuanto a la génesis de tales prácticas normativas y sus consecuencias. Para dar precisión y fijar el alcance de este ideario revisemos dos escenarios, uno académico y el otro profesional.

\section{Escenario 1}

- El estudiante de bibliotecología sabe, por experiencia, que si no entrega tareas es candidato inminente a reprobar.

- Que si reprueba continuamente puede ser expulsado. 
La Infodiversidad y el uso ético del conocimiento...

- Que si copia o plagia también reprueba, aunque no necesariamente amerita la expulsión.

- También sabe que los docentes pueden ser indiferentes a estas prácticas.

- En consecuencia, el estudiante sabe, por experiencia, que no entregar tareas, copiar o plagiar, e incluso reprobar, no necesariamente tiene consecuencias drásticas y, las más de las veces, no es sancionado.

Lo anterior, en términos pedagógicos, es parte del curriculum oculto y se ha sostenido que dicho curriculum constituye el aprendizaje sólido y perdurable de los estudiantes.

\section{Escenario 2}

- El profesional en práctica no conoce los códigos de ética, pero no es impedimento para trabajar en una institución como la biblioteca.

- El profesional en práctica aplica en el mínimo necesario los códigos de ética de la profesión, pero eso no tiene consecuencias.

- Los códigos de ética de la profesión no necesariamente están integrados a las normas institucionales de trabajo (ejemplo: si hay violaciones a la privacidad de datos de un usuario, no pasa nada).

- El profesional o el docente ha publicado exitosamente trabajos con plagio.

- El profesional o el docente son, en la práctica, indiferentes ante las necesidades de los usuarios o los alumnos, pero eso no tiene implicaciones institucionales. 
Un papel para la ética en la comunicación académica...

En términos de desarrollo institucional, lo anterior se denomina premiar la ineficiencia y los estudiosos del tema aseguran que es más usual de lo que se podría imaginar.

Por supuesto, remontar estos escenarios nos conduce a pensar seriamente las características del indisoluble nexo entre la formación, por una parte, y su ejercicio académico y profesional, por la otra. Por ello, si tomamos en consideración los perfiles de egreso de nuestras escuelas de bibliotecología, aparentemente no debería existir preocupación con respecto al académico y al ejercicio profesional; sin embargo, el diagnóstico de la dura realidad lanza alertas constantes respecto a los perfiles esperados y los desempeños concretos de los estudiantes y profesionales.

Se ha demostrado filosóficamente que los seres humanos no podemos vivir sin un sentido práctico de identidad y que gran parte de esta última se construye a partir de las exigencias normativas para la acción. Con base en esta proposición podemos abordar de un modo distinto la identidad práctica de los bibliotecólogos. Aclaro que no estoy en el terreno de la imagen pública de nuestra profesión, ya que mi preocupación está centrada en la incorporación de las normas prácticas de la bibliotecología como fundamento del quehacer profesional y académico. Por lo anterior, es deseable tratar de acercarnos completamente, es decir, con certeza y evidencia, a que lo expuesto en los perfiles de egreso corresponde y distingue a nuestros estudiantes y profesionales de la bibliotecología.

Así, pues, si observamos con cuidado, y con independencia de declararnos documentalistas, bibliotecólogos, científicos de la información o cualquier otra denominación emparentada, nuestra disciplina posee una perspectiva privilegiada de la interacción entre la información y la sociedad a través de los circuitos de comunicación basados en la 
La Infodiversidad y el uso ético del conocimiento...

información socialmente valiosa, los cuales están organizados en torno a la ciencia, la academia, el Estado y las múltiples comunidades que componen la sociedad.

La perspectiva privilegiada debe este adjetivo, por ejemplo, al hecho siguiente: el bibliotecólogo profesional trabaja con citas y referencias, con normas de publicación y arbitraje, con repertorios bibliográficos, además de estándares de registro y recuperación de información, o bien, con normas para la producción y circulación de recursos de información. Sin embargo, estos contenidos, que son aprendidos como reglas o prescripciones, requieren de un contexto de justificación teórica que explique su origen y evolución, así como las consecuencias de su cumplimiento o ausencia. Al agregar el contexto de justificación teórica para dar razón de ser a los contenidos también se tiene una ganancia cognoscitiva de comprensión sobre su naturaleza y perfeccionamiento.

Un ejercicio sencillo puede ayudar para ejemplificar la propuesta. Se trata del Código de ética de la IFLA para bibliotecarios y otros trabajadores de la información, publicado en 2012; se compone de los seis rubros sustantivos siguientes:

1. Acceso a la información.

2. Responsabilidades hacia las personas y la sociedad.

3. Privacidad, confidencialidad y transparencia.

4. Acceso abierto y propiedad intelectual.

5. Neutralidad, integridad personal y habilidades profesionales.

6. Relación de colegas y empleador/empleado. (IFLA, 2012)

El trabajo con este código dentro del aula, así como en las actividades de educación continua de los bibliotecólogos en ejercicio profesional, consistirá en contestar con argumentos académicos sólidos las preguntas siguientes: 
1. ¿Cuál es la situación que se presenta en el país o mi entorno con respecto a cada uno de los conceptos incluidos en cada rubro?

2. ¿Cuáles son las obligaciones y conductas esperadas respecto a mi actuación profesional?

3. ¿Cómo afecta la omisión o violación de estos preceptos en la sociedad y en la profesión?

4. ¿Cuál es el universo de responsabilidad que me compete y ante quién y cómo debo rendir cuenta de ello?

A estas alturas, para el estudiante o el profesional quizá ya no resulte sencillo realizar este ejercicio, sobre todo porque la evidencia de aprendizaje solicitado consiste en un documento escrito, el cual debió elaborarse con citas y referencias verificables, sin incurrir en plagio, con una estructura conceptual organizada, fuentes bibliográficas valiosas, introducción y conclusiones coherentes y consistentes, y expuesto mediante una redacción clara, directa y sin faltas de ortografía. Se esperaría también que el profesor ya habrá comprendido que las feas y dolorosas obligaciones que nos impone la escritura académica son esenciales para dar forma y expresión a las obligaciones profesionales o reglas normativas con las cuales nos estructuramos y actuamos en la vida escolar y profesional.

De igual modo, podemos tomar el Manifiesto de la UNESCO sobre la biblioteca pública (1994), las Leyes de Ranganathan y su actualización elaborada por Crawford y Gorman (1995) hace unos años, e incluso tratar el concepto de uso ético de la información.

He sugerido consolidar una línea de formación que atienda la indagación sobre el origen y genealogía de las normas éticas de la bibliotecología así como de la ciencia. En consonancia con ello, observo que el reconocimiento y la ori- 
La Infodiversidad y el uso ético del conocimiento...

ginalidad en el campo académico son valores que la ciencia premia; para ello toma en cuenta la calidad e impacto de las publicaciones como parte de una trayectoria académica integral.

Si bien es difícil homologar la trayectoria de un científico respecto a la de un estudiante o un profesional en la práctica de la profesión, sí hay al menos un elemento que los articula o donde convergen: se trata de la escritura académica y profesional. Por ejemplo, solicitar trabajos escritos a los estudiantes debería fomentar el deseo de reconocimiento y la búsqueda de originalidad en un campo cognoscitivo en el cual los estudiantes han iniciado su socialización; sin embargo, este sentido no existe en la perspectiva del estudiante simplemente porque su quehacer y trayectoria está orientada, en el mejor de los casos, a superar los esquemas de evaluación institucional.

Por otra parte, los profesores tampoco consideran que la escritura académica sea una parte sustantiva de su trabajo profesional a través de la cual su reconocimiento sea destacado, ya que los sistemas de evaluación se sustentan en otros pilares. En consecuencia, considero que la reflexión desde la perspectiva ética podría ayudarnos a alinear el sentido de la formación de los estudiantes y de los profesionales.

No obstante, también es necesario recuperar algunos antecedentes intelectuales de la historia de la ciencia para ubicar el peso de la tradición académica que desde hace cientos de años se practica: dar el reconocimiento de originalidad al creador, es decir al autor, así como la identificación rigurosa de las fuentes documentales.

En principio, este soporte de erudición, denominado "notas de pie de página", ha dado cuenta de la objetividad que hace valioso un escrito académico o científico y su peso 
ha sido tan extraordinario que Wallerstein prácticamente lo identifica como un elemento indicativo de la construcción histórica de las ciencias sociales a partir del siglo XVIII. Dicho autor ha destacado que la "[...] primera de las disciplinas de la ciencia social que alcanzó una existencia institucional autónoma real fue la historia." (Wallerstein, 1996: 17) Además, dice el autor, dicha disciplina destacó por el énfasis riguroso que ponía en la búsqueda, aspecto cuyo exponente máximo es Ranke con la frase "lo que ocurrió en realidad". De igual modo, indica que:

Es imposible pasar por alto hasta qué punto el lema de Ranke refleja los temas utilizados por las "ciencias" en su lucha con la "filosofía" - el énfasis en la existencia de un mundo real que es objetivo y cognoscible, el énfasis en la evidencia empírica, el énfasis en la neutralidad del estudioso. Además el historiador, al igual que el científico natural, no debía hallar sus datos en escritos anteriores (la biblioteca, lugar de la lectura) o en sus propios procesos del pensamiento (el estudio, lugar de la reflexión), sino más bien en un lugar donde se podía reunir, almacenar, controlar y manipular datos exteriores (el laboratorio/el archivo, lugares de la investigación). (Wallerstein, 1996: 18)

Es así que la nota de pie de página adquiere valor incuestionable en la construcción de las disciplinas sociales nacidas entre los siglos XVIII y XIX, tales como la historia, la economía, la sociología, la ciencia política y la antropología.

Este actor fundamental en la construcción de la comunicación de la ciencia tiene también su propia historia, como relata Anthony Grafton en Tragic Origins of the German Footnote, cuya obra se tradujo al español como Los origenes trágicos de la erudición*. Curiosamente, la portada del libro, publicado por el Fondo de Cultura Económica, contiene una nota de pie de página -que en realidad debería corresponder al subtitulo- y a la letra dice: *Breve tratado sobre la nota de pie de página (Grafton, 1998). No obstante 
La Infodiversidad y el uso ético del conocimiento...

el noble linaje de las notas de pie de página, el autor manifiesta su molestia por el modo con el cual son tratadas y reivindica su relevancia para la creación del conocimiento avanzado:

La nota al pie moderna es tan esencial para la vida histórica civilizada como el retrete; como éste, es un tema de mal gusto en la plática cortés y por lo general sólo llama la atención cuando se descompone. Como el retrete, la nota al pie permite a uno realizar actos desagradables en la intimidad; cómo sucede con aquél, el buen gusto exige que se le coloque en un lugar discreto; últimamente no se la incluye en el pie de página sino al final del libro. Es el lugar que merece recurso tan baladí: ojos que no ven, corazón que no siente.

Sin embargo, el historiador con frecuencia debe hurgar en esos rincones oscuros y hediondos que rehúyen los pueblos civilizados. La exploración de retretes y cloacas ha sido una fuente inagotable de riquezas en materia de población, planificación urbana y olores. Las etapas de su desarrollo permiten distinguir entre las texturas de la vida social moderna y premoderna de manera mucho más gráfica que las pretenciosas cronologías halladas en las historias políticas e intelectuales. (Grafton, 1998: 13-14)

Además de la riqueza de potencial cognoscitivo que contienen las notas, su dominio claramente implica un aprendizaje especializado e imprescindible, aunque en apariencia pueda ser fuente de molestia ya que, como el propio Grafton subraya:

El murmullo de la nota al pie es reconfortante como el zumbido agudo del torno odontológico: el tedio que provoca, como el dolor que provoca el torno, no es aleatorio sino direccional, es parte del costo a pagar por los beneficios de la ciencia y la tecnología moderna.

Como sugiere esta analogía, en la vida moderna la nota al pie está vinculada con la ideología y los procedimientos técnicos de una profesión. Para ser historiador o dentista uno realiza estudios especializados; para practicar la historia o la odontología, uno debe recibir la aprobación de sus maestros, colegas y, sobre todo, 
pacientes (o lectores). Aprender a redactar notas al pie forma parte de esta versión moderna de la vida del aprendiz. (Grafton, 1998: 12-13)

El uso imprescindible de las notas es parte estructural de los textos que se componen de proposiciones que, se presume, son verdaderas y, por lo tanto, están justificadas; en esencia, son instrumentos de defensa y ataque usadas en la difícil arena donde se pelea por el reconocimiento y la prioridad del conocimiento erudito, esto es, en todas las disciplinas. Tal vez por ello el autor citado, refiriéndose a la historia, concluye que:

Las notas al pie de por sí no garantiza nada. Los enemigos de la verdad -y en efecto, existen- pueden usarlas para negar los mismos hechos que los historiadores honestos tratan de confirmar por medio de ellas. Los enemigos de las ideas - que también existen - pueden usarlas para acumular citas y referencias carentes de interés para el lector o atacar cualquier tesis nueva. Sin embargo, las notas al pie constituyen una parte indispensable, aunque desprolija, de esa mezcla indispensable y desprolija de arte y ciencia que es la historia moderna. (Grafton, 1998: 133)

De acuerdo con lo antes expuesto, en la formación de los estudiantes y la actualización de los bibliotecólogos profesionales debe recordarse permanentemente que existen normas fundamentales que rigen la comunicación en la academia y en sus variantes profesionales:

1. El especialista o investigador ha trabajado en función de ganar en la carrera por la prioridad del hallazgo;

2. Quien gana tiene el derecho a ser reconocido cada vez que se haga uso de su aportación.

El distinguido sociólogo de la ciencia Robert Merton realizó estudios desde mediados del siglo XX para comprender 
La Infodiversidad y el uso ético del conocimiento...

los rasgos fundamentales del funcionamiento institucional de la ciencia, lo cual implica analizar algunos aspectos relacionados con la comunicación de la misma. De tales estudios destaco las siguientes conclusiones.

En primer lugar, sintetiza la obligación académica siguiente: "A fin de cuentas, proteger la prioridad de otro sólo es actuar de acuerdo con la norma - que ha cobrado fuerza desde la época de Francis Bacon- que exige a los científicos reconocer su deuda con la labor precedente". (Merton, 1977: 441) Lo anterior es así porque, en palabras de Merton, el rol del científico es promover el conocimiento y en la institución de la ciencia la originalidad es valorada pues le permite a aquél avanzar. El reconocimiento equivale a la obtención del derecho de propiedad, es decir, el "[...] reconocimiento por otros de la parte que le corresponde al científico en el resultado alcanzado". (Merton, 1977: 387)

Por lo tanto, originalidad y el reconocimiento son elementos indisolubles en la promoción y desarrollo de la práctica de comunicación académica; además, son un incentivo fundamental para el avance de la ciencia, por lo cual el estudiante debe saber que es inverosímil dejar de lado la herencia cognoscitiva de la disciplina en la que se socializa y en la que se desempeñará, ya sea desde la academia o el campo profesional, pues las tradiciones de estudio disciplinario y las tradiciones profesionales se entrelazan. Merton lo expone del siguiente modo:

Contemplado en toda su complejidad, desde los epónimos que registran los nombres de los científicos en el lenguaje internacional de la ciencia hasta la inmensa serie de premios parroquiales y efímeros, el sistema de recompensas de la ciencia refuerza y perpetúa el énfasis institucional de la originalidad. En este sentido específico, puede decirse que la originalidad es un importante objetivo institucional de la ciencia moderna, a veces el principal, y el reconocimiento de la originalidad un objetivo derivado, pero 
a menudo de igual importancia. En la competencia organizada para contribuir al conocimiento científico humano, la victoria es para el más veloz, para el que llega primero con su contribución en la mano. (Merton, 1977: 396-397)

El reconocimiento que se practica a través de las notas de referencia explicativas y hasta la inclusión de los compendios bibliográficos adquieren un sentido conmemorativo, pues como afirma el autor citado:

Explorar la bibliografía de un campo científico no sólo es una costumbre útil y por la que se aprende del pasado, sino también una práctica conmemorativa mediante la que se rinde un homenaje a quienes han preparado el camino de la propia labor. (Merton, 1977: 397)

Sin embargo, las conductas de los científicos que se alejan de las normas antes mencionadas llevan a Merton a retomar una consideración de otro autor, pues los problemas derivados de la publicación rápida e ignorar deliberadamente a los científicos reconocidos merecen el calificativo de deshonestidad académica:

Kubie sospecha que está surgiendo lo que llama una "nueva dolencia psicosocial" entre los científicos que tal vez no carezca totalmente la relación con la tradición delictiva de los muchachos que están ante un callejón sin salida. ¿Estamos presenciando la formación de una generación de jóvenes científicos endurecidos, cínicos, amorales, amargados y desilusionados? (Merton, 1977: 418)

Hace más de cuatro décadas que los estudios de Merton se publicaron al español y las dimensiones del plagio no presentaban la gravedad con la cual hoy nos enfrentamos (si bien cabe mencionar que es difícil cuantificarlo); el plagio se ha potenciado y multiplicado por las facilidades de acceso y circulación a través de Internet. El plagio, en el 
La Infodiversidad y el uso ético del conocimiento...

sentido que nos importa, se define en el Diccionario de la Lengua Española (2017) como "Copiar en lo sustancial obras ajenas, dándolas como propias.”

En lo que podemos considerar una versión estándar sobre las formas que asume el plagio en la publicación, se mencionan las siguientes:

1. Copiar el artículo entero de otra persona, o una parte importante del artículo (más del $50 \%$ ) literalmente, sin tener en cuenta al autor original, o bien copiar un trabajo propio previamente publicado.

2. Copiar una gran proporción (20-50 \%) del trabajo de otra persona, o un trabajo propio anterior (publicación redundante), sin crédito.

3. Copiar sin crédito elementos individuales como párrafos, frases e ilustraciones, lo que da como resultado una porción significativa (hasta el $20 \%$ ) de un artículo.

4. Parafraseo sin acreditar de páginas o párrafos de otra fuente.

5. Copia acreditada textualmente de una porción importante de un artículo sin delimitación clara, tal como comillas o sangrías. (IEEE, ed., s.f.)

Cabe mencionar que en la actualidad es sumamente fácil identificar estas formas de plagio gracias al uso de programas de cómputo especializados en la revisión de manuscritos. Así pues, la ironía de esta conducta éticamente inaceptable consiste en valerse de un medio electrónico para cometer plagio y ser identificado en la falta gracias al mismo medio.

En paralelo, observamos que el Manual de estilo de Chicago, obra fundamental en el mundo vinculado a la academia y la publicación especializada, destaca como dos principios sustantivos para consignar las citas o referencias bibliográficas la ética (en general) y el derecho a la reproducción de las obras; hace un llamado a la toma de conciencia: 
La mayoría de las obras, con excepción de la literatura o de los recuentos de experiencias personales, se basan parcialmente tanto en fuentes secundarias (otras publicaciones de la misma área o de temas relacionados) como en fuentes primarias (manuscritos, colecciones, archivos, informes actualizados, bitácoras, libros, entrevistas, entre otros). Los señalamientos de la ética, así como del derecho de reproducción de las obras, instan a los autores a reconocer las fuentes, en especial cuando extraen citas textuales. Las prácticas convencionales para referenciar textos difieren entre disciplinas, editores y revistas científicas. Sin embargo, cada vez más se han esfumado viejas distinciones tales como límites disciplinarios; más que incluso preocuparse por el estado de la cuestión, se exhorta a tomar consciencia y buscar la viabilidad por encima del laxo manejo académico de las fuentes. (The Chicago Manual of Style, 1993: 493. Traducción libre del inglés al español)

Así, si se acepta el principio ético del reconocimiento y, en consecuencia, el registro correcto de la referencia bibliográfica y las notas, enseguida se debe clarificar al máximo cómo citar y comprender cuáles son los momentos cruciales de la producción intelectual y escrita en que se debe recurrir a estos instrumentos imprescindibles de la comunicación académica especializada. Al respecto, Garfield escribió un artículo multicitado durante décadas enumerando las situaciones que requieren utilizar las citas:

1. Respetar a los precursores de las ideas.

2. Reconocer el mérito de los colegas que investigan la misma línea o de los pares académicos.

3. Identificar aspectos instrumentales o de metodología.

4. Proporcionar materiales de lectura que ayuden a la comprensión del objeto de estudio.

5. Aclarar errores que haya en los trabajos de nuestra propia autoría.

6. Corregir errores encontrados en trabajos de terceros.

7. Hacer crítica de trabajos previos.

8. Fundamentar acusaciones y señalamientos. 
La Infodiversidad y el uso ético del conocimiento...

9. Advertir a los investigadores de un campo acerca de obras en prensa.

10.Dar pistas acerca de obras escasamente difundidas, de obras que hayan sido indizadas en pocas bases de datos o que no se hayan citado antes.

11. Dar fe de cierto tipo de datos y hechos (constantes en la Física, etc.).

12. Identificar la publicación original en la cual se haya iniciado la discusión de un concepto o idea primigenia.

13. Identificar la publicación original que incluyan conceptos o términos epónimos, por ejemplo: el Linfoma de Hodgkin, el Principio de Pareto, las reacciones de Friedel-Crafts, entre otros.

14. Refutar ideas o trabajos de terceros (señalamientos negativos).

15. Impugnar solicitudes de prioridad de terceros ("citas negativas"). (Garfield 1996, 452. Traducción libre del inglés al español)

Por su parte, Umberto Eco destaca diez reglas acerca de cuándo y cómo citar, pero antes explica que son de dos tipos: primero se cita un texto que ha de interpretarse y, segundo, se cita un texto en apoyo de la interpretación personal. Posteriormente, enumera las reglas:

Regla 1 - Los fragmentos objeto de análisis interpretativo se citan con amplitud razonable.

Regla 2 - Los textos de literatura crítica se citan sólo cuando con su autoridad corroboran o confirman una afirmación nuestra. [...]

Regla 3 - La cita supone que se comparte la idea del autor citado, a menos que el fragmento vaya precedido o seguido de expresiones críticas.

Regla 4 - En cada cita deben figurar claramente reconocibles el autor y la fuente impresa o manuscrita [...]

Regla 5 - Las citas de las fuentes primarias se hacen normalmente refiriéndose a la edición crítica o a la edición más acreditada [...]

Regla 6 - Cuando se estudia a un autor extranjero, las citas deben ir en la lengua original. [...]

Regla 7- El envío al autor y a la obra tiene que ser claro. [...] 
Regla 8 - Cuando una cita no supera las dos o tres líneas se puede insertar dentro del párrafo entre comillas dobles [...]

Regla 9 - Las citas tienen que ser fieles. [...]

Regla 10 - Citar es como aportar testigos en un juicio. [...] (Eco, 1988: 188-201)

Sin embargo, se han detectado errores comunes para citar. Belcher considera que son los siguientes (Belcher, 2010: 208-210):

1. Citar demasiado una fuente.

2. Citar literatura irrelevante.

3. Exagerar en las citas de definiciones.

4. Atribuir incorrectamente "visiones generales o sistemas de pensamiento enteros a una persona".

5. Citar una cita.

6. Citar fuentes indirectas.

7. Citar fuentes derivadas.

8. Citar demasiado.

9. Omitir citas.

Asimismo, para no incurrir en plagio hay que evitar lo siguiente:

1. Apropiarse de un artículo completo "cambiando cada cuarta o quinta palabra".

2. Crear un artículo a partir de una estructura y argumento de acuerdo con otro autor y únicamente modificar el lenguaje.

3. Traducir un artículo y presentarlo como propio.

4. Incorporar palabras, párrafos o secciones de otro artículo y presentarlo como obra personal.

5. Usar párrafos y frases literales, sin comillas y la mención de la fuente. (Belcher 2010, 212)

Por todo lo expuesto, se constata que el origen de las normas y las reglas que de ellas derivan, así como sus restricciones, están claramente delimitadas. No obstante, el trabajo cuidadoso que implica el aprendizaje y práctica de estas 
La Infodiversidad y el uso ético del conocimiento...

normas, que básicamente se fomentan en cursos escolares o de educación continua en las universidades y escuelas profesionales, deberá ser coadyuvante para que desde el ámbito bibliotecológico se promueva la formación de conductas éticamente válidas en los procesos de comunicación académica y profesional. Desde la perspectiva bibliotecológica puede hacerse mucho, en particular desde las bibliotecas.

Actualmente se dispone de medios audiovisuales apoyados en las redes sociales cuyas plataformas tienen alcances formidables. Esto es muy importante porque la producción de cursos y clases en línea diseñadas para el aprendizaje básico del uso de citas y referencias bibliográficas debe y puede hacerse desde las bibliotecas, junto con otros equipos de trabajo docente. Ahora bien, cabe preguntarnos cuál es el material disponible para apoyar esta tarea; para contestar esta pregunta se procedió a la búsqueda y recuperación de materiales en línea que instruyan a las personas acerca de cómo citar.

En primer lugar se hizo una simple búsqueda de videos tutoriales en YouTube, a semejanza del procedimiento de búsqueda probablemente más socorrido entre los jóvenes. Se escribió en español la frase "Cómo citar" en la caja de diálogo para hacer búsquedas en YouTube y fueron recuperados cerca de 28900 resultados (esta cifra fue obtenida en la primera quincena de enero de 2017). Se observó que una gran cantidad de estos videos tutoriales han sido compartidos por personas que explican cómo utilizar el software propietario del procesador de textos Microsoft Word para añadir notas al pie con el estilo bibliográfico APA. Asimismo, la mayoría se trata de grabaciones que fueron hechas en forma de capturas de pantalla mientras el locutor manipula el procesador de textos. Lamentablemente carecen de interactividad con el espectador y se hace evidente la falta del 
respaldo intelectual de los bibliotecólogos en el tema; esto es así, con excepción de una cápsula informativa del canal Maestro TV SNTE (2015).

Posteriormente, se realizó el mismo ejercicio con una variante de idioma y se escribió en inglés la frase "How to Cite". La recuperación fue de 1380000 resultados, cifra mayor a los resultados en español. De igual manera que con la primera búsqueda, los videos fueron grabados para explicar cómo utilizar Microsoft Word y emplear las normas del estilo bibliográfico APA.

De este ejercicio de recuperación cabe señalar que la diferencia más significativa radica en que existen videos subidos por bibliotecas y éstas han logrado gran cantidad de visitas. Entre algunos ejemplos destacan los siguientes: "APA Reference Page" (King University Libraries, ed. 2011), que ha sido visto 130832 veces; "Citing - How to Cite in Chicago/Turabian Style: A Three Minute Tutorial" (Conestoga College Library Resource Centre, ed. 2014) el cual ha alcanzado 55032 visitas; y "APA Style Reference List: How to Reference Websites” (Memorial University Libraries, ed. 2013), con 50639 visitas.

Adicionalmente, se identificaron los videos mejor calificados que han sido subidos por bibliotecas y se halló lo siguiente: "Citing Books in MLA Format" (Oesterle Library, ed. 2010) ha sido visto 41846 veces y 143 usuarios calificaron positivamente el recurso compartido; asimismo, el video "APA Style Reference List: How to Reference Websites" (Memorial University Libraries, ed. 2013) ha registrado 50 639 visitas y recibió 86 calificaciones positivas.

Ahora bien, es cierto que la cantidad de reproducciones o la tasa de aceptación entre el público difícilmente lograrán las cifras que registran los videos musicales. No obstante, debe matizarse que los casos de éxito referidos han sido 
La Infodiversidad y el uso ético del conocimiento...

producidos con el objetivo de socialización de contenidos a gran escala apoyados profesionalmente por el personal que labora en los servicios bibliotecarios. Es decir, son ejemplos de cómo la extensión de los servicios de consulta en el entorno digital permite a los bibliotecólogos estrechar el acercamiento con los usuarios que requieren orientación para mejorar sus prácticas de comunicación académica, lo cual implica principios éticos, normas profesionales para la elaboración de referencias bibliográficas con un claro objetivo de identificación.

Cabe preguntar: ¿por qué volvemos al tema del reconocimiento y la cita o la nota? La respuesta está estrechamente vinculada al abandono de las conductas éticas surgidas en la institucionalización de la comunicación académica, particularmente contra el plagio. Por lo anterior, vale la pena conocer la consideración hecha por Argüelles:

Todo plagio textual es un robo, incluso si no hubiese, aparentemente, ánimo de lucro. La ganancia, la utilidad del provecho pueden darse en especie: el "prestigio" que suele traducirse en cargos, nombramientos, puestos, etcétera, y que también conduce al dinero. Sea como fuere, el plagio textual es, siempre, una obra imperfecta de las malas artes: tarde o temprano se descubre. El plagio textual nunca es crimen perfecto. Frente a las pruebas no hay defensa. Y no hay prueba más contundente que las huellas digitales impresas en la escritura. (Argüelles, 2017: 9)

Por último, dado que la información disponible en línea cada vez se extiende más el problema se ha hecho más evidente respecto al plagio y, en el mejor de los casos, para citar correctamente las fuentes en dicho medio. Por ello, se ha señalado que:

Los directivos de las universidades han reconocido lentamente la necesidad de asegurarse de que los egresados sean tanto usuarios competentes de tecnologías, como capaces de encontrar y 
Un papel para la ética en la comunicación académica...

usar información. En consecuencia, nuestra responsabilidad ha estado, y por siempre estará, comprometida con suscitar cada vez más conciencia sobre las implicaciones éticas y legales del uso de la información. (Auer y Krupar, 2001: 432)

Por supuesto, tres lustros después de la conclusión anterior el contexto de la comunicación académica subraya la necesidad de intensificar los esfuerzos para formar conciencias críticas y responsables respecto al uso de la información, ya sea como estudiantes en formación, profesionales o académicos.

\section{CONSIDERACIONES FINALES}

La ética, sus fundamentos e implicaciones prácticas llaman a la puerta de la academia y de la profesión bibliotecológica, en su forma de comunicación y ejercicio profesional e incluso con fines de producir investigación original. Es imposible ignorar este llamado, por lo que deberemos actuar responsablemente; en principio, trabajando con los estudiantes de bibliotecología y, en seguida, compartiendo y promoviendo la riqueza que conlleva el trabajo del registro bibliográfico y el uso de información erudita y con valor social. Lo anterior es una oportunidad más de mostrar a la sociedad la relevancia de la disciplina bibliotecológica.

\section{BIBLIOGRAFÍA}

Argüelles, Federico (2017), "Plagio textual: el más imperfecto de todos los crímenes," Campus Milenio. Fabulaciones, 26 de enero: 8-9 [en línea], http://campusmilenio.mx/index. php?option $=$ com_k2\&view $=$ item $\&$ id $=5507$ : plagio-textual-elmas-imperfecto-de-todos-los-crimenes \&Itemid=143 
La Infodiversidad y el uso ético del conocimiento...

Auer, Nicole J., y Ellen M. Krupar (2001), "Mouse click plagiarism: The role of technology in plagiarism and the librarian's role in combating its", Library Trends, 49(3): 415-432.

Belcher, Wendy Laura (2010), Cómo escribir un artículo académico en 12 semanas: guía para publicar con éxito. México: FLACso.

Código de ética de la IFLA para bibliotecarios y otros trabajadores de la información [Países Bajos: IFLA, FAIFE, 2012]. Disponible en línea: http://www.ifla.org/files/assets/faife/codesofethics/ spanishcodeofethicsfull.pdf

Conestoga College Library Resource Centre (ed. 2014, 8 de septiembre), Citing - How to Cite in Chicago/Turabian Style: A Three Minute Tutorial. [Video] YouTube https://youtu. be/0NdT4Y620nE

Crawford, Walt y Michael Gorman (1995), Future Libraries: Dreams, Madness and Reality. Chicago: ALA.

Diccionario de la lengua Española [España: Real Academia Española, 2017]. [en línea], http://dle.rae.es/?w=diccionario

Eco, Umberto (1988), Cómo se hace una tesis. Barcelona: Gedisa.

Garfield, Eugene (1996), "When to cite." Library Quarterly, 66(4): 451-452.

Grafton, Anthony (1998), Los orígenes trágicos de la erudición. México: FCE.

How to Write for Technical Periodicals \& Conferences. [Piscataway, NJ: Institute of Electrical and Electronics Engineers IEEE, s.f.] [en línea], https://www.ieee.org/publications_standards/publications/authors/author_guide_interactive.pdf

King University Libraries (ed. 2011, 28 de noviembre), APA Reference Page. [Video] YouTube https://youtu.be/ld-locTPW5I

Korsgaard, Christine M. (2000), Las fuentes de la normatividad. México: UNAM / Instituto de Investigaciones Filosóficas. 
Maestro TV SNTE (ed. 2015, 4 de agosto), LogIn - Cómo citar en internet TO2E11 - SNTE Nacional. [Video] YouTube: https://youtu.be/HpriV-iC4cU

Manifiesto de la UNESCO sobre la biblioteca pública [s.1.: uNESCO, 1994] [en línea], http://unesdoc.unesco.org/ images/0011/001121/112122so.pdf

Memorial University Libraries (ed. 2013, 11 de septiembre), APA Style Reference List: How to Reference Websites. [Video] YouTube: https://youtu.be/4tNfa2zVuWE

Merton, Robert K. (1977), La sociología de la ciencia: investigaciones teóricas y empíricas. Vol. 2. Madrid: Alianza Universidad.

Oesterle Library (ed. 2010, 25 de febrero), Citing Books in MLA Format. [Video] YouTube: https://youtu.be/2UhzuQC161o

The Chicago Manual of Style. 16th ed. [Chicago: University of Chicago, 2017] [en línea], http://www.chicagomanualofstyle.org

Wallerstein, Immanuel (coord.) (1996), Abrir las ciencias sociales: Informe de la Comisión Gulbenkian para la reestructuración de las ciencias sociales. México: Siglo XXI. 
El uso ético de la información: un diálogo entre bibliotecarios y usuarios

\author{
ESTEla MORALES CAMPOS
}

Universidad Nacional Autónoma de México

$\mathrm{n}$ el siglo actual, los Estados se ha preocupado por
otorgar derechos sociales a los ciudadanos que, a prin-
cipios del siglo $\mathrm{xx}$, se podrían tener como naturales $\mathrm{y}$ sin embargo eran discrecionales en cuanto su cumplimiento por parte de los gobernantes; tales serían: el derecho a la libertad de pensamiento y de expresión, a la libertad intelectual, a la educación, a acceder a la información y a informarse.

El derecho a la información y el derecho a la educación, en efecto, los debe garantizar el Estado. Debe existir esta relación de corresponsabilidad en la cual uno otorga las facilidades, la infraestructura y los medios para que sea un derecho que se puede ejercer, y la ciudadanía pueda hacer uso de la información, pueda educarse, y tener más posibilidades de desarrollo; de esta manera, la colectividad, los grupos sociales y el país contarán con más posibilidades de desarrollo económico y político.

Cuando se tienen estos derechos y las facilidades para beneficiarse de ellos, en el contexto de una realidad global, se tiene que tener en cuenta el marco legal, tanto nacional como internacional, así como los referentes teóricos de 
La Infodiversidad y el uso ético del conocimiento...

cada proceso y las necesidades y realidades de cada pueblo, su actualidad y su historia. Así, las instituciones creadas por el Estado, como la Escuela y la Biblioteca, proporcionarán la información que requieren las personas para que el proceso de educación (no sólo de instrucción) les permita reconocer los saberes que requieren en su vida cotidiana y profesional. Lo anterior busca estimular las habilidades y actitudes para "reconocer al otro", individuo o colectividad, que comparte el espacio local o global y, por lo tanto, para reconocer la creación o autoría de otra persona que realizó su aportación en el espacio y el tiempo, actual o histórico, y no tomar prestado, robar o plagiar las creaciones, conocimientos y aportaciones, sin el debido reconocimiento a la idea original.

El respeto por "el otro", además de relacionarlo con la vida en sociedad, en grupo y con la globalidad, tenemos que ligarlo a aspectos éticos que acepta la sociedad y que pueden estar respaldados o relacionados con normas legales que marcan derechos y obligaciones, a diferencia de los éticos solamente, que pueden ser aceptados por la sociedad, pero que no se tienen los mecanismos legales para obligarlos.

En este trabajo no incluimos los saberes colectivos ancestrales, solamente los saberes registrados mediante la escritura y las protecciones legales de su tiempo. De igual manera, haremos énfasis en la ética profesional del bibliotecario y, por consecuencia, cómo se aplica en las instituciones y organizaciones como la biblioteca y las asociaciones de profesionales.

En términos generales, la ética nos permite formar criterios para distinguir entre actos que atentan la dignidad humana y los que no contribuyen a la consolidación del bien común de los que, por el contrario, propician el respeto "al 
El uso ético de la información: un diálogo entre bibliotecarios...

otro" y la vida en comunidad al interior de grupos sociales específicos o sociedades más amplias, lo cual nos permite formar actitudes y aptitudes para asumir valores colectivos.

La ética profesional compromete a los docentes y a las escuelas a instruir estudiantes y egresados con los conocimientos necesarios para su formación, con valores que garanticen seres humanos comprometidos con el bien común, desde su profesión y como ciudadanos. Para nuestra profesión, es fundamental formar alumnos que puedan distinguir y conocer la conveniencia y los efectos de los vínculos entre el bibliotecario que ofrece los servicios de información, incluyendo a los que hacen procesos que facilitan estos servicios, y los que reciben y se benefician de estos servicios: el usuario y la comunidad con la que están comprometidos. ${ }^{1}$

En la teoría y en la práctica profesional, la ética, sus principios y valores, son parte de la filosofía y están relacionados con varios temas y aspectos del individuo y de la sociedad. No obstante, nos enfocaremos en el uso que se hace en la Sociedad de la Información de su insumo principal, la información, cómo la utiliza y la actitud y responsabilidades del usuario y del bibliotecario que ofrece el servicio. También nos enfocaremos en la preocupación de que el bibliotecario tenga una actitud ética que se refleje en los deberes y obligaciones como profesional y su relación con el usuario para satisfacer sus demandas, sus intereses, sus deseos.

En el acto fundacional de la American Library Association, en 1876, ya se planteaba el tema de los aspectos éticos del servicio bibliotecario, la profesión y las escuelas. Se destacaba que la esencia de la profesión es el servicio a la sociedad y, por lo tanto, se buscaba la disponibilidad de la

1 Víctor Campa Mendoza (2008), Seminario de ética. La ética y la moral. Fundamentos, conceptos y normas, valores y deberes. 
La Infodiversidad y el uso ético del conocimiento...

información que ésta requiere (independientemente de su medio de registro, libro, artículo, reporte, etcétera).

En el siglo XIX, no se enfatizaba la corresponsabilidad del usuario en el manejo y uso de la información solicitada. Lo que sí se analizó en los momentos iniciales de la AlA fue la responsabilidad social del bibliotecario y la necesidad de que tanto las escuelas como las asociaciones impulsaran a un profesionista con imagen y con identidad que lo distinguiera de otros expertos y otras disciplinas. Ya en aquel entonces, al bibliotecario se le pedía tener un comportamiento ético dentro de la sociedad, con las autoridades, con los compañeros, con los colegas y con el público; pero, como a cualquier otro profesional, se le pedía lealtad, discreción y confidencialidad, para evitar conflictos de intereses. Y en especial, por tener como fuente e instrumento de trabajo la información, se le pedía objetividad y neutralidad en actos de censura y propaganda. El mismo Melvil Dewey, en la presentación del primer número de Library Journal, en $1876,{ }^{2}$ retoma lo anterior y demanda un rol dinámico y participativo del bibliotecario; establece la diferencia del espíritu de las bibliotecas de siglos anteriores con las de la segunda mitad del siglo XIX, pues en el pasado eran como museos cuya prioridad era preservar, las de ahora deberían ser una escuela de puertas abiertas para la comunidad donde los objetos donde se registra la información dejaban de ser sagrados para ser medios rápidos y baratos para ofrecer la información requerida. ${ }^{3}$

Los medios de duplicación no existían, la tecnología del momento no la facilitaba y el plagio o robo de ideas y manuscritos caminaba por otras vías; y si bien estaban ausen-

2 Melvil Dewey (1876), “The Profession", Library Journal, pp. 5-6.

3 Jean Preer (2008), Library Ethics, p. 9. 
El uso ético de la información: un diálogo entre bibliotecarios...

tes los facilitadores tecnológicos, no así la imaginación y las habilidades de los interesados en esta práctica.

Es necesario destacar el papel de la ALA porque su trabajo colegiado y de modernización ha sido un referente internacional y, para México, en los inicios del siglo Xx, una fuente de aprendizaje en el despunte de la bibliotecología, las escuelas y la biblioteca. Sobresale el papel destacado que tiene la relación de la biblioteca con la sociedad y el compromiso del bibliotecario con sus usuarios, con su comunidad, a fin de difundir el conocimiento en los procesos de una educación comunitaria, sin olvidar los dos ejes que le dan sentido a la disciplina: la organización de la información, con miras a crear sistemas de información al servicio de la comunidad (procesos técnicos, bibliografía, servicio de consulta), y el comportamiento ético del bibliotecario y su participación en la formación de esta actitud y conducta en el usuario.

La interacción con la sociedad es una constante del ser de la bibliotecología, ya sea con la sociedad en su conjunto o con grupos específicos y especializados; dentro de esta activa relación, siempre están presentes los marcos de referencia legales y normativos que guían a los grupos. Por lo tanto, los bibliotecarios tienen la obligación de considerar los principios éticos de convivencia, de respeto al otro y lo creado, generado y pensado por éste.

En sus inicios, la visión que tuvo la Ala fue el de una base muy generalizada; este aspecto se refleja en los códigos de varias asociaciones profesionales y en la educación bibliotecológica, la cual parte de los principios de una conducta cuyo mayor peso específico recae en el bibliotecario y en la que no se mencionan las responsabilidades éticas del usuario. Al respecto se busca no interferir la oferta de información con las posiciones personales: "no política, no 
La Infodiversidad y el uso ético del conocimiento...

religión, no moral". ${ }^{4}$ Es decir, no interferir es esos aspectos, que pueden estar muy cerca de la censura o manipulación que se pueda ejercer a través de la información sugerida; por supuesto que esta posición tiene que ser aplicada con criterio y tomando en cuenta el entorno social de la biblioteca y del ciudadano a quien se sirve. Si bien todo el conocimiento debe estar abierto a todos los hombres de acuerdo a sus necesidades, y de acuerdo al derecho a decidir de cada individuo, también se deben tomar en cuenta las normas de convivencia, la legislación relativa y las limitantes expresas que norman su uso.

En la actualidad, con las muchas facilidades tecnológicas que benefician el proceso y uso de la información, la comunidad bibliotecaria se enfrenta a una problemática ética. En ésta, la falta o el abuso de ciertos principios universales no se dan precisamente en el bibliotecario como agente que le facilita al científico, al docente, al estudiante, al usuario en general, la información que se está requiriendo, de manera puntual y oportuna, sino en el usuario que no hace un uso ético de esa información que utiliza y que ya tiene un autor que con anterioridad registró sus ideas. En estas situaciones ¿cuál sería la actitud y el trabajo que debería desarrollar el bibliotecario, y su interacción con el usuario?

El bibliotecario es un facilitador, pero también un educador; tiene que observar, ser objetivo y prevenir un delito cuando no se cumplan las normas y la legislación locales e internacionales. Las relaciones entre las necesidades de los usuarios, la biblioteca, el autor y el editor deben ser saludables, respetuosas y benéficas para los cuatro, conciliando los intereses de todos ellos ya que, en algunos aspectos, no ne-

4 Douglas John Foskett (1962), The Creed of a Librarian: No Politics, No Religion, No Morals, pp. 3-12. 
El uso ético de la información: un diálogo entre bibliotecarios...

cesariamente son los mismos y deben estar enmarcados en derechos y obligaciones con el compromiso de cumplirse.

MARCO HISTÓRICO-SOCIAL-POLÍTICO

La preocupación por garantizar al ciudadano el uso libre de la información producto del pensamiento y de la opinión de hombres y mujeres tiene una de sus expresiones más simbólicas y trascendentes en la historia cuando se pronuncian los derechos inherentes al ser humano que han servido como bandera de los movimientos democráticos: la "Declaración de los derechos del hombre y del ciudadano" del 26 de agosto de 1789. Promulgada por la Asamblea Nacional dentro de la Revolución Francesa, su artículo 11 dice: "La libre comunicación de pensamiento y de opinión es uno de los derechos más preciados del hombre: todo ciudadano puede [...] hablar, escribir e imprimir libremente [...]"5

Esta declaración influyó en muchos movimientos libertarios de la época y de años posteriores; así, en los trabajos de construcción y formalización de la Organización de las Naciones Unidas, el espíritu del derecho inherente al ser humano estuvo presente, y en 1948 salió a la luz la "Declaración Universal de los Derechos Humanos", en cuyo artículo 19 recoge el siguiente principio: "Todo individuo tiene derecho a la libertad de opinión y de expresión; este derecho incluye el de no ser molestado a causa de sus opiniones, el de investigar y recibir información y opiniones, y

5 Declaración de los derechos del hombre y del ciudadano (1789) [en línea], http://historico.juridicas.unam.mx/publica/librev/rev/derhum/cont/22/pr/ pr19.pdf 
La Infodiversidad y el uso ético del conocimiento...

el de difundirlas, sin limitación de fronteras, por cualquier medio de expresión" [las cursivas son mías]. ${ }^{6}$

Si bien el "Artículo19" es una cita obligada cuando hablamos de acceso a la información y de tener derecho a ello como seres humanos, el implementarlo para que se pueda ejercer requiere de la participación de varios actores y de la decisión política de los entornos políticos, sociales, educativos y culturales.

Mencionaremos los actores más relevantes y fundamentales para lograr que de la declaración se pase a la acción:

a) El gobernante y los órganos de gobierno principales y derivados son los que tienen asignadas funciones que generarán acciones que le facilitarán y le permitirán conocer al ciudadano su derecho y la infraestructura que lo apoye para ejercer el derecho correspondiente.

b) El ciudadano, quien debe saber que tiene derecho a:

- Libertad de pensamiento.

- Libertad de expresión.

- Libertad intelectual.

- Acceder a la información.

- Derecho a informarse

- Derecho a todas las oportunidades de educación.

Si bien el pueblo y el ciudadano tienen derechos, a la vez adquieren compromisos y obligaciones dentro de la sociedad y su vida en comunidad como:

- Ejercer sus derechos.

- Cumplir sus obligaciones.

6 Declaración Universal de los Derechos Humanos [1948], Artículo 19 [en línea], http://www.ohchr.org/EN/UDHR/Documents/UDHR_Translations/ spn.pdf 
El uso ético de la información: un diálogo entre bibliotecarios...

- Actuar dentro de un marco ético legal.

Dentro de los derechos de las personas, además de los relacionados directamente con la información, menciono a la educación porque el acceso, uso y disponibilidad de la información siempre potencia los procesos de educación de un individuo, ya sea en programas formales o informales, en acciones planeadas o naturales inherentes a la vida cotidiana, pero siempre se va construyendo un proceso educativo, de formación y crecimiento de la persona, sea niño, joven o adulto.

La información es el insumo básico de la educación; sin ella, no llegamos al conocimiento. La información puede ser oral, escrita, visual o audiovisual, de acuerdo con el medio de expresar y registrar el conocimiento, la experiencia, el sentimiento, la percepción y la imaginación, ya sea del entorno o de lo que nos preguntamos de otras fronteras y dimensiones. Este uso de la información para llegar al conocimiento nos permitirá seleccionar y reflexionar sobre el mismo para apropiarnos de él y participar en un proceso de construcción y crecimiento individual y colectivo.

EL RESPETO AL OTRO Y A LA OBRA DEL OTRO

El sistema educativo debe formar individuos con conocimientos, pero además con habilidades y actitudes; entre ellas, la posibilidad de reflexión y la de reconocer al otro ser con el que convivimos como individuo y como colectividad; es necesario "reconocer al otro y respetarlo" en sus individualidades, en sus pensamientos y signos identitarios, lo que nos permite vivir, convivir y desarrollarnos en sociedad, ya sea local o globalmente. 
La Infodiversidad y el uso ético del conocimiento...

El principio de "respeto y reconocimiento al otro" en nuestra área disciplinaria y en todos los procesos que conlleva el proceso de la información, nos mueve en un mundo de ideas, conceptos, frases y datos, que se dejan registrados de diferentes formas y en diferentes medios, ya sea a través del alfabeto, el sonido, la imagen, en medio digital o impreso. Lo digital simplifica el ir y venir de estos registro a través de los espacios, reales o virtuales, provocando un flujo de información potenciado en cantidad de datos a través del planeta y por todas las posibilidades de la globalización.

Esta circulación de las ideas y las facilidades que la tecnología ofrece para suministrar la comunicación del conocimiento vía la información, hace que sea relativamente sencillo que todos podamos conocer lo que piensan otras personas, lo que han creado, lo nuevo y lo viejo que ha ido conformando el conocimiento local y universal. No obstante, al mismo tiempo, esa tecnología que se utilizó en los primeros registro que dejó el hombre sobre la piedra hasta lo último que podemos obtener en los medios digitales también ha permitido que otras personas los conozcan, los lean y, por qué no, los utilicen, ya que de esta manera se va enriqueciendo el ser humano y va creciendo la ciencia. Esto quiere decir que, dependiendo de las circunstancias, de manera natural vamos tomando prestado las ideas, los conceptos y las frases de los demás. Esto, presentado así, es lo que ha pasado en la historia y es inherente al proceso de crecimiento del ser humano. La situación se complica cuando el uso de las "ideas del otro" lleva una carga de abuso; cuando nos apropiamos de ellas haciéndolas nuestras, sin admitir que son producto del esfuerzo y trabajo de alguien más; cuando no respetamos la autoría original "del otro" y no reconocemos el trabajo "del otro". Entonces, estamos consumando un robo o un plagio. Como ya expresamos, 
El uso ético de la información: un diálogo entre bibliotecarios...

queda claro que podemos apoyarnos en las ideas y creaciones ajenas, pero con una conducta ética, distinguiendo el trabajo original de la otra persona y la aportación propia; es decir, debemos dar crédito a la autoría del que registró ese saber, idea o conocimiento en su versión original y registrada con anterioridad.

Por lo tanto, por respeto, y siguiendo las normas de convivencia sociales y legales, si utilizamos las ideas de otra persona — sin importar lugar y tiempo-, se debe dar el crédito correspondiente, de acuerdo con las leyes de protección del derecho de autor nacionales e internacionales.

Como ya se mencionó, los profesionales de la bibliotecología, desde tiempo atrás, se han preocupado por los aspectos éticos que obligan a la disciplina como responsable de los productos informativos que crea el ser humano para su uso por la sociedad local y global; se han comprometido, por otro lado, a un comportamiento ético en su relación con la información y con el usuario, así como a respetar las normas éticas que guían los servicios de información.

\section{LA BIBLIOTECOLOGÍA Y SU COMPROMISO CON VALORES ÉTICOS Y SOCIALES}

En una revisión histórica, la American Library Association, una de las asociaciones profesionales más representativas por sus posiciones de defensa de la disciplina - como ya se indicó-, a través de su órgano informativo, el Library Journal (1876), hizo el análisis sobre ciertos aspectos de valores y actitudes y enfatizó en torno a los siguientes:

- Responsabilidad social. La disciplina es eminentemente humanística y social y, por lo tanto, tiene que tener 
La Infodiversidad y el uso ético del conocimiento...

presente que trabaja con un producto del hombre, la información, para el uso de la sociedad. Su prioridad es hacer la conexión óptima entre la necesidad o deseo de un usuario con la pieza informativa que le será útil, contexto en el cual se debe privilegiar el servicio.

- Objetividad y neutralidad. Los servicios de información y los productos informativos que alimentan la colección de una biblioteca tienen que trabajarse con objetividad y neutralidad en todas las fases del proceso. Las aficiones, los deseos y las predilecciones personales del bibliotecario no deben contaminar ninguna de las etapas del servicio.

- No política, no religión, no moral. Estos tres no representan decisiones y actitudes personales de cada individuo. Dado que cada miembro de un grupo social puede tener sus propias ideas, el bibliotecario no debe influir con posturas políticas y religiosas en los usuarios a través de la pieza informativa que sugiera, o de cualquier servicio de información que se ofrezca.

- No censura; no propaganda. En estrecha relación con los anteriores incisos, el bibliotecario siempre debe tener presente que trabaja con ideas y con personas que representan una pluralidad de pensamiento y de creencias procedentes de una rica diversidad cultural, intelectual y socio-económica. El bibliotecario debe respetar a cada uno de sus usuarios (niños, jóvenes y adultos) y no censurar solicitudes de información a partir de sus propias inclinaciones; asimismo, no es ético usar los servicios de información para promover algún elemento ajeno a los intereses informativos propios de la institución. De igual modo, los grupos de poder no deberían utilizar la biblioteca para adoctrinar o censurar el uso de información que soliciten los usuarios, y menos usar 
El uso ético de la información: un diálogo entre bibliotecarios...

los servicios de información para campañas de propaganda ajenas a los objetivos de la biblioteca.

Si miramos con detenimiento estos cuatro enunciados la responsabilidad ética recaía en el profesional de la información y en su compromiso de satisfacer las necesidades de información con los recursos disponibles; sin embargo, en el manejo de la información los compromisos éticos recaen en varios personajes.

ACTORES CON RESPONSABILIDAD ÉTICA EN EL USO Y MANOJO DE INFORMACIÓN ACADÉMICA

En el ámbito académico, hay actores y profesionales que son parte esencial en la construcción, registro y difusión de nuevo conocimiento, y/o resultado de una nueva investigación; podemos mencionar, entre los más activos, los siguientes:

- El usuario. Cuando recibe u obtiene la información solicitada ¿cómo la usa, para que la utiliza? ¿Conoce el usuario las protecciones legales que están previstas para su uso en el ámbito nacional e internacional? ¿El usuario se ha educado en una cultura de "respeto al otro y a la obra del otro"? Si utiliza la información en el medio académico, ¿se conduce con una actitud ética hacia sus colegas, compañeros y vecinos?

- El evaluador. Cuando un académico crea algo nuevo, lo registra a través de una pieza informativa, ya sea artículo, libro, capítulo de libro, patente, y este documento pasa por una evaluación entre pares que conocen el tema; por lo tanto, ellos podrían conocer el producto y 
La Infodiversidad y el uso ético del conocimiento...

detectar si se ha hecho un uso no ético de la información que se maneja, si se han tomado prestadas ideas con su correspondiente reconocimiento y si no se han robado o plagiado las ideas de otros que fueron registradas con anterioridad.

- El editor. El responsable editorial de un producto informativo también debe velar por la calidad de lo que va a publicar, y verificar si esto es realmente original y ha cumplido con los criterios éticos de respeto a la obra de "el otro" y a las normas legales del derecho de autor.

En la medida en que la tecnología de la escritura y del registro de información se ha desarrollado — desde la piedra, la pluma de ganso, la imprenta o las TIC de última generación-, en esa misma medida se ha potenciado la generación de múltiples copias del documento original, dando la posibilidad de diferentes presentaciones y diferentes formas de leerlo; de forma paralela, aparecen facilidades para fraccionar, reeditar o reconstruir la pieza informativa en cuestión. Estas múltiples copias permiten desde una o muchas reproducciones en las bibliotecas, en los escritorios, en los sitios de Internet y en diferentes sistemas de información. El mundo ha vivido esa situación desde los copistas amanuenses, hasta las posibilidades industriales de la imprenta y el desarrollo potenciado del mundo digital con las Tecnologías de la información y la Comunicación (TIC).

El volumen de copias de un documento facilita la circulación de las ideas, la difusión del conocimiento y el desarrollo de la ciencia, la tecnología y la cultura. Estas tecnologías también facilitan su uso, su lectura y, algunas veces, la tentación de tomar prestadas las ideas. Estas tentaciones, sin dar los reconocimientos correspondientes, siempre han existido, según da cuenta la historia. Las copias y las duplicacio- 
nes, legales e ilegales, han sido un conflicto que la sociedad siempre ha afrontado; lo que ha variado es la dimensión del problema, que está en proporción a las facilidades que la tecnología ha propiciado en el campo de la información.

Si bien la tecnología facilita la usurpación de ideas, párrafos u obras completas, la culpable no es ésta, sino quien la utiliza para un fin no ético. El robo de textos, párrafos o frases se da con el apoyo de la tecnología o sin ella, cuando se tiene acceso a los originales, o manuscritos, de los que se da cuenta en los juicios legales sobre propiedad intelectual, en las denuncias en los medios masivos de comunicación, en documentales y películas que recrean robos célebres.

RECONOCIMIENTO A LAS IDEAS DEL OTRO

El crecimiento de la ciencia se apoya en descubrimientos y observaciones registradas con anterioridad, por lo que tomar como antecedente los logros y las aportaciones culturales es válido y obligado para el crecimiento del saber. Lo que no es ético y legal es no dar crédito al investigador, creador o autor que generó ese conocimiento, esa idea. Quien por primera vez registró la obra original tiene los créditos registrados legalmente, de acuerdo con la legislación de los derechos de autor.

Al reconocer al autor y obra originales, es obligado citarlos; y es el convencimiento de respetar al otro. Cuando no citamos, omitimos al autor o el título original, o de dónde tomamos la idea o el dato; las más de las veces, puede ser por ignorancia, por descuido y también, lamentablemente, por abuso. Esta situación puede hacerse inconsciente o premeditadamente. 
La Infodiversidad y el uso ético del conocimiento...

Lo anterior nos lleva a que, además de un proceso de educación sobre el respeto al otro, se deben dar a conocer las normas legales que obliguen a dar estos reconocimientos y demás regulaciones sobre el derecho de autor. Este proceso educativo puede ser formal o informal y es una de las funciones que debe asumir el bibliotecario, ya sea a través de conferencias, sesiones informativas, folletería o acciones variadas a través de los programas ahora llamados de Alfabetización Informativa (ALFIN).

POLÍTICAS PÚBLICAS Y LEGISLACIÓN QUE INDUCEN AL USO ÉTICO DE LA INFORMACIÓN

Debemos ver las políticas públicas sobre el uso de la información en un contexto más amplio, partiendo de la educación, la ciencia y la tecnología para, desde ahí, destacar la información y su uso como componente del proceso de enseñanza-aprendizaje, como el alfabeto, la escuela, la información impresa y la digital y los apoyos inherentes a este proceso (por ejemplo, la biblioteca y el Internet).

En México, estas políticas tienen como marco o inspiran legislación general o específica sobre el tema, entre las que podemos mencionar a la Constitución Política de los Estados Unidos Mexicanos, en varios de sus artículos: ${ }^{7}$

- Artículo $3^{\circ}$. Establece el derecho a la educación y a la obligatoriedad y gratuidad de la misma.

- Artículo $4^{\circ}$. Toda persona tiene derecho al acceso a la cultura.

7 Constitución Política de los Estados Unidos Mexicanos (Constitución publicada en el Diario Oficial de la Federación el 5 de febrero de 1917. Última reforma publicada DOF 27-01-2016) [en línea], http://www.diputados.gob. $\mathrm{mx} /$ LeyesBiblio/htm/1.htm 
El uso ético de la información: un diálogo entre bibliotecarios...

- Artículo $6^{\circ}$. Plasma el derecho a la información: la manifestación de las ideas no será objeto de ninguna inquisición judicial o administrativa; el derecho a la información será garantizado por el Estado.

- Artículo $7^{\circ}$. Es inviolable la libertad de escribir y publicar escritos sobre cualquier materia y sin censura.

Hay otras leyes que garantizan el acceso a la información específica, como:

- La Ley de Ciencia y Tecnología (del 5 de junio de 2002, con su última reforma). ${ }^{8}$

- Ley Federal de Derecho de Autor (24 de diciembre de 1996; actualizada el 27 de enero de 2012) ${ }^{9}$

- Ley Federal de Transparencia y Acceso a la Información Pública Gubernamental (11 de junio de 2002; última reforma 4 de mayo de 2015$)^{10}$

PAPEL QUE JUEGAN LAS ASOCIACIONES PROFESIONALES Y ORGANISMOS INTERNACIONALES RELACIONADOS CON LA CULTURA Y LA INFORMACIÓN

8 Ley de Ciencia y Tecnología (Nueva Ley publicada en el Diario Oficial de la Federación el 5 de junio de 2002. Última reforma publicada DOF 20-05-2014) [en línea], https://www.inaoep.mx/ jgob/hjg/Facultades/LeyCT.pdf

9 Ley Federal del Derecho de Autor (Nueva Ley publicada en el Diario Oficial de la Federación el 24 de diciembre de 1996. Última reforma publicada DOF 27-01-2012) [en línea], http://www.uaa.mx/direcciones/dgdv/editorial/ docs/lda.pdf

10 Ley Federal de Transparencia y Acceso a la Información Pública Gubernamental (Nueva Ley publicada en el Diario Oficial de la Federación el 11 de junio de 2002. Última reforma publicada DOF 4-05-2015) [en línea], http:// www.dof.gob.mx/nota_detalle.php?codigo $=5391143 \&$ fecha $=04 / 05 / 2015$ 
La Infodiversidad y el uso ético del conocimiento...

En general, las asociaciones profesionales del sector siempre se han preocupado por la conducta ética de sus agremiados en relación con los usuarios; algunas de forma genérica y otras de manera más específica. Más recientemente, esto se vio reflejado en los códigos de ética de las asociaciones que ya han introducido la preocupación no sólo por la conducta del bibliotecario, sino que extienden sus recomendaciones al empleo que hacen los usuarios de la información que obtienen a través de los servicios bibliotecarios. En estos enfoques recientes, las asociaciones toman en cuenta las facilidades tecnológicas y los nuevos derechos sociales como el acceso abierto, que potencia las posibilidades de trasgredir las normas éticas y los preceptos legales.

Hay dos asociaciones de gran liderazgo y cobertura que han encabezado recomendaciones y orientaciones sobre el uso abierto de la información, el derecho de autor y las actitudes del usuario: la American Library Association (ALA) y la International Federation of Library Association and Institutions (IFLA). Estas asociaciones han actuado en estrecha colaboración con un organismo rector mundial como la United Nations Educational, Scientific and Cultural Organization (UNESCO). Todos ellos han trabajado en conjunto, y si bien defienden el libre acceso a la información, también incluyen normas que regulan su uso y fomentan el uso ético de la misma, así como el respeto al derecho de autor.

Vale la pena destacar la "Postura de la IFLA sobre los Derechos de Autor en un Ambiente Digital":

- El derecho de autor equilibrado es para todo el mundo.

- Los bibliotecarios y los profesionales de la información reconocen y se comprometen a apoyar las necesidades de sus usuarios para obtener acceso a las obras protegi- 
El uso ético de la información: un diálogo entre bibliotecarios...

das por el derecho de autor y a la información e ideas que contienen éstas

- Se asume el respeto a las necesidades de los autores y de los titulares de derechos de autor para obtener una remuneración económica justa por su propiedad intelectual. ${ }^{11}$

Aunque se reconoce el liderazgo de la ALA y la IFLA, otras asociaciones de profesionales se han preocupado por la conducta ética de sus agremiados en su relación con la oferta de servicios de información, en su relación con los usuarios y en el uso que hacen éstos de esa información. Otras asociaciones o grupos colegiados incluyen esa inquietud en sus principios rectores. Así, podemos mencionar una de cobertura internacional que, en la actualidad, guía la práctica bibliotecaria y el futuro de la disciplina bibliotecológica y formaciones afines: la International Federation of Library Associations and Institutions (IFLA), que en su "Código de ética de la IFLA para bibliotecarios y otros trabajadores de la información" 12 recoge varios aspectos al respecto, así como transparencia en el uso de la información.

También existen códigos locales por país y por asociación o grupo colegiado, ${ }^{13}$ como por ejemplo el "Código ético para bibliotecarios y profesionales de la información en España” de la Sociedad Española de Documentación e In-

11 Postura de la IFLA sobre los Derechos de Autor en un Ambiente Digital [en línea], http://www.ifla.org/node/7300

12 IFLA, "Código de ética de la IFLA para bibliotecarios y otros trabajadores de la información” [en línea], http://www.ifla.org/files/assets/faife/codesofethics/spanishcodeofethicsfull.pdf

13 Genaro Luis García López (2015), "La privacidad en bibliotecas desde la perspectiva de la ética de la información”, en Jaime Ríos Ortega (Coord.), Análisis sobre tendencias de información propuestas por la IFLA, pp. 157170. 
La Infodiversidad y el uso ético del conocimiento...

formación Científica; ${ }^{14}$ el "Código de Ética de la Asociación Cubana de Bibliotecarios" 15 el "Código de ética profesional" del Colegio de Bibliotecarios de Chile, ${ }^{16}$ y el "Código de ética profesional" del Colegio de Bibliotecarios de México. ${ }^{17}$ En términos generales, cada uno se centra en el comportamiento ético del bibliotecario en cuanto a la imparcialidad, la censura, la relación con el usuario y la protección de su conducta informativa y sus datos personales; como constante, parece ausente la participación preventiva del bibliotecario en los actos de plagio, o robo de ideas de los materiales o información que utilizan los usuarios para preparar un nuevo escrito que asumen como propio, sin reconocer las autorías originales.

\section{INTERACCIÓN ENTRE USUARIOS Y BIBLIOTECARIOS}

En la actualidad, encontramos muchas facilidades tecnológicas que benefician el proceso y uso de la información y, a la vez, los altos costos de la información, sea ésta impresa o digital; por lo tanto, se han desarrollado movimientos sociales y académicos que buscan acceder a la información de manera libre y abierta, y plantean un acceso abierto como derecho social.

El bibliotecario se enfrenta a estas demandas sociales y, al mismo tiempo, a promover en sus usuarios una conduc-

14 Asociación Española de Documentación e Información, "Código de ética para bibliotecarios y profesionales de la información en España" [en línea], http://www.fesabid.org/sites/default/files/repositorio/codigo-etico-esp.pdf

15 Asociación Cubana de Bibliotecarios, "Código de Ética de la Asociación Cubana de Bibliotecarios" [en línea], http://www.cpicmha.sld.cu/metodologias/codigo-de-etica.pdf

16 Colegio de Bibliotecarios de Chile A.G., "Código de ética profesional" [en línea], http://www.ifla.org/files/assets/faife/codesofethics/chile.pdf

17 Colegio de Bibliotecarios de México, "Código de ética profesional" [en línea], http://biblio.colmex.mx/cnb/cnb-codigo.htm 
El uso ético de la información: un diálogo entre bibliotecarios...

ta ética en el uso de la información. La problemática en la bibliotecología es que muchos de los abusos a ciertos principios que respaldan el derecho a la información y el "derecho" de acceso abierto y los derechos de autor a la información no se dan precisamente en el bibliotecario, sino en el usuario, el cual utiliza la información que ya tiene un autor que con anterioridad registró sus ideas. En esta situación, ¿cuál sería la actitud y el trabajo que debería emprender el bibliotecario?

El acto ilegal o falta de ética en el proceso de investigación puede germinarse desde la concepción del proyecto o en alguna de sus fases posteriores: en el planteamiento de la hipótesis, que pretenderá probar algo que no está probado o que no existe evidencia. Además, dependiendo de la metodología, se irá desarrollando todo el proceso que se requiere, ya sea en el laboratorio o en el trabajo de campo y se cerrará el círculo con la publicación de los resultados, previa evaluación y arbitraje.

En todas estas etapas, el bibliotecario debería estar presente guiando, apoyando al grupo de investigación, verificando en fuentes específicas que den fe de otras investigaciones parecidas, de sus resultados, o bien, después de una búsqueda exhaustiva, se compruebe la originalidad de la idea y las correlaciones que se puedan encontrar entre los pares del universo temático de que se trate.

En la etapa de publicación, la biblioteca y el bibliotecario son auxiliares de primer orden para el equipo de investigación, ya que pueden responder muchas preguntas a los redactores, orientarlos acerca de cómo deben citarse las obras consultadas, aquellas que fueran antecedentes o proveedoras de información fundamental para la investigación en curso, así como reconocer a todos los participantes en el 
proceso académico también puede apoyar en los procesos de evaluación, dictamen, arbitraje y edición.

Un marco normativo que ayuda a promover la integridad académica que se refleja en la publicación de resultados es el trabajo del Committe on Publication Ethics (COPE) y la guía que ha generado: "Cooperation between Research Institutions and Journals on Research Integrity Cases." 18

La biblioteca y los bibliotecarios enriquecerán el trabajo del equipo académico verificando toda información que se requiera en el proceso, además de dar los elementos que se vuelven parte de un artículo, una publicación; por ello, también será útil su trabajo con los evaluadores y los editores, al proporcionar tanto la información como el manejo de software y otras TIC que permitan encontrar similitudes con otros textos publicados con anterioridad.

\section{CONSIDERACIONES FINALES}

Las facilidades tecnológicas a las que invita el acceso abierto sin límites, la falta de promoción y la formación de valores en el proceso educativo, han provocado que la legislación internacional del derecho de autor y las versiones locales de cada país pongan más atención en las limitaciones y las excepciones de uso abierto a las obras protegidas por el derecho de autor; asimismo, ha habido un incremento del empleo de medidas de protección tecnológica para acceder

18 Eric C Mah (2014), "How Journals and Institutions can Work Together to Promote Responsible Conduct", pp. 143-145.

COPE, The Committee on Publication Ethics [en línea], http://publicationethics. org/

Cooperation between Research Institutions and Journals on Research Integrity Cases: Guidance from the Committee on Publication Ethics [en línea], http:// www.ncbi.nlm.nih.gov/pmc/articles/PMC3385259/ 
El uso ético de la información: un diálogo entre bibliotecarios...

a la información y a la implementación de restricciones legales de las licencias de uso de las obras protegidas. ${ }^{19}$

En realidad, la sociedad actual se encuentra ante dos derechos que a veces pareciera que van por vías paralelas y a veces divergentes. En ese sentido, necesitamos que, en algún momento, las líneas se vuelvan convergentes y surja un dialogo entre las dos esferas, para beneficio del crecimiento de la ciencia y de los ciudadanos que desean tener acceso al conocimiento y la cultura. Si bien a nivel internacional la ley de derechos de autor tiene sus orígenes con el Convenio de Berna, en el siglo XIX, y si bien el derecho a la información y el acceso abierto son producto más específico con declaraciones y leyes que se dan en el contexto políticosocial de la segunda mitad del siglo xx, también tenemos que ver su evolución y las necesidades que se generan en el contexto de sociedades del siglo XXI y propiciar un diálogo donde las necesidades de información como insumo fundamental de todo proceso educativo se vean reflejadas y que todos confluyan para hacer realidad una Sociedad de la Información y el Conocimiento accesible a todo ser humano: niño, joven, adulto.

Esta divergencia de opiniones ha llevado a que organizaciones relacionadas con la propiedad intelectual, como la Organización Mundial de la Propiedad Intelectual (OMPI), a través de su Comité Permanente de Derecho de Autor y Derechos Conexos, trabajen sobre el tema con la colaboración de asociaciones de bibliotecarios como la ALA y la IFLA y que en su decimoséptima sesión en Ginebra, del 3 al 7 de noviembre de 2008, haya dado a conocer el Estudio sobre las limitaciones y excepciones al derecho de autor en beneficio de bibliotecas y archivos, preparado por Kenneth

19 Organización de las Naciones Unidas para la Educación, la Ciencia y la Cultura [en línea], http://es.unesco.org/ 
La Infodiversidad y el uso ético del conocimiento...

Crews, director de la Oficina asesora de derecho de autor de la Universidad de Columbia. ${ }^{20}$

El trabajo coordinado entre los bibliotecarios y otros organismos - los cuales marcan tendencia sobre aspectos de legislación de derechos de autor, así como políticas públicas sobre derechos humanos y sociales que promueven el uso de la información como derecho- se realiza, cada vez, con más frecuencia. Además, los autores, los usuarios, los bibliotecarios y los legisladores están convencidos de que el uso de la información y las normas éticas y legales que regulan tal empleo son una prioridad de primer orden por la importancia que tiene en la formación, desarrollo y crecimiento de todo ciudadano, así como de la sociedad y el país a que éste pertenece.

\section{BIBLIOGRAFÍA}

Asociación Española de Documentación e Información, "Código de ética para bibliotecarios y profesionales de la información en España" [en línea], http://www.fesabid.org/sites/default/files/ repositorio/codigo-etico-esp.pdf

Asociación Cubana de Bibliotecarios, "Código de Ética de la Asociación Cubana de Bibliotecarios" [en línea], http://www. cpicmha.sld.cu/metodologias/codigo-de-etica.pdf

Campa Mendoza, Víctor (2008), Seminario de ética. La ética y la moral. Fundamentos, conceptos y normas, valores y deberes, Durango, Instituto Tecnológico de Durango.

20 Organización Mundial de la Propiedad Intelectual (OMPI), Estudio sobre las limitaciones y excepciones al derecho de autor en beneficio de bibliotecas y archivos [preparado por Kenneth Crews], Ginebra, Comité Permanente de Derecho de Autor y Derechos Conexos (Decimoséptima sesión Ginebra, 3 a 7 de noviembre de 2008), 2008 [en línea], http://www.wipo.int/edocs/ mdocs/copyright/es/sccr_17/sccr_17_2.pdf 


\section{El uso ético de la información: un diálogo entre bibliotecarios...}

Colegio de Bibliotecarios de Chile A.G., "Código de ética profesional" [en línea], http://www.ifla.org/files/assets/faife/codesofethics/chile.pdf

Colegio de Bibliotecarios de México, "Código de ética profesional" [en línea], http://biblio.colmex.mx/cnb/cnb-codigo.htm

Constitución Política de los Estados Unidos Mexicanos (Constitución publicada en el Diario Oficial de la Federación el 5 de febrero de 1917. Última reforma publicada DOF 27-01-2016) [en línea], http://www.diputados.gob.mx/LeyesBiblio/htm/1.htm

Cooperation between Research Institutions and Journals on Research Integrity Cases: Guidance from the Committee on $\mathrm{Pu}-$ blication Ethics [en línea], http://www.ncbi.nlm.nih.gov/pmc/ articles/PMC3385259/

COPE, The Committee on Publication Ethics [en línea], http://publicationethics.org/

Dewey, Melvil, “The Profession”, Library Journal, Vol. 1, September, 1876, pp. 5-6.

Declaración de los derechos del hombre y del ciudadano (1789) [en línea], http://historico.juridicas.unam.mx/publica/librev/ rev/derhum/cont/22/pr/pr19.pdf

Declaración Universal de los Derechos Humanos [1948], Artículo 19 [en línea], http://www.ohchr.org/EN/UDHR/Documents/ UDHR_Translations/spn.pdf

Foskett, Douglas, John (1962), The Creed of a Librarian: No Politics, No Religion, No Morals, London, The Library Association.

García López, Genaro Luis (2015), "La privacidad en bibliotecas desde la perspectiva de la ética de la información” (pp. 157-170), en Jaime Ríos Ortega (Coord.), Análisis sobre tendencias de información propuestas por la IFLA, México, UNAM / IIBI - IFLA.

IFLA, "Código de ética de la ifla para bibliotecarios y otros trabajadores de la información" [en línea], http://www.ifla.org/files/ assets/faife/codesofethics/spanishcodeofethicsfull.pdf 
La Infodiversidad y el uso ético del conocimiento...

Ley de Ciencia y Tecnología (Nueva Ley publicada en el Diario Oficial de la Federación el 5 de junio de 2002. Última reforma publicada DOF 20-05-2014) [en línea], https://www.inaoep. $\mathrm{mx} / \sim j g o b / h j g /$ Facultades/LeyCT.pdf

Ley Federal del Derecho de Autor (Nueva Ley publicada en el Diario Oficial de la Federación el 24 de diciembre de 1996. Última reforma publicada DOF 27-01-2012) [en línea], http://www.uaa. $\mathrm{mx} /$ direcciones/dgdv/editorial/docs/lda.pdf

Ley Federal de Transparencia y Acceso a la Información Pública Gubernamental (Nueva Ley publicada en el Diario Oficial de la Federación el 11 de junio de 2002. Última reforma publicada DOF 4-05-2015) [en línea], http://www.dof.gob.mx/nota_detalle.php?codigo $=5391143 \&$ fecha $=04 / 05 / 2015$

Mah, Eric C. (2014), "How Journals and Institutions can Work Together to Promote Responsible Conduct", J. Microbiol Biol Educ, 15(2): Dec, pp. 143-145.

Organización de las Naciones Unidas para la Educación, la Ciencia y la Cultura [en línea], http://es.unesco.org/

Organización Mundial de la Propiedad Intelectual (OMPI), Estudio sobre las limitaciones y excepciones al derecho de autor en beneficio de bibliotecas y archivos [preparado por Kenneth Crews], Ginebra, Comité Permanente de Derecho de Autor y Derechos Conexos (Decimoséptima sesión Ginebra, 3 a 7 de noviembre de 2008) [en línea], http://www.wipo.int/edocs/ mdocs/copyright/es/sccr_17/sccr_17_2.pdf

Postura de la IFLA sobre los Derechos de Autor en un Ambiente Digital [en línea], http://www.ifla.org/node/7300

Preer, Jean (2008), Library Ethics, Libraries Unlimited. 


\title{
La ética ciudadana frente al respeto de los saberes individuales y colectivos
}

\author{
Alejandro Ramos CháveZ
}

Universidad Nacional Autónoma de México

INTRODUCCIÓN

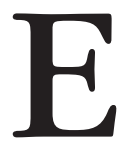

n las discusiones sobre la construcción de ciudadanía, no es frecuente encontrar estudios que aborden el tema de la ética ciudadana, lo cual, de cierta forma, debería guiar la actuación de los ciudadanos en diferentes facetas de su vida social. En este sentido, en el presente documento se toma en consideración el tema de la ética ciudadana y las virtudes cívicas, ejemplificando la discusión teórica con el caso específico del plagio y su impacto social. Por tanto, el objetivo del trabajo no es el de analizar la repercusión que tiene el plagio en el ámbito escolar o de investigación, pues existe una extensa y muy importante bibliografía que ya toma en consideración ese aspecto, sino que el análisis se centrará en el impacto que tiene el plagio en una dimensión más amplia, es decir, en el plano del sentimiento y la forma en la que la sociedad toma los casos de plagio.

En consonancia con este objetivo, el desarrollo estará integrado por cuatro apartados generales. En el primero se 
La Infodiversidad y el uso ético del conocimiento...

tomará en consideración el tema de la ciudadanía, examinando algunas interpretaciones con objeto de diferenciar los planos civil y cívico del concepto.

Posteriormente, en el segundo, se reflexionará el tema de la ética ciudadana y las virtudes cívicas, con objeto de identificar y diferenciar los comportamientos que recaen en un plano específico de actuación del individuo, sobre aquellos comportamientos que tienen un impacto más amplio, es decir, un impacto social.

En el tercer apartado se abordará el concepto de plagio, y cómo éste supera los ámbitos académico, intelectual y profesional en el cual se comete, y cómo su impacto y trascendencia repercuten en un plano de injerencia y castigo social.

Finalmente, en el cuarto apartado se pondrán a consideración algunos casos, en diferentes latitudes, que ilustran cómo el plagio ha desencadenado procesos de repudio y castigo social.

\section{ANOTACIONES SOBRE EL CONCEPTO DE CIUDADANÍA}

Entrando al primero de los elementos, es decir el de ciudadanía, el surgimiento del concepto mismo ha sido analizado desde dos perspectivas interpretativas que no se contraponen, sino que se vinculan para dar cuenta de la idea general de ciudadanía. Ésta es visualizada como un estatus en el que los individuos adquieren tanto derechos como obligaciones; tanto libertades como restricciones; tanto poderes como responsabilidades. En este sentido, la primera perspectiva se relaciona con la civilidad, que según Viera "[...] es la actitud individual de preocupación por el bien público, es decir, la conducta de una persona cuya autoconciencia individual está parcialmente sobredeterminada por su 
La ética ciudadana frente al respeto de los saberes individuales...

autoconciencia colectiva" (1998: 218). En esta perspectiva se enfatizan valores, como el de la participación política, al atribuirles a los individuos un papel fundamental en el desarrollo de una comunidad política. Lo anterior se podría acercar a las premisas de virtud, señaladas por Montesquieu (1942), relacionadas con el amor a la República y a la democracia. La mayoría de trabajos que analizan la temática de la ciudadanía se han centrado fundamentalmente en esta perspectiva, al abordar aspectos como el de la participación ciudadana y la vinculación de los individuos con las formas de gobierno y con la política en general.

Desde esta perspectiva, se vio al individuo no sólo como un ente sin ninguna injerencia en los procesos de gobierno, sino a individuos que, mediante la deliberación y argumentación de ideas, pueden participar en la forma de ejercer el gobierno y en la elaboración de políticas y programas públicos. Lo anterior se dio en gran medida, por lo que se ha señalado en relación a que:

[...] en las últimas décadas del siglo xx la democracia consolidó ampliamente su legitimidad frente a otras formas de gobierno. Sin embargo las dificultades de los países para afrontar los problemas económicos que trae aparejados el capitalismo tardío, generaron una situación de violencia estructural donde la pobreza, la alienación, la corrupción generalizada y la crisis de representación por la falta de credibilidad de las figuras políticas, disminuyen la confianza de la ciudadanía en este régimen (Albarracín, 2002: 254).

Ante estas situaciones, la ciudadanía tomó un papel mucho más dinámico en la forma de ejercer sus opciones de participación política, alejada de los partidos políticos y sindicatos, los cuales anteriormente contaban con un poder fundamental de representación social (Lechner, 2000). 
La Infodiversidad y el uso ético del conocimiento...

En este marco, como lo han llegado a considerar algunos autores, se supondría que todos los ciudadanos tienen la mima capacidad para participar; es decir, que todos los individuos cuenten con una cualificación homogénea para poder participar de la misma forma en los diferentes procesos de toma de decisión política que implica la democracia (Dahl, 1999). Sin embargo, esta igualdad está lejos de ser una realidad en muchos países del orbe. En este sentido, es fundamental tomar en consideración las diferencias y asimetrías existentes en muchas áreas que imposibilitan una participación homogénea. Una de ellas es la del acceso a información socialmente relevante, que les puede permitir a todos los ciudadanos participar. Lejos de que este igualitario acceso a la información sea una realidad, existen brechas muy profundas entre los que tienen información oportuna y relevante - y por ello tienen más posibilidades de participar-, con aquellos que no tienen acceso a información, por lo que su participación es escasa o nula, siendo estas últimas personas las que se encuentran en una posición de vulnerabilidad y atraso en relación con las primeras.

En este marco se ha llegado a argumentar la necesidad de hablar, más que de una igualdad con el concepto de ciudadanía, hacer referencia a ciudadanías diferenciadas (Winocur, 2003), en donde hay ciudadanos de alta intensidad, por su capacidad de obtener información útil y participar, y ciudadanía de baja intensidad que no cuenta con los mecanismos para informarse y participar más que en los procesos coyunturales de elección de representantes mediante el voto. Sin embargo, se ha mencionado que:

[...] hasta en esta ciudadanía de baja intensidad los ciudadanos necesitan información sobre sus derechos, las situaciones políticas, sociales y económicas de su nación, así como las propuestas 
de candidatos a ocupar los cargos públicos, con objeto de ejercer de forma responsable el derecho al voto (Ramos, 2016: 6).

Para algunos autores la definición misma de la ciudadanía se encuentra rebasada (Correa \& Noé, 1998; Dasí, 2005; Habermas, 1998; Kymlicka \& Norman, 1997; Valente, 2000). Por ello, resulta esencial realizar esa diferenciación entre tipos de ciudadanía; tipología que se encuentre fincada en el principio de participación e involucramiento de la ciudadanía con el gobierno, los asuntos públicos y el quehacer gubernamental. En este sentido, existen dos medios por los que en la actualidad la ciudadanía puede obtener información: las Tecnologías de la Información y la Comunicación (TIC) y las bibliotecas públicas.

Por otro lado, existe una segunda perspectiva en los análisis de la ciudadanía relacionada con el civismo, entendido como las pautas de comportamiento que les permiten a los individuos vivir en sociedad. Este civismo se ve reflejado en el respeto mutuo hacia el entorno, hacia los demás individuos y hacia los objetos públicos; y su incumplimiento genera una desaprobación social, como lo es el caso del plagio, según lo veremos con los casos que analizaremos más delante (para una mayor comprensión entre los campos específicos que aborda la civilidad y el civismo ciudadano, véase el Cuadro 1). En esta perspectiva se inserta de forma más amplia el tema descrito por Heller (1989), como la "ética ciudadana y las virtudes cívicas". 
La Infodiversidad y el uso ético del conocimiento...

Cuadro 1.

Campos específicos de la civilidad y el civismo ciudadano

\begin{tabular}{|c|c|}
\hline \multicolumn{2}{|c|}{ Ciudadanía } \\
\hline Civilidad & Civismo \\
\hline $\begin{array}{c}\text { La pertenencia del individuo a una comunidad política } \\
\text { política de la comunidad. }\end{array}$ & Pautas de comportamiento. \\
\hline \begin{tabular}{c} 
La posibilidad de pociedad. \\
\hline $\begin{array}{c}\text { Premisas de virtud como las del amor a la República y a } \\
\text { la Democracia mencionadas por Montesquieu. }\end{array}$
\end{tabular} & $\begin{array}{c}\text { Respeto mutuo hacia el entorno, hacia los demás indivi- } \\
\text { duos y hacia los objetos públicos. }\end{array}$ \\
\hline Formas de gobierno y participación ciudadana. & Ética ciudadana y las virtudes cívicas. \\
\hline
\end{tabular}

Fuente: elaboración propia.

\section{LA ÉTICA Y LAS VIRTUDES CÍVICAS DE LA CIUDADANÍA}

En este apartado se analizarán los temas específicos de las virtudes cívicas y la ética que podría moldear el comportamiento de las personas. En este sentido, Heller (1989), estudiando la moral desde una perspectiva de la relación práctica del individuo hacia las normas y las reglas de buena conducta, menciona que hay tres esferas de toda sociedad: la esfera de lo cotidiano, la esfera de las instituciones políticas y económicas, y la esfera de las ideas y prácticas culturales, siendo esta última la más importante, pues dota de significados a las visiones del mundo, le otorga un sentido a la vida, además de que legitima las otras dos esferas. Todas estas esferas, así como las subdivisiones que se le pueden hacer a cada una de ellas, están determinadas por normas y reglas de conducta que adecuan la relación del individuo para consigo mismo así como para con la sociedad. Lo anterior se acerca a lo que Hegel (1999) denominó como Sittlichkeit, que aunque su traducción literal es la de moralidad (entendida como las costumbres de comportamiento que guían la vida de las personas en sociedad), Hegel la di- 
La ética ciudadana frente al respeto de los saberes individuales...

ferenciaba de ésta e incluía en su definición aspectos como el de la vida ética y el orden ético de las cosas (Wood, 1991).

En este punto, se ha señalado que "[...] existen normas y reglas de conducta adecuada en todos los campos de acción, interacción y comunicación" (Heller, 1989: 215), es decir, en cada campo se generan propias normas comunes de Sittlichkeit. El trabajo intelectual y de investigación no escapa a esto, y los que se dedican a ello tienen, o deberían tener presente, ese desarrollo ético del campo específico de la vida intelectual y de investigación.

En este punto surge la siguiente interrogante: ¿el respeto de la Sittlichkeit o del orden ético del trabajo intelectual sólo impacta al propio campo de la investigación y la docencia, o impacta en un plano social y ciudadano para su aprobación o castigo?

Esta interrogante surge al tomar en consideración lo estipulado por la propia Heller, cuando menciona que el comportamiento que tengamos en otras áreas de la vida, no necesariamente impactan en un ámbito de la ética ciudadana; ante lo cual pone una serie de ejemplos: como lo son el de que se visite o no a un amigo enfermo que está en el hospital, el ser amable o antipático, o el ser generoso o tacaño, pues estos elementos no influyen directamente en el que se sea un buen o mal ciudadano. Estos ejemplos intentan señalar, en pocas palabras, que la ética ciudadana no abarca la ética en su totalidad.

Lo que parece ser una realidad es que en cada campo de actuación de los seres humanos existen códigos específicos, que inclusive llegan a establecerse como una autoridad, la mayoría de las veces de carácter informal por no poseer jurisprudencia específica; sin embargo:

[...] el reconocimiento de la autoridad de la tradición en un campo relevante no es una sumisión irracional que clausura la au- 
La Infodiversidad y el uso ético del conocimiento...

tonomía de las personas que a ella se adhieren, sino que, como argumenta Gadamer, es un acto de la razón y de la libertad de las personas que reconocen relación a los criterios, valores y principios de la tradición sobre su mero juicio personal (Velasco-Gómez, 2000: 31).

En este mismo sentido, esa libertad de criterio frente a los principios establecidos como tradiciones de autoridad en un campo, bajo ningún motivo, pueden darse mediante el engaño o el robo de información que no sea propia, por lo que el plagio, en el campo específico de la producción académica, no puede llegar a atribuirse como criterio utilizable en el quehacer intelectual.

Ante esto, diversos autores han contribuido a buscar las principales virtudes que se podrían considerar como verdaderas condicionantes generales para la buena vida en colectividad, y por ello, llegar a constituir un corpus de virtudes cívicas esenciales aplicables a todos los ciudadanos. Es decir, encontrar un conjunto de virtudes cívicas ciudadanas que se relacionen con los bienes de valor intrínseco comúnmente compartidos. En este sentido Heller (1989) ha enumerado por lo menos seis virtudes cívicas esenciales:

1. Tolerancia radical al reconocimiento de todas las necesidades humanas, y estar en desacuerdo de la utilización humana como mero medio para alcanzar algún propósito, como las situaciones de opresión y dominación, o las prácticas violentas o sádicas. Este tipo de virtud debería guiar una forma de vida que apunte a la lucha por las cuestiones que se consideren injustas, y dejar de lado la tolerancia que muchas veces se genera, sabiéndose de antemano que la situación determinada radica en cuestiones de fuerza y opresión. 
La ética ciudadana frente al respeto de los saberes individuales...

2. Valentía cívica, de alzar la voz ante las injusticias, aunque con ello podamos acarrearnos ciertas problemáticas personales. Es decir, poseer la virtud a pesar de llegar a ubicarnos en posiciones y situaciones de desventaja de donde partimos, tales como posición laboral o social, la pertenencia a asociaciones e inclusive poder llegar a quedar aislados por defender nuestro punto de vista.

3. La solidaridad, tanto al interior de los grupos específicos a los que se pertenezca, pero también a los otros en los que no se participe directamente, mediante un sentimiento de simpatía o empatía. Lo anterior implica sentimientos de equidad que apuntan a la necesidad de revertir o disminuir los distintos tipos de desigualdades socialmente existentes entre los individuos.

4. La justicia, que es considerada como la virtud cívica de más antigua data, que implica el obrar y juzgar siendo respetuoso con la verdad, otorgándole a cada quien lo que le corresponde. En este sentido, y haciendo una alusión directa a la información, se ha mencionado que "[...] el juicio justo ha de estar también bien informado. Se pueden rechazar opiniones y justificaciones una vez que se hayan escuchado, pero no antes" (Heller, 1989: 229).

5. La fronesis o la prudencia, que se traduce en el buen juicio de actuación social, es decir, en la negación de:

[...] basarnos sólo en la prudencia para determinar si una norma es buena o mala, correcta o equivocada. Pero si en el proceso de deliberación o contestación ciertas normas y reglas resultan ser buenas, correctas, mejores o más correctas que las otras, tenemos que aplicarlas del modo debido, y es precisamente en el proceso que aplicación cuando necesitamos la virtud de la fronesis (Heller, 1989: 230). 
La Infodiversidad y el uso ético del conocimiento...

Por último, pero quizá la virtud cívica que se vincula de forma más directa con lo discutido en este capítulo, se encuentra:

6. La virtud intelectual, que ha sido señalada como la virtud más sobresaliente del buen ciudadano, pues es la capacidad propia que tenga cada individuo para participar, mediante el discurso o la redacción, en la forma en la que vive la sociedad. En este sentido, parte fundamental de esta virtud intelectual la constituye precisamente el respeto a los saberes individuales y colectivos. La contradicción a este último valor podría manifestarse en el plagio, pero debido a que es un valor esencial, tendría una repercusión y castigo social. Estos elementos serán abordados en el siguiente apartado.

\section{PLAGIO Y SU IMPACTO SOCIAL}

Dando una definición para contextualizar el uso del concepto de plagio, se pueden mencionar las contribuciones de Soto (2012), que argumenta que:

- El plagio ocurre cuando se toman ideas o palabras escritas por otros sin reconocer de forma directa el haberlo hecho.

- Se produce también al presentar como propio un trabajo de forma parcial o total sin ser el autor o autora de dicho trabajo.

- Al actuar de mala fe deliberadamente al copiar la propiedad intelectual de otros para producir un daño a los autores originales.

- Se considera que se comete plagio al copiar cualquier objeto de fondo o de forma, ya sea una situación, un desarrollo o incluso una simple frase (Soto, 2012: 2). 
La ética ciudadana frente al respeto de los saberes individuales...

El mismo autor refiere que el plagio puede llegar a considerarse en la actualidad como un problema muy serio, pues al tiempo que atenta contra los derechos de autor, también resulta en un acto que es éticamente reprochable, y desafortunadamente, pese a su gravedad, se está convirtiendo en un problema común (Soto, 2012). Lo anterior tiene como marco de referencia la amplia oferta de literatura especializada, trabajos científicos y contenidos digitales que son distribuidos de forma libre por Internet, así como por la cada vez más notoria tendencia de la utilización de ese conjunto de redes para encontrar información, tanto en buscadores, en bases de datos especializadas, así como en bibliotecas digitales. Esto último implica una simplificación del copiado de los textos originales a los plagiados; sin embargo, las herramientas y aplicaciones de búsqueda de plagios en cualquier documento encuentran en Internet a su mejor aliado, al realizar búsquedas exhaustivas para corroborar la autenticidad de los documentos. Lo anterior apunta a comprender a Internet como una herramienta de doble filo para los plagiarios, pues al tiempo que facilita los procesos de copia, simplifica la búsqueda de los plagios.

En este contexto se han tratado de establecer conceptos que hagan referencia precisamente al copiado de textos desde Internet, como lo es el de "ciber-plagio". De forma específica se ha hecho mención a que:

[...] la irrupción de las tecnologías de la información y la comunicación (TIC) también ha provocado o facilitado importantes cambios que no pueden valorarse de forma positiva. Es el caso del llamado ciber-plagio académico. Adoptar y presentar como propias ideas, teorías e hipótesis de otros no es algo nuevo, pero las tecnologías asociadas a la Sociedad de la Información (SI), sobre todo Internet y más concretamente el World Wide Web (www), facilitan enormemente esta práctica éticamente reprobable y académicamente incorrecta (Comas \& Sureda, 2007). 
La Infodiversidad y el uso ético del conocimiento...

Tomando en consideración el aumento en los casos de plagio académico encontrados alrededor del mundo, se ha llegado a argumentar que se debería considerar el plagio científico como un delito, por lo cual se ha recomendado sea tratado como tal por las siguientes razones:

1. Es un acto consciente de apropiación de ideas o textos pertenecientes a otros;

2. Se oculta la fuente original, sea omitiendo declararla o citándola en un contexto o ubicación distinta a la que haría reconocer su identidad con el "nuevo" texto de la obra;

3. Tiene la intención de engañar al lector, pretendiendo que atribuya al plagiario el mérito de originalidad de la idea que se expresa o del texto al que se alude (Reyes, 2009).

Con estos antecedentes cabría preguntarse por qué el plagio resulta en una cuestión socialmente reprobable al no quedarse en un mero acto de la realización de un trabajo específico, en este caso el académico o el de investigación. Por el contrario, el plagio genera un descontento social por su connotación negativa a la ética cívica. En este sentido, realizando una retrospección a la noción de ciudadanía y su vínculo directo con la civilidad, se ha mencionado que la civilidad encierra una noción de amabilidad y posible llegada a acuerdos, así como de acciones que no redunden en procesos de incivilidad (Villavicencio, 2007). Por lo tanto, los actos del robo de ideas y del engaño que se da en los casos de plagio son acciones que se ubican en sentido contrario a cada una de las ideas generales de civilidad y, en consecuencia, están sujetas a un castigo social. Algunos ejemplos de casos y su repercusión social serán brevemente abordados en el siguiente apartado. 
La ética ciudadana frente al respeto de los saberes individuales...

CASOS DE PLAGIO Y SU CASTIGO SOCIAL

Desafortunadamente hay varios casos sobre la temática del plagio y su impacto en la sociedad, relacionados en el plano académico, los cuales han tenido una resonancia importante en los medios de comunicación. Ejemplo de ello en México son unos casos muy sonados que se dieron en el año 2015 y que pusieron en entredicho no sólo a las instituciones en las que laboraban los investigadores y plagiarios, sino al Sistema Nacional de Investigadores (SNI) del Consejo Nacional de Ciencia y Tecnología (CONACyT), tanto por lo ventilado de los casos en los medios como por su viralización en redes sociales, donde los ciudadanos reprochaban fuertemente el inapropiado comportamiento de los plagiarios, así como cuestionaban el pago de los estímulos académicos que poseían los plagiarios; estímulos que por otra parte tenían como financiamiento el erario. En este sentido, existen muchos otros casos que dan muestra de plagios, así como el impacto social que han tenido, en un plano más político que académico, además de las consecuencias que han desatado esas mismas prácticas. A continuación algunos de estos casos serán puestos a consideración, con objeto de conocer el impacto social y los efectos socio-políticos que han tenido.

\section{Proceso electoral presidencial del Perú del 2016}

El primer caso analizado se dio en el proceso electoral presidencial del Perú. En enero del año 2016 Cesar Acuña (de la Alianza para el Progreso del Perú) se ubicaba en el segundo lugar de intención de voto, con el $15.2 \%$ de la preferencia electoral, sólo superado por la candidata del partido Fuerza Popular, Keiko Fujimori, con el 32.1\% de la preferencia. A fi- 
La Infodiversidad y el uso ético del conocimiento...

nales de ese mismo mes, enero, se dio a conocer que la tesis de doctorado de Cesar Acuña, llevada a cabo en la Universidad Complutense de Madrid, era un plagio y que copiaba íntegramente grandes apartados de otros trabajos, a lo que el mismo candidato aludiría que como el título y las conclusiones sí eran originales, no se podía hablar de plagio. A consecuencia de este escándalo Cesar Acuña pasó en menos de un mes del segundo al cuarto lugar en la intención del voto y del $15.2 \%$ al $7.3 \%$ de intención de votos, lo que representó la pérdida de más del $50 \%$ de sus preferencias en sólo 15 días, según la Compañía peruana de estudios de mercados y opinión pública (CPI). A final de cuentas, en marzo del 2016 y en la antesala de las elecciones, el Jurado Nacional de Elecciones del Perú decidió por unanimidad quitar la candidatura a Cesar Acuña, no precisamente por ese antecedente del plagio, sino por manejos indebidos de recursos monetarios durante su campaña política. Lo que parece ser una verdad del caso es que su campaña estuvo dividida en dos grandes momentos, separados justamente por el efecto que implicó el plagio, por la pérdida de credibilidad y apoyo social.

\section{Casos de Alemania}

En Alemania ha existido todo un movimiento por conocer los trabajos académicos (sobre todo su originalidad) de los funcionarios públicos. En la actualidad personajes como Martin Heidingsfelder, mejor conocido como el "cazador de plagiarios", mediante una página en Internet, la cual tiene muchos suscritores, publica información sobre sus hallazgos de plagios de políticos. El nombre de la página es el VroniPlag ${ }^{1}$ debido al primer caso que documentó, el de Ve-

1 http://de.vroniplag.wikia.com/wiki/Home 
La ética ciudadana frente al respeto de los saberes individuales...

ronica Sass, prestigiosa abogada y figura del partido alemán Unión Social Cristiana de Baviera (CSU), partido hermano del Unión Demócrata Cristiana (CDU) de la canciller Angela Merkel, la cual, después de demostrársele el plagio de su tesis doctoral, renunció al título y se alejó de la vida pública. Posteriormente a este caso, en el año 2011 se comprobó que el ministro de defensa alemán, entonces en funciones, Zu Guttenberg, también había plagiado prácticamente la totalidad de su tesis doctoral, lo que ocasionó tanto la pérdida de su título así como su dimisión del cargo. De igual forma, en el año 2013, la entonces ministra de educación, la democristiana Anette Schavan, fue sustituida del cargo por instrucciones de Merkel, al demostrársele también el plagio de su tesis doctoral, por lo que también se le revocó su título de doctora. Esto representó un duro golpe para Merkel pues Shavan era una de sus aliadas más firmes no sólo en el partido CDU, sino también en el gobierno. En total son cinco cancilleres los que han caído en Alemania por plagio en sus trabajos de tesis desde el 2011, y uno más, también dado a conocer por Martin Heidingsfelder, está tomando los reflectores de la vida política en Alemania, pues está en entredicho la originalidad de 27 páginas de la tesis doctoral en medicina de la actual ministra de defensa (desde 2013), Ursula von der Leyen, quien por otro lado ha dejado de manifiesto su interés de postularse al cargo de canciller en Alemania.

\section{Más casos}

Un caso más es el del ex primer ministro rumano Victor Ponta (durante el periodo 2012-2015), quien renunció públicamente en el año 2014, sin que hasta el momento lo haya realizado formalmente, al grado de doctor en derecho 
La Infodiversidad y el uso ético del conocimiento...

de la Universidad de Bucarest, al demostrársele en la publicación de una noticia de la página de la revista Nature, ${ }^{2}$ el plagio en por lo menos 80 páginas de su tesis doctoral. Este caso no repercutió directamente en su destitución, sino que quedó reflejado en una denuncia penal que no le impidió terminar su periodo en el gobierno. Este caso resulta interesante porque el castigo, a pesar de la existencia de un malestar social generalizado por el plagio realizado, además de una aceptación personal de Ponta de haberlo hecho, no desembocó, como en los casos alemanes, en una revocación de sus funciones públicas, lo que se traduce en que el entramado político-institucional superó en fuerza a la opinión pública.

De igual forma, en la actualidad está en investigación la revocación del grado de doctor, por un caso por plagio de tesis, que está realizando la Universidad de Barcelona, una vez que una comisión técnica acreditó la copia de por lo menos cuatro páginas de la tesis ${ }^{3}$ del líder europeo del Consejo Ejecutivo de Convergencia (CDC) y exvicepresidente del Partido Alianza de los Liberales y Demócratas por Europa (ALDE), Marc Guerrero. Este caso, más que un impacto político en la carrera de Guerrero, se ha enfrascado en una discusión en el que él acusa de difamación e injuria, pues ha alegado que si bien hay unos párrafos copiados, éstos no alteran la propuesta de fondo de su investigación doctoral. En general, se da cuenta tanto de la viralización que pueden llegar a alcanzar en muy pocos días estos casos, así como del descontento y malestar ciudadano que orillan a implementar castigos ejemplares a los mismos.

2 http://www.nature.com/news/conflicting-verdicts-on-romanian-prime-minister-s-plagiarism-1.11047

3 http://ccaa.elpais.com/ccaa/2016/04/16/catalunya/1460835697_655467.html 
La ética ciudadana frente al respeto de los saberes individuales...

\section{REFLEXIONES FINALES}

El concepto de ciudadanía hace referencia a por lo menos dos perspectivas de responsabilidad e involucramiento de los individuos. En primer lugar, desde un punto de vista de civilidad se hace referencia a la vinculación e interés ciudadano por participar en la forma en que son atendidos los asuntos públicos y en la política en general. Por otro lado, desde una perspectiva cívica se hace alusión a virtudes cívicas que todos los ciudadanos deben de cultivar, pues atribuyen valores intrínsecos a instituciones comúnmente compartidas que posibilitan y refuerzan la vida en sociedad.

El respeto a los saberes individuales o colectivos forma parte de la ética ciudadana, al relacionarse con una de las virtudes cívicas ciudadanas mencionadas anteriormente, la de la virtud intelectual, por lo que, como lo mostraron los ejemplos mencionados, su incumplimiento genera un malestar social y por el peso de viralización que se puede dar de los casos en la actualidad, por el uso de las TIC, pueden desembocar en castigos ejemplares.

En este sentido, Internet se ha venido consolidando como un lugar que permite obtener información y enriquecer los trabajos intelectuales y científicos; sin embargo, su mal uso puede facilitar prácticas deshonestas como el plagio. En este mismo sentido, a la par de que Internet se constituye como la herramienta más utilizada para realizar plagios, también es el principal medio para encontrarlos, y dependiendo de su nivel de impacto, influir en un castigo ejemplar.

Finalmente, sería oportuno compartir el punto de vista de que las bibliotecas públicas, en su entendimiento, siguiendo los aportes de Barbara Ford (2002), como terceros espacios en donde se desarrollan actividades como el de la información y el encuentro social, también deberían de ser 
La Infodiversidad y el uso ético del conocimiento...

lugares en los cuales se refuercen las virtudes cívicas y la ética ciudadana, como valores primigenios para garantizar la vida social. En este sentido, el respeto a los saberes individuales y colectivos es, y debería enfatizarse más en ello, parte fundamental de las virtudes éticas que permitirían un mejor desempeño de los individuos en sociedad.

\section{BIBLIOGRAFÍA}

Albarracín, D. (2002). Democracia y competencia cívica en tiempos de economías posnacionales. Violencia, instituciones educación, (1), 254-259.

Comas, R., \& Sureda, J. (2007). Ciber-Plagio Académico. Una aproximación al estado de los conocimientos. Revista TEXTOS de la CiberSociedad, (10). Recuperado a partir de: http://www. cibersociedad.net/textos/articulo.php?art=121

Correa, E., \& Noé, M. (Eds.) (1998). Nociones de una ciudadanía que crece. Santiago de Chile: FLACSO-Chile.

Dahl, R. (1999). La democracia. Una guía para ciudadanos. Buenos Aires: Taurus.

Dasí, J. (2005). Nuevas formas de gobernanza para el desarrollo sostenible del espacio relacional. Ería, 67, 219-235.

Ford, B. J. (2002). Todos son bienvenidos: la biblioteca pública como espacio de integración ciudadana. En I Congreso Nacional de Bibliotecas Públicas (pp. 191-200). Recuperado a partir de: http://dialnet.unirioja.es/servlet/articulo?codigo=3136439

Habermas, J. (1998). Facticidad y validez. Madrid: Trotta.

Hegel, G. W. F. (1999). Principios de la filosofía del derecho. Barcelona: Edhasa. 
Heller, Á. (1989). Ética ciudadana y virtudes cívicas. En Á. Heller \& F. Fehér (Eds.), Políticas de la postmodernidad (pp. 215-231). Barcelona: Ediciones Península.

Kymlicka, W., \& Norman, W. (1997). El retorno del ciudadano. Una revisión de la producción reciente en teoría de la ciudadanía. Agora, 7, 5-42.

Lechner, N. (2000). Nuevas Ciudadanías. Revista de estudios sociales, (5), 25-31.

Montesquieu, J. J. (1942). El espíritu de las leyes. Buenos Aires: Editorial Albatros.

Ramos, A. (2016). Construyendo ciudadanía desde la biblioteca pública. El papel de la información para una mejor participación ciudadana en el gobierno abierto. Ciudad de México: UNAM / IIBI.

Reyes, H. (2009). El plagio en publicaciones científicas. Revista médica de Chile, 137(1), 7-9.

Soto, A. (2012). El plagio y su impacto a nivel académico y profesional. E-Ciencias de la Información, 2(1), 13.

Valente, V. (2000). Una reflexión feminista de la ciudadanía. Estudios feministas, 8(2), 17.

Velasco-Gómez, A. (2000). Ética e Historia (¿Universalismo ético o relativismo moral?). En L. Villoro (Ed.), Los linderos de la ética (pp. 18-34). México: UNAM / CEIICH - Siglo XXI Editores.

Vieira, L. (1998). Ciudadanía y control social. En N. Cunill \& L. C. Bresser (Eds.), Lo público no estatal en la reforma del Estado (pp. 215-256). Buenos Aires: Paidós Ibérica. Recuperado a partir de: http://dialnet.unirioja.es/servlet/articulo?codigo=610311

Villavicencio, S. (2007). Ciudadanía y civilidad: acerca del derecho a tener derechos. Colombia Internacional, (66), 36-51. 
La Infodiversidad y el uso ético del conocimiento...

Winocur, R. (2003). La invención mediática de la ciudadanía. En P. Ramírez (Ed.), Espacio público y reconstrucción de ciudadanía (pp. 231-252). México: Miguel Ángel Porrúa.

Wood, A. W. (Ed.) (1991). Hegel: Elements of the Philosophy of Right. Cambridge: Cambridge University Press. 
La escritura académica y los códigos de ética en el aula: el papel del docente frente al plagio académico

José A. VERDUGo SÁNCHEZ

Universidad Autónoma de Baja California Sur, México

INTRODUCCIÓN

\begin{abstract}
n los últimos años los casos de plagio académico -1 -entendido en su acepción más básica como la apropiación indebida e injustificada de ideas o palabras de otros $-{ }^{1}$ han sido cada vez más frecuentes. Sin embargo, resulta un lugar común decir que este fenómeno no es nuevo en las universidades. Los casos que han trascendido públicamente se centran en investigadores o figuras que, pese al control de las instituciones de educación y centros de investigación, han logrado pasar por encima de las reglas éticas que impone la carrera académica. Si bien este fenómeno habla de un problema institucional, por su misma notoriedad se esconde otro problema más profundo; es decir, revela todas aquellas faltas en las que incurren los estudian-
\end{abstract}

1 Martha Patricia Campos García, "Apuntes sobre redacción y plagio académico". 
La Infodiversidad y el uso ético del conocimiento...

tes que, en cierto modo, son la fuente de futuras conductas deliberadas de apropiación indebida de ideas ajenas.

Una de las principales causales del plagio es el desconocimiento de las normas de la escritura académica y, justamente, éste es el punto de atención que se abordará en el presente trabajo. Es muy importante la labor que realizan los profesores universitarios en ese rubro, toda vez que, a lo largo del proceso de formación, es en las aulas universitarias donde se abordan más seriamente los principios éticos que, posteriormente, guiarán el desempeño profesional. En este sentido, la formulación de normas y códigos éticos respecto al uso de fuentes resulta una tarea impostergable en la que los profesionales de la información juegan un papel central, ya que son ellos quienes, a través de las bibliotecas y centros de información, pueden incidir en la elaboración y divulgación de múltiples herramientas para evitar y detectar las conductas que violentan la propiedad intelectual.

El presente trabajo está dividido en cuatro partes. En la primera se aborda el fenómeno del plagio académico y se analizan sus repercusiones. En el segundo apartado, se expone la importancia de la escritura académica y se destacan algunas recomendaciones que sería deseable que fuesen incorporadas a la formación de los estudiantes universitarios desde los primeros semestres. La penúltima parte trata sobre el campo de acción de los profesionales de la información y sobre lo que pueden aportar en cuanto al manejo y utilización de la información, respecto a la generación de una cultura de respeto por las ideas ajenas. Finalmente, se concluye con algunas reflexiones sobre el plagio académico y su relación con el desarrollo del conocimiento disciplinar. 


\section{EL PLAGIO ACADÉMICO}

El plagio académico es un fenómeno complejo porque afecta la lógica de la producción de conocimiento. Por una parte, implica una transgresión deliberada de las normas éticas del particular "modo de hacer" que exige el quehacer disciplinar y, por otra, implica descrédito para la comunidad académica, de cara a la sociedad.

Existen distintas situaciones en las que los casos de plagio aparecen reiteradamente. Los más ejemplares son aquellos donde investigadores "consolidados" se apropian de artículos, capítulos de libros o libros enteros. Una vez que se ha asentado el polvo de los escándalos, las principales razones que han expuesto las personas que se han apropiado del trabajo ajeno son que la presión impuesta por la lógica evaluadora de la academia los sobrepasó, o que todo empezó con una falta leve que se les "salió de las manos".

Del lado de las víctimas del plagio, se ha señalado que los mecanismos para evitar la apropiación indebida de ideas son, todavía, muy laxos. Además de que se carece de instrumentos de vigilancia sistemática y, sobre todo, de castigos ejemplares para todos aquellos que incurren en dichas prácticas. Asimismo, se advierte que la mayoría de casos quedan impunes, sobre todo cuando no trascienden públicamente o cuando, de manera deliberada, se protege desde las instituciones al que comete el ilícito.

Estas dos posturas reflejan la complejidad del tema. Por una parte, efectivamente, el plagio es una conducta no deseada ni deseable dentro de las academias; sin embargo, se puede afirmar que difícilmente podrá erradicarse mediante la aplicación de castigos más severos; ni tampoco se puede dar por cierto que los investigadores serán más honestos porque así lo decrete la mayoría. 
La Infodiversidad y el uso ético del conocimiento...

Del mismo modo, es poco realista pensar que la implementación de mecanismos estrictos de vigilancia podrá erradicar la apropiación indebida de ideas. Además este argumento, indirectamente, sugiere que los mecanismos de vigilancia y de validación de la producción académica funcionan mal o que, simplemente, no funcionan, lo cual no es necesariamente así. Por el contrario, se puede sostener que los instrumentos de validación de los productos académicos, que se han construido a lo largo de los años, son adecuados en su mayoría y son suficientemente efectivos cuando son bien aplicados. Tal es el caso de las revisiones que realizan las revistas científicas o la dirección de tesis doctorales.

Sin embargo, debajo de estos aspectos más visibles sobre el plagio académico, existen otras causales que suelen estar presentes en aquellos lugares que no se ven, pero que son fundamentales en la formación de profesionistas: las aulas universitarias.

En estos espacios es donde los estudiantes universitarios pasan la mayor parte del tiempo durante su formación y donde adquieren los elementos básicos para aprender a pensar dentro de los límites disciplinares, así como a apropiarse de las distintas vías para generar nuevas ideas. Por tanto, es fundamental que desde los primeros ciclos de la formación universitaria se transmitan todas aquellas herramientas que sean útiles para organizar la información y, sobre todo, para dar el crédito a quién corresponda. En el siguiente apartado se abordará la importancia de la escritura académica y se hará referencia a las reglas que ésta impone a todos aquellos que participan o pretenden participar en alguna comunidad académica. Asimismo, se argumentará sobre la labor clave que realizan los profesores 
La escritura académica y los códigos de ética en el aula...

para transmitir dichos códigos a los estudiantes desde las primeras etapas de formación.

\section{LA DEONTOLOGÍA DE LA ESCRITURA ACADÉMICA}

Se puede afirmar que en las nuevas ideas que se generan en un ámbito disciplinar siempre están presentes, ya sea en su parte teórica, contextual, o en ambas, ideas de otros autores que, desde otra perspectiva o desde otra época, abordaron antes el mismo problema. Por lo tanto, la cuestión está en atribuir adecuadamente los conocimientos en los que - desde un trabajo de clase, hasta una investigación de tesina o tesis - están basadas las afirmaciones y argumentos que se exponen.

Existen dos condiciones básicas que debe tratar de cumplir todo proyecto de investigación en ciernes: ${ }^{2}$ la primera de ellas atañe a que el problema de investigación que planteen los alumnos tiene que referirse a un problema real; es decir, tiene que estar encaminado a detectar un problema o a resolver una necesidad. La segunda condición es que tiene que aportar algo nuevo a la teoría o, de forma general, al campo disciplinar. Esto implica que los trabajos que se realizan en la universidad deben de buscar, en todo momento, contribuir en "algo" al quehacer de los profesionales del campo.

Estas dos condiciones son esenciales para la práctica académica y, en consecuencia, deben considerar en todo momento un manejo adecuado de las fuentes. Particularmente en el aula es muy común que los alumnos incurran en prácticas indebidas de apropiación de ideas ajenas. Cabe seña-

2 G. King, R. O. Keohane y S. Verba, El diseño de la investigación social. La inferencia científica en los estudios cualitativos. 
La Infodiversidad y el uso ético del conocimiento...

lar que la palabra "apropiación" se puede utilizar en dos sentidos distintos. El primero de ellos es aquel del que ya hemos hablado arriba; es decir, la acción de tomar para sí, de forma deliberada, algo que sabemos que no es nuestro, en ocasiones con el agravante de simular que lo es.

La segunda acepción está relacionada con el quehacer académico. Esto significa que cuando leemos, a través de la comprensión, nos apropiamos de las ideas centrales del texto. Es decir, interiorizamos la información de manera subjetiva y, en consecuencia, ésta pasa a formar parte de nuestro acervo cognoscitivo. Esta forma de apropiación de conocimiento es la que debe transmitirse a los estudiantes ya que es la fuente de la creación del pensamiento original y crítico.

En este orden de ideas, la escritura académica establece una estructura básica para todo trabajo, ya sea escolar o de investigación. Esto significa que, de manera general, todo trabajo tiene por lo menos tres partes: una parte teórica, una contextual y otra de aplicación. A menos que se trate de la réplica de una investigación, generalmente las partes más conflictivas para el manejo de referencias son la teórica y la contextual.

Es en dichos apartados donde el alumno suele confundir el contenido textual o contextual de las fuentes con sus propias aportaciones. Aquí el trabajo previo en el aula es de vital importancia, ya que una vez que se ha redactado el escrito, poco se puede hacer, puesto que solo restaría tratar de identificar plagios y, de lo que se trata, es de evitarlos. En este sentido, existen numerosos textos que ilustran sobre la manera de dar un tratamiento adecuado a las fuentes, los cuales suelen incluir algunas reglas básicas como las mencionadas por Day, ${ }^{3}$ desde su experiencia como bibliotecario:

3 Robert A. Day, Cómo escribir y publicar trabajos científicos. 
- En primer lugar, deben enumerarse sólo obras importantes y publicadas. Las referencias a datos no publicados, obras en prensa, resúmenes, tesis y otros materiales de importancia secundaria no deben abarrotar la sección de Referencias o de Obras citadas. Si una referencia de esa clase parece absolutamente esencial, se podrá añadir al texto entre paréntesis o como nota de pie de página.

- En segundo lugar, coteje todas las partes de cada referencia contra la publicación original antes de presentar el manuscrito $y$, tal vez, de nuevo en la fase de corrección de pruebas de imprenta. Esto lo sé porque en otro tiempo fui bibliotecario: hay muchos más errores en la sección de Referencias de un artículo científico que en cualquier otra de sus partes.

- Y [finalmente] como comprobación final, asegúrese de que todas las referencias citadas en el texto figuran realmente en las Obras citadas y todas las referencias que figuran en las Obras citadas se mencionan en algún pasaje del texto.

Estas recomendaciones resultan sumamente ilustradoras; sin embargo, lo que se requiere es un trabajo sistemático de los profesores a fin de que los estudiantes interioricen la importancia de citar las fuentes correctamente, ya que esto no sólo da más valor a sus trabajos académicos, sino que ayuda a crear una cultura de respeto a las ideas de otros, lo cual repercute positivamente en las disciplinas.

EL PAPEL DEL DOCENTE ANTE LA ESCRITURA ACADÉMICA Y EL ESTUDIANTE

Este tema es por demás de primer orden; si bien el estudiante debe contar con información precisa y correcta sobre la forma de hacer sus pronunciamientos y trabajos escolares, lo es tan cierto como que el docente debe guiarlos en varias aristas; estas caras de la temática están íntimamente relacionadas con las normas internacionales para realizar la citas correctas en sus trabajos. Distinguir una cita textual 
La Infodiversidad y el uso ético del conocimiento...

de una referencial; un comentario o un apoyo de los que se dice del autor, lo dice el autor o simplemente de los que refiere el autor.

Conocer las distintas formas y maneras que pueden ser citados los soportes tan variados que contienen la información, también es un conocimiento que el docente debe tener muy preciso para poder ayudar $u$ orientar al estudiante o tesista en su caso.

Es muy recurrente en nuestras universidades encontrarse este tipo de plagio y lo atribuimos a varias causas:

- Desinformación para hacerlo.

- Carencia de elementos para hacerlo.

- Desconocimiento de la(s) técnica(s) para hacerlo.

- Ausencia de conciencia crítica sobre sus implicaciones, y

- Lo más grave, hacerlo plenamente consiente sin importar las consecuencias del robo de ideas para hacerlas propias.

Pese a ello, y a todas las demás particularidades del caso, el hecho consumado es considerado como plagio académico o robo de ideas que han sido expuestas por alguien más antes que nosotros.

El docente que guía al estudiante debe tener a cabalidad un respeto ético por el trabajo de los demás, y es eso lo que debe transmitir al educando.

LOS PROFESIONALES DE LA INFORMACIÓN FRENTE AL PLAGIO

El papel de los profesionales de la información frente a las conductas de apropiación indebida de ideas es crucial. No obstante, no se trata de que los bibliotecarios se convier- 
tan en guardianes del buen hacer académico, ni de que adopten atribuciones que no les corresponden. Se trata de que, desde las bibliotecas universitarias y de investigación, transmitan a los estudiantes todas aquellas habilidades necesarias para el manejo de herramientas tecnológicas y documentales que, de manera positiva, pueden incidir en la prevención de casos de plagio académico.

Cabe señalar que una de las principales funciones de la biblioteca universitaria es dar soporte a los planes de estudio. En este sentido, desde su ámbito de acción, los bibliotecarios pueden añadir a sus programas de formación de usuarios aquellos cursos y actividades encaminadas a la utilización correcta de fuentes documentales. Lo anterior contribuirá, sin duda, a la generación de una cultura de respeto por las ideas ajenas entre la comunidad universitaria.

La búsqueda, recuperación, organización y utilización de la información, como actividades sustantivas del profesional de la información, deben estar presentes en todo momento durante la formación de los universitarios. Finalmente, se trata de transmitir la praxis del manejo de la información a los estudiantes y con ello, además, contribuir al desarrollo de las disciplinas.

\section{A MANERA DE CONCLUSIÓN}

Hasta aquí se han abordado distintas aristas sobre el fenómeno del plagio académico y se han expuesto algunos elementos que señalan la complejidad del tema. Si bien es necesario que se sigan manteniendo y mejorando los controles sobre los productos académicos, también es necesario que se redoblen los esfuerzos por formar una conciencia colectiva que desacredite la apropiación indebida de ideas. 
Es necesario que desde las primeras etapas de formación se transmitan a los estudiantes todas aquellas reglas y códigos que impone la escritura académica y, en particular, todas a aquellas buenas prácticas que se llevan a cabo en la disciplina donde participa.

En la actualidad existe un sinnúmero de herramientas para gestionar bibliografías así como para detectar textos mal atribuidos o, en su caso, plagiados. La experiencia de los bibliotecarios es crucial para entender y atacar este fenómeno, pues son ellos quienes, desde las bibliotecas universitarias o de cualquier otro tipo, son los especialistas en gestionar las fuentes de información.

Por último, es importante considerar que estamos ante un problema que tiene múltiples variables; desde motivaciones individuales, hasta factores institucionales, donde no se cuenta con mecanismos adecuados para prevenir este tipo de conductas. Sin embargo, todo aquello que se hace en las aulas que está encaminado a la transmisión de los códigos de la escritura académica, así como el trabajo de los profesionales de la información en la gestión de los recursos de información, son aspectos esenciales que, a mediano y largo plazo, redundarán en conductas más éticas respecto a las ideas ajenas. 
La escritura académica y los códigos de ética en el aula...

\section{BIBLIOGRAFÍA}

Campos García, Martha Patricia (2006), "Apuntes sobre redacción y plagio académico", Revista Virtual Universidad Católica del Norte, 19, septiembre-diciembre.

Day, Robert A. (2005), Cómo escribir y publicar trabajos científicos, Washington, DC., Organización Panamericana de la Salud.

King, G.; Keohane, R. O., y Verba, S. (2000), El diseño de la investigación social. La inferencia científica en los estudios cualitativos, Madrid, Alianza Editorial. 


\section{Derecho a la información y acceso a la información}




\title{
El Derecho de autor y derecho de acceso a la Infodiversidad
}

\author{
ROSA MARÍA MARTÍNEZ RIDER
}

ADRIANA MATA PUENTE

EDUARDO OlIVA CRUZ

Universidad Autónoma de San Luis Potosí, México

\section{INTRODUCCIÓN}

T a Infodiversidad tiene una agenda pendiente para que se apliquen los derechos de autor y de propiedad inteSlectual a todos los individuos que crean y conservan el patrimonio cultural de los pueblos indígenas.

Este derecho implica una serie de valores morales y patrimoniales que se deben aplicar, en el marco del respeto, la justicia y la equidad nacional.

Se presenta el marco jurídico nacional en esta materia; la situación de los pueblos indígenas, en particular del estado de San Luis Potosí; y los resultados de una encuesta exploratoria en relación con estos derechos. 
La Infodiversidad y el uso ético del conocimiento...

\section{El DERECHO DE AUTOR Y LA INFODIVERSIDAD}

En México, la Ley Federal del Derecho de Autor decreta en el Artículo $1^{\circ}$ que tiene como finalidad:

[...] la salvaguarda y promoción del acervo cultural de la Nación; protección de los derechos de los autores, de los artistas intérpretes o ejecutantes, así como de los editores, de los productores y de los organismos de radiodifusión, en relación con sus obras literarias o artísticas en todas sus manifestaciones, sus interpretaciones o ejecuciones, sus ediciones, sus fonogramas o videogramas, sus emisiones, así como de los otros derechos de propiedad intelectual. $^{1}$

Esta última corresponde al apoyo en favor de "[...] actividades industriales y comerciales del país [que] tenga lugar un sistema permanente de perfeccionamiento de sus procesos y productos"2 garantizando la innovación y la transferencia de tecnología dentro de un marco legal.

El derecho de autor y la propiedad intelectual se refieren a normas jurídicas, que además de amparar la expresión de las ideas, tutelan la defensa de las diferentes manifestaciones de la Infodiversidad, que se relacionan con la capacidad de crear saberes, conocimientos e información en distintos ámbitos y escenarios.

La Ley del Derecho de Autor se caracteriza porque de ésta se derivan los derechos morales, sustentados en la divulgación, los cambios y el acceso a las obras, que son producto de la creación del individuo; y los derechos patri-

1 México, Ley Federal del Derecho de Autor. Última reforma publicada en el Diario Oficial de la Federación del 13 de enero de 2016 [en línea], http:// www.indautor.gob.mx/documentos_normas/leyfederal.pdf

2 México, Ley de la Propiedad Industrial. Última reforma publicada en el Diario Oficial de la Federación del $1^{\circ}$ de junio de 2016 [en línea], http://www. diputados.gob.mx/LeyesBiblio/pdf/50_010616.pdf 
moniales, que corresponden al factor económico, como la reproducción y distribución de éstas.

Además, es un derecho universal que se aplica en todos los contextos sociales, independientemente de los grados de su cumplimiento; protege fielmente las ideas, los descubrimientos y las invenciones de los individuos, obteniendo así el control de la originalidad del titular y, por lo general, los productos son una mercancía para sus creadores (Figura 1), no así para la Infodiversidad.

Figura 1.

Características del derecho de autor

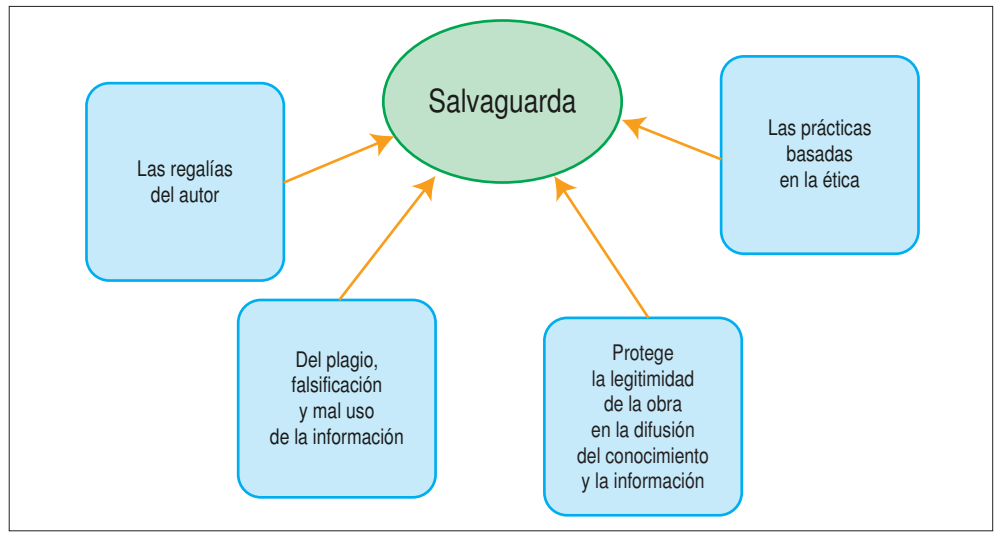

Fuente: elaboración propia.

Pabón, ${ }^{3}$ en su investigación histórica, alude a las diversas funciones que ha tenido el derecho de autor de acuerdo con el contexto geográfico y social de algunas culturas.

Por ejemplo, indica que el Estatuto de la reina Ana de Inglaterra, en 1710, creó un régimen subjetivo de protección que eliminó el sistema de privilegios en las obras.

3 Jhonny Antonio Pabón Cadavid (2009), "Aproximación a la historia del derecho de autor: antecedentes normativos”, pp. 59-104. 
La Infodiversidad y el uso ético del conocimiento...

Señala que, en 1725, Louis de Héricourt defendió la postura de que el derecho de propiedad es resultado de un trabajo; y en España, la Orden del 20 de octubre de 1764 decreta el carácter hereditario de los privilegios de los autores.

Destaca el hecho de que en Europa, hasta el siglo XVIII, los privilegios tienen un carácter del derecho administrativo, centrado en las sanciones, y se alejaron del concepto patrimonial individualista.

El derecho de autor ha transitado por varias culturas y contextos para que la expresión de las ideas, los descubrimientos o los inventos se reconozcan en el mundo.

En México, la protección de este derecho nace de una controversia en el siglo XIX, y actualmente es el Instituto del Derechos de Autor (INDAUTOR) ${ }^{4}$ el que se encarga de las siguientes actividades:

- La inscripción de obras literarias y artísticas.

- La inscripción de actos, convenios y contratos por los cuales se transmitan los derechos patrimoniales.

- Asesorar en materia de Derecho de Autor y Derechos Conexos.

- El otorgamiento de reservas de derechos.

- Otorgar el Número Internacional Normalizado del Libro o ISBN, y el Número Internacional Normalizado para Publicaciones Periódicas o ISSN.

Por lo que se refiere a la Reserva de Derechos al Uso Exclusivo, indica, es la facultad de usar y explotar en forma exclusiva:

4 Instituto Nacional del Derecho de Autor [en línea], http://www.indautor. gob.mx/accesibilidad/accesibilidad_reservas.html 
- Títulos de publicaciones periódicas, como folletos, periódicos, directorios y revistas, entre otros.

- Títulos de difusiones periódicas, como programas de televisión, radio o vía red de cómputo.

- Nombres y características de personajes humanos de caracterización, ficticios o simbólicos.

- Nombres o denominaciones de personas o grupos dedicados a actividades artísticas.

- Promociones publicitarias.

El Instituto también está facultado para la corrección de registro; la búsqueda de antecedentes registrales o expedición de copias certificadas; y a petición del autor, hacer anotaciones marginales.

Este derecho es fundamental en las bibliotecas y se basa en tres categorías: la libertad de leer sobre cualquier tema, conociendo al responsable que plasma las ideas en un soporte físico; el control sobre las reproducciones de los materiales; y otorgar el crédito que le corresponde a los responsables de tales ideas (Figura 2).

Figura 2.

El derecho de autor en las bibliotecas

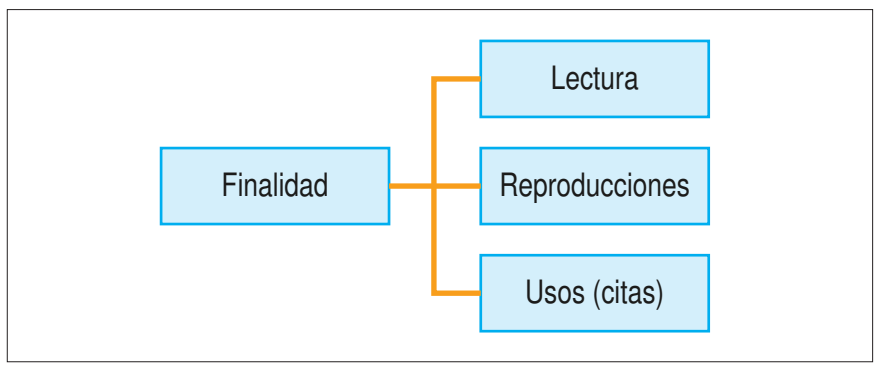

Fuente: elaboración propia. 
La Infodiversidad y el uso ético del conocimiento...

En este sentido, la Infodiversidad, definida por Mora-

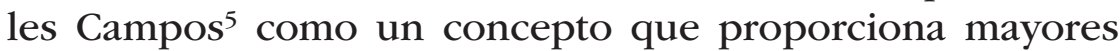
oportunidades para acceder a los conocimientos, saberes o información con una variedad de posturas, enfoques, tendencias, análisis y reflexiones, debe asegurar los valores morales y patrimoniales de todas las culturas.

El derecho de autor y la propiedad intelectual protegen el patrimonio de la humanidad, el natural, el cultural mueble, inmueble y el intangible a través de las expresiones de diferentes culturas, como las referidas a los pueblos indígenas, que incluyen la herbolaria, las formas de alimentación, de los cultivos, de las relaciones sociales, las cosmogonías, las tradiciones y las costumbres, entre otros aspectos, que sin embargo, "[...] plantean algunas cuestiones jurídicas y políticas particulares" y que se atienden de forma distinta en muchas leyes nacionales y regionales así como con la labor de la Organización Mundial de la Propiedad Intelectual, ${ }^{6}$ ya que han sido de plagiadas con fines de lucro.

En 1998 y 1999, esta organización llevó a cabo nueve misiones exploratorias en 28 países del Pacífico Sur, África Meridional y Oriental, Asia Meridional, América del Norte, América Central, África Occidental, los países árabes, América del Sur y el Caribe. Entre algunos debates y resultados por países, se discutieron los valores económicos de los conocimientos tradicionales, así como la importancia del registro y catalogación de los conocimientos tradicionales, cuando menos a nivel local.

5 Estela Morales Campos (2003), Infodiversidad, globalización y derecho a la información.

6 IMPO, Expresiones culturales tradicionales [en línea], http://www.wipo.int/ tk/es/folklore 
Linder y Ordoñez ${ }^{7}$ explican la conveniencia de que los indígenas inscriban marcas, avisos y nombres comerciales, patentes de invención, modelos de utilidad, secretos industriales, denominaciones de origen y diseño industrial para resguardar los derechos de autor y propiedad intelectual.

La Infodiversidad en las sociedades del conocimiento, de la información y en el derecho a la información, promueve el libre acceso, nuevos canales de difusión y la democratización de los saberes y los conocimientos.

Son una fuente para hacer visibles los productos generados por estas comunidades mediante las tecnologías de información y comunicación, aunque en este tema particular la situación es disímbola y socialmente contrastante.

Además de la protección de los derechos de autor en la Infodiversidad, la agenda pendiente es dotar, en todo el país, el acceso a las Tecnologías de la Información y la Comunicación (TIC), donde en ocasiones el único medio de comunicación es la radio.

Sandova ${ }^{8}$ explica que el acceso indígena a las TIC se encuentra asociado con los derechos colectivos, los derechos humanos, la cultura, la cosmovisión, las lenguas, la organización autonómica, y la superación de la miseria; añade que, por esta razón, los habitantes de algunos lugares han creado páginas web, con diferentes finalidades, para tener presencia en Internet y para reivindicar sus derechos.

A continuación se presenta el panorama del estado de San Luis Potosí en esta materia.

7 Hedwig A. Linder López y José Emilio R. Ordóñez Cifuentes (1994), "La propiedad de los grupos indígenas de México" [en línea], http://historico. juridicas.unam.mx/publica/librev/rev/critica/cont/15/teo/teo7.pdf

8 Eduardo A. Sandoval-Forero (2013), "Los indígenas en el ciberespacio", pp. 235-256. 
La Infodiversidad y el uso ético del conocimiento...

Se asentaron en este territorio tres grupos, los huastecos, los pames y los guachichiles. Actualmente, el grupo de los huastecos (teenek) habitan:

[...] los municipios de Aquismón, Tanlajás, Tampacán, Ciudad Valles, Huehuetlán, San Antonio y Tancanhuitz de Santos; los nahuas se encuentran asentados fundamentalmente en los municipios de Tamazunchale, Axtla de Terrazas, Xilitla, San Martín Chalchicuautla y Coxcatlan, y los pames en el municipio de Tamasopo.?

Están protegidos por la Ley para el Instituto de Desarrollo Humano y Social de los Pueblos y Comunidades Indígenas del Estado de San Luis Potosí, ${ }^{10}$ la cual señala que se les brindará atención personalizada en materia jurídica cuando lo soliciten, "[...] para defender sus derechos colectivos cuando sea factible, según la problemática; o canalizarlas a las instituciones competentes."

La Ley de Justicia Indígena y Comunitaria para el Estado de San Luis Potosí11 ${ }^{11}$ tampoco puntualiza en el tema de derechos de autor. En 2010, el Consejo Nacional de Población afirmó que de los 22 municipios del estado que registran presencia de población indígena, en 14 hay un alto índice de marginación.

Para conocer la opinión de la ciudadanía potosina en este tema, se aplicó un cuestionario exploratorio a 150 personas al azar: 70 mujeres y 80 varones de edades indistintas en la capital de San Luis Potosí, sobre la protección de los

9 Patricia Gallardo Arias (2004), Huastecos de San Luis Potosí, p. 5.

10 Ley para el Instituto de Desarrollo Humano y Social de los Pueblos y Comunidades Indígenas del Estado de San Luis Potosí [en línea], http://www. cndh.org.mx/sites/all/doc/Programas/Indigenas/OtrasNormas/Estatal/SLP/ Ley_IDHSPCISLP.pdf

11 Ley de Justicia Indígena y Comunitaria para el Estado de San Luis Potosí [en línea], http://www.cndh.org.mx/sites/all/doc/Programas/Indigenas/ OtrasNormas/Estatal/SLP/Ley_JICSLP.pdf 
derechos de autor y propiedad intelectual de los pueblos indígenas.

Se obtuvieron los siguientes resultados en las siguientes cinco preguntas.

1. Para usted, ¿qué elementos forman el patrimonio cultural de los pueblos indígenas?

2. ¿Considera que el patrimonio de los pueblos indígenas está valorado?

3. ¿Sabía usted que la Ley de Derechos de autor protege el patrimonio cultural de los pueblos indígenas?

4. ¿Cuál es el impacto positivo de la protección de este patrimonio?

5. Para usted, ¿qué problemas se generan cuando los pueblos indígenas no tienen acceso a las Tecnologías de la Información y la Comunicación con relación a los derechos de autor?

Se destacan cuatro elementos entre los encuestados: a) la música y danza folklórica que han presenciado más de una vez; b) la compra de textiles y de las artesanías para uso familiar o para obsequiar; c) quienes reconocen el patrimonio cultural como un todo; d) sólo un pequeño porcentaje alude a la historia oral, las tradiciones y la gastronomía (Gráfica 1). 
La Infodiversidad y el uso ético del conocimiento...

Grafica 1.

Elementos del patrimonio cultural de los pueblos indígenas

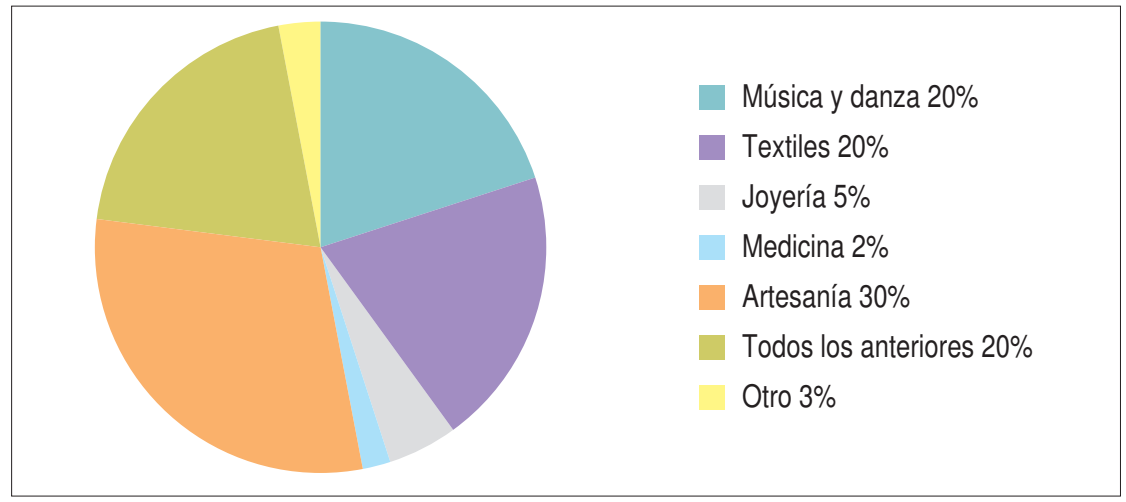

Fuente: elaboración propia.

La mayoría coincide en que se debe sensibilizar y expandir la conciencia social sobre la importancia local y mundial del patrimonio cultural de los pueblos indígenas, en particular porque, con el mercado mundial, se valora más lo extranjero (Gráfica 2).

Gráfica 2.

Valoración del patrimonio cultural de los pueblos indígenas

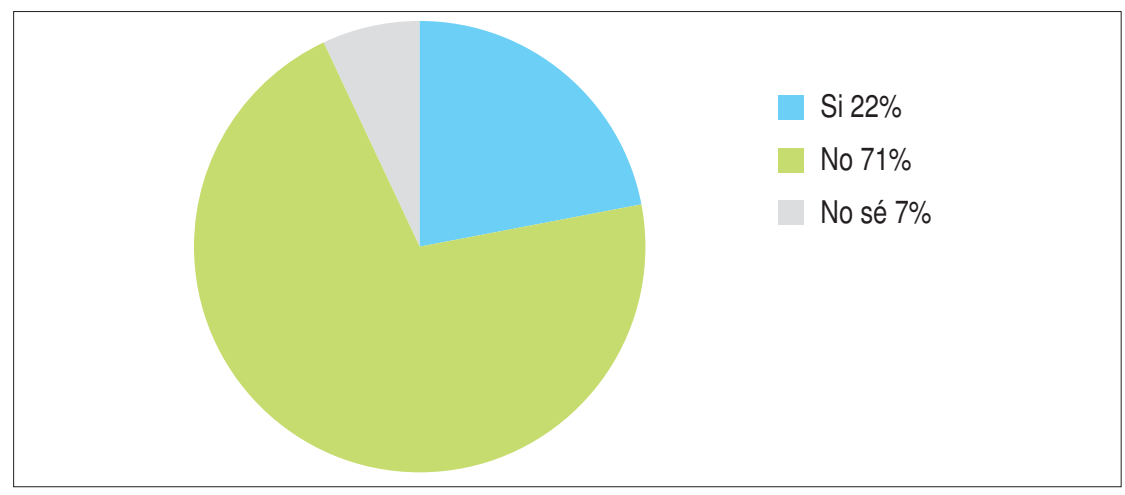

Fuente: elaboración propia. 
Los encuestados señalaron que se debe dar más importancia a nuestras raíces desde la educación básica, pero no sólo como los primeros pobladores de México, sino como aquellos compatriotas que son parte de nosotros en el siglo XXI, con la base del respeto y reconocimiento a su forma de pensar y vivir (Gráfica 3).

\section{Gráfica 3.}

¿Sabe que este patrimonio está protegido por el derecho de autor?

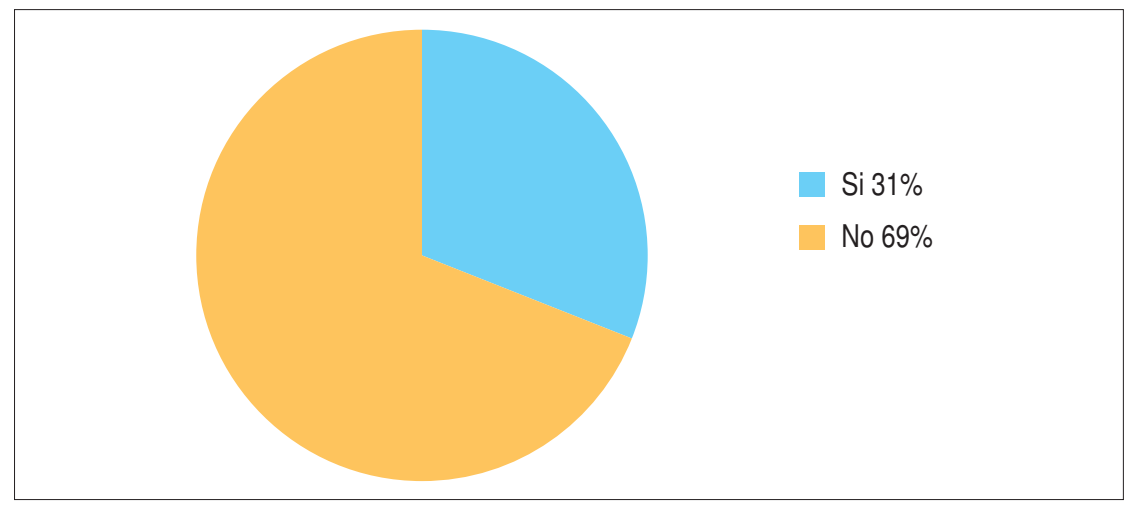

Fuente: elaboración propia.

El grueso de los encuestados desconoce está situación básicamente porque consideran que los saberes y productos tienen una larga tradición milenaria y son propiedad de los ciudadanos; por ejemplo, el uso de la herbolaria.

Los que sí lo saben proponen que estudie más este derecho y que se aplique efectivamente, porque se podría patentar en el extranjero la propiedad de los indígenas (Gráfica 4). 
La Infodiversidad y el uso ético del conocimiento...

Grafica 4.

Impacto positivo de la protección del patrimonio cultural de los pueblos indígenas

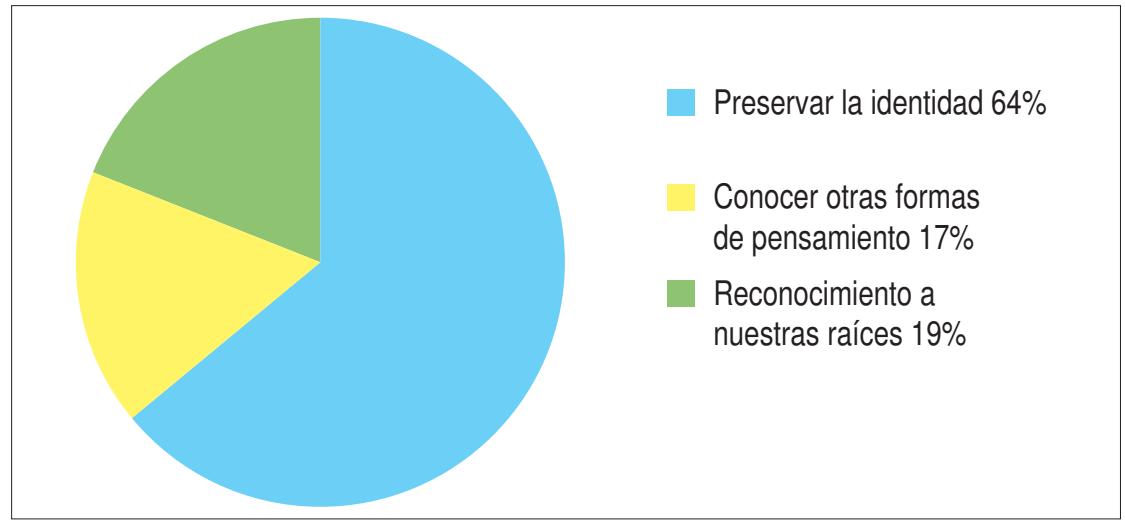

Fuente: elaboración propia.

La mayor parte de los encuestados afirma que, fundamentalmente, la protección del patrimonio se dirige a preservar la identidad no sólo de los indígenas, sino de todos los mexicanos.

Quienes conocen otras formas de pensamiento rescatan los ritos, el concepto de la naturaleza y costumbre de los pueblos indígenas. Por ejemplo, la Peregrinación a Wirikuta, de Real de Catorce, donde el marakame conduce a los peyoteros para purificarse.

Quienes reconocen nuestras raíces expresan que no se deben perder tradiciones como la del Altar de Muertos y saber de dónde vienen algunas expresiones; por ejemplo Tangamanga, que significa empalizada (Gráfica 5). 
Gráfica 5.

Falta de acceso de las Tecnologías de la Información y la Comunicación

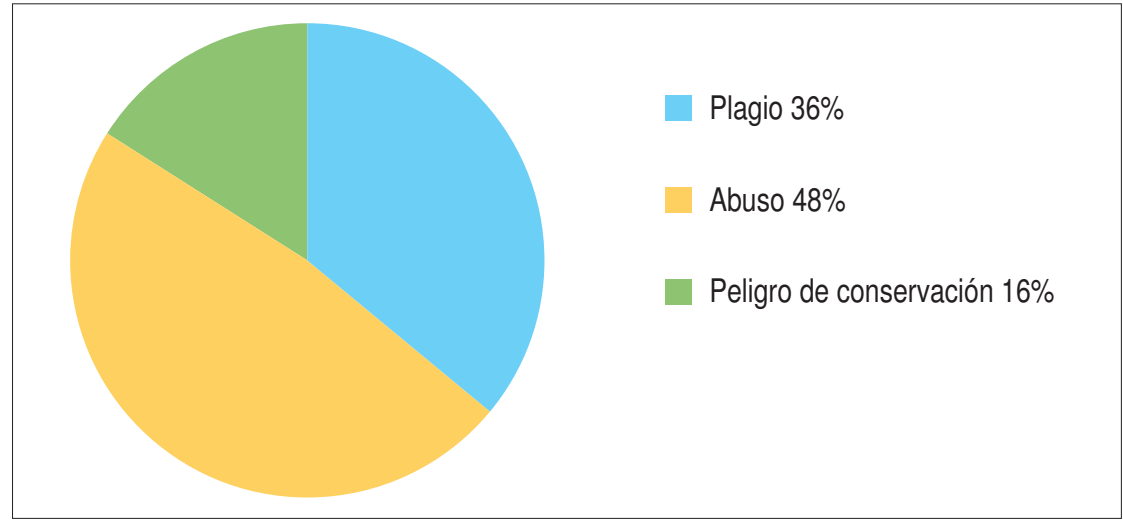

Fuente: elaboración propia.

Por último, los encuestados comentaron que en la época en que vivimos todos los mexicanos debemos tener acceso a las Tecnologías de la Información y la Comunicación.

Afirmaron que es importante el dominio del español y la alfabetización en la lecto-escritura para evitar los abusos a los pueblos indígenas por discriminación o fines de lucro.

Algunos mencionaron la importancia de las TIC para conservar y divulgar el patrimonio cultural de los pueblos indígenas, así como para plasmar la autoría de sus ideas y productos.

\section{CONSIDERACIONES FINALES}

La difusión de la ciencia y la cultura toma distintas posturas, de acuerdo con la concepción del grupo social que comparte la Infodiversidad.

El derecho de autor y de propiedad intelectual se aplica por igual en un marco legal que protege las expresiones y 
La Infodiversidad y el uso ético del conocimiento...

los productos de los pueblos indígenas; sin embargo, hay que aplicar programas sociales que involucren este aspecto para que se asuman los derechos morales y patrimoniales.

Aunque el uso del Internet tiene problemas de plagio, es una herramienta para la alfabetización informativa, la difusión de la cultura y el respeto a la autoría de los pueblos indígenas.

El derecho a la información es una ciencia con restricciones jurídicas en su acceso y en su ejercicio, tanto en las bibliotecas como en los archivos, pues se aplica en distintos grados, de acuerdo con las diferentes realidades que tienen un avance económico, político y cultural distinto. Se debe trabajar en el derecho a la Infodiversidad.

Estas unidades de información deben contar con programas de asesoría y apoyo para la protección de los derechos de autor y la propiedad intelectual de los pueblos indígenas.

\section{BIBLIOGRAFÍA}

Gallardo Arias, Patricia (2004). Huastecos de San Luis Potosí. MéxiCO, CDI: PNUD.

IMPO. Expresiones culturales tradicionales [en línea], http://www. wipo.int/tk/es/folklore

Ley de Justicia Indígena y Comunitaria para el Estado de San Luis Potosí [en línea], http://www.cndh.org.mx/sites/all/doc/Programas/Indigenas/OtrasNormas/Estatal/SLP/Ley_JICSLP.pdf

Ley para el Instituto de Desarrollo Humano y Social de los Pueblos y Comunidades Indígenas del Estado de San Luis Potosí [en línea], http://www.cndh.org.mx/sites/all/doc/Programas/Indigenas/OtrasNormas/Estatal/SLP/Ley_IDHSPCISLP.pdf 
Linder López, Hedwig A. y Ordoñez Cifuentes, José Emilio R. (1994). "La propiedad de los grupos indígenas de México" [en línea], http://historico.juridicas.unam.mx/publica/librev/rev/critica/ cont/15/teo/teo7.pdf

México. Instituto Nacional del Derecho de Autor [en línea], http:// www.indautor.gob.mx/accesibilidad/accesibilidad_reservas. html

México. Ley Federal del Derecho de Autor. Última reforma publicada en el Diario Oficial de la Federación del 13 de enero de 2016 [en línea], http://www.indautor.gob.mx/documentos_ normas/leyfederal.pdf

México. Ley de la Propiedad Industrial. Última reforma publicada en el Diario Oficial de la Federación del $1^{\circ}$ de junio de 2016 [en línea], http://www.diputados.gob.mx/LeyesBiblio/ pdf/50_010616.pdf

Morales Campos, Estela (2003). Infodiversidad, globalización y derecho a la información. Buenos Aires: Sociedad de Investigaciones Bibliotecológicas.

Pabón Cadavid, Jhonny Antonio (2009). "Aproximación a la historia del derecho de autor: antecedentes normativos", Revista La Propiedad Inmaterial (13): 59-104.

Sandoval-Forero, Eduardo A. (2013). "Los indígenas en el ciberespacio”, Agricultura, sociedad y desarrollo, 10 (2): 235-256. 


\title{
¿Hasta dónde la creatividad intelectual y el acceso abierto a la información atentan contra el derecho de autor?
}

\author{
Jesús GARCÍA PÉREZ \\ Universidad Nacional Autónoma de México
}

\section{INTRODUCCIÓN}

especto a las forma en que se genera, disemina y dis-
tribuye la información científica y humanística a tra-
vés de Internet, los escenarios actuales indican, por una parte, que dicha información se produce sobre todo en instituciones educativas, y por la otra, que se han tenido que desarrollar y adecuar a los contextos actuales exigidos por las Tecnologías de la Información y la Comunicación (TIC).

Los documentos se resguardaban, al igual que hoy, en las bibliotecas; posteriormente los documentos electrónicos en biblioteca virtuales, y ahora la tendencia es la creación y el desarrollo de repositorios temáticos e institucionales a fin de que la información se encuentre disponible para su socialización; sin embargo, no se advierten a profundidad las implicaciones que pueda tener en los escenarios de la propiedad intelectual, en su organización, su resguardo y el uso de los contenidos en entornos virtuales y digitales. 
La Infodiversidad y el uso ético del conocimiento...

Por ello, en el presente trabajo se abordan los aspectos relevantes en el trinomio que resulta de la propiedad intelectual, el acceso abierto y las bibliotecas.

\section{LA CREATIVIDAD INTELECTUAL}

Para Nettel Diaz ${ }^{1}$ existen tres épocas importantes de los derechos de autor, "1) desde la antigüedad hasta el siglo XVIII; 2) desde el siglo XVIII hasta antes de la Conferencia de Berna (1866) y 3) los desarrollos de los derechos de autor a partir del Convenio de Berna". ${ }^{2}$

Épocas importantes para la Propiedad Intelectual, ya que en 1873:

[...] surge el Convenio de París para la Protección de la Propiedad Industrial. Este acuerdo internacional representa el primer paso tomado para asegurar a los creadores que sus obras intelectuales estén protegidas en otros países. La necesidad de protección internacional de la propiedad intelectual, a propósito de la Exposición Internacional de Invenciones de Viena, a la que se negaron a asistir algunos expositores extranjeros por miedo a que les robaran las ideas para explotarlas comercialmente en otros países. ${ }^{3}$

Algunos de los estudiosos de la materia argumentan que:

[...] se puede remontar a la antigua Grecia para encontrar los primeros ejemplos de reconocimiento de la creatividad y el trabajo intelectual. En el año 330 a. C., una ley ateniense ordenó que se depositaran en los archivos de la ciudad copias exactas de las obras de los grandes clásicos. Entonces, los libros eran copiados en forma manuscrita, en consecuencia, el costo de las copias era

1 Ana Laura Nettel Díaz, "Derecho de autor y plagio" [en línea], http://www. corteidh.or.cr/tablas/r32329.pdf

2 Ibid.

3 OMPI, "Reseña histórica de la ompi" [en línea], http://www.wipo.int/aboutwipo/es/history.html 
¿Hasta dónde la creatividad intelectual y el acceso abierto...

muy alto y su número total muy limitado. Este hecho, sumado a la escasez de personas capacitadas para leer y en condiciones de poder adquirirlas, determinó el nacimiento de un interés jurídico específico para su protección. ${ }^{4}$

\section{Winegar Goans, al respecto, señala que:}

[...] es un área del derecho que se ocupa de los derechos de propiedad sobre cosas intangibles. Proporciona un medio para fomentar el progreso mediante la protección de los derechos sobre nuevas creaciones de la mente, recompensa el comercio honesto y promueve la satisfacción del consumidor mediante la reglamentación de determinados aspectos de la conducta comercial. La propiedad intelectual se utiliza principalmente como herramienta y reconoce asimismo ciertos valores no económicos de las obras creativas. $^{5}$

La intangibilidad no se refiere al contexto de los documentos electrónicos o virtuales, sino a que las creaciones de la mente producto del intelecto son intangibles al momento de concebirse.

En este milenio, la propiedad intelectual se divide en dos grandes ramas: la propiedad industrial y el derecho de autor; de ahí que en muchas ocasiones se traten indistintamente y sea difícil distinguir entre una y otra.

Es importante señalar que, bajo esta estructura, la propiedad industrial protege las invenciones, las creaciones, las marcas y los signos distintivos. Los derechos de autor protegen:

[...] la creación y titularidad de las obras artísticas o literarias. Una obra es la expresión de ideas de forma original y susceptible de reproducción. Las obras amparadas por el derecho de autor abarcan una extensa variedad de formas que van desde la poe-

4 Instituto Autor, "Antecedentes históricos de la propiedad intelectual" [en línea], http://institutoautor.org/story.php?id=3156

5 Judy Winegar Goans, Propiedad intelectual: principios y ejercicio, p. 1. 
La Infodiversidad y el uso ético del conocimiento...

sía hasta los programas informáticos, desde los dibujos técnicos hasta las pinturas y esculturas, y desde la música hasta los planos arquitectónicos. ${ }^{6}$

En el caso de México, el instrumento jurídico que regula los derechos de autor es la Ley Federal de Derecho de Autor; el Instituto Nacional del Derecho de Autor (INDAUTOR), por su parte, es el órgano que se encarga de proteger y fomentar los derechos de autor; promover la creatividad; controlar y administrar el registro público del derecho de autor; en tanto que la propiedad industrial tiene como instrumento jurídico la Ley de Propiedad Industrial, y como entidad reguladora al Instituto Mexicano de la Propiedad Industrial (IMPI) (Figura 1).

Figura 1.

La propiedad intelectual en México: actores involucrados

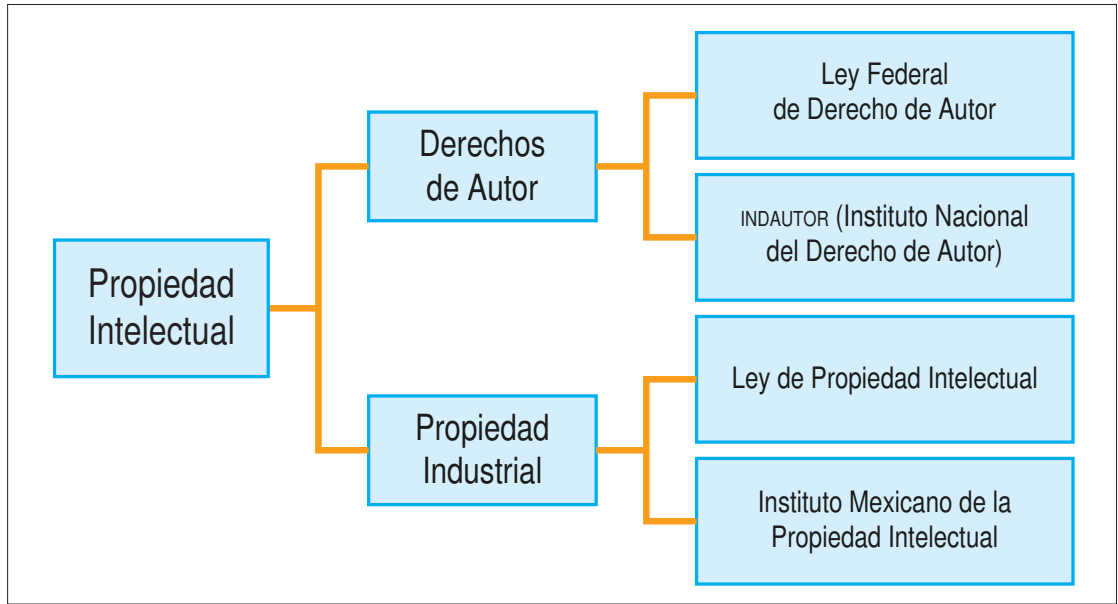

Fuente: elaboración propia, a partir de Virginia del Rocío Navarro Boullosa, "Fundamentos de la administración de la propiedad intelectual y patentes" [en línea], http://www.monografias.com/trabajos101/ fundamentos-administracion-propiedad-intelectual-y-patentes/fundamentos-administracion-propiedad-intelectual-y-patentes.shtml

6 Ibid., p. 2. 
Entonces, al referirme en este trabajo a la creatividad intelectual, por obvias razones, abarcaré lo concerniente a la propiedad industrial y a los derechos de autor, para así incluir las características y las categorías que cada una de estas propiedades protege y que se engloban en la definición y categorización de lo que se define como propiedad intelectual.

La OMPI se refiere a estos dos derechos como propiedad intelectual, ya que:

[...] en la terminología jurídica, la expresión derecho de autor se utiliza para describir los derechos de los creadores sobre sus obras literarias y artísticas. Las obras que abarca el derecho de autor van desde los libros, la música, la pintura, la escultura y las películas hasta los programas informáticos, las bases de datos, las publicidades, los mapas y los dibujos técnicos. ${ }^{7}$

La propiedad industrial, según la ley mexicana,

[...] establece las bases para que, en las actividades industriales

y comerciales del país, tenga lugar un sistema permanente de perfeccionamiento de sus procesos y productos, [...] la propiedad industrial protege mediante la regulación y otorgamiento de patentes de invención; registros de modelos de utilidad, diseños industriales, marcas, y avisos comerciales; publicación de nombres comerciales; declaración de protección de denominaciones de origen, y regulación de secretos industriales. ${ }^{8}$

El derecho de autor y la propiedad industrial, desde el punto de vista jurídico, forman parte de un cuerpo más amplio denominado propiedad Intelectual. "La propiedad inte-

7 OMPI, “¿Qué es la propiedad intelectual?” [en línea], http://www.wipo.int/ about-ip/es/

8 Ley de Propiedad Industrial [en línea], http://www.diputados.gob.mx/LeyesBiblio/pdf/50_010616.pdf 
La Infodiversidad y el uso ético del conocimiento...

lectual tiene que ver con la información o los conocimientos que pueden incorporarse en objetos tangibles."

Así, desde la perspectiva bibliotecológica, podemos decir que la propiedad intelectual es todo lo que nace de la creatividad de las personas, ya que el abanico de producción de obras producto del intelecto es cada día más amplio.

Anteriormente nos referíamos y hablábamos de proteger libros y revistas, pero con la incorporación masiva de la www y de Internet, tenemos que referirnos a la propiedad intelectual para así abarcar las obras literarias; musicales, con o sin letras; obras dramáticas, dancísticas, pictóricas o de dibujo; escultóricas y de carácter plástico; caricaturas e historietas; arquitectónicas; cinematográficas y obras audiovisuales; programas de radio y televisión; programas de cómputo; fotografías; obras de arte aplicado que incluyen el diseño gráfico o textil; y de compilación, integradas por las colecciones de obras, tales como las enciclopedias, las antologías, y obras u otros elementos como las bases de datos, siempre que dichas colecciones, por su selección o la disposición de su contenido o materias, constituyan una creación intelectual concernientes a los derechos de autor. Igualmente las invenciones, patentes, innovaciones, modelos de utilidad, diseños industriales (modelos y dibujos industriales), trazados de circuitos, secretos industriales y los signos distintivos, compuestos por marcas, avisos y nombres comerciales y denominaciones de origen, protecciones de la propiedad industrial, entre otros (Figura 2).

9 OMPI, "Principios básicos de la propiedad industrial" [en línea], http://www. wipo.int/edocs/pubdocs/es/intproperty/895/wipo_pub_895.pdf 
¿Hasta dónde la creatividad intelectual y el acceso abierto...

Figura 2.

Elementos de la propiedad intelectual

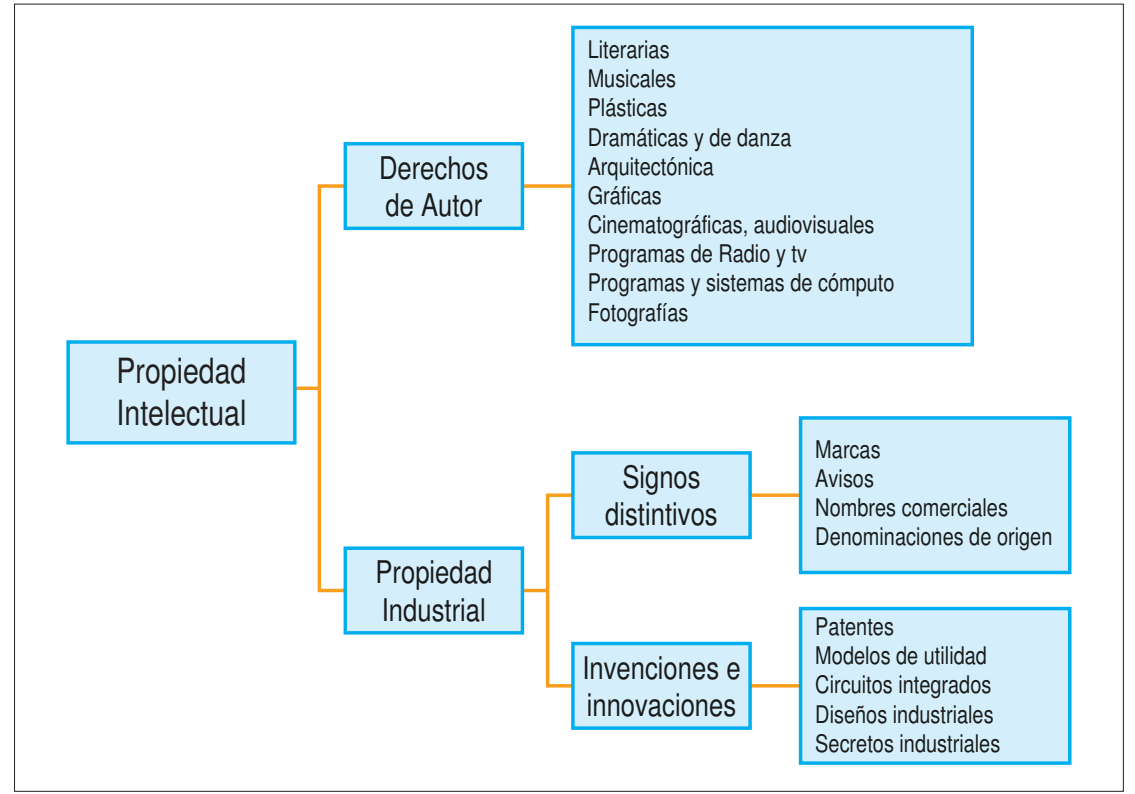

Fuente: elaboración propia, a partir de Virginia del Rocío Navarro Boullosa, "Fundamentos de la administración de la propiedad intelectual y patentes", Op. cit.

La perspectiva bibliotecológica demuestra y enfatiza desde el más puro concepto de la biblioteca que, a través de los siglos y las épocas, siempre se han encargado de organizar, construir, resguardar, conservar y mantener un sinfín de documentos y que éstos puedan ser consultados por los usuarios.

El MOVIMIENTO ACCESO ABIERTO

El Open Access (OA) o Acceso Abierto (AA) es definido como un "[...] movimiento internacional cuyo objetivo es que cualquier persona en el mundo, con una conexión a In- 
La Infodiversidad y el uso ético del conocimiento...

ternet, pueda acceder libremente sin ninguna restricción de tipo económico, técnico o legal a la información científica, académica y cultural."10

Entre los antecedentes más relevantes, encontramos que este movimiento surge hace más de tres décadas, por el incremento de los precios en las revistas científicas, lo que generó a su vez una influencia negativa en el factor de impacto entre los investigadores y la comunidad científica, ya que los altos costos no permitieron más consultas a los trabajos publicados, debido a que el factor se mide por las veces que ha sido consultado, lo que se refleja en las citas que éste recibe.

Otro de los argumentos que ocasionó el despunte de este movimiento, fue la demostración de que bajo el esquema de los derechos de autor, se impide el acceso a muchos documentos para realizar trabajos de docencia e investigación. Las editoriales no retienen los derechos patrimoniales, sino que en la práctica, los autores son los que ceden estos derechos para que las editoriales puedan explotar de manera exclusiva su obra o autorizan a otros su explotación en cualquier forma y otorgan licencias de uso, exclusivas o no.

La www e Internet lograron que los artículos diseminados y disponibles en la red sean más accesibles para los usuarios y, por lo tanto, más consultados, leídos y citados y plagiados, sin dar los créditos correspondientes infringiendo los derechos de autor.

En la Declaración de Budapest (Budapest Open Access Initiative), se establecen dos rutas para alcanzar el Open Access: la ruta dorada o de publicación en revistas de acceso abierto, y la ruta verde, que alude al archivo o depósito de recursos digitales en repositorios institucionales o temáticos.

10 Redalyc, "Declaración sobre Acceso Abierto" [en línea], http://www.redalyc. org/info.oa?page=/acceso-abierto/declaracionoa.html 
Como se ha descrito en líneas anteriores, en sus inicios el Acceso Abierto se encaminó principalmente a la difusión de las revistas científicas y a los artículos académicos; sin embargo, hoy en día se debe considerar el acceso abierto en todos los aspectos concernientes a la información y a todo tipo de documentos.

La actual tendencia con las redes de información es la de otorgar libre acceso a material digital en línea de forma gratuita y con la mínima restricción de derechos de autor. De esta manera, el AA elimina las barreras físicas y económicas (suscripciones, pago de licencias, cuotas de pago por visión) que impiden el acceso a la información de los usuarios que más la requieren. ${ }^{11}$

Pero no todo lo que está en acceso abierto es sinónimo de gratuidad, ya que muchas editoriales están adoptando modelos híbridos:

[...] el caso más puro según la definición de Open Access sería aquella revista que ni lector ni autor paga por publicar y son los autores los que retienen el copyright sobre sus trabajos cediendo los derechos no exclusivos de publicación a la revista. Obviamente alguien "tiene que pagar", en este caso, las revistas generalmente pertenecen a instituciones académicas o sociedades profesionales, cuyos recursos incluyen también el mantenimiento de estas publicaciones. Existen casos de revistas totalmente Open Access en que el autor/institución paga por su publicación, como son las revistas de BioMed Central o de a Public Library of Science (PLoS). Entre uno y otro modelo se dan casi todas las posibles combinaciones entre pago y derechos de copyright. Cuando coexisten artículos Open Access junto con los de pago por suscripción, estaríamos hablando de modelos híbridos. ${ }^{12}$

No obstante, es primordial destacar tres aspectos: los recursos digitales denominados repositorios, la concepción

11 Acceso Abierto y Repositorio de Documentos [en línea], https://hipertextual.com/archivo/2014/10/importancia-acceso-abierto/

12 Ibíd. 
La Infodiversidad y el uso ético del conocimiento...

de la biblioteca y las restricciones respecto a los derechos de autor específicamente.

\section{LOS REPOSITORIOS}

Desde mi perspectiva y con base en la información analizada, esta tendencia a la creación de repositorios institucionales y temáticos ha cobrado gran importancia y protagonismo a nivel mundial. Son considerados como espacios virtuales donde se almacenan recursos digitales, los cuales se componen de una infinidad de documentos:

[...] (textuales, de imagen o sonido, en general llamados objetos digitales) surgen de la llamada comunidad e-print, preocupada por maximizar la difusión y el impacto de los trabajos depositados en los mismos. Si el repositorio responde a unas áreas de conocimiento en particular, hablaremos de repositorios temáticos y si los objetos digitales almacenados responden a los de una institución hablaremos de repositorios institucionales. ${ }^{13}$

En los últimos años, el movimiento de Acceso Abierto ha tomado fuerza y en nuestro país no es la excepción, con la aprobación de la Ley de Ciencia y Tecnología y la Ley General de Educación, los documentos producidos por los científicos mexicanos se encontrarán disponibles en acceso abierto en una base de datos institucional, en donde se establece que cualquier investigación realizada en instituciones públicas, o bien, que tenga infraestructura o reciba recursos públicos, estará disponible en formato de acceso abierto a través de plataformas en línea.

Desde la perspectiva bibliotecológica, y con base en las lecturas y autores consultados, estos repositorios carecen

13 Ibid. 
de una adecuada catalogación, normalización y organización de los documentos que albergan y se les confunde y se les da la misma conceptualización, en muchas ocasiones como una biblioteca virtual o digital, tema en el cual no se ahondará en este documento.

En el blog de Scielo $^{14}$ se argumenta que, dentro de los antecedentes de éstos, encontramos que en la década de los setenta: "[...] se lanza el Proyecto Gutenberg [...] por Michael Hart". Para los ochenta, las revistas Psycoloqy y The Public-Access Computer Systems Review se ponen online de acceso libre. En 1998 David Shulenburger propone el Repositorio Nacional Electrónico de Artículos (The National Electronic Article Repository -NEAR $)^{15}$ como un repositorio de acceso abierto. Para el año 2007, “[...] la Social Science Research Network lanza oficialmente la Red de Investigaciones en Humanidades (Humanities Research Network), una colección de repositorios en acceso abierto en diferentes campos de las ciencias humanas." ${ }^{16}$

\section{LA CONCEPCIÓN DE BIBLIOTECA}

Es importante destacar, como lo hace Arévalo, que:

[...] de la segunda mitad del siglo $\mathrm{xx}$, el valor fundamental de la biblioteca y del bibliotecario fue su carácter conservador, es decir, la integridad y transmisión de la biblioteca concebida como colección de libros en el tiempo en el único y exclusivo formato disponible que era el papel [...] en los años 60 se fueron incorporando a las bibliotecas de manera generalizada otros soportes audiovisuales como discos, películas y audiciones. La biblioteca,

14 Scielo en Perspectiva, "Evolución del Acceso Abierto - breve histórico" [en línea], http://blog.scielo.org/es/2013/10/21/evolucion-del-acceso-abiertobreve-historico/\#.WHgSfpJt0wQ

15 Ibíd.

16 Ibíd. 
La Infodiversidad y el uso ético del conocimiento...

cuyo valor esencial era la conservación, deja paso a la biblioteca técnica allá por los años 80 del pasado siglo [...] en los años 90 se consagran aspectos relativos a la gestión y calidad de los servicios y las colecciones; estos años coinciden con la introducción en la biblioteca de los primeros ordenadores, las primeras bases de datos en CD-ROM y una orientación al valor del servicio sobre cuestiones técnicas. ${ }^{17}$

Se refieren a la biblioteca con otros nombres como centro de información, centro de documentación, entre otros.

Pero, sin lugar a dudas, el fenómeno realmente revolucionario lo supuso la llegada de Internet, cuando en 1993 el mayor centro de Internet en Europa, el European High-Energy Particle Physics Lab, crea la World Wide Web, utilizando tres nuevos recursos: HTML (Hypertext Markup Language), HTTP (Hypertext Transfer Protocol) y un programa cliente, llamado Web Browser. ${ }^{18}$

Surgen las denominadas bibliotecas electrónicas, virtuales y digitales e incluso nombres como bibliotecas sin paredes. Bajo estos argumentos convergen en cierto punto de la historia las bibliotecas digitales y los repositorios; de ahí la confusión en los términos y usos de estos conceptos.

\section{RESTRICCIONES DE LOS DERECHOS DE AUTOR}

Los aspectos de regulación de los usos en materia de legislación y derecho de autor en los ochenta y noventa, en México, eran muy específicos en cuanto a los materiales impresos, y para esos años desde la perspectiva de la bibliote-

17 Julio Alonso-Arévalo, et al., La propiedad intelectual y los derechos de autor en bibliotecas y centros de información: revistas digitales y acceso abierto, p. 144 [en línea], http://eprints.rclis.org/18064/1/alonsopropiedad.pdf

18 Ibíd., p. 145. 
cología se denominaban materiales librarios y materiales no librarios para referirse a otro tipo de materiales de la época.

Para los albores de los noventa se pasa de la copia analógica a las copias digitales, cobrando auge la edición de libros en formato digital, ocasionando revuelo e incertidumbre en el sector editorial y de la información, ya que "[...] el fenómeno realmente revolucionario lo supuso la llegada de Internet." ${ }^{19}$ Estos acontecimientos hacen que se tomen medidas drásticas y de otra índole en cuanto a la propiedad intelectual se refiere.

En los últimos años,

[...] las innovaciones tecnológicas han transformado la manera en que se procesa, se guarda, se accede, se comparte y se analiza la información. Las tecnologías de la información han introducido cambios de importante alcance en este proceso estanco durante siglos. La invención de la imprenta supuso la necesidad de especialización, la creación de unas infraestructuras industriales y comerciales necesarias para la edición. El factor fundamental en este proceso ha sido el cambio de soporte, del formato tradicional impreso al digital. [...] Por esto, los modelos tradicionales de edición y comunicación están sujetos permanentemente a nuevos análisis en el contexto del panorama actual definido por las tecnologías de la información. ${ }^{20}$

Desde la perspectiva general de la propiedad intelectual y particularmente desde la postura de los derechos de autor en México, no existe un concepto de publicación electrónica, digital o virtual como tal. La Ley Federal de Derecho de Autor en México, como en muchos otros países, se encuentra rebasada por los contextos y avances tecnológicos y sólo se advierte en el Artículo 27 que:

19 Ibíd., p. 145

20 Ibid., p.148. 
La Infodiversidad y el uso ético del conocimiento...

Los titulares de los derechos patrimoniales podrán autorizar o prohibir:

I. La reproducción, publicación, edición o fijación material de una obra en copias o ejemplares, efectuada por cualquier medio ya sea impreso, fonográfico, gráfico, plástico, audiovisual, electrónico, fotográfico u otro similar.

II. La comunicación pública de su obra a través de cualquiera de las siguientes maneras:

a) La representación, recitación y ejecución pública en el caso de las obras literarias y artísticas;

b) La exhibición pública por cualquier medio o procedimiento, en el caso de obras literarias y artísticas, y

c) El acceso público por medio de la telecomunicación;

III.La transmisión pública o radiodifusión de sus obras, en cualquier modalidad, incluyendo la transmisión o retransmisión de las obras por:
a) Cable;
b) Fibra óptica;
c) Microondas;
d) Vía satélite, o
e) Cualquier otro medio conocido o por conocerse. ${ }^{21}$

Como se puede observar, no se especifica que sea un medio electrónico o digital; la leyenda "cualquier otro medio conocido o por conocerse" deja un abanico de posibilidades de interpretación y de cómo tomar legalmente esta leyenda. No se ha advertido que:

[...] el entorno digital facilita de distintas maneras la concesión de licencias de derecho de autor, entre otras, al permitir localizar y reconocer rápidamente a los licenciantes y los licenciatarios,

21 Ley Federal del Derecho de Autor. Nueva Ley publicada en el Diario Oficial de la Federación el 24 de diciembre de 1996. Texto Vigente. Última reforma publicada DOF 14-07-2014 [en línea], http://www.indautor.gob.mx/ documentos_normas/leyfederal.pdf 
¿Hasta dónde la creatividad intelectual y el acceso abierto...

creando plataformas virtuales de intercambio y automatizando los contratos, el pago y la entrega de productos y servicios. ${ }^{22}$

Entre ellos, se destaca el Creative Commons y los programas informáticos de código abierto, ya que "[...] constituyen una forma de distribución que se basa en los derechos exclusivos del titular del derecho de autor."23

Rubén Vázquez afirma que:

[...] tal parece que Internet y los derechos de autor no se llevan. Cualquiera sabe que al publicar algo en la red, el contenido parece convertirse en dominio público, es decir, cualquier obra intelectual que se publique en la web, está en peligro de ser copiada, pirateada, distribuida y/o comercializada sin la autorización del autor. ${ }^{24}$

Aunque el concepto de dominio público se puede malinterpretar o tener connotaciones diferentes, no podemos considerar que la información que está en la www está libre de barreras de acceso o de reutilización, sin tomar en consideración todo lo relacionado con la protección de la propiedad intelectual, ya que en el artículo 29 de la LFDA vigente se establecen las condiciones en que las obras pueden ser libremente empleadas una vez que dejaron de ser vigentes los derechos patrimoniales del autor o el titular de éstos, por ello la importancia de conocer y analizar la legislación vigente y no confundir o malinterpretar los términos relacionados.

22 OMPI, "La Concesión de Licencias de Derecho de Autor en el Entorno Digital" [en línea], http://www.wipo.int/copyright/es/activities/copyright_licensing.html

23 Ibid.

24 Rubén Vázquez, "La difícil relación entre derechos de autor e Internet" [en línea], http://www.forbes.com.mx/la-dificil-relacion-entre-derechos-de-autor-e-internet/\#gs.TQuiSuo 
La Infodiversidad y el uso ético del conocimiento...

En ese sentido, Internet es una especie de hoyo negro de los derechos de autor. Y es aquí donde se abre un debate profundo sobre la pertinencia de los contenidos en la red. Por una parte, la naturaleza de Internet es la de compartir, la de hacer que la información fluya de manera libre y que el conocimiento no se convierta en el patrimonio de unos cuantos, sino en un bien común de la humanidad. ${ }^{25}$

Actualmente, la industria editorial y de la información trabaja y se ha dado a la tarea de desarrollar modelos de negocio para el acceso y la recuperación del contenido de los materiales con sello editorial en la red y así lograr la rentabilidad por la venta y distribución de contenidos.

\section{PROHIBIDO PRESTAR; CITAR Y NO PLAGIAR}

En el siglo XXI son cada día más las problemáticas que presenta el uso de información con la utilización de sofisticadas y muy diversas TIC, propiciando nuevas y variadas formas de explotación de las obras registradas como propiedad intelectual, ya que las innovaciones y desarrollos tecnológicos representan nuevas problemáticas en las legislaciones en los ámbitos nacional e internacional en materia de propiedad intelectual.

Sin embargo, desde las épocas más remotas ya había diversas problemáticas para el uso de la información y se consideraba la prohibición para el acceso a ésta, ya sea para leer o distribuir. Así, tenemos que en la época de Cicerón, al referirse a la cosa incorpórea, se entendía como la facultad que se tiene de poseer una cosa u objeto dentro de los límites legales permisibles y se consideraban dos ámbitos en esta época referentes a los derechos de autor. Por un lado,

25 Ibíd. 
los derechos personales de los autores; y por otro, los derechos reales, que se referían a las regulaciones y relaciones que se establecían entre la persona y el objeto.

En Grecia, el arte y la cultura eran de suma importancia en la época de Alejandro Magno. En esa época la lectura y por consiguiente el acceso a ciertas obras era censurada por las autoridades políticas y religiosas, lo cual denota la represión de los derechos, la libre manifestación de las ideas, el acto y la voluntad unilateral de un soberano que condiciona y regula la difusión de las obras.

En el siglo XIII, en España aparece el Código de las Partidas de Alfonso el Sabio, en el cual se establece (aunque no explícitamente) la regulación de unos contratos de alquiler de originales manuscritos de las bibliotecas universitarias para su copia total o parcial que podían ser únicos $\mathrm{y}$, en el mejor de los supuestos, escasos.

Actualmente, con la revolución tecnológica se han desarrollado "candados" y prohibiciones en el entorno digital que han dado pauta al desarrollo de sofisticados sistemas de protección y gestión para las obras que se diseminan en la www, como por ejemplo los Digital Rights Management (DRM. Administrador o Gestor de Derechos en el Entorno Digital), los Electronic Copyright Management Systems (ECMS) y los TPMs (Tecnologías de Manejo de Derechos Digitales, o DRM), que regulan, controlan y dan acceso a los contenidos.

\section{CONCLUSIONES}

Hay que tener presentes los contextos de propiedad intelectual y cómo está conformada, ya que con las Tecnologías de la Información y la Comunicación ya no podemos hablar de derechos de autor por un lado y de propiedad industrial por 
La Infodiversidad y el uso ético del conocimiento...

el otro. La diversidad de materiales que se difunden en el entorno tecnológico fundamenta lo anterior y tenemos que referirnos a ellos con el término de propiedad intelectual.

Existe una gran confusión entre repositorios y bibliotecas digitales; el paradigma dentro del contexto bibliotecológico es cómo tenemos y debemos organizar las colecciones de acceso abierto, cómo se debe organizar una biblioteca digital o electrónica con fundamentos de catalogación y clasificación para conformar colecciones y cuál será la organización que también deben considerar fundamentaciones bibliotecológicas, la información contenida en los repositorios temáticos e institucionales.

Si bien dentro del contexto de la www los metadatos sirven para describir, catalogar, etiquetar y referir un recurso con objeto de su búsqueda y recuperación, no necesariamente siguen las normas bibliotecológicas para catalogar y describir los recursos de información que éstos contienen. Las bibliotecas tradicionales y las bibliotecas virtuales organizan sus colecciones con base en sistemas de clasificación universalmente conocidos, o al menos las bibliotecas virtuales deberían seguir esta organización; los repositorios son simplemente, desde mi perspectiva, sistemas de almacenamiento de información que etiquetan y describen en algunos casos los recursos presentes en la www para su búsqueda y recuperación.

Dentro de los aspectos más importantes en el contexto de la era digital entre el acceso abierto y la propiedad intelectual, se encuentran el derecho de reproducción, el derecho a la distribución, el derecho a la comunicación y el derecho a la transformación, debido a que el entorno digital es un parteaguas en estos cuatro derechos, y es el gran reto que afrontan los repositorios de acceso abierto. 
¿Hasta dónde la creatividad intelectual y el acceso abierto...

\section{BIBLIOGRAFÍA}

Acceso Abierto y repositorio de documentos [en línea], https://hipertextual.com/archivo/2014/10/importancia-acceso-abierto/

Alonso-Arévalo, Julio et al. (2011). "La propiedad intelectual y los derechos de autor en bibliotecas y centros de información: revistas digitales y acceso abierto". En Javier Torres Ripa y Antonio Hernández Gómez (Coord.) El copyright en cuestión. Diálogos sobre propiedad intelectual (pp. 143-168). Bilbao: Deusto [en línea], http://eprints.rclis.org/18064/1/alonsopropiedad.pdf

García Giménez, Daniel (2010). "Redes sociales: posibilidades de Facebook para las bibliotecas públicas”, BID: textos universitaris de biblioteconomia i documentació, 24 (juny) [en línea], http://bid.ub.edu/24/garcia2.htm

Instituto Autor. "Antecedentes históricos de la propiedad intelectual" [en línea], http://institutoautor.org/story.php?id=3156

Labastida Juan, Ignasi; Iglesias Rebollo, César (2006). Guía sobre gestión de derechos de autor y acceso abierto en bibliotecas, servicios de documentación y archivos. Madrid: SEDIC.

Ley de Propiedad Industrial. Nueva Ley publicada en el Diario Oficial de la Federación el 27 de junio de 1991. Texto vigente. Última reforma publicada Dof 01-06-201 [en línea], http://www. diputados.gob.mx/LeyesBiblio/pdf/50_010616.pdf

Ley Federal del Derecho de Autor. Nueva Ley publicada en el Diario Oficial de la Federación el 24 de diciembre de 1996. Texto vigente Última reforma publicada DOF 14-07-2014 [en línea], http://www.indautor.gob.mx/documentos_normas/leyfederal. pdf

Mazzone, Jason (2016). "Copyfraud", NYU Law Review 81(3): 10261100 [en línea], http://www.nyulawreview.org/sites/default/ files/pdf/NYULawReview-81-3-Mazzone.pdf 
La Infodiversidad y el uso ético del conocimiento...

Nettel Díaz, Ana Laura (2013). Derecho de autor y plagio. Alegatos (83): 136-137, [en línea], [consulta 26 enero 2017]. Disponible en web: http://www.corteidh.or.cr/tablas/r32329.pdf

OMPI. ¿Qué es la propiedad intelectual" [en línea], http://www. wipo.int/about-ip/es/

OMPI. "La Concesión de Licencias de Derecho de Autor en el Entorno Digital" [en línea], http://www.wipo.int/copyright/es/activities/copyright_licensing.html

OMPI. "Principios básicos de la propiedad industrial" [en línea], http://www.wipo.int/edocs/pubdocs/es/intproperty/895/ wipo_pub_895.pdf

OMPI. "Reseña histórica de la OMPI" [en línea], http://www.wipo.int/ about-wipo/es/history.html

Rodríguez, Gladys Stella (2013). "Régimen de Derechos de Autor frente a contenidos abiertos", Revista de Filosofía Jurídica, Social y Política, 20(2): 263-278.

Scielo en Perspectiva, "Evolución del Acceso Abierto - breve histórico" [en línea], http://blog.scielo.org/es/2013/10/21/evoluciondel-acceso-abierto-breve-historico/\#.WHgSfpJt0wQ

Vázquez, Rubén (2017). "La difícil relación entre derechos de autor e Internet", Forbes México [en línea]: http://www.forbes.com. $\mathrm{mx} /$ la-dificil-relacion-entre-derechos-de-autor-e-internet/\#gs. TQuiSuo

Winegar Goans, Judy (2009). Propiedad intelectual: principios y ejercicio. [Colombia:] Nathan Associates Inc. 


\title{
La máquina de la creatividad y la copia: Internet y el dilema de los derechos de autor
}

\author{
JONATHAN HERNÁNDEZ PÉREZ \\ Universidad Nacional Autónoma de México
}

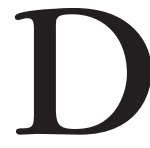

urante los últimos años, el desarrollo de la infodiversidad digital ha permitido que los flujos de información circulen y lleguen a lugares en los que de forma física no podrían llegar tan fácilmente ni con tanta rapidez. El rescate de la información impresa a través de mecanismos como la digitalización, la rápida indización de páginas web en los motores de búsqueda, sumado a la proliferación de redes sociales y el desarrollo de software colaborativo, han tenido consecuencias importantes en nuestras actividades cotidianas.

Para quienes vivimos los primeros años de la web en una etapa adolescente, se puede decir que tuvimos una cultura del download en la cual obtener música y otras manifestaciones informativas no representaba ningún problema más que ciertas habilidades tecnológicas que nacían en ese momento. En la actualidad, el grado de complejidad para obtener cualquier tipo de información en Internet puede variar, especialmente si ésta se encuentra protegida por alguna legislación del derecho de autor. Esto no quiere decir que sea imposible de obtener; la innovación en los sistemas de 
La Infodiversidad y el uso ético del conocimiento...

copiado y distribución de información, a menudo, es más rápida que los sistemas para detectar contenido protegido y, en consecuencia, deshabilitarlo.

Si bien esta cultura del download permitió que esas generaciones desarrollaran determinadas habilidades digitales, de alguna manera también acostumbró a obtener la información rápida y gratuita, y es que en una red interconectada con miles de computadoras a lo largo del mundo, diseñada para compartir información, no habría por qué pensar que no debería de ser así.

En este sentido, el desarrollo de Internet trajo consigo la representación digital de diferentes aspectos que se encontraban en el mundo físico, desde los medios tradicionales (televisión, radio, cine), las instituciones (universidades, bibliotecas, archivos) hasta las interacciones cotidianas plasmadas en chats, correos electrónicos, mensajes de voz y videollamadas. A medida en que estos aspectos se desarrollaban en su versión digital y la infodiversidad crecía continuamente, otros ámbitos comenzaron a surgir en el terreno digital; uno de ellos es el jurídico, específicamente en lo relacionado con la propiedad intelectual y el derecho de autor, el cual, a lo largo de los últimos años, ha tenido fuertes implicaciones para la "salud de Internet", algunas veces dañándola, otras tratando de protegerla y, en la mayoría de los casos, actuando como un placebo para la convivencia entre libertades y derechos.

De tal forma que la propiedad intelectual, el derecho de autor y el pago de derechos son temas con un fuerte debate alrededor del mundo, convirtiéndose en un aspecto fundamental y controversial en la agenda política de numerosos países.

El debate se orienta hacia la forma de conciliar el potencial tecnológico y social de Internet con los enfoques de la 
propiedad intelectual y el derecho de autor. Según la Internet Society, ${ }^{1}$ a lo largo de estos debates, han surgido dos enfoques principales:

- La aplicación de estos enfoques en los Intermediarios de Internet;

- El uso de medidas técnicas para evitar el acceso a contenidos no autorizados.

En este sentido, el desarrollo de la infodiversidad digital plantea importantes retos en materia de propiedad intelectual y derecho de autor, pues en principio las diferentes manifestaciones informativas tienen características propias, lo cual dificulta su protección a un mismo nivel; por ejemplo, los nombres de dominio normalmente son vinculados con las marcas comerciales. Sin embargo, en 2012 la Corporación de Internet para la Asignación de Nombres y Números (ICANN) dio a conocer la lista de los nuevos Dominios de Nivel Superior Genéricos (GTLD), la compañía Amazon Inc. solicitó el dominio amazon —entre otros más-, lo cual le daría sin duda una mayor visibilidad comercialmente, pues el nombre oficial y registrado de esa empresa es Amazon; sin embargo, Brasil y Perú, países por los que fluye el río Amazonas, se opusieron a esta solicitud argumentando que el dominio hace referencia a una zona geográfica. Tras varios debates la ICANN rechazó la solicitud de la empresa. El mismo caso sucedió con la empresa Patagonia Inc., que intentó registrar un dominio con ese nombre (.patagonia) después de que Argentina y Chile se opusieron con el argumento de que podría generar una confusión con la región

1 Internet Society (ISOC), "Intellectual Property" [en línea], http://www.internetsociety.org/intellectual-property 
La Infodiversidad y el uso ético del conocimiento...

de la Patagonia. Finalmente, la empresa decidió retirar la petición.

Por otro lado, la información científica tiene también sus particularidades. Por una parte, existen empresas que proveen acceso a estas investigaciones mediante una suscripción, la cual normalmente tiene un alto costo para las instituciones, particularmente para las bibliotecas. El pago por el uso de estos materiales representa un obstáculo para el acceso a la información, sin mencionar los candados legales y tecnológicos impuestos por las empresas o las propias instituciones para evitar la distribución, copia, almacenamiento e impresión de los materiales. Por otra parte, se encuentra el terreno del respeto y el reconocimiento de las ideas tanto en la información de acceso abierto como en la de suscripción y en general en la información que se produce desde y para la academia. Al no respetar los principios éticos en el uso de la información se incurre en fuertes delitos como el plagio en todas sus formas, con sus respectivas consecuencias legales y sociales.

Sin embargo, no sucede lo mismo con la música, los videos y otras manifestaciones artísticas, las cuales no basta con que se reconozca la autoría, sino que muchas veces se exige un pago por la explotación continua de la obra, incluso si el usuario adquirió ese material el contrato lo imposibilita para compartirlo aun entre sus propios dispositivos.

Si bien se han desarrollado nuevos modelos para tratar de armonizar las exigencias de la industria con el potencial tecnológico de Internet, como el servicio de streaming, el cual ha tomado auge y se posiciona como una manera legal de acceder a este tipo de material, todavía no existe un adecuado equilibro, ya que se siguen desarrollando iniciativas como ACTA, SOPA, PIPA o el Acuerdo Estratégico Transpacífico de Asociación Económica (TPP), que en aras de prote- 
ger el derecho de autor y la propiedad intelectual limitan y afectan el acceso a la información así como criminalizan al usuario por compartir contenido. Aunque también se han desarrollado importantes iniciativas y movimientos por parte de organizaciones como Creative Commons International o Article 19, que han emitido directrices o principios para tratar de armonizar todos estos aspectos, esta última, en 2013, emitió una serie de principios bajo el título de un posible "Derecho a compartir", los cuales buscan garantizar que la libertad de expresión y la capacidad de compartir conocimiento y cultura gocen de protección plena y no pesen sobre ella restricciones indebidas impuestas por los grupos dominantes en material de propiedad intelectual de la era digital. $^{2}$

Conviene subrayar que tanto la propiedad intelectual, el pago de derechos y particularmente la legislación sobre el derecho de autor tienen un fuerte impacto en la mayor parte del trabajo bibliotecario. Así lo ha argumentado la IFLA en diferentes foros y directrices. Particularmente en el año 2000, esta institución emitió su Postura sobre los Derechos de Autor en un Ambiente Digital, la cual enfatiza lo siguiente:

La IFLA sostiene que a menos que las bibliotecas y los ciudadanos sean excepciones que permiten el acceso y la utilización sin pago para fines que redunden en el interés público y de conformidad con los usos justos, como la educación y la investigación, existe el peligro de que sólo aquellos que pueden pagar serán capaces de tomar ventaja de los beneficios de la Sociedad de la Información. Esto llevará a una división aún mayor entre los ricos y los pobres en información. Además, no debe existir discriminación en las leyes de derechos de autor contra las personas discapacitadas visualmente, auditivamente o en su aprendizaje. El reformateo del

2 Article 19 "El Derecho a Compartir: Principios de la Libertad de Expresión y los derechos de propiedad intelectual en la Era Digital" [en línea], https:// www.article19.org/resources.php/resource/3716/es/El\%20Derecho\%20 a\%20Compartir 
La Infodiversidad y el uso ético del conocimiento...

material para que sea accesible no debe considerarse como una infracción del derecho de autor y sí debe considerarse como un acceso razonable. ${ }^{3}$

En este sentido, López Guzmán y Estada Corona enumeran seis puntos sobre la problemática del derecho de autor en el entorno de Internet:

1. La facilidad para hacer reproducciones.

2. La fácil distribución de las reproducciones.

3. La buena calidad de las reproducciones.

4. Pueden combinarse los formatos de las obras.

5. La fácil alteración de las obras digitales.

6. La obtención de copias idénticas al original.

Sin embargo, además de estos puntos, las normativa de cada país, los intereses globales de la industria, el activismo de los usuarios y principalmente la naturaleza abierta de Internet hacen difícil la conciliación entre las libertades, responsabilidades y derechos. En ese sentido, el intento por conciliar estos tres aspectos han originado intensos debates que se han convertido en verdaderas guerras socio-cibernéticas en las cuales se pueden apreciar distintos actores: usuarios, activistas, artistas, industria e incluso la academia. Cada uno de estos actores, desde sus trincheras, han planteado posibles soluciones al dilema de los derechos de autor en Internet y han llegado a débiles o nulos acuerdos para armonizar los aspectos anteriormente mencionados. Por una parte, algunos gobiernos en conjunto con las grandes corporaciones del entretenimiento han impulsado leyes que, en aras de proteger el material que producen, llegan a

3 International Federation of Library Associations and Institutions (IFLA), "Postura de la IFLA sobre los Derechos de Autor en un Ambiente Digital" [en línea], http://www.ifla.org/node/7300 
dañar las libertades de los usuarios. Por otro lado, proliferan comunidades virtuales asociadas al hacktivismo, como Anonymous, que mientras que su estandarte es la lucha por la libertad de expresión, la independencia y completa libertad de Internet, originan ataques cibernéticos a compañías privadas y sitios web gubernamentales; también destaca el desarrollo de asociaciones mediáticas, como Wikileaks, que si bien buscan denunciar irregularidades del Estado o de compañías internacionales que afectan a los ciudadanos, lo hacen principalmente a través de filtraciones de documentos diplomáticos confidenciales o correos electrónicos personales, en donde incluso han comprometido la privacidad de grupos vulnerables. ${ }^{4}$ Es importante mencionar que, a través de estos dos grupos, se han denunciado importantes ataques a los derechos humanos y un sinnúmero de irregularidades en distintos gobiernos. Asimismo, se han desarrollado representaciones políticas a favor de la libertad de expresión y la libre circulación de contenidos en Internet, como es el caso del Partido Pirata originado en 2006 en Suecia, cuyo objetivo es abogar por la revisión de los regímenes de la propiedad intelectual y el derecho de autor particularmente en Internet. Además de defender derechos como la privacidad y la libertad de información, entre otros, este Partido tiene representaciones en más de 60 países a lo largo del mundo. En esta batalla entre derechos y libertades también se afectan aspectos sensibles, como la privacidad y la vigilancia. Como caso local, se destaca el uso de herramientas de transmisión en vivo como Periscope por parte de autoridades para la denuncia de ciudadanos que come-

$4 \quad$ Nicky Wook, "WikiLeaks posted medical files of rape victims and children, investigation finds", The Guardian [en línea], https://www.theguardian. $\mathrm{com} / \mathrm{media} / 2016 / \mathrm{aug} / 23 /$ wikileaks-posts-sensitive-medical-informationsaudi-arabia 
La Infodiversidad y el uso ético del conocimiento...

ten actos delictivos, dejándolos a la merced del escarnio público sin una sólida base legal para realizar esta actividad.

\section{SOBRE LA CREATIVIDAD Y LA COPIA}

Si bien el discurso reiterativo respecto a Internet es que nos ha facilitado la obtención de información, lo cierto es que también nos ha hecho saber la medida en que nuestras ideas son innovadoras, pues basta con ingresar al motor de búsqueda y teclear unas cuantas palabras de lo que pensaríamos son proyectos originales e innovadores, o temas que creíamos que nadie ha planteado, para darnos cuenta de que probablemente ya lo ha hecho alguien más, en algún otro lugar del mundo; o quizá nuestro compañero al que le relatamos esa idea la escribió en un blog, lo cual se refleja en los resultados del motor de búsqueda. Pero también esta facilidad para obtener información ha permitido la inspiración para transformar ideas que encontramos en la red, adaptarlas, transformarlas o, en otros casos, copiarlas sin ningún tipo de escrúpulo.

Respecto a esto último, Marcus Boon en su libro Elogio a la copia ${ }^{5}$ expone el miedo y la fascinación que sentimos por la copia, argumentando que la copia en su acepción más general es una parte fundamental del ser humano; desde el nivel molecular hasta nuestras prácticas sociales estamos impregnados por copias. El autor sostiene que debemos de tomar en cuenta las distintas prácticas de copia que existen y se desarrollan en el mundo, desde la producción masiva de productos tecnológicos y textiles, la circulación "no autorizada" de textos en las universidades o la propia cir-

5 Marcus Boon, In Praise of Copying [en línea] http://www.hup.harvard.edu/ features/in-praise-of-copying/In-Praise-of-Copying-by-Marcus-Boon-HUPfree-full-text.pdf 
culación autorizada de ejemplares en bibliotecas, hasta los elaborados rituales de la imitación y simulación en muchas culturas tradicionales. El punto central de Boom es que sólo cuando veamos a la copia en un nivel macro, de manera holística podemos ver lo sesgado que resulta el actual régimen del derecho de autor y también el enorme desperdicio en hacerlo cumplir.

Conviene mencionar que cuando la Universidad de Harvard publicó este libro, en 2010, únicamente se podía acceder a él comprándolo; tras algunas críticas, el autor pugnó para que esa universidad lo distribuyera libremente en PDF. ${ }^{6}$

La copia entonces como concepto y como fenómeno social particularmente en Internet ha sido abordado desde distintas perspectivas. La copia como inspiración para la transformación, combinación o edición de material existente, con o sin derechos de autor, ha dado pie a lo que autores como Lawrence Lessig ${ }^{7}$ el creador de las populares licencias Creative Commons, ha denominado "Cultura del Remix”, un término que alude al reúso de software, música, imágenes, texto, etcétera, es decir, en términos generales alude a remezclar la infodiversidad para crear más infodiversidad. Evidentemente la cultura del remix no es nueva ni de los últimos años, pero ha tenido un mayor eco con el desarrollo de Internet.

Sin embargo, no todas las dimensiones de la copia deben de ser tratadas por igual ni todas tienen el mismo impacto. No podemos colocar en la misma bandeja la situación de la copia en países como China, donde la práctica de la producción de material copiado, falsificado o imitado está fuer-

6 Jess Row, "Reproductive Rights", New Republic [en línea], https://newrepublic.com/article/81291/praise-copying-marcus-boon

7 Lawrence Lessig, "Remix: Cultura de la remezcla y derechos de autor en el entorno digital" [en línea], http://www.icariaeditorial.com/pdf_libros/REMIX.pdf 
La Infodiversidad y el uso ético del conocimiento...

temente arraigado a su cultura, o el problema de la copia en la industria musical, o la copia en el contexto académico.

En este sentido, una de las vertientes de la copia es la relacionada con el robo de ideas presentándolas como propias. De la misma forma en la que Internet fomenta la creatividad al ofrecer una rica infodiversidad al alcance de un par de clics, también facilita el plagio y a su vez hace más fácil su detección.

En 2004 cuando Google comenzó a digitalizar los millones de libros provenientes de distintas bibliotecas académicas se enfrentó a numerosas demandas por parte de las editoriales que argumentaban infracciones al derecho de autor. Tras varias disputas, el proyecto vio la luz de la legalidad en 2015 cuando el Tribunal de Apelaciones en Estados Unidos indicó que Google Books representa un servicio público. Incluso uno de los jueces, durante la resolución, argumentó que:

Por casi 300 años, poco después del nacimiento de los derechos de autor en Inglaterra, los tribunales han reconocido que en determinadas circunstancias cuando se les otorga el control absoluto a los autores sobre todas las copias de sus obras, se tiende a limitar el conocimiento público, en el caso de Google Books enfatizó que debido a que son mayoritariamente fragmentos de texto no infringe el uso justo de la información, por el contrario, la finalidad de este tipo de reproducción es transformadora. ${ }^{8}$

Este innovador servicio de Google, capaz de vincular los libros digitalizados con los libros del catálogo de la biblioteca más cercana al usuario, dio pie a distintas indagaciones sobre el plagio. El reconocimiento del texto en los libros bastó para que al ingresar unas cuantas palabras nos

8 Robinson Meyer, "After 10 Years, Google Books Is Legal", The Atlantic [en línea], http://www.theatlantic.com/technology/archive/2015/10/fair-usetransformative-leval-google-books/411058/ 
diéramos cuenta si algún texto había sido plagiado. Paul Collins en su artículo de 2006 "La sociedad de los plagiarios muertos" lanzaba la pregunta respecto a que si Google Books destaparía a los plagiarios enterrados que hoy son autores consagrados. Lo anterior debido a ciertos ejercicios prácticos que realizó en esta plataforma y que demostraban párrafos sospechosamente similares entre diversos autores. Esto dio como resultado, entre otras cosas, el desarrollo de software dedicado exclusivamente a detectar el plagio en Google Books.

Un último ejemplo que conviene destacar es el desarrollo de Wikipedia, una poderosa enciclopedia colaborativa que muchas veces irrita a los más tradicionales académicos por su señalada falta de rigor científico y fuente de inspiración para plagiarios, menospreciando la capacidad creativa y colaborativa de esta herramienta. En la actualidad, un número importante de escuelas, instituciones y sobre todo bibliotecas alrededor del mundo se han sumado a proyectos de Wikipedia para fomentar la creación de contenidos especializados. Estos proyectos de edición colectiva sobre un tema específico o general llamados "editatones" se han vuelto muy populares alrededor del mundo. Como ejemplo de lo anterior, en el sector bibliotecario se destaca la campaña \#1Lib1Ref (Un bibliotecario, una referencia), la cual tuvo lugar en enero del 2016 y tiene como objetivo que cada bibliotecario del mundo colabore en la Wikipedia añadiendo una referencia. La propia IFLA ${ }^{10}$ ha manifestado el poder que

9 Paul Collins, "Dead Plagiarists Society", Slate [en línea], http://www.slate. com/articles/arts/culturebox/2006/11/dead_plagiarists_society.html

10 International Federation of Library Associations and Institutions (IFLA), "Opportunities for Public Libraries and Wikipedia", [en línea], http://2016.ifla. org/wp-content/uploads/sites/2/2016/08/112-IFLAWikipediaandPublicLibrariesDiscussionDRAFT.pdf 
La Infodiversidad y el uso ético del conocimiento...

puede tener Wikipedia para el desarrollo de las bibliotecas públicas.

Si vemos a la Wikipedia como una oportunidad para el desarrollo de la creatividad y la colaboración en lugar de señalarla por su carencia de credenciales académicas, tendríamos una mayor producción de información por parte de los profesionales de la bibliotecología.

Finalmente, en el terreno bibliotecario, si bien la enseñanza de habilidades para utilizar bases de datos, motores de búsqueda y journals nos ayudan en la formación de estudiantes comprometidos y creativos, también puede aumentar las posibilidades de un plagio, a otro nivel, con un poco más de trabajo, pero igual sería plagio, pues el alumno instruido podría buscar material en una base de datos en otro idioma, que sólo la comparten ciertas universidades en determinada región del mundo. Después obtendría el material, lo traduciría o en su caso lo mandaría a traducir, lo revisaría en algún software especializado en detección de plagio y podría pasar totalmente desapercibido. Por tal motivo, es importante idear estrategias que involucren a todos los actores responsables en la cadena de la producción de información; los valores éticos pueden ser transmitidos desde la biblioteca, pero en concordancia con los demás eslabones de la sociedad.

\section{CONCLUSIONES}

La mayor parte de lo que hoy se produce está fuertemente influido por otros saberes, por información que vemos, leemos y asimilamos. En Internet, la dualidad de la creatividad y de la copia seguirán conviviendo como lo harán en el mundo físico; sin embargo, debemos de aprovechar las 
oportunidades que nos ofrece Internet: desde los recursos de información más especializados hasta las redes sociales y las herramientas de colaboración en línea.

La disciplina bibliotecológica enfrenta diversos desafíos en cuanto al uso de la información. Hemos pasado de una cultura del download a una del remix; nuestros esfuerzos deben de estar encaminados a evitar el fortalecimiento de la cultura del plagio y, en su lugar, propiciar una cultura en la que se aproveche la información, se acceda a ella, se utilice, se lea y se produzcan contenidos a través del enriquecimiento creativo y comunitario de todos los actores involucrados.

Por otra parte, en cuanto al ámbito de la educación, la creatividad se verá mermada en la medida en que las visiones académicas sean tradicionales y limitantes. Exigir innovación y creatividad también dependerá de la actitud de nosotros como docentes, investigadores o responsables de bibliotecas.

Al mismo tiempo que se menciona enfáticamente no plagiar, también debemos de enseñar a transformar, a reinterpretar la información, a realizar un remix con significado, con utilidad y con un estilo personal, otorgando siempre el crédito a quien le corresponda.

\section{BIBLIOGRAFÍA}

Article 19 "El Derecho a Compartir: Principios de la Libertad de Expresión y los derechos de propiedad intelectual en la Era Digital", Article 19 [en línea], https://www.article19.org/resources.php/resource/3716/es/El\%20Derecho\%20a\%20Compartir 
La Infodiversidad y el uso ético del conocimiento...

Boon Marcus, In Praise of Copying, London: Harvard University Press, 2010 [en línea], http://www.hup.harvard.edu/features/ in-praise-of-copying/In-Praise-of-Copying-by-Marcus-BoonHUP-free-full-text.pdf

Collins Paul, "Dead Plagiarists Society", Slate 21 de noviembre de 2006 [en línea], http://www.slate.com/articles/arts/culturebox/2006/11/dead_plagiarists_society.html

IFEX. "Copyright law as a tool for State censorship of the Internet." [en línea], https://www.ifex.org/united_states/2014/12/08/copyright_law_tool/

International Federation of Library Associations and Institutions (IFLA). "Manifiesto de la IFLA/UNESCO sobre Internet." International Federation of Library Associations and Institutions [en línea], http://www.ifla.org/files/assets/faife/publications/policy-documents/Internet-manifesto-guidelines-es.pdf

International Federation of Library Associations and Institutions (IFLA). "Postura de la IFLA sobre los Derechos de Autor en un Ambiente Digital." International Federation of Library Associations and Institutions [en línea], http://www.ifla.org/node/7300

Internet Society (ISOC), "Intellectual Property", [en línea], http:// www.Internetsociety.org/intellectual-property

International Federation of Library Associations and Institutions (IFLA) "Opportunities for Public Libraries and Wikipedia”, [en línea], http://2016.ifla.org/wp-content/uploads/ sites/2/2016/08/112-IFLAWikipediaandPublicLibrariesDiscussionDRAFT.pdf

Internet Society (ISOC). "Introducción a los actores y conceptos de interconexión en Internet.” Internet Society [en línea], http:// www.isoc.org/pubpolpillar/community/wtdc2010.shtml

Internet Society (ISOC). "Nuestro ecosistema de Internet." Internet Society [en línea], http://www.Internetsociety.org/es/ qui\%C3\%A9n-lo-hace-funcionar 
Lessig Lawrence, "Remix: Cultura de la remezcla y derechos de autor en el entorno digital”. En Florencio Cabello y María García Perulero (Eds.), Barcelona: Icaria Editorial, 2012 [en línea], http://www.icariaeditorial.com/pdf_libros/REMIX.pdf

Martel, Frédéric. Smart, Internet (s): la investigación [traducción de Núria Petit Fontserè] [España:] Taurus, 2014.

Meyer Robinson, "After 10 Years, Google Books Is Legal", The Atlantic, 20 de octubre de 2015, [en línea], http://www.theatlantic.com/technology/archive/2015/10/fair-use-transformativeleval-google-books/411058/

Morales Campos, Estela. "La infodiversidad, un canal de expresión de nuestra diversidad”, en Ma. De los Ángeles Rivera y Sergio López Ruelas (coord.), Infodiversidad, la biblioteca como centro multicultural, Guadalajara: Universidad de Guadalajara, 2008.

Morozov, Evgeny, "Siervos y señores de Internet." El País, 15 de mayo de 2015 http://elpais.com/elpais/2015/05/05/opinion/1430842193_759913.html

Row Jess, "Reproductive Rights", New Republic 22 de mayo de 2011 [en línea], https://newrepublic.com/article/81291/praisecopying-marcus-boon

Wook Nicku, "WikiLeaks posted medical files of rape victims and children, investigation finds" The Guardian, 24 de agosto de 2016 [en línea], https://www.theguardian.com/media/2016/ aug/23/wikileaks-posts-sensitive-medical-information-saudiarabia 


\title{
En busca del equilibrio entre propiedad intelectual y acceso libre a la información y al conocimiento
}

\author{
Hugo Alberto Figueroa Alcántara \\ Universidad Nacional Autónoma de México
}

INTRODUCCIÓN

n el marco de la temática general del uso ético de
la información y la práctica del libre acceso, en el
presente capítulo se explican diversos elementos que
son relevantes en la búsqueda de un equilibrio entre los
intereses de los creadores - protegidos por la propiedad
intelectual- y los intereses de la sociedad - a través del
acceso libre a la información y al conocimiento-. Estos ele-
mentos, que promueven un mayor equilibrio al respecto, se
analizan en tres dimensiones: principios relacionados con
la información; derechos humanos e información; y marco
jurídico vinculado con la información: leyes y licencias tipo
creative commons. 
La Infodiversidad y el uso ético del conocimiento...

PRINCIPIOS RELACIONADOS CON LA INFORMACIÓN

\section{Principios éticos}

En nuestro devenir individual y colectivo cotidianamente realizamos una serie de actos, los cuales implican - consciente o inconscientemente- posiciones éticas, que pueden cambiar con base en un conjunto de factores tales como: las circunstancias históricas; el entorno político, social, cultural, educativo, etcétera; la complejidad de la problemática; las diversas perspectivas que sobre un tópico se tengan; los conflictos y polarizaciones que se generan, entre otros elementos.

Si bien existe la ética como disciplina filosófica de carácter general, también existen diferentes éticas especiales, según el tema a tratar. En este sentido, los diversos problemas éticos vinculados con la información son tratados por la ética de la información.

La ética de la información puede definirse como el campo disciplinario especial de la ética aplicada que abarca preguntas concernientes a problemas éticos en los campos de los medios de comunicación e información, de las tecnologías de la información, de la bibliotecología, de las computadoras y las bases de datos, de la bioética, de los circuitos de información financieros y empresariales y del ciberespacio (el entorno digital generado a través de las redes de telecomunicación y de computadoras, de Internet y de la web) (Severson, 1997; Floridi, 2013; Moore, 2005; Buchanan, 2009; Schultz, 2006; Capurro, 2005 y 2007).

Las tareas más importantes de la ética de la información son, entre otras: la observación, análisis, estudio e investigación, así como la reflexión y críticas fundamentadas de la conducta individual y social en el campo de la información; el análisis de las estructuras de poder asociadas con los 
flujos de información; examen y propuestas sobre la generación, uso y difusión de la información; conflictos éticos en el entorno de la información, entre múltiples temas.

La ética de la información se sustenta en cuatro principios esenciales, íntimamente vinculados con los derechos humanos fundamentales (Samek, 2007):

- Principio de libertad de expresión.

- Principio de libertad de información.

- Principio de acceso abierto a la información y al conocimiento.

- Principio de transparencia.

A continuación se explican con detalle estos principios.

\section{Principio de libertad de expresión}

En nuestro mundo moderno, el principio de libertad de expresión es un pilar fundamental de la esfera pública, la convivencia humana y el progreso de la humanidad, en todos los sentidos, porque permite el intercambio de ideas, información y conocimientos, elementos clave para la evolución de la civilización humana.

La libertad de expresión garantiza la libre circulación de ideas, opiniones e información de todo tipo, que pueden difundirse a través de cualquier medio de comunicación, sin que existan fronteras territoriales para tal fin (Article 19 (organización no gubernamental), 2013 : 7). Esto incluye todas las manifestaciones del ser humano: cultura, política, educación, ciencia, tecnología, etcétera (Cendejas Jáuregui, 2011: 13).

Por ello, esta libertad de expresión implica no solamente el derecho de comunicar, sino que también está estrecha- 
La Infodiversidad y el uso ético del conocimiento...

mente relacionada con el derecho de buscar, difundir y recibir información, el cual está avalado por el principio de libertad de información.

\section{Principio de libertad de información}

El principio de libertad de información garantiza que todo ser humano es libre de buscar, diseminar y recibir información de cualquier tipo que le permita satisfacer sus intereses y necesidades, porque este proceso es indispensable para conocer y hacer valer otros derechos, refuerza la democracia, permite el desarrollo individual y colectivo y posibilita la toma de decisiones. Sin libre circulación de información se dificulta drásticamente la generación de nuevo conocimiento, el desarrollo humano y la diversidad cultural, los cuales son baluartes y patrimonio común de la humanidad.

El disfrute pleno y libre de la información tiene una clara repercusión en que las personas emitan opiniones informadas, obtengan nuevos conocimientos y participen de manera más activa en la esfera pública, en debates de todo tipo y en la producción social para beneficio de las comunidades. También apremia a los gobiernos, a las instituciones y a las empresas a ser más abiertas, transparentes y responsables. Permite, además, un cambio drástico en el paradigma del flujo de información, mediante una transición visible de modelos basados en el secretismo y la opacidad a modelos cimentados en la máxima divulgación y en la transparencia (Article 19 (organización no gubernamental), 2013b). Crea las condiciones, en síntesis, para un mundo mejor, más justo, participativo, democrático y transparente.

Sobre todo, en nuestra época actual, caracterizada por la importancia cada vez más creciente de los flujos de información en todas las actividades humanas, ambos principios, 
En busca del equilibrio entre propiedad intelectual...

entrelazados, buscan garantizar que la libertad de expresión y la capacidad de compartir información, conocimiento y cultura gocen de garantía plena y no sean objeto de limitaciones desmesuradas, instrumentadas por los grupos dominantes en materia de propiedad intelectual.

En tal perspectiva, estos dos principios requieren de otro fundamental: el principio de acceso abierto a la información y al conocimiento.

\section{Principio de acceso libre a la información y al conoci- miento}

Intrínsecamente emparentado con los principios de libertad de expresión y libertad de información, queda claro el propósito esencial de este principio: acceder de manera abierta a la información y al conocimiento, sobre todo en nuestro mundo actual, caracterizado por la globalización, el poder estratégico de la información y el papel vital que juegan Internet y la digitalización para facilitar el intercambio de la misma. Este principio es primordial, pues permite conformar un frente común ante los embates cada vez más restrictivos en materia de propiedad intelectual, telecomunicaciones, control de la información, entre otros aspectos, promovidos por las grandes corporaciones, por los acuerdos internacionales de comercio y por los gobiernos.

En tal sentido, puede afirmarse que el principio de acceso libre a la información y el conocimiento es vital para el desarrollo humano sostenible y participativo y es un pivote primordial para construir entornos democráticos, porque es condición necesaria para la realización de los derechos humanos. Además, permite a las personas ser activas económicamente, aprender habilidades nuevas y exigir responsabilidades al gobierno, a las empresas y a todos los sectores 
La Infodiversidad y el uso ético del conocimiento...

de convivencia humana: sector político, sector científico, sector educativo, sector cultural, etcétera (Article 19 (organización no gubernamental), 2013).

En suma, este principio contribuye al desarrollo humano y a lograr una justicia distributiva, que permitan a nivel mundial mejorar las capacidades humanas para acceder, usar, compartir, colaborar y contribuir con la creación de información y conocimiento, para beneficio de todos (Kapczynski, 2010 y Krikorian, 2010). Para ello es necesario que la información sea accesible y oportuna, así como crear un entorno propicio para la participación pública y el compromiso cívico (Article 19 (organización no gubernamental), 2013).

Como bien puede observarse, el principio de acceso libre a la información y al conocimiento implica, entre otros aspectos, el redimensionamiento de las capacidades humanas para compartir, colaborar y contribuir con la constante renovación de la información y el conocimiento, por lo que tal principio está profundamente relacionado con otro principio cardinal: principio de transparencia.

\section{Principio de transparencia}

El principio de transparencia lo podemos definir como el derecho del público a saber qué acciones están llevando a cabo los diversos sectores e instituciones (gobierno, entidades científicas, instituciones educativas, empresas, etcétera) con los que interactúa, cuáles son los resultados, beneficios - o saldos negativos - y consecuencias (Oliver, 2004), así como exigir cuentas y responsabilidades (Schedler, 2008). Para ejercer la transparencia, se requiere estar bien informado, disponer de datos acerca del quehacer de las insti- 
tuciones o empresas para así poder evaluarlas sistemática y permanentemente (Ackerman, 2005).

Por otra parte, puede afirmarse que la información y conocimientos compartidos, el debate público, la transparencia y la confianza que de ella emana son elementos clave de un entorno abierto y democrático (Cruz Revueltas, 2009: 13). Todo tipo de instituciones y empresas, al estar cada vez más al descubierto, necesitan abrir su información y sus actos deben reflejar integridad y honestidad. El principio de transparencia, en síntesis, implica la comunicación veraz de la información (Tapscott, 2013).

Todos estos principios previamente tratados son vitales en la articulación de una serie de derechos humanos, donde el acceso libre a la información y al conocimiento es un componente crucial.

\section{DERECHOS HUMANOS E INFORMACIÓN}

Desde una perspectiva ideológica-política, el acceso libre a la información y al conocimiento se concibe como parte de un conjunto de derechos humanos esenciales, los cuales están plasmados en declaraciones, pactos y otros documentos de carácter internacional, a los que diversos países se han adherido, entre ellos México. A continuación, se detallan algunos de ellos, de gran trascendencia (en los textos específicos de los artículos referidos, se destaca en cursiva las partes directamente vinculadas con los principios tratados en el apartado previo).

El artículo 19 de la Declaración universal de los derechos bumanos (1948) es fundamental. En este artículo se proclaman dos derechos fundamentales, la libertad de expresión y la libertad de información y difusión de la misma: Todo 
La Infodiversidad y el uso ético del conocimiento...

individuo tiene derecho a la libertad de opinión y de expresión; este derecho incluye el de no ser molestado a causa de sus opiniones, el de investigar y recibir informaciones $y$ opiniones, y el de difundirlas, sin limitación de fronteras, por cualquier medio de expresión.

Asimismo, el artículo 19 del Pacto Internacional de Derechos Civiles y Políticos (1966) refrenda y detalla estos derechos cardinales: Toda persona tiene derecho a la libertad de expresión; este derecho comprende la libertad de buscar, recibir $y$ difundir informaciones e ideas de toda indole, sin consideración de fronteras, ya sea oralmente, por escrito o en forma impresa o artística, o por cualquier otro procedimiento de su elección.

En el mismo sentido, el artículo 13 del Pacto de San José de Costa Rica, emanado de la Convención Americana sobre Derechos Humanos (1969) también retoma estos derechos primordiales: Toda persona tiene derecho a la libertad de pensamiento y de expresión. Este derecho comprende la libertad de buscar, recibir y difundir informaciones $e$ ideas de toda indole, sin consideración de fronteras ya sea oralmente, por escrito o en forma impresa o artística, o por cualquier otro procedimiento de su elección.

En años más recientes, tanto desde una perspectiva de derechos humanos esenciales como de derechos culturales, los acuerdos emanados de la Convención sobre la protección y promoción de la diversidad de las expresiones culturales, organizada por la Unesco (2005), destacan -entre otros aspectos - que: la diversidad cultural es una característica esencial de la humanidad y constituye un patrimonio común de la humanidad que debe valorarse y preservarse en provecho de todos, misma que se fortalece mediante la libre circulación de las ideas y se nutre de los intercambios y las interacciones constantes entre las culturas. En tal contexto, 
sobresale el primer principio del Artículo 2: Sólo se podrá proteger y promover la diversidad cultural si se garantizan los derechos bumanos y las libertades fundamentales como la libertad de expresión, información y comunicación, así como la posibilidad de que las personas escojan sus expresiones culturales.

Posteriormente, la Carta Cultural Iberoamericana (2006) resalta la importancia de equilibrar los derechos de autor y el derecho del acceso universal a la información, al conocimiento y a la cultura, como elementos imprescindibles del bienestar y desarrollo de las naciones: Se incentivarán y protegerán las creaciones expresadas en las obras culturales, científicas y educativas, asumiendo que los derechos de los creadores, equilibrados con la garantía del acceso universal a la información, al conocimiento y a la cultura, son fuentes de desarrollo y bienestar en las naciones. Se promoverán alternativas para articular el resguardo de los derechos de autor, el desafío planteado por las nuevas tecnologías, el acceso masivo a innovadoras formas de creación y la difusión de bienes y servicios culturales.

De todo este conjunto de derechos humanos esenciales conectados con la libre circulación de la información y el conocimiento se nutre un derecho humano emergente: el derecho de acceso libre a la información y al conocimiento, el cual es la base para instrumentar una serie de tratados, leyes, licencias, etcétera, que permitan cumplir este derecho, tema que se trata a continuación. 
La Infodiversidad y el uso ético del conocimiento...

MARCO JURÍDICO VINCULADO CON LA INFORMACIÓN: LEYES Y LICENCIAS TIPO CREATIVE COMMONS

\section{Leyes relacionadas con la propiedad intelectual}

La legislación en materia de propiedad intelectual abarca dos campos: derechos de autor y derechos de patentes y marcas. No obstante, en el debate ideológico, político, etcétera, representan la misma temática: propiedad intelectual.

En tal contexto, no hay que perder de vista que las primeras legislaciones relacionadas con los derechos de autor (por ejemplo el Estatuto de la reina Anna (1710) sobre copyright), nacieron con la idea primigenia de resguardar los derechos de la sociedad y alimentar el dominio público para acceder libremente a las obras, por lo que sólo se otorgaban derechos temporales, con límites estrictos, a autores y editores, como una manera de incentivar la creatividad. En esa época el dominio público era la prioridad, mientras que los derechos de autor el beneficio secundario (Boyle, 2003). Sin embargo, con el paso del tiempo la idea original de legislar a favor de los intereses de la sociedad se fue pervirtiendo, en beneficio de la iniciativa privada y las grandes corporaciones que controlan y manipulan con excesivas ganancias patrimoniales segmentos significativos de la creatividad humana. Lo mismo ha sucedido con los derechos de patentes y marcas.

Por ello en nuestros días - a nivel mundial- los derechos de autor y de patentes y marcas son cada vez más restrictivos. Esta dinámica incrementa los conflictos entre los derechos de propiedad intelectual y los derechos de libertad de expresión y de información, dos derechos humanos fundamentales. Adicionalmente, Internet y las tecnologías digitales amplían exponencialmente las posibilidades de acceso, intercambio y difusión de la información. Todo esto 
conforma un complejo campo de batalla donde confluyen elementos ideológicos, políticos, legales, económicos, tecnológicos, etcétera.

En tal contexto, una vertiente global emergente - en la que cada vez se unen más voces- pugna por una reinterpretación positiva de la propiedad intelectual, de tal modo que se favorezca la libertad de expresión y la libre circulación de la información, pues éstas son la base de la diversidad cultural, la innovación y la creatividad, motores vitales del progreso humano en todos los sentidos.

En esta perspectiva se han formulado diversos principios que buscan influir y provocar cambios en las legislaciones internacionales y nacionales relativas a la propiedad intelectual. Entre ellos destacan los siguientes:

- Promover que la libertad de expresión y las múltiples posibilidades de compartir conocimiento y cultura gocen de protección justa y no pesen sobre ellas restricciones abusivas forzadas por los grupos dominantes en materia de propiedad intelectual de la era digital.

- La libertad de expresión protege la información, las opiniones y las ideas de todo tipo que se difundan a través de todo medio de comunicación, con total independencia de los límites territoriales que pudieren existir.

- La libertad de expresión comprende el derecho no sólo de comunicar, sino también de buscar y de recibir información. En tal contexto es imprescindible conceptualizar y mantener Internet como bien público que se ha vuelto imprescindible para el ejercicio y goce eficaz de la libertad de expresión a una escala exponencialmente creciente.

- La propiedad intelectual goza de amparo limitado en el derecho internacional de los derechos humanos, pues 
La Infodiversidad y el uso ético del conocimiento...

forma parte del derecho de propiedad; y al igual que el derecho a la propiedad considerado en sí mismo, no es un derecho absoluto y hay que equilibrarla en conformidad con el interés general.

- La libertad de expresión y la propiedad intelectual son complementarias, puesto que el propósito de la propiedad intelectual es la promoción de la creatividad literaria, musical y artística, el enriquecimiento del patrimonio cultural y la difusión de los bienes del conocimiento y de la información al público general.

- El dominio público es la suma neta de la totalidad de información y de bienes culturales que no es objeto de los derechos de propiedad intelectual y que el público general puede aprovechar e intercambiar sin restricción alguna. Forma parte del patrimonio cultural de toda la humanidad que se debe preservar y usar al máximo.

- El plazo por el cual se extenderá el derecho de propiedad intelectual no debería prolongarse más que el que sea necesario para alcanzar su propósito sin perjudicar la libertad de expresión. Debería juzgarse que proteger la propiedad intelectual más allá del tiempo de vida del autor es una restricción injustificada impuesta al dominio público y a la libertad de expresión y al derecho a la información, y se debería derogar (Article 19 (organización no gubernamental), 2013a: 7-11).

Este cambio de paradigma, reflejado en los principios previos, es de particular importancia para el desarrollo humano, los derechos humanos y la democracia y, por lo tanto, dentro de este marco, también para las bibliotecas, archivos y otras unidades de información, quienes sistemáticamente han demostrado su afán para contribuir al libre intercambio 
de información, aunque a nivel global en muchos casos las actividades al respecto se han realizado en un limbo legal.

Esto queda demostrado en el valioso estudio de Kenneth Crews (2008): Estudio sobre las limitaciones y excepciones al derecho de autor en beneficio de bibliotecas y archivos. En relación con el tema referido, él analizó las legislaciones de ciento cuarenta y nueve países de un total de ciento ochenta y cuatro que son miembros de la Organización Mundial de la Propiedad Intelectual y encontró notables variaciones, entre ellas:

- En veintiún países no hay ningún tipo de excepciones explícitas para bibliotecas y archivos.

- En veintisiete países hay excepciones generales exclusivamente para las bibliotecas.

- En setenta y cuatro países se permite la copia de obras para fines de investigación o estudio.

- En setenta y dos países se permite la copia de obras para su preservación.

- En setenta y siete países se permite la copia para el reemplazo de los originales desgastados cuando no están disponibles para su compra.

- Sólo en diecisiete países se ampara legalmente el suministro de documentos.

- Sólo en seis países hay preceptos legales para el préstamo interbibliotecario.

- Sólo en veintiséis países es legal por parte de bibliotecas y archivos el uso de dispositivos dedicados a la neutralización de medidas de protección tecnológica de obras.

En congruencia con los principios anteriormente señalados y como una medida para amplificar legalmente las 
La Infodiversidad y el uso ético del conocimiento...

limitaciones y excepciones a los derechos de autor para beneficio de las bibliotecas y archivos, han surgido dos propuestas de gran importancia:

- Proyecto de tratado de la OMPI sobre excepciones y limitaciones para las personas con discapacidad, las instituciones docentes $y$ de investigación, las bibliotecas $y$ los archivos: propuesta del Grupo Africano, por parte del Grupo Africano del Comité Permanente de Derecho de Autor y Derechos Conexos de la Organización Mundial de la Propiedad Intelectual (2011).

- Propuesta de tratado sobre limitaciones y excepciones a los derechos de autor para las bibliotecas y los archivos, por parte de la IFLA (2012).

El documento de la IFLA reconoce, retoma, complementa y perfecciona la propuesta del Grupo Africano, por lo que cubre más temas y es más amplio en sus alcances. A la vez, ambas propuestas refrendan la gran importancia que tiene el libre intercambio de información, ideas y conocimientos para el progreso de la humanidad.

Algunos de los aspectos más relevantes de la propuesta de la IFLA son:

- Se requiere mantener un balance entre los derechos de los autores y el interés público.

- Es necesario un nivel mínimo de armonización legislativa internacional que garantice la libre circulación de la información, condición fundamental para la igualdad global en el acceso a la investigación, las ideas y la innovación. 
- Las limitaciones y excepciones para el acceso a la información deben gozar de la misma condición jurídica que los derechos exclusivos de autor (IFLA, 2012).

Los derechos específicos que se buscan proteger con la propuesta son (siempre bajo un principio de uso justo y abarcando medios impresos, analógicos y digitales):

- Artículo 5. Derecho de importación paralela a la realizada por librerías, etcétera.

- Artículo 6. Derecho a préstamos de bibliotecas y acceso temporal a usuarios y otras bibliotecas.

- Artículo 7. Derecho a la reproducción y suministro de copias de bibliotecas y archivos a usuarios y otras bibliotecas y archivos.

- Artículo 8. Derecho de preservación del material de las bibliotecas y archivos por medio de la reproducción.

- Artículo 9. Derecho a usar obras y materiales protegidos por derechos conexos en beneficio de personas con discapacidades.

- Artículo 10. Derecho de acceso a obras objeto de retractación o retiradas.

- Artículo 11. Derecho de uso de obras huérfanas y de material protegido por derechos conexos.

- Artículo 12. Derecho a los usos transfronterizos.

- Artículo 13. Derecho a la traducción de obras por parte de bibliotecas y archivos.

- Artículo 14. Obligación de respetar las excepciones al derecho de autor y los derechos conexos por parte de los países adherentes al tratado.

- Artículo 15. Derecho de las bibliotecas y archivos a usar dispositivos que neutralicen las protecciones tecnológicas a obras. 
La Infodiversidad y el uso ético del conocimiento...

- Artículo 16. Limitación sobre la responsabilidad de las bibliotecas y archivos en caso de querellas por presunta infracción de derechos de autor.

- Artículo 17. Obligación del depósito legal.

- Artículo 18. Los países adherentes pueden establecer mayores excepciones y limitaciones siempre que no se contrapongan a las señaladas en el tratado (IFLA, 2012).

Sin duda, la aprobación de este tratado -y su consecuente instrumentación por parte de los países signatarios - tendrá una profunda repercusión en el balance entre derechos de propiedad intelectual y derechos de acceso a la información, así como en el papel que juegan las bibliotecas y archivos.

\section{Leyes relacionadas con el derecho de acceso a la infor- mación}

El derecho de acceso a la información puede definirse como el derecho de tiene toda persona, sin ningún tipo de distinción, a informarse y conocer, con la finalidad de tomar decisiones informadas, vivir una vida autónoma y desarrollarse como ser humano y actor social (Article 19 (organización no gubernamental), 2007). Su importancia vital radica en que es un elemento indispensable para el ejercicio de los derechos políticos y es un componente imprescindible para la realización de otros derechos humanos (Comisión Interamericana de Derechos Humanos, 2011: 10).

El derecho de acceso a la información centra su interés, aunque no exclusivamente, en:

- Que toda la información pública emanada de instituciones de gobierno - en sus diferentes niveles, federal, 
estatal y municipal - e instituciones públicas esté disponible de manera adecuada y oportuna.

- Que toda la información - publicaciones, reportes técnicos, datos base (también denominados datos primarios), etcétera- derivada de investigación financiada con recursos públicos esté disponible a través de repositorios de acceso abierto o modalidades afines.

- Que los datos y metadatos producidos por instituciones gubernamentales e instituciones públicas de carácter educativo, cultural y de investigación, etcétera - alojados en bases de datos, portales, sitios web, repositorios de acceso abierto, etcétera-, estén basados en estándares abiertos, sean interoperables y puedan ser utilizados, reutilizados, combinados, redistribuidos libremente y de manera universal por cualquier persona, con la finalidad de crear sistemas y servicios de información de valor agregado, que contribuyan al desarrollo y bienestar humanos.

Todo esto tiene como finalidad esencial contribuir en la construcción de sociedades más democráticas, participativas, trasparentes y abiertas.

Para llevarlo a la práctica, a nivel internacional se han generado tres tipos de leyes: leyes de acceso a la información pública, leyes de acceso abierto a la investigación financiada con recursos públicos y leyes de datos abiertos. A continuación se tratan con detalle.

\section{Leyes de acceso a la información pública}

De las tres modalidades de leyes emparentadas con el derecho de acceso a la información, la correspondiente a leyes de acceso a la información pública es la que: 
La Infodiversidad y el uso ético del conocimiento...

- Cuenta con más años de antigüedad en legislarse en diferentes países.

- Cuenta con mayor número de países con legislación al respecto.

- Goza de un corpus teórico conceptual más consolidado.

- Tiene mayor jurisprudencia, tanto a nivel nacional como internacional.

- Cuenta con mayor número de estudios sobre el tema y tópicos relacionados.

A la fecha, de acuerdo con el Global right to information rating (Access Info Europe (España), 2017) ciento once países han proclamado leyes sobre acceso a la información pública. Este índice de clasificación es muy interesante y útil, por lo que se recomienda mucho su consulta, pues contiene información muy valiosa acerca de cuáles países cuentan con ley al respecto, se incluye en archivo PDF el texto de cada ley y se ordena a los países de acuerdo con la calidad de su ley, con base en un conjunto de indicadores estandarizados, cuidadosamente diseñados. Con los datos ofrecidos pueden establecerse comparaciones y definir modelos idóneos de acceso a la información pública, al cotejar debilidades y fortalezas entre países.

Por ejemplo, en el caso de México, vale la pena destacar que ocupa el primer lugar de un total de ciento once países, lo cual está bastante bien, es decir, comparativamente a nivel mundial, tenemos una ley fuerte, precisa y de calidad, que ha permitido nutrir tres elementos fundamentales de la esfera pública, que derivan de la idea del gobierno abierto y de derecho a la información: transparencia, rendición de cuentas y participación ciudadana (The Transparency and Accountability Initiative, 2013). 
En busca del equilibrio entre propiedad intelectual...

Leyes de acceso abierto a la investigación financiada con recursos públicos

A diferencia de las leyes de acceso a la información pública, las relativas al acceso abierto a la investigación financiada con recursos públicos cuenta con una tradición más corta, por lo que podemos afirmar que se trata de un núcleo legal en proceso de consolidación. Pero no hay que perder de vista que en tal propósito, además de la vía jurídica, confluye un combativo y sólido movimiento de acceso abierto a la información científica y académica, que a través de iniciativas, declaraciones y acciones concretas ha logrado, en poco más de 10 años, conformar una masa crítica notable, con evidentes repercusiones en los flujos de la información y el conocimiento, así como en la visibilidad de los resultados de investigación y el avance de la ciencia.

La idea fundamental del movimiento de acceso abierto se sustenta en que el conocimiento y la cultura son bienes comunes primarios, indispensable tanto para el desarrollo de las personas como de la sociedad en su conjunto (Ríos, 2011: 180), pues es de gran importancia considerar el acceso al conocimiento como un derecho social de uso colectivo (Morales Campos, 20011, 2011a). Por lo tanto debe crearse, desarrollarse y sostenerse un conjunto de mecanismos, estrategias y alternativas que promueva el acceso irrestricto a dicho conocimiento.

Es en la primera década de este siglo - aunque antes ya existían algunos esfuerzos aislados- que emergieron tres declaraciones a favor del acceso abierto, las de Budapest (Iniciativa de Budapest para el Acceso Abierto, 2002), la de Bethesda (Declaración de Bethesda sobre Publicación de Acceso Abierto, 2003) y la de Berlín (Declaración de Berlín sobre Acceso Abierto al Conocimiento en las Ciencias y las Humanidades, 2003), mismas que lograron amplia difusión, 
La Infodiversidad y el uso ético del conocimiento...

convenciendo, a nivel mundial, a extensas comunidades y múltiples sectores involucrados, además de que permitieron articular consistentemente los criterios generales de los dos modelos básicos de gestión de sistemas de acceso abierto, los cuales son vigentes hasta nuestros días (aunque, claro, existen paralelamente estrategias híbridas o alternativas):

- El camino dorado, que se enfoca en la creación y desarrollo de revistas científicas y académicas en acceso abierto.

- El camino verde, mediante la construcción y robustecimiento de repositorios de acceso abierto (Suber, 2012).

Los principios fundamentales en que se basan dichos sistemas de acceso abierto son:

- Las obras deben estar disponibles gratuitamente en Internet y debe permitirse que cualquier usuario pueda acceder a ellas y sus metadatos.

- Los autores tendrán el control sobre la integridad de su obra así como el derecho de ser reconocidos y citados apropiadamente (Iniciativa de Budapest para el Acceso Abierto, 2002).

- Los usuarios tendrán el derecho universal y perpetuo para acceder, utilizar y distribuir las obras en cualquier medio digital, con cualquier finalidad responsable, sujeta a la apropiada atribución de la autoría.

- Una versión digital completa de cada obra debe ser depositada y accesible, de forma inmediata a la publicación de ésta, en por lo menos un repositorio abierto, disponible en línea, que cumpla con los principios básicos de facilitar el acceso abierto, la distribución sin restricciones, la interoperabilidad y su permanencia a 
En busca del equilibrio entre propiedad intelectual...

largo plazo (Declaración de Bethesda sobre Publicación de Acceso Abierto, 2003).

- El acceso abierto abarca todas las áreas del conocimiento: ciencias duras, ciencias sociales y humanidades.

- Internet es la plataforma tecnológica-social del acceso abierto global al conocimiento científico y la reflexión humana (Declaración de Berlín sobre Acceso Abierto al Conocimiento en las Ciencias y las Humanidades, 2003).

- El acceso abierto es cien por ciento compatible con los derechos de autor, con el arbitraje de las publicaciones y la calidad de publicaciones.

Estos principios y modelos de acceso abierto han incidido en el diseño de las leyes sobre tal tema que en algunos países se han formulado, como por ejemplo Estados Unidos (Federal research public access act, 2006), España (Ley 14/2011, de junio, de la ciencia, la tecnología y la innovación, 2011), Perú (Ley que regula el repositorio nacional digital de ciencia, tecnología e innovación de acceso abierto, 2013) y Argentina (Ley 26899: creación de repositorios digitales institucionales de acceso abierto, propios o compartidos, 2013).

En el caso de México, el 20 de mayo de 2014 entró en vigor el Decreto por el que se reforman y adicionan diversas disposiciones de la Ley de ciencia y tecnología, de la Ley general de educación y de la Ley orgánica del Consejo Nacional de Ciencia y Tecnología (México, Secretaría de Educación Pública, 2014). Este decreto tiene como propósito fundamental la creación y desarrollo de repositorios (institucionales, por disciplinas, nacional, etcétera) de acceso abierto a la información científica tecnológica y de innovación, financiada con recursos públicos, con el fin de: 
La Infodiversidad y el uso ético del conocimiento...

[...] fortalecer las capacidades del país para que el conocimiento universal esté disponible a los educandos, educadores, académicos, investigadores, científicos, tecnólogos y población en general. La estrategia buscará ampliar, consolidar y facilitar el acceso a la información científica, tecnológica y de innovación nacional e internacional a texto completo, en formatos digitales (México, Secretaría de Educación Pública, 2014: 2).

\section{Leyes de datos abiertos}

Las leyes específicas y ex profeso sobre datos abiertos representan el segmento más emergente de la legislación especializada vinculada con el derecho de acceso a la información. Aunque existen ejemplos concretos, como el de España (Ley 37/2007, de 16 de noviembre, sobre reutilización de la información del sector público 2007), en un porcentaje significativo de países, los aspectos legales concernientes al uso y reutilización de datos abiertos provenientes de las entidades públicas o están incluidos de manera explícita en las leyes de acceso a la información pública o bien se da por sobre entendido que su uso, reutilización, remezcla con otros datos, etcétera, está permitido.

Por otra parte, existen directivas - a nivel internacional-, como la de la Unión Europea (2013): Directiva 2013/37/ UE del Parlamento Europeo y del Consejo de 26 de junio de 2013 por la que se modifica la Directiva 2003/98/CE relativa a la reutilización de la información del sector público, que obliga a todos los estados miembros a autorizar la reutilización de todos los documentos y datos de carácter público (salvo las excepciones legales en cada país) y sin que esto afecte o modifique las regulaciones legales sobre acceso a la información pública vigentes en cada nación.

En el caso de México, la Ley federal de transparencia y acceso a la información pública (2016) no contempla de manera explícita aspectos relativos a la reutilización de da- 
En busca del equilibrio entre propiedad intelectual...

tos abiertos, por lo que se puede interpretar que tal acción está implícitamente permitida.

\section{Licencias tipo creative commons}

Como podemos observar, la puesta en marcha de diversas leyes relacionadas con el derecho de acceso libre a la información, aunada a múltiples acciones a favor del acceso abierto a la información y al conocimiento por parte de diferentes sectores de la sociedad, ha repercutido en que millones de obras, documentos, datos y otros recursos de información estén disponibles para cualquier persona sin restricciones, la mayor parte de las veces en versión digital y a través de Internet, por lo que la distribución, copia, reutilización, etcétera, de información adquiere dimensiones globales.

No obstante, tales leyes no regulan los derechos intelectuales de las obras, ideas, etcétera, pues eso corresponde a las leyes de propiedad intelectual, en sus dos categorías básicas: leyes de derecho de autor y leyes de propiedad intelectual.

Sin embargo, estas leyes de propiedad intelectual se basan en una cultura del permiso: todos los derechos reservados, mientras que lo que se requiere es una transfiguración a una cultura de la libertad: algunos derechos reservados (Lessig, 2005: 279-283).

Es en ese marco de evolución hacia un marco legal basado en un paradigma libertario que surgen, se desarrollan y aplican las licencias creative commons y similares, como una alternativa para compartir obras e información. Desde un punto de vista jurídico, el modelo creative commons puede definirse como un conjunto de textos legales desarrollado con el propósito de que los autores o responsables 
La Infodiversidad y el uso ético del conocimiento...

editoriales puedan ceder algunos derechos de autor sobre sus obras y se reserven otros, para facilitar la libre difusión de las mismas (Viñas, 2010: 6).

Por lo tanto, las licencias creative commons no se contraponen a los derechos de autor, ni los reemplazan, más bien los complementan y actualizan en el entorno de nuestra era digital. Al aplicar las licencias creative commons, los autores o responsables de la publicación y difusión de una obra, en vez de conservar todos los derechos como primera opción, típica de las leyes de propiedad intelectual, decide qué derechos le interesa conservar y cuáles liberar, mediante un total de siete opciones que representan diversos grados de flexibilidad, de más a menos:

- Dominio público, ningún derecho reservado.

- Reconocimiento/atribución.

- Atribución-compartir obras derivadas igual.

- Atribución-sin obras derivadas.

- Atribución-no comercial.

- Atribución-no comercial-compartir obras derivadas igual

- Atribución-no comercial-sin obras derivadas (Creative commons, 2017).

Así, el modelo creative commons ofrece un sistema flexible de derechos de autor para facilitar el trabajo creativo (Zapata Rendón, 2009: 3), revolucionando el ejercicio de los derechos de propiedad intelectual en Internet (Viñas, 2010: 5).

El modelo de licencias creative commons representa un marco jurídico de carácter general, que resulta conveniente adecuarlo localmente a nivel nacional, según el contexto legal de cada país. Por ejemplo, en el caso de México a través del sitio web: http://www.creativecommons.mx/ (Creative 
En busca del equilibrio entre propiedad intelectual...

Commons (México), 2017), podemos consultar las diferentes licencias, adaptadas para nuestra nación.

\section{BIBLIOGRAFÍA}

Access Info Europe (España) y Centre for Law and Democracy (Canada) (2017). Global right to information rating [en línea], http://www.rti-rating.org/index.php

Ackerman, John M. y Sandoval, Irma E. (2005). Leyes de acceso a la información en el mundo. México: Instituto de Acceso a la Información Pública [en línea], http://www.cdc.gob.cl/wpcontent/uploads/documentos/ackerman_\&_sandoval_laip.pdf

Argentina (2013). Ley 26899: creación de repositorios digitales institucionales de acceso abierto, propios o compartidos [en línea], http://repositorios.mincyt.gob.ar/recursos.php

Article 19 (organización no gubernamental) (2007). Access to information: an instrumental right to empowerment [en línea], http://www.article19.org/data/files/pdfs/publications/ati-empowerment-right.pdf

Article 19 (organización no gubernamental) (2013). El acceso a la información, elemento esencial de la agenda para el desarrollo post-2015 [en línea], http://www.article19.org/data/files/ medialibrary/37393/Access-to-information-post-2015-ES-A4. pdf

Article 19 (organización no gubernamental) (2013a). El derecho a compartir: principios de la libertad de expresión y los derechos de propiedad intelectual en la era digital. London: Article 19 [en línea], http://www.article19.org/data/files/ medialibrary/3716/13-04-23-right-to-share-SP.pdf

Article 19 (organización no gubernamental) (2013b). Libertad de información [en línea], http://www.article19.org/pages/es/ freedom-of-information.html 
La Infodiversidad y el uso ético del conocimiento...

Buchanan, Elizabeth A. y Henderson, Kathrine A. (2009). Case studies in library and information science ethics. Jefferson, N.C.: McFarland \& Co.

Capurro, Rafael (2005). Towards an ontological foundation of information ethics [en línea], http://www.capurro.de/oxford.html

Capurro Rafael, Frühbauer Johannes y Hausmanninger, Thomas (editors) (2007). Localizing the Internet: ethical aspects in intercultural perspective. München: Wilhelm Fink.

Carta Cultural Iberoamericana (2006) [en línea], http://www. gestionculturana.org/attachments/184_La\%20carta\%20cultural\%20iberoamericana.pdf

Cendejas Jáuregui, Mariana (2011). El derecho a la información: delimitación conceptual. Derecho Comparado de la Información, (15), enero-junio de 2011, 3-47 [en línea], http://biblio.juridicas.unam.mx/revista/pdf/DerechoInformacion/15/art/art1.pdf

Comisión Interamericana de Derechos Humanos (2011). El derecho de acceso a la información en el marco jurídico interamericano [en línea], http://www.oas.org/es/cidh/expresion/docs/ publicaciones/ACCESO $\% 20 \mathrm{~A} \% 20 \mathrm{LA} \% 20$ INFORMACION\%20 2012\%202da\%20edicion.pdf

Convención Americana sobre Derechos Humanos (1969). Pacto de San José de Costa Rica [en línea], https://www.scjn.gob.mx/ libro/InstrumentosConvencion/PAG0259.pdf

Creative Commons (Sitio web oficial) (2017). Licencias [en línea], http://creativecommons.org/licenses/.

Creative Commons (México) (Sitio web oficial) (2017) [en línea], http://www.creativecommons.mx/

Crews, Kenneth (2008). Estudio sobre las limitaciones y excepciones al derecho de autor en beneficio de bibliotecas y archivos. Ginebra: Organización Mundial de la Propiedad Intelectual. 
En busca del equilibrio entre propiedad intelectual...

Cruz Revueltas, Juan Cristóbal (2009). Moral y transparencia. México: Instituto de Acceso a la Información Pública [en línea], http://inicio.ifai.org.mx/Publicaciones/cuadernillo15.pdf

Declaración de Berlín sobre Acceso Abierto al Conocimiento en las Ciencias y las Humanidades (2003) [en línea], http://oa.mpg. de/files/2010/04/Berlin-I-2.pdf

Declaración de Bethesda sobre Publicación de Acceso Abierto (2003) [en línea], http://ictlogy.net/articles/bethesda_es.html

Declaracion Universal de los Derechos Humanos (1948) [en línea], http://www.ohchr.org/EN/UDHR/Documents/UDHR_Translations/spn.pdf

España (2007). Ley 37/2007, de 16 de noviembre, sobre reutilización de la información del sector público [en línea], http://boe. es/buscar/pdf/2007/BOE-A-2007-19814-consolidado.pdf

España (2011). Ley 14/2011, de junio, de la ciencia, la tecnología y la innovación. Boletín Oficial del Estado, (131), jueves 2 de junio de 2011, pp. 54387-54455.

Estados Unidos (2006). Federal research public access act [en línea], http://cornyn.senate.gov/doc_archive/05-02-2006_COE06461_ xml.pdf

Floridi, Luciano (2013). The ethics of information. Oxford: Oxford University Press.

IFLA (2012). Propuesta de tratado sobre limitaciones y excepciones a los derechos de autor para las bibliotecas y los archivos [en línea], http://www.ifla.org/files/assets/hq/topics/exceptionslimitations/documents/traduccion_espanol_texto_propuesta_ tratado_iflajuno2012.pdf

Iniciativa de Budapest para el Acceso Abierto (2002) [en línea], http://www.opensocietyfoundations.org/openaccess/translations/spanish-translation 
La Infodiversidad y el uso ético del conocimiento...

Kapczynski, Amy (2010). Access to knowledge: a conceptual genealogy. En Gaëlle Krikorian y Amy Kapczynski (Editors). Access to knowledge in the age of intellectual property (pp. 17-56). New York: Zone Books (Distribuited by The MIT Press).

Krikorian, Gaëlle (2010). Access to knowledge as a field of activism. En Gaëlle Krikorian y Amy Kapczynski (Editors). Access to knowledge in the age of intellectual property (pp. 57-95). New York: Zone Books (Distribuited by The MIT Press).

Lessig, Lawrence (2005). Por una cultura libre: cómo los grandes grupos de comunicación utilizan la tecnología y la ley para clausurar la cultura y controlar la creatividad. Madrid: Traficantes de Sueños [en línea], http://www.traficantes.net/sites/ default/files/pdfs/Por\%20una\%20cultura\%20libre-TdS.pdf

México (1996). Ley federal del derecho de autor [en línea], http:// www.diputados.gob.mx/LeyesBiblio/pdf/122_140714.pdf

México (2016). Ley federal de transparencia y acceso a la información pública. Diario Oficial de la Federación, 9 de mayo de 2016 [en línea], http://www.diputados.gob.mx/LeyesBiblio/ pdf/LFTAIP.pdf

México. Secretaría de Educación Pública (2014). Decreto por el que se reforman y adicionan diversas disposiciones de la Ley de ciencia y tecnología, de la Ley general de educación y de la Ley orgánica del Consejo Nacional de Ciencia y Tecnología. Diario Oficial de la Federación, 728 (15), martes 20 de mayo de 2014, edición vespertina, 2-6 [en línea], http://www.dof. gob.mx/index.php?year $=2014 \&$ month $=05 \&$ day $=20$

Moore, Adam D. (2005). Information ethics: privacy, property, and power. Seattle: University of Washington Press. 
Morales Campos, Estela (2011). La disponibilidad social del conocimiento: una responsabilidad del bibliotecario. En Filiberto Felipe Martínez Arellano (Coordinador), Coloquio Acceso abierto a la información en las bibliotecas académicas de América Latina y el Caribe (pp. 3-12). México: UNAM / Centro Universitario de Investigaciones Bibliotecológicas.

Morales Campos, Estela (2011a). La universidad pública y su compromiso social en la producción del conocimiento. En Estela Morales Campos (Coordinadora). Derecho a la información, bien público y bien privado: acceso comunitario y acceso individual (pp. 163-174). México: UNAM / Centro Universitario de Investigaciones Bibliotecológicas.

Oliver, Richard W. (2004). What is transparency? New York: McGraw-Hill.

Organización Mundial de la Propiedad Intelectual. Comité Permanente de Derecho de Autor y Derechos Conexos. Grupo Africano (2011). Proyecto de tratado de la OMPI sobre excepciones y limitaciones para las personas con discapacidad, las instituciones docentes y de investigación, las bibliotecas y los archivos: propuesta del Grupo Africano. Ginebra, Suiza: OMPI.

Pacto Internacional de Derechos Civiles y Políticos (1966) [en línea], http://www.ordenjuridico.gob.mx/TratInt/Derechos\%20 Humanos/D47.pdf

Perú (2013). Ley que regula el repositorio nacional digital de ciencia, tecnología e innovación de acceso abierto [en línea], http://www2.congreso.gob.pe/sicr/comisiones/2012/com2012ciencia.nsf/0/cb7c863ded37261e05257b3b007c029c/\$FI LE/1188_Sustitutoria_27MAR2013.pdf 
La Infodiversidad y el uso ético del conocimiento...

Ríos Ortega, Jaime (2011). La información como bien público: la responsabilidad social del bibliotecólogo. En Estela Morales Campos (Coordinadora). Derecho a la información, bien público y bien privado: acceso comunitario y acceso individual (pp. 175-186). México: UNAM / Centro Universitario de Investigaciones Bibliotecológicas.

Samek, Toni, (2007). Librarianship and human rights: a twentyfirst century guide. Oxford, England: Chandos.

Schedler, Andreas (2008). ¿Qué es la rendición de cuentas? México: Instituto de Acceso a la Información Pública [en línea], http:// inicio.ifai.org.mx/Publicaciones/cuadernillo3.pdf

Schultz, Robert A., (2006). Contemporary issues in ethics and information technology. Hershey, PA: IRM Press.

Severson, Richard James (1997). The principles of information ethics. Armonk, New York: M.E. Sharpe.

Suber, Peter (2012). Open access. Cambridge, Massachusetts: The MIT Press.

Tapscott, Don (2013). Radical openness and the smart world. Toronto, Ontario: Tapscott Group.

The Transparency and Accountability Initiative (2013). Open government guide: right to information [en línea], http://www. law-democracy.org/live/wp-content/uploads/2013/12/Opengovguide-Right-to-Information-061213.pdf

Unesco (2005). Convención sobre la protección y promoción de la diversidad de las expresiones culturales. París: Unesco.

Unión Europea (2013). Directiva 2013/37/UE del Parlamento Europeo y del Consejo de 26 de junio de 2013 por la que se modifica la Directiva 2003/98/CE relativa a la reutilización de la información del sector público. Diario Oficial de la Unión Europea, 27 de junio de 2013, 1-8 [en línea], http://eur-lex. europa.eu/LexUriServ/LexUriServ.do?uri=OJ:L:2013:175:0001: 0008:ES:PDF 
Viñas, Mariela (2010). Las fronteras del acceso abierto en las bibliotecas. Primera Jornada de Intercambio y Reflexión acerca de la Investigación en Bibliotecología, 6 y 7 de diciembre de 2010, La Plata, Argentina [en línea], http://www.memoria.fahce.unlp. edu.ar/trab_eventos/ev.773/ev.773.pdf

Zapata Rendón, Martha Cecilia (2009). Derechos de autor y licencia creative commons [en línea], http://aprendeenlinea.udea.edu. $\mathrm{co} / \mathrm{lms} / \mathrm{men} /$ docsoac1/0104_licenciamiento.pdf 


\title{
Los derechos de autor de los archivos sonoros en la era de la información digital
}

Perla Olivia Rodríguez Reséndiz

Universidad Nacional Autónoma de México

LA ESCUCHA EN LA ERA DE LA INFORMACIÓN DIGITAL

\begin{abstract}
C ada día son escuchados, a través de Internet, millones de contenidos sonoros. Desde hace algunos años, la escucha de discos compactos fue sustituida por las descargas de contenidos en formato MP3 y por los servicios de streaming a través de Internet. Derivado de estas formas de consumo sonoro, el uso del disco compacto como soporte sonoro ha sido progresivamente desplazado por computadoras y dispositivos móviles.

En 2015 , el $71 \%$ de los usuarios de Internet escuchaba música a través de servicios de streaming (Shi, 2016). Este servicio es una tendencia a la alza, sobre todo entre los jóvenes de 16 a 24 años, que prefieren escuchar más música en smartphone que en computadoras (IFPI, 2016). De acuerdo con estudios recientes (Shi, 2016; IFPI, 2016) se proyecta que en los próximos años las descargas sean sustituidas por el uso de streaming como forma de escucha y consumo sonoro.
\end{abstract}


La Infodiversidad y el uso ético del conocimiento...

Se estima que en el año 2022, el $95 \%$ de la música que se escuche será a través de streaming y por medio de los smartphones o teléfonos inteligentes. Lo que significa que las descargas y los soportes físicos serán relegados a un 5\% (Shi, 2016). Probablemente por ello, es cada vez más evidente que las computadoras y los autos nuevos ya no están equipados con estos dispositivos. El disco compacto es ya un soporte obsoleto.

Conviene añadir que también la radio, el medio sonoro por excelencia, ha perdido presencia en los hábitos de escucha frente a la aparición de nuevos medios digitales, como la ciberradio o radio por Internet. La expansión de la radio a través de Internet ha sido contundente. Este nuevo medio digital se ha desarrollado de una forma constante desde hace más de dos décadas.

En tanto, la radio digital, considerada como un nuevo medio que sustituiría a la radio analógica de AM y FM, no ha tenido el desarrollo esperado. En algunos países, la radio digital nació con fecha de caducidad. En España y México, entre otros países, la radio digital captó la atención y creó muchas expectativas y no logró desarrollarse y tener la presencia que sí está teniendo la televisión digital. Afectaron el desarrollo de la radio digital entre otros factores "[...] el alto precio de los receptores digitales (más de 100 euros), la ausencia de publicidad institucional y el poco interés de las grandes cadenas por pasarse a este sistema ha motivado el fracaso" (El País, 2016: s/p). Sólo en algunos países ha tenido un éxito rotundo, como por ejemplo en Noruega. Se ha dado a conocer que en Noruega las frecuencias de FM se apagarán en 2017 (BBC, 2016) y la radio sólo será digital.

Frente al crecimiento y desarrollo de la radio por Internet, la radio digital pierde relevancia. La ciberradio se escucha a través de dispositivos móviles, ha incorporado 
innovadoras formas de comunicación e interacción en tiempo real. Además, ha aportado la generación de nuevos productos y servicios de información sonora, como el podcast y los audioblogs (Cebrián, 2009). Su cobertura es mundial y la calidad de escucha digital, en la mayoría de los casos, es mejor que la ofrecida por la AM y FM.

Las plataformas de contenidos digitales sonoros y la ciberradio son dos múltiples medios a partir de los cuales se aprecia una nueva forma de escucha en la era de la información digital. Esta nueva forma de escucha es: inmaterial, móvil y personal. La escucha es inmaterial, porque ya no se necesita un soporte sonoro para reproducir los contenidos. Las descargas almacenadas en la nube y los servicios de streaming ocupan el lugar de las colecciones individuales de discos, casetes, discos compactos, entre otros soportes, que se almacenaban como parte del patrimonio personal. La escucha es móvil, porque se puede escuchar en prácticamente cualquier lugar y como acompañamiento al desarrollo de diversas actividades. Cada quien elige los lugares y momentos en qué desea escuchar. La escucha es personal porque la actividad de oír es individual. La escucha colectiva ha perdido terreno frente a la escucha personal como un acto privado.

El consumo de contenidos sonoros es una tendencia al alza, sólo superada por el interés de ver contenidos audiovisuales, como series o películas, a través de streaming en Internet. Napster inició los servicios de descarga sonora en 1999, a través del uso de la tecnología P2P (peer to peer), considerada como una red que permitía descargar música gratuita entre internautas (Aparicio, 2015). Desde entonces, los servicios de streaming y descarga de contenidos sonoros se incrementan día a día. 
La Infodiversidad y el uso ético del conocimiento...

En la actualidad se ofrecen servicios comerciales en Internet como: Spotify, Deezer, Apple Music, Google Play, Rhapsody, Xbox Music, Tidal, 7digital, rara.com y iTunes, Rdio, entre otros. En estas plataformas se puede tener acceso a $280 \mathrm{mi}$ llones de canciones, podcasts de programas de radio y audio libros, entre otros productos sonoros (Portaltic, 2016; Aparicio, 2015; Summers, 2013). Asimismo, los usuarios pueden diseñar y programar radios on line gracias a los contenidos sonoros que tienen a su disposición. El acceso a estas plataformas fue en un principio gratuito; después, se estableció una cuota mensual de aproximadamente 10 euros.

En la búsqueda por incrementar el número de usuarios y posicionarse en el mercado de los contenidos digitales sonoros, las plataformas han emprendido alianzas estratégicas con los proveedores de contenidos. Es sabido que Deezer firmó un acuerdo con Disney para poner a disposición de sus usuarios contenidos musicales de películas, bandas sonoras, series y animaciones (Deezer, 2015). Por otra parte, se ha documentado que Spotify ha publicado los catálogos de empresas discográficas como Universal Music, Sony BMG, EMI Music y Warner Music, entre otros (Aparicio, 2015) (Cuadro 1).

Cuadro 1.

Plataformas de distribución de contenidos sonoros

\begin{tabular}{|c|c|}
\hline Plataforma & Cantidad de canciones a disposición \\
\hline Spotify & 30 millones \\
\hline Deezer & 40 millones \\
\hline Apple Music & 30 millones \\
\hline Google Play & 30 millones \\
\hline Rhapsody & 32 millones \\
\hline Xbox Music & 38 millones \\
\hline Tidal & 25 millones \\
\hline Rdio & 32 millones \\
\hline 7 digital & 23 millones \\
\hline
\end{tabular}

Fuente: Elaboración propia con información de Portaltic, 2016; Aparicio 2015; Summers, 2013. 
PROPIEDAD INTELECTUAL VERSUS DOMINIO PÚBLICO

Tenemos a nuestra disposición una colosal cantidad de contenidos sonoros. La cantidad de grabaciones sonoras a nuestro alcance es tal que, probablemente, en toda una vida no logremos escuchar los materiales que se distribuyen en diversas plataformas a través de Internet.

Esta situación es paradójica. Se ofrecen millones de contenidos digitales, por medio de servicios de pago, en formatos de compresión como el MP3 y, en contraste, una gran cantidad de materiales sonoros que se resguardan en archivos y bibliotecas tienen un acceso limitado debido a las restricciones que establecen los derechos de autor. Más aún, los documentos sonoros a disposición de los usuarios, mediante un servicio de pago, superan el número de grabaciones que resguardan la mayoría de los archivos de radio, de investigación, las bibliotecas, e incluso en muchos casos los archivos nacionales.

Frente a este escenario, la propiedad intelectual y el dominio público son términos en torno a los cuales los archivistas sonoros reflexionan de forma constante. La propiedad intelectual es el derecho de explotación exclusiva que la ley reconoce, durante un determinado tiempo, sobre obras literarias y artísticas (DRAE, 2017). En tanto, el dominio público es la cualidad que tienen las obras de ser reproducidas, presentadas y editadas toda vez que ha vencido el plazo del derecho a su explotación exclusiva por parte del autor (DRAE, 2017). El vínculo entre la propiedad intelectual y el dominio público es importante para la cultura, la ciencia y la tecnología (Boyle, 2008) y también lo es para los archivos y las bibliotecas, sobre todo en el dominio digital. Entre la propiedad intelectual y el dominio público se origina una tensión intelectual en torno a las tareas de preservación debido 
La Infodiversidad y el uso ético del conocimiento...

a las restricciones que imponen los derechos de autor y la misión de dar acceso a una mayor cantidad de documentos.

La conservación y el acceso son procesos clave de la preservación. Sin acceso, carece de sentido la conservación de colecciones sonoras, aun cuando se encuentren en las mejores condiciones de almacenamiento. Y sin conservación, es imposible dar acceso a las grabaciones sonoras.

Estas premisas, ampliamente debatidas en foros internacionales, son principios que la Unesco ha establecido en diversos instrumentos publicados en torno a la preservación del patrimonio sonoro y audiovisual de la humanidad. Entre otros se pueden señalar las Recomendaciones sobre la Salvaguardia y Conservación de las Imágenes en Movimiento, considerado el primer documento que puso en valor las grabaciones sonoras y audiovisuales, y en el que se estableció que se "[...] debería facilitar el más amplio acceso posible a las obras y fuentes de información que representan las imágenes en movimiento adquiridas, salvaguardadas y conservadas públicas o privadas de carácter no lucrativo" (Unesco 1980 : s/p). En tanto que en las Directrices para la Preservación del Patrimonio Digital se publicó que "[...] el objetivo de la conservación del patrimonio digital es que éste sea accesible para el público de modo permanente" (Unesco, 2003: s/p).

Conservar y dar acceso son metas a alcanzar por parte de los archivos sonoros. Y son los procesos documentales fundamentales en la preservación. En el entorno analógico, el acceso estaba restringido. Por ello, se emprendió la carrera contra el tiempo, para digitalizar en el menor tiempo posible la mayor cantidad de documentos sonoros.

Digitalizar para dar acceso fue el objetivo de los primeros archivos que emprendieron esta tarea. Una vez que se contó con un volumen de materiales digitalizados, los archivos se 
vieron ante la necesidad de comprender que no se podía dar acceso libre a las colecciones. Debieron afrontar las restricciones establecidas por los derechos de autor. Porque, más allá de la buena voluntad de poner a disposición de los usuarios los contenidos digitalizados, se necesita contar con la autorización de los creadores de los materiales, en los diversos roles que intervienen en la producción sonora, para poder poner en acceso público los materiales.

En el ámbito de los archivos sonoros, los derechos de autor son un ámbito poco conocido. Esta situación ha inhibido durante muchos años la potencialidad de los documentos que se resguardan en un archivo sonoro, porque como ha señalado Kofler (1990) la mayoría de los países "[...] carecen de una legislación o cuando existe está incompleta”.

Los convenios internacionales que regulan los derechos de autor son la Convención Universal sobre Derechos de Autor, el Convenio de Berna; la Convención de Roma, el Acuerdo TRIP (Trade Related Intellectual Property Rigths) y el Convenio para la protección de los productores de fonogramas contra la reproducción no autorizada de sus fonogramas. Es importante subrayar que:

[...] los convenios, acuerdos y recomendaciones internacionales relacionados con los derechos de autor y derechos conexos, que se han creado a lo largo de la historia, hacen alusión a las grabaciones audiovisuales en general, pero no recuperan las necesidades que en esta materia tienen los archivos sonoros. (Rodríguez, 2012: 67)

En el caso de México, las grabaciones sonoras están protegidas por la Ley Federal de Derechos de Autor, que reconoce dos tipos de derechos: morales y patrimoniales. El primero "[...] está unido al autor y es inalienable, imprescriptible, irrenunciable e inembargable" (LFDA, 2016: 5); es el derecho que tiene al autor de que se le reconozca como 
La Infodiversidad y el uso ético del conocimiento...

creador de la obra. Por su parte, el derecho patrimonial "[...] corresponde al autor el derecho de explotar de manera exclusiva sus obras, o de autorizar a otros su explotación, en cualquier forma, dentro de los límites que establece la presente Ley y sin menoscabo de la titularidad de los derechos morales" (LFDA, 2016: 6). Gracias a los derechos patrimoniales, una obra puede retransmitirse y el autor puede recibir regalías. En esta tarea participan, en favor de los autores, las Sociedades de Autores y Compositores de Música de cada país.

La Ley establece que los derechos "[...] patrimoniales estarán vigentes durante: I. La vida del autor y, a partir de su muerte, cien años más. Cuando la obra le pertenezca a varios coautores los cien años se contarán a partir de la muerte del último." (LFDA, 2016: 7) En comparación con otras legislaciones, la mexicana es más extensa. Por ejemplo, los países de la Comunidad Económica Europea protegen los derechos de autor por un periodo de 75 años. Después de ese tiempo, las obras son de dominio público.

La Ley establece que se puede hacer una copia del documento sonoro que se resguarde en un archivo o biblioteca "por razones de seguridad y preservación" y cuando la obra "se encuentre agotada, descatalogada y en peligro de desaparecer" (LFDA, 2016: 23). Por lo tanto, la tarea de los archivos y bibliotecas se circunscribe a la creación de una copia para preservación, o bien, cuando las obras estén en riesgo de desaparecer.

Los derechos de autor son el punto de intersección entre la propiedad intelectual y el dominio público. Muchos archivos han digitalizado o bien desean iniciar sendos proyectos de digitalización, no sólo para conservar sino también para poner en valor sus colecciones a través del acceso. Pero el proceso no es sencillo. El acceso abierto, en línea a través 
de Internet, a las colecciones sonoras está condicionado por los derechos de autor. Es decir, por los alcances o limitaciones que hayan establecidos los autores de los materiales que se encuentran a resguardo en los archivos.

Esta situación paraliza a muchas instituciones por la falta de conocimiento y claridad en relación con los derechos de autor. Los fondos sonoros se han creado gracias a las donaciones, entrega en comodato, adquisición y compra de colecciones que provienen de diversas personas e instituciones. Entre otros, conviene señalar que instituciones que producen documentos sonoros, como las radiodifusoras o instituciones productoras de materiales sonoros, donan sus colecciones para que estén en mejores condiciones de resguardo. Por otra parte, hay coleccionistas que han dedicado gran parte de su vida a almacenar grabaciones sonoras, sobre todo de discos editados en diversos formatos. En algunos casos, los familiares de investigadores y productores sonoros también acumulan grabaciones que entregan para su conservación a los archivos sonoros. En la mayoría de los casos la buena voluntad y el deseo de que los materiales sean conservados en condiciones adecuadas de almacenamiento motiva a los donadores a entregar sus colecciones al archivo sonoro. No obstante, en muchas ocasiones las personas o instituciones que donan o entregan en comodato las colecciones, ni siquiera son los dueños de los derechos de autor. Ante cualquier circunstancia los archivos sonoros deben tomar en consideración que los derechos de autor constituyen la variable a considerar para la preservación a largo plazo.

Durante el proceso de acopio, los derechos de autor deben quedar claramente establecidos. Se deben firmar los instrumentos legales con los poseedores de los derechos de los documentos sonoros que se acopian. Y desde el mo- 
mento en que un documento se incorpora al archivo deben ser registrados, como parte de los metadatos de ingreso, el estatus de los derechos de autor. Se debe conocer si la obra puede ser consultada in situ, en la audioteca, y a través de Internet en la página de la fonoteca; además, si puede tener un futuro reúso educativo o cultural. La falta de precisión en este proceso, en apariencia sencillo, es el motivo por el cual muchas colecciones que han sido digitalizadas no pueden ser consultadas de forma remota.

Los documentos sonoros que se resguardan en un archivo sonoro pueden estar en cualquiera de las condiciones que a continuación se citan:

1. Documentos en dominio público que pueden ser utilizados libremente por cualquier persona, con la sola restricción de respetar los derechos morales de los respectivos autores.

2. Documentos sonoros protegidos por derechos de autor cuyos titulares permiten que, una vez digitalizados, puedan ser consultados, con limitación en su uso y reaprovechamiento educativo y cultural a futuro. Este tipo de documentos puede inhibir la potencialidad que tiene el documento como recurso de información.

3. Documentos sonoros protegidos por los derechos de autor, cuyo titular permite el ejercicio de algunos derechos de explotación conforme al esquema Creative Commons.

4. Documentos sonoros cuyos derechos de autor no están claramente identificados y establecidos. En este caso, lo recomendable es investigar la información que permita contactar al titular de los derechos. 
5. Obras huérfanas. Se desconoce quién es el autor o autores de la obra y tampoco se cuentan con datos de la institución que la creó.

Una gran cantidad de obras musicales son reexplotadas comercialmente. Obviamente los dueños de estos derechos no quieren que la obra se publique de forma abierta en Internet. Esta situación es comprensible porque un autor espera, sobre todo en circuitos comerciales, regalías de su trabajo intelectual creativo. $Y$ también hay una gran cantidad de documentos que han sido creados en la última década que no se reeditan y que nadie consulta porque tienen derechos de autor.

En muchos casos, ni siquiera se sabe quiénes poseen los derechos de autor. Muchas compañías disqueras, por ejemplo, han desaparecido. En otros casos, no se cuenta con la información de las personas que crearon la obra. Hay una gran cantidad de obras huérfanas que no se pueden digitalizar porque se desconoce a quién se debe pedir permiso para transferir los contenidos a otro soporte.

La situación se hace más compleja cuando tratamos de identificar los derechos de autor de los materiales que han sido publicados en Internet. Gran cantidad de estos materiales no cuenta con las referencias mínimas para saber a quiénes pertenecen los derechos. Muchas páginas cambian y los materiales desaparecen.

En gran medida, debido a esta circunstancia, las fonotecas, archivos sonoros y bibliotecas no publican en Internet las colecciones sonoras que han digitalizado. Sólo ofrecen la consulta in situ, en la audioteca. Porque la falta de conocimiento en torno a los derechos de autor no exime de responsabilidad a quien reutiliza un documento sonoro. 
La Infodiversidad y el uso ético del conocimiento...

Los derechos de autor protegen al creador, pero son al mismo tiempo una barrera que restringe su uso. Los derechos de autor no son la única razón que restringe el uso de la obra; también la obsolescencia limita el uso de los materiales. Los contenidos que han sido grabados en soportes analógicos deben ser digitalizados para poder ser escuchados en reproductores digitales. Y este proceso cuesta dinero. Por ello, los derechos de autor son una variable a considerar en la digitalización de colecciones sonoras. Porque no tiene sentido invertir recursos humanos y económicos para digitalizar grabaciones que no pueden volver a escucharse.

La disponibilidad de contenidos digitales con fines educativos y culturales potencia su valor económico y patrimonial. Así, uno de los más relevantes propósitos de las instituciones culturales se ha orientado a la creación, difusión y preservación de objetos digitales. De hecho, las instituciones culturales del futuro sentarán sus bases en este circuito de creación, intercambio, uso, reaprovechamiento y conservación de contenidos digitales.

\section{CONSIDERACIONES FINALES}

Aun cuando la industria audiovisual y las Tecnologías de la Información y la Comunicación han abierto nuevos modos de distribución y acceso a contenidos sonoros y audiovisuales y, además, han generado nuevas oportunidades comerciales para las imágenes y sonidos, el derecho público al acceso gratuito de contenidos pierde terreno ante los imperativos jurídicos (Edmondson, 2004).

Los gobiernos reaccionan ante la presión empresarial con el endurecimiento e incremento de años que protegen los 
derechos de autor. Como se ha señalado, en México los derechos de autor se extienden hasta 100 años después de que ha muerto el autor (LFDA, 2016). En contraste, la piratería aumenta y se hace cada vez más sofisticada. La transgresión de los derechos de autor es un problema importante. La tercera parte de los usuarios de Internet acceden a contenidos de música sin licencia. Esta cifra es sobre todo relevante en países como México, Brasil y Estados Unidos (IFPI, 2016). Por ello, se establecen sistemas informáticos para detectar en Internet violaciones y usos no autorizados de obras, sobre todo musicales. Uno de estos sistemas es el DRM (digital rights management).

En divergencia con la vigilancia y control de los contenidos, gana presencia la discusión pública encaminada a buscar soluciones para contar con un mayor número de contenidos sonoros que no estén sujetos a los derechos de autor.

Autores como Boyle (2016) se han pronunciado por pensar en conceptos que se opongan a la propiedad. Porque, de acuerdo con Boyle (2016), lo opuesto a la propiedad es un término más importante cuando entramos al mundo de las ideas, la información, la expresión y la invención en la era de la información digital.

Comparte esta posición Europena, definida como una biblioteca digital europea, de la que derivó la rama Europeana sounds. La Estrategia 2015-2020 de Europeana establece como prioridad dar acceso a la mayor cantidad posible de documentos de las instituciones participantes en este proyecto. Para ello, se estableció la necesidad de priorizar la digitalización de las obras que sean de dominio público, para que estén disponibles, de forma gratuita y sin restricción alguna (Europeana, 2015). Se estableció que "[...] el dominio público es un recurso compartido que constituye las bases 
La Infodiversidad y el uso ético del conocimiento...

de la actual sociedad. La digitalización del conocimiento y de la información conlleva a menudo la utilización de contratos legales que dificultan el libre acceso al dominio público digitalizado" (Europea, 2010). Esta condición es contraria no sólo para Europeana sino para todos los archivos que han emprendido la digitalización de sus colecciones.

Sumado al dominio público se ha expresado la necesidad de que el material que no esté sujeto a derechos de autor esté disponible no sólo in situ en las audiotecas, sino también a través de servicios en línea. Una propuesta de avance, encaminada a posibilitar el acceso abierto a los contenidos de los archivos, es ofrecer los metadatos abiertos para que un mayor número de personas puedan conocer las colecciones (Europeana, 2015). Esta iniciativa se desarrolla bajo la premisa de que los metadatos derivados de la catalogación no tienen derechos de autor. Así, se ofrece a los usuarios la posibilidad de conocer qué documentos se conservan y en qué archivos se localizan estos materiales.

A este escenario se suma la adopción de la licencia Creative Commons como una tendencia sobre todo para los documentos de origen digital. Cada vez se producen más documentos y se crean repositorios digitales bajo la licencia Creative Commons. Gracias a esta licencia, los autores asumen que sus contenidos se pueden compartir en Internet de un modo sencillo para que puedan ser utilizados sin pedir autorización directa al autor y sólo citando al creador de la obra.

El surgimiento de estas iniciativas es aún incipiente, la mayor parte de la creación cultural del siglo Xx que resguardan los archivos sonoros y las bibliotecas tiene derechos de autor y, en muchos casos, no están disponibles (Boyle, 2008). Probablemente por ello, Boyle (2008) ha considerado que en la era de la información es necesario crear un 
movimiento similar al que se ha creado en torno al medio ambiente para preservar el dominio público. El desarrollo industrial provocó que volviéramos la mirada al medio ambiente. También el entorno de producción de información digital debe motivar a crear un movimiento que ensanche las posibilidades del dominio público. Los derechos de propiedad intelectual tienen un papel importante después de la innovación, facilitan la explotación eficiente y permiten a los creadores presentar sus invenciones a los circuitos comerciales y obtener ganancias por ello. Pero también la creación de la humanidad merece ser conocida, escuchada y disfrutada por la sociedad. Más aún, los archivos sonoros merecen ser preservados y escuchados por las generaciones del futuro.

\section{BIBLIOGRAFÍA}

Aparicio, D. (2015). El negocio de la música en 'streaming' sigue en auge : Apple Music se suma a Spotify , Deezer ... 20 minutos [en línea], http://www.20minutos.es/noticia/2498542/0/applemusic/spotify/musica-en-streaming/.

BBC (2017). "El fin de una era: Noruega, primer país del mundo en apagar su señal de FM", BBC Mundo [en línea], http://www. bbc.com/mundo/noticias/2015/04/150421_tecnologia_noruega_radio_fm_cambio_digital_ig?ocid=socialflow_twitter

Boyle, J. (2008). The Public Domain: Enclosing the Commons of the Mind. London.

Convención Universal sobre Derecho de Autor (1971). Revisada en París el 24 de julio de 1971 [en línea], http://www.cerlalc.org/ documentos/cupara.pdf (9 de abril de 2010). 
La Infodiversidad y el uso ético del conocimiento...

Deezer (2015). "La magia de Disney llega a Deezer", en Deezer [en línea], http://www.deezer-blog.com/press/la-magia-dedisney-llega-a-deezer/

Edmondson, R. (2004). Filosofía y principios de los archivos audiovisuales. Unesco.

El País (2016). La radio digital terrestre se apaga anates de nacer. El País [en línea], http://economia.elpais.com/economia/2015/08/22/actualidad/1440272026_485720.html

Europeana (2010). Carta del dominio publico de Europeana, p. 4 [en línea], http://pro.europeana.eu/documents/10602/556a29c26408-404e-bcce-4bde413e9706

Europeana (2015). "We transform the world with culture" [en línea], http://pro.europeana.eu/files/Europeana_Professional/Publications/Europeana\%20Presidencies\%20White\%20Paper.pdf

IFPI (2016). Music Consumer Insight Report 2016. IFPI.

LFDA (2016). Ley Federal del Derecho de Autor.

Kofler, B. (1990). Legal issues facing audiovisual archives. PGI-91/ WS/5. Unesco, Paris.

Portaltic (2016). "Deezer ya es el servicio con más canciones, por delante de Spotify o Apple Music”, Portaltic [en línea], http://www. europapress.es/portaltic/sector/noticia-deezer-ya-serviciomas-canciones-delante-spotify-apple-music-20160120181919. html?fuente $=$ www 20 minutoses

Rodríguez, P. (2011). Modelo de desarrollo de la Fonoteca Nacional de México. Madrid: Universidad Complutense de Madrid.

Shi, W. (2016). Global Mobile Music Forecast 2010-2022. Ed. Strategy Analitics.

Summers, N. (2013). Open music platform firm 7digital to power the Music Hub app on Samsung's Galaxy S4 Have a cookie Download Free Trial Now. 
Los derechos de autor de los archivos sonoros en la era...

Unesco (1980). Recomendación sobre la Salvaguardia y la Conservación de las Imágenes en Movimiento: Unesco [en línea], http:// portal.unesco.org/es/ev.php-URL_ID=13139\&URL_DO=DO_ TOPIC\&URL_SECTION=201.html.

Unesco (2003). Directrices para la preservación del Patrimonio Digital [en línea], en: http://unesdoc.unesco.org/ images/0013/001300/130071s.pdf. 
La academia y el uso de la información 


\title{
El plagio, un acto de deshonestidad intelectual y una falta de respeto al trabajo del otro
}

\author{
Beatriz Casa Tirao \\ Universidad Nacional Autónoma de México
}

\section{INTRODUCCIÓN}

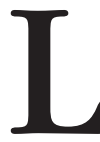

os seres humanos regimos nuestra conducta a través de una serie de normas o pautas que son las que orientan nuestras acciones en uno u otro sentido: es en estas circunstancias cuando entra en juego la ética. Hay que recordar que ella es la parte de la filosofía que examina los distintos hechos y valores que afectan la vida de los individuos y determinan si son convenientes para el logro de aquellos fines individuales y sociales que suelen formar parte de los objetivos de búsqueda del sujeto.

Para hacer posible este análisis, la ética trata fundamentalmente acerca de la moral, revisa las pautas de diversos grupos sociales y estudia aquello que es específico en cuanto a comportamiento humano; asimismo norma principios que determinan toda la conducta de los hombres y las mujeres. Es la disciplina que formula marcos reguladores integrados por normas y códigos que definen las características 
La Infodiversidad y el uso ético del conocimiento...

de un buen comportamiento y marcan el camino para su desarrollo de los seres y los países.

La ética es un fenómeno que nos acompaña siempre y que determina la calidad de nuestros actos. Así, podemos apreciar que ella se extiende por encima de nuestras actitudes y está presente en cada acto y en cada manifestación de nuestra vida, en nuestro ámbito y en nuestra profesión.

Sobre la base de lo expresado es posible dirigir nuestra reflexión hacia temas que tienen relación con estos planteamientos. Probablemente el primer paso será examinar algunas cuestiones en relación con nuestro quehacer en los asuntos de nuestro interés.

En nuestra actividad docente debemos evaluar hasta qué punto hemos transmitido a los estudiantes el concepto de honestidad intelectual, fundamental en el tema que planteamos. Esta honestidad intelectual debe formar parte tanto de nuestro bagaje profesional como del personal, y debe ser parte importante de nuestro quehacer diario. Sobre esa base se presentan las reflexiones que consideraremos a continuación.

CONCEPTO Y BREVE HISTORIA DEL PLAGIO

La palabra plagio se aplica a la acción que tiene como fin copiar algo y luego presentarlo como creación personal. Son muchas las cosas que es posible copiar y el avance de la tecnología ha multiplicado esas posibilidades. Con este proceder la labor intelectual, científica o artística, y de igual modo el quehacer humanístico, se ven burlados. Pero, ¿qué es en definitiva un plagio? La respuesta es sencilla: un plagio es un robo, y como todo robo constituye un delito, y como tal debe aplicarse, en casos como éste, el castigo 
adecuado. El trabajo intelectual, artístico o del pensamiento que elabora un individuo es probablemente el bien más preciado ya que por su origen es algo más propio que cualquier otra posesión, ya que es fruto de su trabajo y de su propia creación.

El plagio en sí es un fraude que ha pasado a formar parte de una gama poco honesta de procedimientos relacionados generalmente con el trabajo intelectual. En esto se apoya, por ejemplo, la publicación de datos supuestamente científicos que sólo provienen de la mente de los "investigadores" y no de una investigación seria tal como lo demanda la ciencia. $^{1}$

Las formas del plagio son diversas y dependen de la "creatividad", por así llamarla, de cada individuo la manera como lo aborda. Empieza quizá en la escuela primaria, donde se desarrolla la capacidad del niño para copiar el trabajo que está llevando a cabo su compañero de banca y sigue con el tiempo por caminos más tortuosos y difíciles. Esto es así porque, analizado desde nuestro punto de vista, el plagio perjudica a quien es víctima del mismo y también a quien lo comete pues ésa no es una acción intelectual honesta sino que, por el contrario, evidencia una actitud ajena a la que debe regir todo trabajo que se lleve a cabo.

Esta práctica del plagio debe ser puesta en evidencia y recibir el castigo previsto en la ley.

Plagio EN LA COMUNidAd ACADÉMICA E INTELECTUAL

El plagio es un hecho al cual es posible referirse en diversos periodos de la historia, ya que prácticamente existe desde

1 Wiliam Board y Nicholas Wade, Betrayers of the truth; fraud and deceit in the halls of science, p. 7. 
La Infodiversidad y el uso ético del conocimiento...

que el ser humano aprendió a comunicarse. De igual manera, a través del tiempo se pueden recoger diversos testimonios referentes al plagio que configuran una verdadera antología. Independientemente de ello, podemos afirmar que existe la posibilidad de estudiar el hecho desde diferentes puntos de vista atendiendo a sus propias características. Vale la pena agregar que otra denominación común que recibe el plagio es la de piratería, en alusión a lo deshonesto del procedimiento para apropiarse de un producto cuya creación no pertenece al plagiario. Este abuso de confianza generalmente se realiza entre científicos y especialmente, si es para el autor del plagio un hecho repetido, y se le facilita su realización.

El robo de datos o materiales no publicados es más fácil que el de material publicado ya que aquél aún no tiene autor conocido, aunque en cualquiera de los casos son conductas reprochables.

Aproximadamente un $25 \%$ de científicos se quejan de haber sufrido el robo de sus trabajos o, al menos, de sus ideas. La oportunidad de cometer plagio puede ser propiciada por las propias instituciones evaluadoras cuando los trabajos son sometidos a arbitraje. ${ }^{2}$ En los centros respectivos se reciben para su evaluación y crítica los trabajos de los científicos para ser revisados por sus pares. Si éstos no han sido seleccionados cuidadosamente, el riesgo que se corre es que utilicen la información que se pone a su consideración. De ahí la importancia de la privacidad que se debe guardar en un trabajo de este tipo, ya que los evaluadores son científicos del mismo campo que el evaluado. Es conveniente entonces no enviar los trabajos a posibles competidores de los autores y, en general, hacer una selección de evaluadores de probada conducta.

2 Alexander Kohn, False prophets. Fraud and error in science and medicine. 
Otra forma de plagio es el autoplagio. Esto suele suceder cuando un autor presenta un trabajo para ser evaluado en dos organismos evaluadores diferentes y no retira a tiempo uno de los ejemplares y el resultado es que ambos trabajos son publicados.

Existen algunos otros tipos de plagio, como el del sujeto que cita o presenta un trabajo no existente con la supuesta autoría de una persona o escritor famoso. En el curso de nuestras actividades es posible que en ocasiones tropecemos con el plagio y no lo reconozcamos. Afortunadamente existen hoy recursos para poder identificarlo en casi todos los casos, sin embargo, el problema del plagio subsiste hasta la fecha. Al hablar del mismo generalmente solemos referirnos al campo científico; no obstante, en el ámbito literario se observa una tendencia bastante acentuada a la repetición de este hecho. Esto permite pensar que el fenómeno del plagio es posible encontrarlo en cualquier material y tema del que se trate, de ahí la universalidad del mismo.

En el ámbito académico, el plagio suele ser un procedimiento bastante común que ha provocado no pocos conflictos. De hecho, la existencia de plagio en documentos escolares o universitarios simboliza lo que es un fraude académico.

Dentro del quehacer académico hay dos actores principales: profesores y estudiantes. Miembros de ambos grupos son susceptibles de ser seducidos por el plagio. Desde el niño que en la escuela primaria copia un ejercicio de algún compañero, hasta el profesional que para confeccionar un artículo supuestamente de su autoría, se beneficia de todo o parte de un trabajo, publicado o no, de un colega con igual especialidad que la propia. También puede ocurrir que acuda a una fuente de un autor no conocido y efectúe el plagio, pero siempre se valdrá del prestigio de sus pares. 
La Infodiversidad y el uso ético del conocimiento...

Este hecho que, como dijimos antes, constituye en sí un delito, perjudica en primer término a quien lo comete y después al autor o autores a quienes defraudó. Quienes se acercan a un autor de esta manera ponen en evidencia la pobreza de su mundo intelectual, así como la incapacidad para producir un trabajo legítimo.

Por su parte, el afectado, si aún está vivo, se ve envuelto en un asunto tan desagradable como éste a pesar del respeto que seguramente goza en su vida académica.

El avance de la tecnología, paradójicamente, ha facilitado el plagio a través de Internet y otras aplicaciones. El antiguo "cortar y pegar" se ha transformado actualmente en una herramienta de trabajo de suma utilidad para el estudiante pero que, a la vez, lo aleja de la investigación y de la búsqueda del conocimiento.

La historia del plagio no es reciente. Desde la época clásica, por ejemplo, se conocen reclamos de diversos poetas de entonces que se quejaban con frecuencia acerca de los plagios que solían sufrir sus obras. De igual manera, los filósofos cuyas ideas eran plagiadas aún a través del conocimiento que de ellas se tenía por la comunicación verbal de su verdadero autor. Con el desarrollo de la humanidad numerosos casos de plagio han ido saliendo a la luz.

El plagio llega realizarse sobre diversos temas, pero también a partir a de diferentes materiales de origen. De esta manera se han plagiado obras de arte, canciones, películas, diseños, etcétera, además del clásico plagio de los trabajos científicos y literarios. De esta manera muchos nombres, inclusive famosos algunos de ellos, han pasado a formar parte de la historia del plagio.

El estudio del plagio y, por lo tanto, el del fraude que él representa, mostró que los resultados ofrecidos por la ciencia no siempre responden a la realidad sino que mu- 
chos científicos publican resultados ficticios. ${ }^{3}$ Es necesario agregar que en ocasiones puede ocurrir que esos resultados pertenezcan a otras personas.

Ante la pregunta acerca de la importancia de evitar el plagio, McMillan y Veyers responden que hay motivos interconexos que obligan a ello y que son:

1. La necesidad de mantener la integridad académica, es decir la honestidad profesional, al mencionar las fuentes consultadas para evitar el plagio.

2. La necesidad de mostrar las habilidades del pensamiento crítico, o sea de analizar información compleja con las herramientas obtenidas durante la vida académica. ${ }^{4}$

En cuanto a las razones que existen para realizar plagio son diversas. En general se pueden mencionar las siguientes:

- La poca familiaridad con los textos académicos, lo cual redunda en falta de conocimiento del contenido de los mismos. Esto trae como resultado el uso indiscriminado de los textos para copiarlos todos o en parte y, además, la ignorancia del acervo de aquello que puede servir como bibliografía y así permitir la hechura de un trabajo dentro de los límites de la honestidad intelectual.

- Premura por entregar un trabajo, ya sea en la línea académica o profesional.

- Miedo al fracaso. En la mayor parte de los casos está ligado a una baja autoestima que, conectada con una baja disposición para el trabajo, configura un clima propicio para el plagio.

3 Kathleen McMillan y Jonathan Veyers, Citar, referenciar y evitar plagio en la educación.

$4 \quad$ Ibíd., p. 28. 
La Infodiversidad y el uso ético del conocimiento...

- Rapidez. Actualmente resulta más fácil y rápido hacer una copia de Internet que un trabajo de propia creación sobre la base de una bibliografía adecuada.

- En el caso de los estudiantes, si provienen de un ambiente en el que "copiar del libro" o utilizar los conocimientos de los demás sin darles el correspondiente crédito es premiado o estimulado, los estudiantes muestran en su mayoría una franca tendencia al plagio. Esto no obsta para que el estudiante de nivel económico más elevado y con mayor capacidad de acceso a las tecnologías se dedique a los mismos menesteres.

- Poca habilidad o carencia de ella para la investigación. Los plagiarios reemplazan esas carencias con la inclusión de textos elaborados por otros autores ignorando sus créditos.

- Dificultad para expresar sus ideas por escrito.

- Fácil acceso frente a las posibilidades que ofrece la tecnología en cuanto a favorecer el plagio.

- Falta de facilidad para expresar por escrito sus ideas.

- Deshonestidad evidente por parte del promotor del plagio. Algunas personas creen que el plagio es una acción aceptable y no miden el grado de perjuicio que cometen contra los autores de la obra original. ${ }^{5}$

FORMAS DE DETECTAR EL PLAGIO

Hay algunos síntomas sencillos que pueden ayudar a detectar un plagio, naturalmente no muy elaborado. Algunos de ellos son los siguientes:

5 Ídem. 
- El estilo de escribir de una persona suele ser peculiar de cada uno y, por lo tanto, identificable. Si no es el mismo estilo y éste varía es probable que el trabajo no sea de su autoría.

- Igualmente sucede cuando el estilo del escrito no guarda relación con el grado de preparación del supuesto autor.

- A veces, una conclusión que no corresponde a la introducción del trabajo revela la existencia de plagio.

- Repetición de los errores que se encuentran en la obra original, lo cual, generalmente, pone en evidencia el plagio.

- Uso de varios estilos en un mismo texto.

- Texto tomado exactamente igual que el texto original.

De igual manera que lo que sucede con los materiales bibliográficos, ocurre con otro tipo de materiales, como los audiovisuales, musicales, diseños y otros.

En este punto es pertinente citar algunas recomendaciones con respecto al plagio y que son dadas por Pérez Fuentes y Cantoral Domínguez:

1. Determinar si quien invoca la protección sobre el bien intelectual es el titular del derecho reclamado.

2. Si ese bien inmaterial tiene características de originalidad para calificar como obra y gozar de la protección por el derecho de autor.

3. Si existen en identidades o semejanzas, totales o parciales, simuladas, entre dicha obra y la subsiguiente que según el reclamante es un plagio de la primera. ${ }^{6}$

6 Gisela María Fernández Fuentes y Karla Cantoral Domínguez, Formatos televisivos y derechos de autor. 
La Infodiversidad y el uso ético del conocimiento...

Estas pautas mínimas quizá puedan ser el inicio de una nueva actitud acerca del plagio que lleve a un mayor y mejor control de este fenómeno. Con la observación de estas normas será posible instrumentar procedimientos que actúen por el camino de la convicción anteponiendo la responsabilidad y la honestidad en el camino del desarrollo personal.

\section{AlgunOS PlAGIOS NOTABLES}

Uno de los plagios más misteriosos, y todavía no totalmente aclarado, es el que corresponde a las obras de William Shakespeare.

En 1955, un autor norteamericano publicó un libro biográfico acerca del escritor inglés en el cual cuenta cómo un autor llamado Christopher Marlowe evadió la justicia de la reina escapándose de su país. Su protector simuló la muerte de Marlowe, que había huido desde Inglaterra hacia el continente y le enviaba sus obras manuscritas que el protector hacía transcribir para evitar que fuera reconocida la su letra. Bajo el nombre de William Shakespeare, un oscuro actor de tercera, el protector de Marlowe dio a conocer la obra del autor inglés. ${ }^{7}$

Posteriormente, puede verse que el fenómeno se repite. En nuestra época, numerosos y connotados intelectuales han sido acusados de plagio o ellos mismos han resultado víctimas de él.

Camilo José Cela fue acusado de plagio por su obra $L a$ cruz de San Andrés. La muerte del escritor en 2002 dejó en suspenso los trámites legales que contra él se seguían.

7 Calvin Hoffman, The man who was Shakespeare. 
En su momento el mismo Carlos Fuentes fue acusado de plagio por Víctor Celorio. En este caso un juez dio por terminado el pleito y absolvió a Fuentes.

El Nobel José Saramago fue demandado por un periodista mexicano, Huerta Moreno, por haber utilizado como propio un texto que le había enviado para su consideración.

Termino esta muy breve lista de celebridades vinculadas en algún momento con el asunto del plagio y cito para ello al argentino Jorge Luis Borges cuya viuda, María Kodama, pidió al escritor Agustín Fernández Tello retirar de circulación una obra suya en la cual había insertado pasajes propiedad intelectual de Borges, quien detentaba los derechos de autor.

En esta presentación se enumeran nombres de algunas personas famosas involucradas con el plagio ya como víctimas, ya como autores del mismo. La lista es breve si se toma en cuenta que en la revisión de este tema es posible encontrar otros numerosos casos que avalan el estudio del mismo.

\section{Algunas CONSECUENCIAS DEL Plagio}

Como ya se dijo, el plagio tiene consecuencias negativas no sólo para el que lo recibe sino también para quien lo lleva a cabo. En el primer caso las razones son obvias; en el segundo, si bien es cierto que el plagio produce muchos efectos concurrentes, el más importante es el hecho que su autor se priva del derecho y la obligación de pensar. Esta carencia de ejercicio mental tiene como consecuencia el adormecimiento de las facultades por falta de aplicación de sus capacidades.

Cuando el plagio tiene lugar en el campo científico las consecuencias son de gravedad, pues implican el robo de 
La Infodiversidad y el uso ético del conocimiento...

investigaciones sobre determinados problemas y no en pocos casos también el de las soluciones y propuestas. En el terreno humanístico los daños no son menores, probablemente porque el plagio siempre representa un robo.

Según expresa Soto Rodríguez, dando el ejemplo de Costa Rica,

[...] no existe una ley que lo castigue apropiadamente en forma penal, sólo a nivel moral y civil lo cual hace que haya cierta impunidad cuando se cometen actos de plagio, esto sumado a que pareciera que existe un desinterés público en este tema lo cual hace que las personas no tomen conciencia sobre la gravedad que presenta el cometer plagio. ${ }^{8}$

Hay formas que permiten evitar el plagio y que están al alcance de la mano y no ofrecen mayores dificultades. Quizá la primera es cumplir con lo que mandata la ley de derechos de autor y evitar de esa manera que el trabajo personal quede desprotegido.

También debe ponerse en evidencia a toda persona que cometa plagio, sin temor de llevarla a los tribunales y ante los cuerpos juzgadores de los miembros de su profesión. En este punto hay que cuidarse de una falsa solidaridad que puede llevar a dar pasos en falso. Como dijimos al principio, el plagio es un delito y cómo tal hay que tratarlo.

No obstante lo anterior, es posible aplicar al plagio dos formas simultáneas de corrección. La primera, haciendo que el plagiario conozca que existe un castigo para su falta y la segunda estimulando la toma de conciencia acerca de la gravedad del caso.

8 Armando Soto Rodríguez, El plagio y su impacto a nivel académico y profesional, p. 12. 
El plagio, un acto de deshonestidad intelectual...

\section{AlgunAS REFLEXIONES ACERCA DEL PLAGIO}

Es probable que las razones que se alegan para evitar el plagio parezcan obvias. Sin embargo, reflexionar acerca de ellas no deja de ser un ejercicio necesario en cualquier tipo de trabajo que se lleve e cabo y que ponga en juego no sólo la capacidad investigativa en la búsqueda de la verdad sino también la creatividad en la etapa de aplicación de los conocimientos.

De acuerdo a lo comentado a lo largo del presente trabajo podemos afirmar que no sólo la actividad académica sino todo aquello que suponga una manifestación del individuo es, en última instancia, una acción ligada a una escala de valores a través de la ética. A partir de este pensamiento se establece una relación fundamental entre el trabajo intelectual y lo calidad moral de quien lo realiza. Indudablemente éste es el punto crucial donde aparece el plagio, entre otras cosas, como tabla de salvación frente al desafío de crear.

Es en este punto donde se crea un interrogante que cuestiona severamente la honestidad en el quehacer intelectual y los puntos oscuros del mismo, entre los cuales está el plagio.

El plagio es el resultado de una posición personal de minusvalía que genera en el individuo una carga emocional que se traduce en un bloqueo mental que impide el desarrollo de sus actividades.

Por otro lado, debe pensarse que no todas las personas tienen iguales capacidades ni la misma vocación para desempeñarse en las distintas áreas. Cuando asumen con inteligencia esa realidad el problema deja de serlo y las dificultades para realizar un trabajo de creación disminuyen en la medida en que el presunto autor acepta sus propias limitaciones en ese campo. 
La Infodiversidad y el uso ético del conocimiento...

El problema surge cuando alguien en situación similar decide echar manos a la obra ajena. Esto lo hacen con diversa suerte. Existen algunos plagiarios que realizan su obra como verdaderos artistas y logran reemplazar la mayor parte de los párrafos plagiados y lo que plagian, en realidad, son las ideas que esos párrafos contienen y no las palabras, tan grave una como otra cosa.

En el caso de los estudiantes su forma de plagiar tiene diferentes características. Generalmente reúnen partes de diferentes documentos y realizan una especie de "collage" que en ocasiones comparten con sus compañeros a través de la aportación que realizan de diversos fragmentos.

En ocasiones los alumnos, buscando cumplir con la tarea encomendada por el maestro, o más bien tratando de hacer que cumplen con ello, buscan páginas web y transcriben su contenido cuando, en realidad, lo que se les pidió es el análisis de un hecho u objeto y no la descripción del mismo.

Los castigos que reciben los plagiarios varían desde la observación hasta la suspensión por parte de los cuerpos o instituciones a las que pertenece. Los llamados "cazadores de plagios" cuentan hoy con mayores recursos, sobre todo en el campo de la informática, que facilitan el éxito de su tarea.

No obstante lo anteriormente mencionado, el plagio sigue siendo una práctica muy frecuente que aparece en todos los estratos sociales cada vez que éstos son propicios a las actividades en las cuales son susceptibles de involucrarse.

Este último párrafo nos lleva a pensar en la necesidad de la inclusión de la ética en la formación de los individuos. Las diversas actividades y profesiones exigen de cada uno de nosotros una actitud profundamente ligada a la moral. Tanto la formación que se recibe en el hogar como la de la escuela y aun de la misma universidad debe tender a formar 
hombres y mujeres no sólo libres y trabajadores, sino también fuertes de espíritu y honestos.

\section{BIBLIOGRAFÍA}

Board, Wiliam y Wade, Nicholas (1982). Betrayers of the truth; fraud and deceit in the halls of science. New york: Simon \& Schuster.

Fernández Fuentes, Gisela María y Cantoral Domínguez, Karla (2015). Formatos televisivos y derechos de autor. México [las autoras]: 2015.

Hoffman, Calvin (1955). The man who was Shakespeare. London: Max Parrish.

Kohn, Alexander (1996). False prophets. Fraud and error in science and medicine. New York, Basil: Blackwell.

McMillan, Kathleen y Veyers, Jonathan (2015). Citar, referenciar y evitar plagio en la educación. México: Trillas.

Soto Rodríguez, Armando (2009). El plagio y su impacto a nivel académico y profesional. E- ciencias de la información. Rev. electrónica semestral, 2(1), feb.-jun. 


\section{La educación bibliotecológica en México ante el plagio}

María Graciela Martha Tecuatl Quechol Escuela Nacional de Biblioteconomía y Archivonomía, México

a sociedad humana, en su evolución, ha trascendido su
pensamiento a través de símbolos, escritura, impresos
y, actualmente, por medio de la computadora. Desde las primeras culturas, surgieron también las bibliotecas, para resguardar las ideas y los escritos; aunado a ello, se conformó el trabajo bibliotecario, lo que permitió, en los primeros tiempos, la elaboración de listas de autores y de sus obras (auténticas y espurias). "Las falsificaciones eran marcadas como gnesioi (hijos ilegítimos) o nothoi (bastardos)" (Perromat Augustín, 2010: 33)

Saber escribir involucró la creación de los primeros textos firmados y la correspondencia entre el discurso y el nombre de quien lo ideó. "Se ha invocado un texto datado en el 2300 a. C. y asociado al nombre propio de una princesa sumeria (Enheduanna) como el primer testimonio de autoría reconocida" (Perromat Augustín, 2010: 18).

En el devenir histórico se ha resaltado la figura del autor y de la autoridad textual, y con el establecimiento de las universidades se estableció "[...] una nueva manera autorizada de citación; las referencias a los textos y los autores." (Perromat Augustín, 2010: 86-87). Posteriormente, con 
La Infodiversidad y el uso ético del conocimiento...

la implementación de la imprenta como medio de divulgación del conocimiento, se estableció el uso de la portada, del colofón y de la marca del impresor, lo que permitió la identidad de los impresos. La invención de la imprenta permitió separar la creación intelectual de la producción de ejemplares, la cual ejerció el gremio de los impresores; sin embargo, el ejercicio de tal oficio se limitó a través de un instrumento jurídico del privilegio (privilegio de introducción de la imprenta). Según Ong, "[...] la impresión creó un nuevo sentido de la propiedad privada de las palabras." (Ong, 1987: 129)

En 1557, se creó la Stationers Company, en Londres, para fiscalizar los derechos de los autores, impresores, editores (Ong, 1987: 130) y posteriormente se manifestaron los antecedentes del derecho de autor, con el Estatuto inglés de la reina Ana en 1710, reconocido como el primero en el mundo, aunque se centra en la copia y no en el autor.

Posteriormente se concedieron privilegios al editor y al autor en Francia (1777). En Estados Unidos se estableció la primera regulación legal de la propiedad intelectual a partir de la Ley de Derecho de autor (1790). En tal ley se protege la copia para estimular la creación intelectual y favorecer el progreso de la ciencia y del arte.

En el siglo XIX (1886) surgió el convenio de Berna para la protección de las obras literarias y artísticas, para armonizar los derechos de autor a nivel internacional. El convenio, después, tuvo diversas revisiones: París (1896); Berlín (1908); Berna (1914); Roma (1928); Bruselas (1948), Estocolmo (1967).

La creación de la Organización Mundial de la Propiedad Intelectual (OMPI), en 1967, fue el antecedente para establecer el Tratado de la OMPI sobre derecho de autor; en 1996 se aprobaron dos tratados para actualizar los Derechos de 
Autor en el Entorno Digital (entre ellos los programas de computadora, bases de datos), y en materia de los derechos de autor aborda el derecho de distribución, de alquiler y de comunicación al público.

La protección de los autores y de sus obras, por su importancia, ha sido patente a lo largo de siglos anteriores y, en la actualidad, la IFLA (2000) declaró su posición sobre tales derechos, en "Postura de la IFLA sobre los derechos de autor en un ambiente digital" (IFLA).

Desde 2014, la IFLA estableció la necesidad de normas de derecho de autor internacionales que se actualicen acordes a las necesidades digitales, y que contemplen limitaciones y excepciones que equilibren los ámbitos del derecho de autor, de los usuarios y de los autores como creadores de obras protegidas. "Las excepciones del copyright permiten a las bibliotecas preservar y hacer accesibles las obras" (IFLA, 2013), y enfatiza los ambientes de los archivos digitales y aprendizajes virtuales. Resalta las Leyes restrictivas del copyright que obstaculizan el acceso y la reproducción de materiales para fines de intercambio de conocimiento.

Al momento actual, Internet y los formatos digitales han permitido que autores que no habían publicado sus obras en los medios impresos coloquen en la actualidad sus aportaciones para que se utilicen, modifiquen y se hagan otras obras, sin necesidad de pedir permiso. Lo anterior ha modificado a la propiedad intelectual a través de licencias abiertas del tipo copyleft.

Los autores, la propiedad intelectual, la legislación que de ellas emane, las innovaciones de formatos y formas de acceso, son parte importante de la formación del bibliotecólogo, y por tanto su contacto con tal entorno es de respeto a los autores, a sus saberes, a su creatividad intelectual. Por otra parte, en la formación bibliotecológica se enfrenta un 
La Infodiversidad y el uso ético del conocimiento...

desafío trascendental para formar al profesional responsable de integrar, organizar, poner a disposición y gestionar a la información documental, que ha sido creada por autores en diferentes soportes y formatos.

El entorno educativo establece que las instituciones de educación superior y, por ende, las instituciones de educación bibliotecológica (IEB) se centren en el estudiante, en el aprendizaje autónomo, en el desarrollo del pensamiento crítico, en el aprendizaje a lo largo de toda la vida, pero también que sean comunidades de aprendizaje (alumnos, docentes, directivos, personal).

Las IEB, además, posibilitan un paradigma en el uso de la información y en crear comunidades estratégicas que se involucren en el uso de la información y la generación del conocimiento a través del acceso y uso de materiales documentales organizados y disponibles en unidades de información y bibliotecas.

Ante tales apremios, las IEB han repensado cómo formar a los futuros profesionales de la bibliotecología, en ambientes de aprendizaje que integren los saberes del bibliotecólogo para realizarlos en diferentes ámbitos (impresos y digitales) y para lo que se requiere de la alfabetización digital, así como de la alfabetización informacional (AI). Lo anterior da nuevos significados a la enseñanza y al aprendizaje (E-A) enmarcada en las Tecnologías de la Información y la Comunicación (TIC). La Unesco estableció que:

La Alfabetización Informacional yace en el centro del aprendizaje de por vida. Potencia a las personas en las vías para buscar, evaluar, usar, y crear información en forma efectiva para alcanzar sus metas personales, sociales, ocupacionales y educacionales. Es un derecho humano básico en el mundo digital y promueve la inclusión social de todas las naciones. (IFLA-Unesco, 2016) 
Catts y Lau arguyeron que la AI faculta a las personas para:

- Reconocer sus necesidades de información.

- Localizar y evaluar la calidad de la información.

- Almacenar y recuperar información.

- Hacer un uso eficaz y ético de la información.

- Aplicar la información para crear y comunicar conocimiento. (Catts y Lau, 2009: 8)

Los autores también especifican que: "Para utilizar la [Alfabetización informacional] en una sociedad del conocimiento, resultan prerrequisitos indispensables para las personas tanto el acceso a la información como la capacidad para usar las TIC's" (Catts y Lau, 2009: 8). Son entonces necesarias en el entorno actual la AI y la Alfabetización en el uso de las TIC.

En cuanto a la alfabetización en el uso de las Tic, se considera que, más allá de utilizar computadoras y aplicaciones informáticas y utilizar internet, se tendrá que avanzar a la Alfabetización Digital, que según Levis Czernik "[...] implica, al menos, asegurar la comprensión lingüística y técnica de los sistemas de codificación digital" (Levis Czernik, 2006: 81), ya que se arguye que una verdadera alfabetización digital "[...] permitirá darle un sentido social y cultural más profundo a la incorporación de las computadoras." (Levis Czernik, 2006: 81)

Para la educación superior, existen las normas de Alfin para la educación superior, que propuso la Asociación de Bibliotecas Universitarias y de Investigación (ACRL), y que posteriormente sirvieron de base para países como Australia, Reino Unido y México (American Library Association). Durante las últimos dos décadas, los bibliotecarios del orbe han respaldado la importancia de la alfabetización informacional y han desarrollado normas. 
La Infodiversidad y el uso ético del conocimiento...

Se pondera entonces que las Instituciones de Educación Bibliotecológica (IEB) se constituyan en comunidades de aprendizaje que posibiliten un cambio de paradigma que vivifique al bibliotecario como profesional de la información para resignificar sus saberes, para beneficio de la sociedad de la que forman parte. Se considera que la alfabetización informacional y la alfabetización digital son parte trascendental de la formación del bibliotecológico, por lo que es importante investigar cómo se están formando.

¿CUÁlES ESTRATEGIAS ESTÁN SIGUIENDO LAS IEB DEL PAÍS PARA FORMAR A SUS ESTUDIANTES DE LICENCIATURA, EN ÁMBITOS DE ALFABETIZACIÓN INFORMACIONAL Y DIGITALES?

Al analizar las mallas curriculares de siete de las IEB del país, se denota que se han actualizado sus planes y programas; se está trabajando por competencias.

Considerando que la alfabetización informacional y la digital son parte importante del proceso formativo, se piensa que como son piedra angular para desarrollar destrezas básicas tanto de lectura y comprensión como complejas de análisis, pensamiento crítico y toma de decisiones.

Las competencias o habilidades, que forman parte de la alfabetización informacional (ALFIN), resumen la formación necesaria para conseguir que los estudiantes de bibliotecología desarrollen la capacidad de investigar y resolver problemas, de aprender a aprender, a lo largo no sólo de su estancia en la licenciatura de bibliotecología, sino de toda la vida. El desarrollo de tales habilidades las utilizarán los alumnos, primero, para solucionar los aspectos académicos 
de su formación y, después, para solucionar los problemas de información de los usuarios.

Cada IEB tiende a formar bibliotecólogos líderes, con competencias para la gestión de la información y para la investigación; ambas, con el fin de aprender, generar y transmitir el conocimiento bibliotecológico.

En la alfabetización informacional, están inmersos el respeto y el reconocimiento público a los autores a través de la debida representación de cada autor presente en la biblioteca, a través de los registros que elaboran los bibliotecólogos y que se representan para su recuperación en catálogos, bases de datos, repositorios, etcétera.

El respeto a la obra de los autores es parte medular de la formación del bibliotecólogo y es toda una línea de formación. Otra parte importante de la formación bibliotecológica se contempla al hacer uso del contenido intelectual de las obras, de citarlas y referenciarlas y que se realiza primero para las actividades académicas en la LB para después transmitirlas a los usuarios en las unidades de información. Ambas se abordan en bibliotecología con intensidad.

La alfabetización informacional y la digital son dos de los pilares para la formación del bibliotecólogo, y se ubican como parte del cambio en las Instituciones de Educación Bibliotecológica (IEB).

Por lo que respecta a la alfabetización tecnológica o digital, Manuel Area y Amador Guarro indican que el desarrollo requiere de cinco ámbitos o dimensiones: instrumental, cognitivo-intelectual, sociocomunicativa, axiológica, emocional (Area y Guarro, 2012: 66):

- A la dimensión instrumental le corresponde el dominio técnico de cada tecnología y de sus procedimientos lógicos de uso: adquirir el conocimiento práctico y las 
La Infodiversidad y el uso ético del conocimiento...

habilidades para el uso del hardware (montar, instalar y utilizar los distintos periféricos y aparatos informáticos) y del software o programas informáticos (bien del sistema operativo, de aplicaciones, de navegación por Internet, de comunicación, etcétera).

- En cuanto a la dimensión cognitivo-intelectual, le corresponde la adquisición de los conocimientos y habilidades cognitivas específicas que permitan buscar, seleccionar, analizar, interpretar y recrear la enorme cantidad de información a la que se accede a través de las nuevas tecnologías, así como comunicarse con otras personas mediante los recursos digitales. Aprender a utilizar de forma inteligente la información para acceder a la misma, otorgarle significado, analizarla críticamente y reconstruirla personalmente.

- La dimensión socio-comunicativa implica un conjunto de habilidades relacionadas con la creación de textos de naturaleza diversa (hipertextos, audiovisuales, icónicos, etcétera), difundirlos a través de diversos lenguajes y poder establecer comunicaciones fluidas con otros sujetos a través de las tecnologías. Asimismo, supone adquirir y desarrollar normas de comportamiento que impliquen una actitud social positiva hacia los demás, como puede ser el trabajo colaborativo, el respeto y la empatía en redes sociales.

- En la dimensión axiológica se toma conciencia de que las TIC inciden significativamente en el entorno cultural y político de nuestra sociedad, con la adquisición de valores éticos y democráticos en cuanto al uso de la información y de la tecnología, evitando conductas de comunicación socialmente negativas.

- La dimensión emocional involucra afectos, sentimientos y emociones provocadas por la experiencia en los 
entornos digitales. Éstas tienen lugar con las acciones desarrolladas, con la comunicación interpersonal en redes sociales, con el aprendizaje del control de emociones negativas, con el desarrollo de la empatía y con la construcción de una identidad digital caracterizada por el equilibrio afectivo-personal en el uso de las TIC.

Area y Guarro (2012: 62) establecen que una enseñanza es auténtica si logra que los alumnos:

1. Construyan significado y produzcan conocimiento.

2. Usen la investigación para construir significado.

3. Orienten su trabajo hacia la producción de discursos, productos y aplicaciones que tienen valor o significado.

¿CÓMO SE REFLEJA LA ALFABETIZACIÓN INFORMACIONAL Y DIGITAL EN LAS MALLAS CURRICULARES

DE SIETE IEB DEL PAÍS?

Se analizó las mallas curriculares de siete IEB, para ubicar aquellas asignaturas que lleven al alumno al desarrollo de la alfabetización informacional y digital.

\section{Escuela Nacional de Biblioteconomía y Archivonomía (ENBA)}

En el programa vigente de la ENBA, Plan 2000, se ubica la línea metodológica para desarrollar las habilidades informativas, con siete asignaturas, y la línea de automatización para las habilidades digitales con seis asignaturas (Escuela Nacional de Biblioteconomía y Archivonomía, 2016) 
La Infodiversidad y el uso ético del conocimiento...

En la nueva propuesta 2016 de la Licenciatura en Biblioteconomía, se refuerza la línea metodológica. Se proponen materias optativas para reforzar las habilidades informativas. La tecnología se distribuye de manera horizontal en diversas asignaturas. La licenciatura se cursa en nueve semestres. Se considera que se han contemplado las dos alfabetizaciones (Tabla 1).

\section{Tabla 1.}

ENBA. Propuesta Plan 2016

\begin{tabular}{|c|c|c|c|}
\hline Institución & Sem. & $\begin{array}{c}\text { Asignaturas. } \\
\text { Línea Metodológica }\end{array}$ & Optativas \\
\hline $\begin{array}{c}\text { ENBA. } \\
\text { Propuesta Plan } \\
2016\end{array}$ & $\begin{array}{c}1 \\
2 \\
3 \\
4 \\
5 \\
7 \\
7-9\end{array}$ & $\begin{array}{l}\text { Fundamentos de las ciencias sociales. } \\
\text { Metodología de la investigación social. } \\
\text { Investigación documental. } \\
\text { Estadística descriptiva. } \\
\text { Investigación de campo. } \\
\text { Introducción a la Bibliometría. } \\
\text { Seminarios de investigación. }\end{array}$ & $\begin{array}{l}\text { Ética profesional. } \\
\text { Habilidades y competencias informativas y de } \\
\text { comunicación. } \\
\text { Aplicación de las tecnologías de información y } \\
\text { comunicación. } \\
\text { Elaboración de reportes. } \\
\text { Habilidades de lectura y comunicación oral y } \\
\text { escrita en inglés. }\end{array}$ \\
\hline
\end{tabular}

Fuente: Informe y Propuesta Curricular. Licenciatura en Biblioteconomía. Licenciatura en Archivonomía. Enero de 2016. Documento interno.

\section{Colegio de Bibliotecología de la Universidad Nacional Autónoma de México}

En el Colegio de Bibliotecología de la UNAM, se cursa la Licenciatura en Bibliotecología y Estudios de la información en ocho semestres.

Las áreas que se abordan son las seis enlistadas, conformadas por cincuenta y un asignaturas; de ellas cuarenta y dos son obligatorias y nueve son optativas:

- Recursos Bibliográficos y de Información.

- Organización Bibliográfica y Documental.

- Administración de Servicios de Información. 
- Servicios Bibliotecarios.

- Tecnología de la Información.

- Investigación y Docencia en Bibliotecología.

- Asignaturas Optativas (9).

El programa educativo tiene las áreas de: Investigación y docencia en Bibliotecología y la de Tecnología de la información, con seis y siete asignaturas respectivamente. Ambas apoyan las alfabetizaciones informacional y digital (Tabla 2).

Tabla 2.

Colegio de Bibliotecología (UNAM). Licenciatura en Bibliotecología

y Estudios de la Información

\begin{tabular}{|c|c|c|c|c|}
\hline Institución & Sem. & $\begin{array}{c}\text { Área de Investigación y Docencia en } \\
\text { Bibliotecología }\end{array}$ & Sem. & Área Tecnología de la Información \\
\hline $\begin{array}{l}\text { FFyL-UNAM } \\
\text { Colegio de } \\
\text { Bibliotecología } \\
\text { (plan 2014) }\end{array}$ & $\begin{array}{l}1 \\
2 \\
3 \\
7 \\
8 \\
8\end{array}$ & $\begin{array}{l}\text { Introducción a la investigación. } \\
\text { Metodología de investigación cuantita- } \\
\text { tivos. } \\
\text { Metodología de investigación cualitativos. } \\
\text { Seminario de titulación I. } \\
\text { Seminario de titulación II. } \\
\text { Didáctica de la Bibliotecología. }\end{array}$ & $\begin{array}{l}3 \\
4 \\
5 \\
6\end{array}$ & $\begin{array}{l}\text { Computación aplicada a la tecnología. } \\
\text { Tecnología de la información en } \\
\text { bibliotecas. } \\
\text { Bases de datos. } \\
\text { Telecomunicaciones en las unidades de } \\
\text { información. } \\
\text { Sistemas y programas de automatización } \\
\text { de bibliotecas } \\
\text { Administración de sistemas automati- } \\
\text { zados. } \\
\text { Recursos digitales y multimedia. }\end{array}$ \\
\hline
\end{tabular}

Fuente: Universidad Nacional Autónoma de México. Colegio de Bibliotecología. Mapa curricular de la Licenciatura en Bibliotecología y Estudios de la Información, Plan 2016 (Universidad Nacional Autónoma de México, 2016).

\section{Facultad de Ciencias de la Información de la Universidad Autónoma de San Luis Potosí}

En la Facultad se imparte la Licenciatura en Gestión de la Información, que se cursa en ocho semestres. Se tienen asignaturas relacionadas con la investigación (1), y con las 
tecnologías (2), que se complementan con asignaturas optativas (Tabla 3).

\section{Tabla 3.}

Facultad de Ciencias de la Información (UASLP).

\begin{tabular}{|c|c|l|c|l|}
\hline Institución & Sem. & \multicolumn{1}{|c|}{ Asignaturas (1) } & Sem. & \multicolumn{1}{|c|}{ Asignaturas (2) } \\
\hline Facultad de & 1 & Metodología de la investigación. & 1 & Introducción a las TIC \\
Ciencias de la & 2 & Técnicas de investigación. & 3 & Bases de datos. \\
Información. & 7 & Seminario de investigación. & 4 & Redes y sistemas de información. \\
UASLP & 8 & Seminario de titulación. & 4 & Digitalización y documentos electrónicos. \\
& 8 & Taller de alfabetización informativa. & 6 & Diseño de sitios web. \\
& & & 7 & Redacción de documentos. \\
\hline
\end{tabular}

Fuente: Universidad Autónoma de San Luis Potosí. Facultad de Ciencias de la Información. Oferta educativa. Mapa curricular (Universidad Autónoma de San Luis Potosí, 2016).

\section{Licenciatura en Bibliotecología y Ciencias de la Información de la Universidad Autónoma de Nuevo León}

\section{La Licenciatura en Bibliotecología y Ciencias de la Informa- ción se cursa en diez semestres. Se detectaron siete asignatu- ras que apoyan las habilidades de ALFIN y la digital (Tabla 4).}

Tabla 4.

Licenciatura Bibliotecología y Ciencias de la Información (UANL)

\begin{tabular}{|c|c|l|c|l|}
\hline Institución & Sem. & \multicolumn{1}{|c|}{ Asignaturas } & Sem. & \multicolumn{1}{|c|}{$\begin{array}{c}\text { Asignaturas del Área Curricular } \\
\text { Formación General Universitaria }\end{array}$} \\
\hline Facultad de & 4 & Metodología de la investigación. & 1 & Competencia comunicativa. \\
Filosofía y & 5 & Métodos cuantitativos de investigación. & 2 & Aplicación de las tecnologías de \\
Letras. & 6 & Métodos cualitativos de investigación. & & información. \\
UANL & 9 & Seminario de investigación. & & \\
& 10 & Ética sociedad y profesión. & & \\
\hline
\end{tabular}

Fuente: Universidad Autónoma de Nuevo León. Licenciatura Bibliotecología y Ciencias de la Información. Malla curricular (Universidad Autónoma de Nuevo León, 2016). 


\section{Licenciatura en Ciencias de la Información Documental de la Universidad Autónoma del Estado de México}

La Licenciatura en Ciencias de la Información Documental se cursa en tres modalidades de trayectoria, que varían en el número de semestres. La Trayectoria Académica Mínima se cursa en ocho semestres; la Ideal se cursa en diez semestres y la Máxima se cursa en doce semestres.

Se anotan las asignaturas que se consideran corresponden a TIC e investigación, de la trayectoria Ideal (Tabla 5).

Tabla 5.

Licenciatura en Ciencias de la Información Documental (UAEM) (Trayectoria Ideal)

\begin{tabular}{|c|c|c|l|}
\hline Facultad de & Trayectoria Académica & 2 & Técnicas de lectura y redacción. \\
Humanidades. & Ideal & 6 & Ética profesional. \\
UAEM & 8 & Análisis de géneros y textos literarios. \\
& 9 & Estudios métricos de la información. \\
& 9 & Desarrollo de habilidades informativas. \\
& 10 & Investigación en ciencias de la información documental. \\
& 11 & El proceso de la investigación I. \\
& 12 & El proceso de la investigación II. \\
\hline
\end{tabular}

Fuente: Universidad Autónoma del Estado de México. Facultad de Humanidades. Licenciatura en Ciencias de la información documental (Universidad Autónoma del Estado de México, 2016).

\section{Licenciatura en Bibliotecología y Gestión de la informa- ción de la Universidad Autónoma de Chiapas}

La Licenciatura en Bibliotecología y Gestión de la Información se cursa en nueve semestres. Las asignaturas que apoyan a las dos alfabetizaciones son las que se muestran en la Tabla 6. 
La Infodiversidad y el uso ético del conocimiento...

Tabla 6.

Licenciatura en Bibliotecología y Gestión de la información (UNACH)

\begin{tabular}{|c|c|l|}
\hline Institución & Sem. & \multicolumn{1}{|c|}{ Asignaturas } \\
\hline Facultad de & 1 & Herramientas básicas de computación. \\
Humanidades & 1 & Aprender a aprender. \\
UNACH & 1 & Promoción lectora. \\
& 6 & Métodos de investigación Cualitativos aplicados a la Bibliotecología \\
& 7 & Seminario de investigación bibliotecológica. \\
& 9 & Taller de titulación. \\
\hline
\end{tabular}

Fuente: Universidad Autónoma de Chiapas. Facultad de Humanidades. Licenciatura en Bibliotecología y Gestión de la información (Universidad Autónoma de Chiapas, 2016).

\section{Licenciatura en Ciencias de la Información de la Uni- versidad de Chihuahua}

La Licenciatura en Ciencias de la Información (Plan 2013) se cursa en nueve semestres. Se ubicaron las siguientes asignaturas, en apoyo a las dos alfabetizaciones (Tabla 7).

Tabla 7.

Licenciatura en Ciencias de la Información (UACH)

\begin{tabular}{|c|c|l|}
\hline \multicolumn{1}{|c|}{ Institución } & Sem. & \multicolumn{1}{|c|}{ Asignaturas } \\
\hline Facultad de Filoso- & 1 & Tecnologías de la Información. \\
fía y Letras. & 2 & Redacción aplicada. \\
UACH & 3 & Comunicación oral. \\
& 3 & Estadística. \\
& 4 & Estudios métricos de la información. \\
& 6 & Metodología de la investigación científica. \\
& 9 & Alfabetización informacional. \\
\hline
\end{tabular}

Universidad de Chihuahua. Facultad de Filosofía y Letras. Licenciatura en Ciencias de la Información. Mapa curricular (Universidad de Chihuahua, 2016).

La revisión anterior indica que las IEB han establecido asignaturas tendientes a que el alumno tenga pleno uso de la información y de las TIC, lo cual presupone que actúen a favor del respeto y el reconocimiento a la creatividad de 
los saberes ya sean individuales o colectivos y a manera de antídoto contra el plagio. ${ }^{1}$

Las IEB tendrán que impulsar permanentemente el uso ético de la información y promover que como profesionistas impulsen ese uso ético con los usuarios de las unidades de información de la que formen parte. A manera de antídoto se tendrá que observar que no se realice el plagio.

A manera de diagnóstico se preguntó a los alumnos de la ENBA, de dos de los grupos del octavo semestre del plan 2000, sobre tres aspectos:

1. ¿Qué es para usted el plagio?

2. ¿Cuáles considera que sean las causas del plagio?

3. ¿Cómo evitar el plagio?

Las respuestas a la pregunta 1 indican que el $100 \%$ reconoce qué es el plagio.

Respecto a la pregunta 2, se establecen como causas del plagio:

- Falta de habilidades de búsqueda y recuperación de la información.

- Falta de creatividad.

- Desconocimiento de un tema.

- Desconocimiento del citado y su uso.

- Facilidad de usar la tecnología e Internet.

- Falta de ética, deshonestidad.

- No saber investigar.

- Presión para cumplir en entrega de trabajos.

1 Diccionario de la Real Academia Española: "copiar en lo sustancial obras ajenas, dándolas como propias." 
La Infodiversidad y el uso ético del conocimiento...

Respecto a la pregunta 3, proponen para evitarlo:

- Citar a los autores.

- Conocer y difundir la Ley de Derechos de Autor.

- Manejar estilos de citación.

- Buscar información segura y autores con autoridad.

- Denunciar el plagio.

- Acceso parcial a los documentos digitales.

- Pláticas o talleres sobre citado (desde los estudios básicos).

- Difundir repercusiones del plagio.

- Incrementar el análisis de la información y formular ideas propias.

Las respuestas indican que en la ENBA se tendrá que fortalecer permanentemente, desde los primeros semestres, el respeto a los autores, a sus saberes y a su creatividad con el debido citado y referenciado de sus obras.

Por otra parte, sin duda las TIC facilitan el plagio, lo que implica mayor atención por parte de los docentes en:

- Desarrollar estrategias docentes específicas, con actividades que privilegien el pensamiento crítico y analítico; el desarrollo de habilidades informativas, integrar la teoría con la práctica.

- Revisar los trabajos que entregan los alumnos (tareas y sobre todo el trabajo recepcional, en cuanto a referencias y citas).

- Verificar fuentes utilizadas.

- Supervisar el proceso de investigación.

- Intensificar el uso de normas para citar a los autores y fuentes utilizadas (incluidas imágenes, videos, sonido, 
entre otros elementos), a través de referencias precisas y organizadas.

El plagio es una llamada de atención a toda una comunidad educativa, para participar de manera conjunta en los procesos de aprendizaje que propicien la honestidad académica. Se considera necesario que los docentes desarrollen en los alumnos las habilidades que fortalezcan la honestidad académica y eviten el plagio; sin embargo, se requiere reconocerlo en sus diferentes tipos. Hexham (2016) señala los siguientes:

1. Plagio directo: ocurre cuando se modifica la estructura de la oración (cambia, omite, adiciona o borra palabras). Cuando se omite al autor y no se utilizan las comillas para indicar el texto usado. Cuando se hacen cambios mínimos en el texto del autor (modificar la estructura de las palabras, cambiar letras minúsculas por mayúsculas o, al contrario, entre otros cambios que alteren la apariencia del texto para presentarlo como original.

2. Plagio por el uso de citas (inadecuado). No obstante se reconoce al autor real, ocurre el plagio porque el texto original se reproduce con cambios menores sin utilizar comillas o citas (no hay paráfrasis).

3. Plagio usando una referencia. Cuando existe una referencia al autor, pero no se utilizan las comillas (o algún dato de identificación), de acuerdo a las reglas de citación. Hay cambios ligeros para aparentar que el texto es diferente al original.

4. Plagio complejo usando una referencia. Sucede cuando existen varios cambios y paráfrasis de texto extenso, pero sin uso apropiado de comillas. Existe la 
La Infodiversidad y el uso ético del conocimiento...

referencia al autor aunque no se anote la página correcta y se utilizan muchas palabras y frases del texto original. Se usa paráfrasis para resumir argumentos, pero sin las indicaciones del parafraseo, ni se usan comillas cuando se requieren. Otra manera de plagio es cambiar la apariencia, pero no el contenido, ni las oraciones, para hacer el plagio menos notable.

5. Plagio con comillas suspendidas. El plagiario utiliza comillas (en una parte de la cita textual), pero continúa utilizando el texto después del cierre de comillas.

6. Paráfrasis como plagio. Se realiza plagio al parafrasear sin referencia a la fuente original. Cuando el parafraseo es continuo y extenso, aunque se cite la fuente, pero sin que se adicione texto que interactúe con los párrafos parafraseados o se agregue nueva información. El parafraseo legitimo se realiza cuando se reconoce la fuente y donde la paráfrasis se limita al material sobre el que se discute, se explica, y se argumenta. El parafraseo es aceptable cuando:

- No se domina el trabajo de quien escribe.

- La paráfrasis permite al autor interactuar críticamente con los puntos de vista de otra persona.

- Cuándo el argumento del texto original es reescrito con palabras diferentes.

7. El autoplagio. Se realiza cuando no se indica que el trabajo está siendo reciclado o cuando dos trabajos sólo difieren en su apariencia.

Como medida extrema quizá sea necesario tener programas que permitan verificar el plagio de textos. 
La educación bibliotecológica en México ante el plagio

\section{CONCLUSIONES}

La educación bibliotecológica va en doble vía: formar a sus alumnos con habilidades en el uso de la información (AI) y alfabetización digital, para que, a su egreso, resuelvan las necesidades informativas de los usuarios y repliquen en ellos las habilidades informativas y digitales necesarias para el uso ético de la información.

El docente de bibliotecología es importante para impulsar en la profesión el derecho de autor, el uso respetuoso de la información y transmitir las afectaciones que produce el plagio en toda comunidad académica. Favorecer que la comunidad haga uso ético de la información, y que se refuerce la integridad académica.

También es importante investigar sobre el plagio (qué tipo de plagio se presenta, qué lo motiva, cómo se evita, entre otros aspectos). Se considera que el plagio y sus consecuencias deban estar enunciados en los reglamentos institucionales.

Las respuestas de los alumnos del octavo semestre sobre el plagio permiten actuar e intensificar el uso de citas y parafraseo. Reforzar el pensamiento crítico y las habilidades del pensamiento. Incrementar las destrezas en investigación. En la ENBA, ante el cambio de planes y programas, ya se contemplan tales aspectos.

\section{BIBLIOGRAFÍA}

American Library Association (s.f.). Normas sobre aptitudes para el acceso y Uso de la Información en la Enseñanza Superior [en línea], http://www.ala.org/ala/mgrps/divs/acrl/standards/ informationliteracycompetency standards.cfm 
La Infodiversidad y el uso ético del conocimiento...

Area, M. y Guarro, A. (2012). La alfabetización informacional y digital: fundamentos pedagógicos para la enseñanza y el aprendizaje competente. Revista Española de Documentación Científica, 35 (Monográfico), 46-74 [en línea], http://dx.doi. org/10.3989/redc.2012.mono.977

Catts, R. y Lau, Jesús (2009). Hacia unos indicadores de alfabetización informacional. Con una lista de posibles indicadores internacionales para el suministro y el acceso a la información, y las competencias relacionadas, establecida por el Instituto de Estadística de la UNESCO. Madrid: Ministerio de Cultura [en línea], http://travesia.mcu.es/portalnb/jspui/bitstream/10421/3141/1/IndicadoresUNESCOesp4.pdf

Escuela Nacional de Biblioteconomía y Archivonomía. (ENBA, Editor) Obtenido de Plan de estudios de la licenciatura en biblioteconomía [en línea], http://www.enba.sep.gob.mx/codes/ licenciatura_biblio.html

Hexham, I. (2005). The plague of plagiarism: academic plagiarism defined [en línea], http://people.ucalgary.ca/ hexham/content/articles/plague-of-plagiarism.html

IFLA (2013). Limitaciones y excepciones del derecho de autor (copyright) para bibliotecas y archivos [en línea], http://www.ifla. org/ES/copyright-tlib

IFLA (2000). Postura de la IFLA sobre los derechos de autor en un ambiente digital [en línea], http://www.ifla.org/node/7300

IFLA-Unesco (2005). "Faros de la Sociedad de la Información", Coloquio de Alto Nivel sobre Alfabetización Informacional. Proclamación de Alejandría acerca de la Alfabetización Informacional y el Aprendizaje de por vida [en línea], http://www. bibalex.org/infolit2005/Proclamation/alexprocspa.doc

Levis Czernik, D. S. (2006). Alfabetos y saberes. La alfabetización Digital. Comunicar: Revista científica iberoamericana de comunicación y educación, Núm., 26, 78-82 [en línea], https:// dialnet.unirioja.es/servlet/articulo?codigo $=1985777$ 
Merges, R. P. (s.f.). Locke for the masses: Property Rights and the products of Collective creativity [en línea], http://dx.doi. org/10.2139/ssrn. 1323408

Miró Llinares, F. (2007). El futuro de la propiedad intelectual desde su pasado. La historia de los derechos de autor y su porvenir ante la revolución de internet. Revista de Sociales y Jurídicas [en línea], https://revistasocialesyjuridicas.files.wordpress. com/2010/09/02-tm-06.pdf.

OMPI. Convenio de Berna para la protección de las obras literarias y artísticas [en línea], http://www.culturalrights.net/descargas/ drets_culturals394.pdf

Ong, W. J. (1987). Oralidad y escritura. México: FCE.

Perromat Augustín, K. (2010). El plagio en las literaturas hispánicas [en línea], www.ugr.es/ plagio_hum/ Documentacion/06Publicaciones/LIB003.pdf

Universidad Autónoma de Chiapas. Facultad de Humanidades. Licenciatura en Bibliotecología y Gestión de la Información [en línea], http://www.unach.mx/images/documentos/program_ edu/licenciatura_en_bibliotecologia.pdf

Universidad Autónoma de Nuevo León. Licenciatura Bibliotecología y Ciencias de la Información. Malla curricular [en línea], http://www.filosofia.uanl.mx:8080/web/wp-content/ uploads/2013/06/malla_curricular_BYCI_2013.pdf

Universidad Autónoma de San Luis Potosí. Facultad de Ciencias de la Información. Oferta educativa. Mapa curricular [en línea], http://www.eci.uaslp.mx/OE/LGIDEF/OELGIMC

Universidad Autónoma del Estado de México. Facultad de Humanidades. Licenciatura en Ciencias de la Información Documental [en línea], http://humanidades.uaemex.mx/wp-content/ uploads/2014/06/Plan-de-estudios-CID.pdf 
La Infodiversidad y el uso ético del conocimiento...

Universidad de Chihuahua. Facultad de Filosofía y Letras. Licenciatura en Ciencias de la Información. Mapa curricular [en línea], http://ffyl.uach.mx/ciencias.html

Universidad Nacional Autónoma de México. Colegio de Bibliotecología. Mapa curricular de la Licenciatura en Bibliotecología y Estudios de la Información, Plan 2016 [en línea], http://colegiodebibliotecologia.filos.unam.mx/files/2016/01/Mapa-2014. pdf

Yen, A. C. (1990). Restoring the natural law: Copyright as Labor and possession. Obio State Law Journal, 51, 517-559 [en línea], http://ssrn.com/abstract=916110 


\title{
Alfabetización informativa como apoyo para evitar el plagio académico
}

\author{
Celia Mireles CÁRdenas
}

Universidad Autónoma de San Luis Potosí, México

\section{INTRODUCCIÓN}

s innegable que el desarrollo tecnológico en la ac-
tualidad potencia el libre acceso a la información; sin
embargo, no significa que su uso se realice de manera

Lo anterior se debe a una amplia gama de situaciones, que van desde el desconocimiento de las normas existentes para de su buen uso, hasta el mal uso premeditado. En cualquiera de las situaciones, las consecuencias del mal uso de la información son impredecibles y pueden afectar no sólo al individuo que incurre en él, sino también al prestigio de las instituciones a las que pertenece, ya sea del ámbito político, académico, de investigación o periodístico.

En los últimos años hemos visto una gran gama de casos de plagio en distintas disciplinas tanto a nivel local como internacional, que exponen de forma mediática las faltas de honestidad en las que se incurren. Lo anterior, debido a que el mismo desarrollo tecnológico permite acceder y utilizar 
La Infodiversidad y el uso ético del conocimiento...

indiscriminadamente la información disponible en los medios de comunicación, como Internet, además de detectar, cada vez con mayor exactitud, los plagios realizados por parte de cualquier persona en cualquier ámbito en que se desarrolle.

Por supuesto, son varios los factores que influyen en estas situaciones, pero, en cualquier caso, es indudable la importancia de crear una cultura responsable y respetuosa del trabajo intelectual de las personas, entorno en el cual los principios que se establecen en los programas de alfabetización informativa se tornan cada vez más pertinentes.

\section{USO ÉTICO Y LEGAL DE LA INFORMACIÓN}

El documento es concebido en términos generales en el ámbito bibliotecológico, como información registrada en cualquier soporte y realizado con la finalidad de comunicar información. Las formas, soportes y contendidos documentales han evolucionado junto con los avances culturales, tecnológicos y científicos de su creador: el ser humano. Por tanto, en la actualidad, encontramos una gran variedad de tipos documentales que pueden ser recuperados y utilizados de forma casi inmediata y completa.

En este entorno, la recuperación de información puede realizarse, en términos generales (con sus excepciones), sin mayor problema, pero no pasa lo mismo con la apropiación del contenido intelectual, el cual se encuentra vulnerable en relación con su uso ético y apropiado.

El término de plagio se utiliza comúnmente para referirse al uso inadecuado de la información documental, sea escrita, en imagen o audiovisual, que se realiza de forma premeditada o por el desconocimiento de las personas sobre 
las normas éticas y legislativas que existen para proteger la propiedad intelectual.

García (2013: 21) refiere que el concepto de propiedad intelectual incluye las iniciativas regulatorias, tanto para la propiedad industrial (invenciones, marcas registradas, modelos industriales, dibujos, denominaciones de origen, entre otros) como los derechos de autor (relativos a las obras literarias, musicales, artísticas, fotográficas y audiovisuales, entre otras).

Volviendo al tema del plagio, Alfaro (2014: 4) explica muy claramente los tipos de plagio, al mencionar que:

Copiar una obra o parte de ella y se presenta como propia, utilizar en los trabajos académicos y científicos frases, párrafos, gráficos, datos, fotografías, material multimedia de obras de otros autores, sin citar la procedencia; comprar trabajos en internet para atribuirle la autoría; poner el nombre de compañeros como coautores sin que hayan participado en la elaboración el mismo; copiar cualquier tipo de documento en soporte tradicional, analógico o digital, audio, video, obras multimedia, páginas web, música, etc., sin citar la fuente y el autor, es plagiar. Incluso, copiar nuestros propios trabajos y presentarlos como novedosos también es plagiar, aunque en este caso sea un autoplagio, es un engaño, un fraude, ya que presentamos una investigación o trabajo académico novedoso cuando en realidad no lo es.

Para complementar lo anterior, nos remitimos a Soto (2012), quien clasifica los tipos de plagio en:

1. Forma (autoplagio, falsa autoría, envío doble, robo de material, copias sin autorización de código fuente).

2. Método (copiar y pegar, parafraseo inapropiado; referencia perdida, referencia falsa, fabricación de datos, robo de ideas).

3. Propósito (intencional, accidental o sin intención). 
La Infodiversidad y el uso ético del conocimiento...

Por último, para tener un panorama general de los tipos de plagio, se presenta la definición brindada por parte de Urbina (en Domínguez, 2012: 499), que refiere al ciberplagio como:

Aquellos materiales fruto del trabajo personal, que en realidad han sido copiados parcial o totalmente mediante procedimientos informáticos sin mencionar su autoría original, la procedencia de los mismos es mayoritariamente de internet, si bien puede tratarse de otras fuentes como enciclopedias en CD ROM, o trabajos de compañeros.

Las consecuencias del plagio son diferentes en cada contexto. Las sanciones van desde una administrativa o disciplinaria, hasta el desprestigio de la persona y/o institución en que labora. Por tanto, es común que diferentes entidades académicas establezcan su postura al respecto, como el Código de Ética de la Universidad Nacional Autónoma de México (2015), que fija su postura en relación al plagio, y que deriva en que las entidades académicas difundan información al respecto, como es el caso de la Facultad de Derecho de esa Universidad (Figura 1).

Pero, sobre todo, las consecuencias más lamentables es que, además de afectar el derecho de otras personas, se limita la capacidad del ser humano para crear, ser creativo y pensar por sí mismo. 
Alfabetización informativa como apoyo para evitar el plagio...

Figura 1.

10 formas más comunes de cometer plagio

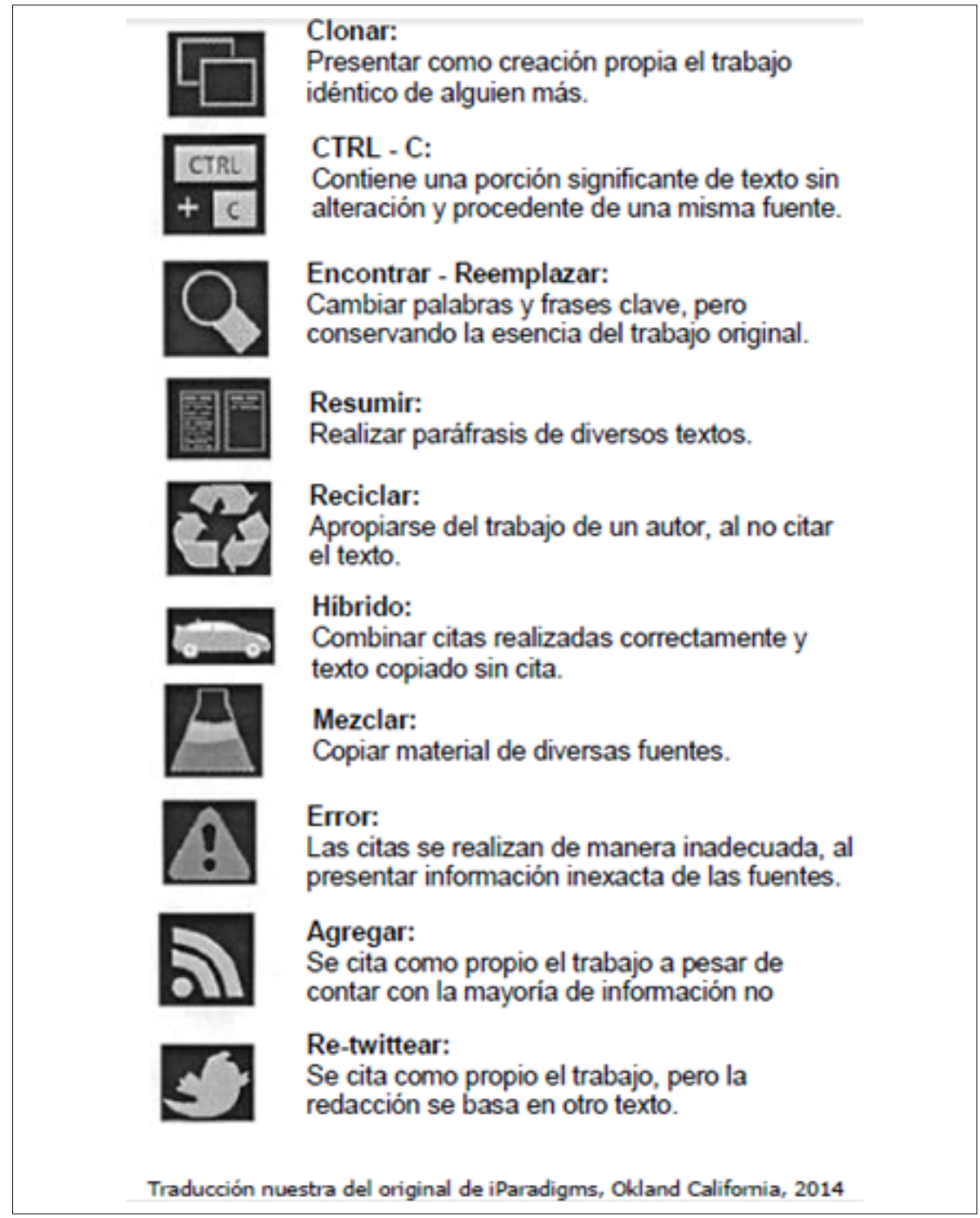

Fuente: Guía rápida sobre plagio y derechos de autor. Facultad de Derecho de la UNAM [en línea], http:// www.derecho.unam.mx/integridad-academica/pdf/guia-plagio-derecho-autor.pdf 
La Infodiversidad y el uso ético del conocimiento...

Plagio EN EL ÁMBito UNIVERSITARIO

Al revisar el tema del plagio en el ámbito universitario, nos damos cuenta de que existe una amplia bibliografía en la que se abordan las experiencias vertidas en diversas instituciones sobre tres aspectos principales: definición de los conceptos desde el punto de vista normativo, análisis de la problemática que genera el plagio, así como las experiencias obtenidas en diferentes instituciones para su identificación, prevención y solución.

Por ejemplo, George, Costigan y O'hara (2013) realizan una revisión de literatura en el que se identifica que el plagio es un tema que ha incrementado el interés en los últimos años debido, principalmente, a los factores ligados con la tecnología. De esta forma, esa práctica abarca un amplio rango de factores demográficos y sociales, puesto que es innegable la influencia del contexto cultural de las personas, lo que incluye el dominio de diferentes idiomas, principalmente el inglés, en la poca o nula observancia de las reglas de citación adecuadas. En este entorno, el sector juvenil es el más propenso a incurrir en el plagio. (Costigan y O'hara, 2013: 142)

Asimismo, el documento da cuenta de los resultados obtenidos en el programa sobre la conciencia sobre el plagio (Plagiarism Awarensess Program), que se llevó a cabo en la Universidad de Bradford's, en el cual los estudiantes relataron sus experiencias con el plagio, además de llevar sesiones con ejercicios para reflexionar sobre la importancia y consecuencias sobre el tema, y por supuesto, clases para que aprendan a redactar adecuadamente, entre otras actividades. (Costigan y O'hara, 2013: 146)

Por su parte, Loudovico y Wittig (2015) refieren que los estudios longitudinales sobre la citación establecen una 
oportunidad de conversación en los campus y para desarrollar el pensamiento crítico, así como las habilidades de redacción y escritura. El estudio que realizaron en la Universidad de Richmond del Reino Unido refiere que los estudiantes pueden encontrar la información fácilmente, pero tienen dificultades para interactuar y comprender la forma correcta de citación y redacción. Por ello, la importancia de realizar cursos sobre el tema.

Precisamente, Gunnarsson, Kulesza y Pettersson (2014) establecieron la importancia de la colaboración entre los profesores y bibliotecarios para el desarrollo de las habilidades a las que refiere la Alfabetización Informativa en general, y en particular lo relacionado al uso ético de la información. Con este este trabajo colaborativo se pueden compartir las experiencias realizadas para la corrección y adecuada citación en los trabajos académicos. Al analizar la literatura sobre el tema, el artículo enfatiza en la recomendación realizada por Carroll y Zetterling (Gunnarsson, Kulesza y Pettersson, 2014: 414), que sugieren utilizar varios métodos de instrucción, como lecturas, conferencias, discusiones, trabajos escritos, cursos de literatura, ejercicios interactivos con exposiciones de los estudiantes en donde se discutan diferentes perspectivas sobre el plagio. Importante es mencionar que los autores exponen que la detección del plagio es un servicio que puede ofrecer la biblioteca a la comunidad.

Por supuesto, en esta revisión también se encuentran propuestas para integrar la instrucción basada en el anti plagio en el currículo. Lampert (2004) enfatiza la importancia de la colaboración docente en la enseñanza efectiva de los estudiantes a través de la revisión ética y correcta en sus trabajos. Resalta la importancia en prestar atención en estilos de citación y la ética de la información en varias dis- 
La Infodiversidad y el uso ético del conocimiento...

ciplinas, en particular el periodismo, dados los casos que al respecto se han suscitado en los últimos años. El autor señala la importancia de relacionar la alfabetización informativa para desarrollar cursos sobre el tema y sugiere incluir en las sesiones aspectos como:

- Reinvertir lo que el plagio significa en el contexto de una disciplina particular.

- Familiarizarse con el formato de estilo de una disciplina y códigos de ética.

- Examinar las normas curriculares necesarias para la acreditación disciplinaria.

- Identificando los códigos de ética de las asociaciones profesionales.

- Demostración de una voluntad de hacer recursos disponibles para ayudar en el estudio de la ética de la información en disciplina siempre donde sea apropiado. (Lampert, 2004: 353)

Domínguez Aroca (2012) acota que al ser Internet la principal fuente de información de los jóvenes y por el desconocimiento en su buen uso, es preciso que el tema se encuentre presente en la normativa universitaria, así como la necesidad de este presente en la educación de los estudiantes y en la preparación de los profesores. La autora enfatiza que el plagio es un:

[...] acto egoísta que cercena la creatividad e innovación del ser humano (que debe ser responsable de la veracidad y calidad de su trabajo), y además puede entrañar responsabilidades penales o sanciones académicas, pero sobre todo, supone vulnerar los derechos morales relacionados con la autoría, una de las partes más importantes de los derechos de autor. (Domínguez Aroca, 2012: 499)

También menciona los diferentes resultados de encuestas realizadas sobre el tema, en las cuales se coincide con otros estudios aquí referidos, que "[...] una de las causas de co- 
meter plagio es la falta de formación para la realización de trabajos académicos." (Domínguez Aroca, 2012: 499) Éste, más otros aspectos, representa la oportunidad para que la biblioteca amplíe su presencia en la comunidad a través de servicios y productos interesantes y creativos.

\section{EL USO ÉTICO DESDE LA PERSPECTIVA DE LA ENSEÑANZA BIBLIOTECOLÓGICA}

En un primer acercamiento documental en las nueve ofertas educativas que actualmente existen en el país y que refieren al estudio bibliotecológico, ${ }^{1}$ al revisar la malla curricular, sólo se detectan de forma directa, por el título de la asignatura, dos casos que refieren al tema de forma directa y tres que refieren a la alfabetización informativa (Tabla 1).

1 Ciencias de la Información de la Universidad Autónoma de Chihuahua; Ciencias de la Información Documental, de la Universidad Autónoma del Estado de México; Licenciatura en Bibliotecología y Ciencias de la Información, de la Universidad Autónoma de Nuevo León; Licenciatura en Gestión de la Información, de la Universidad Autónoma de San Luis Potosí; Bibliotecología y Gestión de la Información, de la Universidad Autónoma de Chiapas; Licenciatura en Bibliotecología y Gestión de la Información, de la Universidad de Oriente; Licenciatura en Biblioteconomía, de la Escuela Nacional de Biblioteconomía y Archivonomía; Licenciatura en Bibliotecología y Estudios de la Información, de la Universidad Nacional Autónoma de México; Bibliotecología y Gestión del Conocimiento de la Universidad de Guadalajara. 
La Infodiversidad y el uso ético del conocimiento...

Tabla 1.

Asignaturas relacionadas directamente con el uso ético de la información

\begin{tabular}{|c|c|c|}
\hline Licenciatura & Asignaturas generales & $\begin{array}{c}\text { Asignaturas relacionadas con la } \\
\text { Alfabetización informativa. }\end{array}$ \\
\hline $\begin{array}{l}\text { Ciencias de la Información de } \\
\text { la Universidad Autónoma de } \\
\text { Chihuahua }\end{array}$ & $\begin{array}{l}\text { Legislación documental (8vo. Semestre). } \\
\text { Ética de la información (9ํㅗㄹ semestre). } \\
\text { Introducción al Derecho de autor. Materia } \\
\text { optativa de la Facultad de Filosofía y Letras. }\end{array}$ & $\begin{array}{l}\text { Alfabetización informacional } \\
\text { (6º Semestre). }\end{array}$ \\
\hline $\begin{array}{l}\text { Ciencias de la Información } \\
\text { Documental de la Universidad } \\
\text { Autónoma del Estado de } \\
\text { México. }\end{array}$ & Ética Profesional (5ํsemestre). & $\begin{array}{l}\text { Desarrollo de Habilidades informativas } \\
\text { ( }{ }^{\circ} \text { semestre). }\end{array}$ \\
\hline $\begin{array}{l}\text { Licenciatura en Gestión de la } \\
\text { Información de la Universidad } \\
\text { Autónoma de San Luis Potosí }\end{array}$ & & $\begin{array}{l}\text { Taller de Alfabetización Informativa ( } 8^{\circ} \\
\text { semestre). }\end{array}$ \\
\hline
\end{tabular}

Fuente: Planes de estudios de las Licenciaturas, en José Luis Hernández Martínez (2016). Necesidades y búsqueda de información de los estudiantes de la licenciatura en bibliotecología modalidad presencial y a distancia en México. México: UNAM / Tesis para obtener el grado de Maestro en Bibliotecología y Estudios de la Información.

Por supuesto, es deseable realizar un análisis más profundo para detectar en dónde se revisan los aspectos que refieren al uso ético de la información, como pueden ser las asignaturas de metodologías o seminarios de investigación, fuentes de información, normatividad o legislación, como sucede con la asignatura Tipología Documental de la Licenciatura en Gestión de Información de la Universidad Autónoma de San Luis Potosí (UASLP), en la cual, en un rubro del programa, se analiza la Ley de Derechos de autor y de Propiedad Intelectual, pero en relación con los códigos de normalización de los documentos.

En el caso de la Licenciatura en Ciencias de la Información de la Universidad Autónoma de Chihuahua, en el $8^{\circ}$ semestre, se imparte la asignatura Legislación documental, la cual establece como objetivo general:

Que el estudiante será capaz de aplicar de forma correcta las legislaciones nacionales e internacionales vigentes relacionadas con las ciencias de la información, diferenciando aquellas ten- 
dientes a regular la protección de la generación de conocimiento a través de la divulgación impresa amplia, la legislación que protege la creación y divulgación de conocimiento de forma restringida y aquella reglamentación que define la forma de proceder en el desarrollo de sistemas de información públicos. (Legislación documental. Programa de la asignatura)

En esta asignatura se enfatiza el análisis de las leyes de Propiedad Intelectual; Derechos de Autor y Propiedad Industrial. Adicionalmente, en la Facultad de Filosofía y Letras, se ofrece como materia optativa Introducción al Derecho de Autor.

Por supuesto, el uso ético de la información en estos planes de estudio se observa en mayor detalle en las asignaturas que refieren a la formación de usuarios, o como actualmente se denominan: alfabetización informativa, puesto que una de las competencias o habilidades en el uso de la información son referidas en las distintas normas que asociaciones internacionales han emitido al respecto (Tabla 2).

Tabla 2.

Normas en alfabetización informativa que aluden al uso ético de la información

\begin{tabular}{|l|l|}
\hline \multicolumn{1}{|c|}{ Normas en Alfabetización informativa. } & \multicolumn{1}{c|}{ Norma especifica } \\
\hline $\begin{array}{l}\text { ACRL/ALA } \\
\text { (Association of College and Research Libraries / } \\
\text { American Library Association). }\end{array}$ & $\begin{array}{l}\text { Norma 5: El estudiante competente en el acceso y uso de la } \\
\text { información comprende muchos de los problemas y cuestiones } \\
\text { económicas, legales y sociales que rodean al uso de la infor- } \\
\text { mación, y accede y utiliza la información de forma ética y legal. }\end{array}$ \\
\hline $\begin{array}{l}\text { ANZIIL/CAUL } \\
\text { Australian and New Zealand Institute for Infor- } \\
\text { mation Literacy / Council of Australian University } \\
\text { Librarian) }\end{array}$ & $\begin{array}{l}\text { Norma 6: La persona alfabetizada en información utiliza la } \\
\text { información con sensibilidad y reconoce los problemas y } \\
\text { cuestiones culturales, éticas, económicas, legales y sociales } \\
\text { que rodean el uso de la información. }\end{array}$ \\
\hline $\begin{array}{l}\text { Directrices Internacionales para la Alfabetización } \\
\text { Informativa de la Federation of Library Associations } \\
\text { and Institutions (IFLA). }\end{array}$ & $\begin{array}{l}\text { Norma 5. Uso de la información } \\
\text { Norma 6. Comunicación y uso ético de la información. }\end{array}$ \\
\hline $\begin{array}{l}\text { Normas de Alfabetización Informativa para el } \\
\text { Aprendizaje (Ciudad Juárez). }\end{array}$ & $\begin{array}{l}\text { Norma 8. Respeto a la propiedad intelectual y a los derechos } \\
\text { de autor. }\end{array}$ \\
\hline
\end{tabular}

Fuente: Carolina Sofía Ferrer Torres (2012). Integración de la Alfabetización Informacional en la educación superior. Propuesta para el diagnóstico de competencias informacionales. (pp. 54-61). San Luis Potosí: UASLP / Tesis para obtener el título de Licenciado en Bibliotecología e Información de la Escuela de Ciencias de la Información. 
La Infodiversidad y el uso ético del conocimiento...

Por lo anterior, no es de extrañar que este aspecto también tenga gran presencia en los servicios y actividades que ofrecen las diferentes bibliotecas académicas del país, entre ellas, las que pertenecen al Sistema de Bibliotecas de la UASLP, como se detalla en el siguiente apartado.

\section{ACERCAMIENTO AL COMPORTAMIENTO Y USO ÉTICO DE LA INFORMACIÓN EN LA UASLP}

Como consecuencia de los casos de plagio detectados por diversos investigadores a nivel nacional en el año de 2015 y que fueron ampliamente difundidos por la prensa (CONACyT, 2015), la UASLP aprobó un código de ética en el cual, si bien no alude a la palabra plagio, apela al sentido de honestidad académica del universitario en las diferentes actividades que realiza. (Universidad Autónoma de San Luis Potosí, 2015) No obstante lo anterior, en diferentes normativas internas de entidades académicas, como en el caso de la Facultad de Ciencias Sociales y Humanidades, se considera el plagio como causa de suspensión del programa de Posgrado. (Facultad de Ciencias Sociales y Humanidades, 2015)

En la actualidad, el Sistema de Bibliotecas de la UASLP se conforma por una Dirección General, cuatro departamentos generales, ocho centros de información, de los cuales dependen administrativamente catorce unidades de informativas, además de la biblioteca virtual creativa. Estos centros atienden a toda la población universitaria, lo cual permite contribuir a la formación de la comunidad, brindándole espacios adecuados para el acceso y uso de la información. (Sistema de Bibliotecas de la UASLP, 2015)

Los lineamientos generales que guían la formación de usuarios establecen que las actividades están orientadas a 
toda la comunidad universitaria y los programas están alineados a los objetivos estratégicos del Plan de Desarrollo del Sistema de Bibliotecas. Con base en la información que presentan la páginas web de los centros de información, los programas están apoyados en las normas emitidas por la Association of College \& Research Libraries (ACRL) y por la Australian and New Zealand Institute for Information Literacy (ANZIIL), mismas que se ofrecen a través de cursos y talleres con temas como: Elaboración de bibliografías; Gestores bibliográficos; Citación; Elaboración y presentación de trabajos escritos; Principios básicos de redacción; Escribir para publicar, y Derechos de autor y propiedad intelectual, los cuales están programados de manera fija o pueden solicitarse por parte de los usuarios.

En forma complementaria, se ofrece acceso a diferentes normas y tutoriales para citar trabajos académicos, como se muestra en la Figura 2.

Figura 2.

Formación de usuarios en el Sistema de Bibliotecas de la UASLP

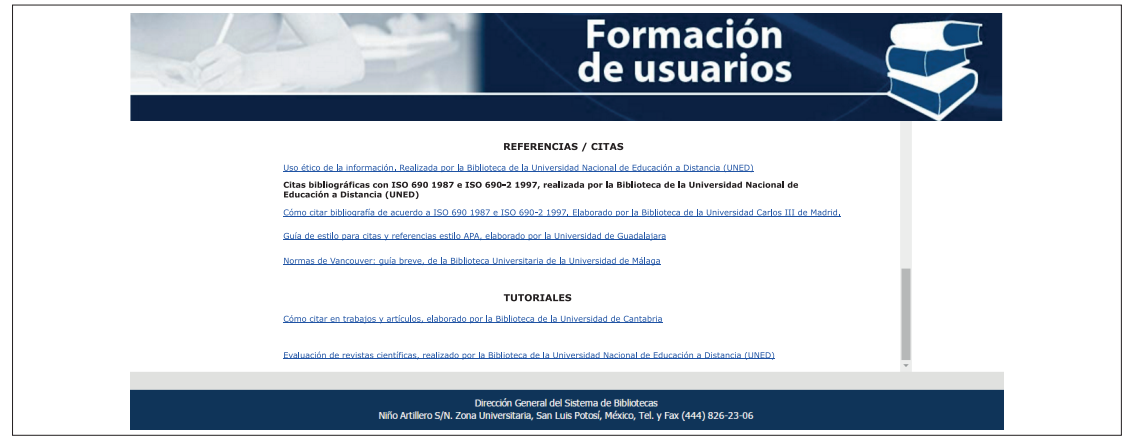

Fuente: http://bibliotecas.uaslp.mx/formacion_usuarios.html

A pesar de lo anterior, diferentes estudios realizados para identificar el grado de conocimiento que tienen los estudiantes sobre estas actividades, así como la forma de citar, 
muestra que existe una área de oportunidad para que el Sistema de Bibliotecas haga presencia positiva en las diferentes comunidades, tal como lo sugieren las lecturas analizadas y los casos de éxito expresados en las mismas.

Brevemente, hacemos referencia a las encuestas realizadas en diferentes trabajos de tesis para la obtención del título de Licenciado en Bibliotecología, los cuales han establecido como uno de los objetivos analizar las competencias informativas de los estudiantes de la UASLP. En estas encuestas, los apartados que refieren al tema del plagio y uso ético de la información brindan resultados semejantes a lo revisado a nivel internacional, en donde se observa un desconocimiento, de casi $50 \%$ de la comunidad, sobre las formas adecuadas de citar, y en los comentarios vertidos de manera libre, los alumnos solicitan este tipo de información (Tabla 3).

Tabla 3.

Estudios de tesis realizados para identificar las competencias informativas en los estudiantes de la UASLP

\begin{tabular}{|c|c|c|}
\hline Tesis & Licenciaturas encuestadas & No. De encuestas \\
\hline $\begin{array}{l}\text { (Tesis 1) Adelita Bravo Castillo (2017). Propuesta } \\
\text { para el desarrollo de un programa de alfabetización } \\
\text { informacional en la Coordinación Académica Región } \\
\text { Huasteca Sur. }\end{array}$ & $\begin{array}{l}\text { Licenciaturas en Ingeniera Mecánica } \\
\text { Eléctrica; Enfermería con Orientación } \\
\text { en Obstetricia; Ingeniería Agroindustrial; } \\
\text { Contaduría Pública. }\end{array}$ & 116 \\
\hline $\begin{array}{l}\text { (Tesis 2) Cesar Alejandro Bonilla Gómez y Jesús } \\
\text { Martin Velázquez Torres (2014). Competencias de } \\
\text { Alfabetización Informacional en usuarios de nivel } \\
\text { licenciatura del Centro de Información en Ciencias } \\
\text { Sociales y Administrativas. }\end{array}$ & $\begin{array}{l}\text { Facultad de Derecho. Licenciatura en } \\
\text { Derecho. } \\
\text { Facultad de Contaduría. Licenciaturas en } \\
\text { Administración, y de Contador Público. }\end{array}$ & 579 \\
\hline $\begin{array}{l}\text { (Tesis 3) Beatriz de Lourdes Guzmán Cortés } \\
\text { (2014). Alfabetización informativa en alumnos de la } \\
\text { Universidad Autónoma de San Luis Potosí. Escuela } \\
\text { de Ciencias de la Información. }\end{array}$ & $\begin{array}{l}\text { Facultad de Ciencias de la Información: } \\
\text { Licenciatura en Archivología, y Licencia- } \\
\text { tura en Bibliotecología. }\end{array}$ & 301 \\
\hline $\begin{array}{l}\text { (Tesis 4) Carolina Sofía Ferrer Torres (2012). } \\
\text { Integración de la Alfabetización Informacional en la } \\
\text { educación superior. Propuesta para el diagnóstico } \\
\text { de competencias informacionales. }\end{array}$ & $\begin{array}{l}\text { Facultad de Ciencias de la Información: } \\
\text { Licenciatura en Archivología, y Licencia- } \\
\text { tura en Bibliotecología. }\end{array}$ & 57 \\
\hline
\end{tabular}

Fuente: trabajos de tesis 
En los resultados obtenidos, así como en los comentarios realizados por los alumnos, se infiere que los estudiantes pueden tener la sensación de que no son informados adecuadamente sobre el tema (Anexo 1 y 2). Lo anterior coincide con Núñez — citado por Soto (2012: 9)—, quien indica que las razones principales que llevan al estudiante a incurrir en el plagio son, principalmente, que considera la asignación como una pérdida de tiempo; que no cuenta con suficiente tiempo para realizar el trabajo; que el profesor no toma acción ante casos de plagio; que por presión de sus compañeros de grupo que también lo hacen, no sabe citar.

Precisamente, Soto concluye en la importancia que tiene el profesor para educar debidamente sobre el tema ya que, cuando se realizan las observaciones pertinentes en los trabajos, se puede apoyar para que el alumno corrija desde un inicio estas prácticas.

\section{CONCLUSIONES}

La importancia y preocupación de las prácticas deshonestas en la elaboración de trabajos académicos que se realiza a través de los diferentes tipos y modalidades del plagio, se refleja en la amplia literatura internacional que refiere al tema.

En el análisis documental que se realizó en la elaboración del presente documento, queda constatada la necesidad de atender el tema, ante las facilidades que brindan las tecnologías de la información, representadas principalmente en Internet para cometer este tipo de delito.

Si bien es cierto que se constata importancia de revisar, actualizar y elaborar una normativa nacional o institucional que regule las sanciones que corresponden a esta práctica - como ya lo han hecho varias instancias universitarias-, 
La Infodiversidad y el uso ético del conocimiento...

es evidente que la prevención es la mejor forma de combatir este problema.

Las experiencias que se exponen en la literatura de actividades que van desde la sensibilización hasta la formación en diferentes comunidades, con base en la colaboración entre el docente y el bibliotecario, el apoyo de la biblioteca y las competencias que se establecen por el alfabetización informativa, principalmente la normas que refieren al uso ético y legal de la información.

En el caso de la Universidad Autónoma de San Luis Potosí, como en otras universidades del país, si bien se realizan actividades aisladas, es deseable iniciar la colaboración entre los profesores y los bibliotecarios para brindar la asesoría necesaria a los alumnos. Los resultados que muestran las tesis realizadas sobre el tema que se refiere a la alfabetización informativa en esta comunidad permiten observar un interés por el alumnado para la redacción apropiada de sus trabajos académicos.

La colaboración entre las facultades y el sistema de bibliotecas beneficiaría a toda la comunidad, ya que, por una parte, se atendería una problemática real, y por otra, los servicios que al respecto se ofrecen en los distintos centros de información serían conocidos y utilizados en mayor medida, fortaleciendo con ello la imagen y pertinencia de las bibliotecas y la profesión bibliotecaria.

Por último, la difusión de las buenas prácticas académicas en este tema nos lleva a reforzar la idea de que en los procesos de aprendizaje e investigación académica, el proceso es tan o más importante que los resultados, ya que permiten generar oportunidades para crear, innovar $\mathrm{y}$, sobre todo, pensar. 
Alfabetización informativa como apoyo para evitar el plagio...

\section{BIBLIOGRAFÍA}

Alfaro Torres, Paloma y de Juan Juárez, Teresa (2014). El plagio académico: formar en competencias y buenas prácticas universitarias. RUIDERA: Revista de Unidades de Información, (6), 1-20.

Bravo Castillo, Adelita (2017). Propuesta para el desarrollo de un programa de alfabetización informacional en la Coordinación Académica Región Huasteca Sur. San Luis Potosí: UASLP / Tesis para obtener el título de Licenciado en Bibliotecología de la Escuela de Ciencias de la Información.

Bonilla Gómez, Cesar Alejandro y Velázquez Torres, Jesús Martin (2014). Competencias de Alfabetización Informacional en usuarios de nivel licenciatura del Centro de Información en Ciencias Sociales y Administrativas. San Luis Potosí: UASLP / Tesis para obtener el título de Licenciado en Bibliotecología de la Escuela de Ciencias de la Información.

Comas Forgas, Rubén; Sureda Negrete, Jaume y Oliver Trobat, Miquel (2011). Prácticas de citación y plagio académico en la elaboración textual del alumnado universitario. Teoría de la Educación: Educación y Cultura en la Sociedad de la Información, 12(1), 359-385 [en línea], http://campus.usal.es/ reseñas_trabajo/index.php/revistatesi/article/view/7837/786

CONACYT (2015). CONACYT no tolera faltas éticas que ponen en duda la integridad del Sistema Nacional de Investigadores [en línea], http://conacyt.gob.mx/index.php/comunicacion/comunicados-prensa/492-conacyt-no-tolera-faltas-eticas-que-ponen-enduda-la-integridad-del-sistema-nacional-de-investigadores

Código de Ética de la Universidad Autónoma de San Luis Potosí [en línea], http://www.uaslp.mx/Documents/Universidad/Codigo\%20de\%20Etica.pdf 
La Infodiversidad y el uso ético del conocimiento...

Domínguez Aroca, María I. (2012). Lucha contra el plagio desde las bibliotecas universitarias. El profesional de la información, 21(5), sep.-oct., 498-503 [en línea], http://dx.doi.org/10.3145/ epi.20012.sep.08

Ferrer Torres, Carolina Sofía (2012). Integración de la Alfabetización Informacional en la educación superior. Propuesta para el diagnóstico de competencias informacionales. San Luis Potosí: UASLP / Tesis para obtener el título de Licenciado en Bibliotecología e Información de la Escuela de Ciencias de la Información.

García Pérez, Jesús Francisco (2013). Derechos de autor en Internet. México: unAm / Coordinación de Estudios de Posgrado.

George, Sarah; Costigan, Anne, y O'hara, Maria (2013). Placing the Library at the Heart of Plagiarism Prevention: The University of Bradford Experience. New Review of Academic Librarianship, 19(2), 141-160 [en línea], http://dx.doi.org/10.1080/1361 4533.2013 .800756

Germek, George (2012). The Lack of Assessment in the Academic Library Plagiarism Prevention Tutorial. College \& Undergraduate Libraries, 19(1), 1-17 [en línea], http://dx.doi.org/10.10 $80 / 10691316.2012 .652547$

Gunnarsson, Jenny; Kulesza, Wlodek, y Pettersson, Anette (2014). Teaching International students how to Avoid Plagiarism: Librarians and Faculty in Collaborations. The Journal of Academic Librarianship, 40, 413-417 [en línea], http://dx.doi. org/10.1016/j.acalib.2014.04.006

Guzmán Cortés, Beatriz de Lourdes (2014). Alfabetización informativa en alumnos de la Universidad Autónoma de San Luis Potosí. Escuela de Ciencias de la Información. San Luis Potosí: UASLP / Tesis para obtener el título de Licenciado en Bibliotecología de la Escuela de Ciencias de la Información. 
Jaramillo Valbuena, Sonia y Rincón Belalcázar, Néstor F. (2014). Los estudiantes universitarios y la sociedad de la información: una combinación que ha facilitado el plagio académico en las aulas colombianas. Información, cultura y sociedad, (30), 127-137.

Lampert, Lynn D. (2014). Integrating discipline-based anti-plagiarism instruction into the information literacy curriculum. Reference Service Review, 34(4), 347-355 [en línea], http://dx.doi. org/10.1108/00907320410569699

Legislación documental. Asignatura de curso de la Licenciatura en Ciencias de la Información (s/f.). Universidad Autónoma de Chihuahua / Facultad de Filosofía y Letras.

Loudovico, Carrie y Wittig, Carol (2015). A Universe of Information, One citation at a time: How Students Engager with scholarly sources. Journal of Library and Information Services in Distance Learning, 9(1-2), 30-39. [en línea], http://dx.doi.org/10. 1080/1533290X.2014.946343

Hernández Martínez, José Luis (2016). Necesidades y búsqueda de información de los estudiantes de la licenciatura en bibliotecología modalidad presencial y a distancia en México. México: UNAM / Tesis para obtener el grado de Maestro en Bibliotecología y Estudios de la Información.

Reglamento General de Estudios de Posgrado. Facultad de Ciencias Sociales y Humanidades [en línea], http://sociales.uaslp.mx/ Paginas/Posgrado/Doctorado/ReqPerD.aspx

Singh, Parmjit y Thambusamy, Roslind (2016). "To Cheat or not To Cheat, That is the Question": Undergraduates' Moral Reasoning and Academic Dishonesty. En Chan Yuen Fook; Gurnam Kaur Sidhu et al. (Eds.) (pp. 471-752). 7th International Conference on University Learning and Teaching. (InCulT 2014). Proceedings. Springer, Singapore [en línea], DOI 10.1007/978981-287-664-5_58

Sistema de Bibliotecas de la Universidad Autónoma de San Luis Potosí [en línea], http://bibliotecas.uaslp.mx/ 
La Infodiversidad y el uso ético del conocimiento...

Soto Rodríguez, Armando (2012). El plagio y su impacto a nivel académico y profesional. E-Ciencias de la Información, 2(1), ene.-jun., 1-13 [en línea], http://revistaebci.ucr.ac.cr/

\section{ANEXO 1}

Resultados obtenidos en los apartados que refieren a la organización y uso de la información

\begin{tabular}{|c|c|c|c|}
\hline \multirow{2}{*}{ Preguntas } & \multicolumn{3}{|c|}{ Porcentaje de respuestas correctas } \\
\hline & TESIS 4 & TESIS 3 & TESIS 2 \\
\hline Los manuales de estilo de bibliográfico deben ser utilizados para: & $47 \%$ & $50 \%$ & $51 \%$ \\
\hline $\begin{array}{l}\text { Cuando recopilas fuentes para un ensayo o algún trabajo académico } \\
\text { debes: }\end{array}$ & $49 \%$ & $57 \%$ & $49 \%$ \\
\hline $\begin{array}{l}\text { La lista de todas las fuentes que has citado y consultado en un documento } \\
\text { académico es conocida como: }\end{array}$ & $91 \%$ & $86 \%$ & $84 \%$ \\
\hline $\begin{array}{l}\text { Se realiza una lista de todas las fuentes que se han consultado al final de } \\
\text { un trabajo para: }\end{array}$ & $46 \%$ & $43 \%$ & $51 \%$ \\
\hline Citar es: & $32 \%$ & $41 \%$ & $30 \%$ \\
\hline Parafrasear es: & $47 \%$ & $65 \%$ & $61 \%$ \\
\hline $\begin{array}{l}\text { Señale cuál de las siguientes opciones refleja mejor el motivo por el que } \\
\text { es necesario citar las fuentes utilizadas en nuestros trabajos académicos. }\end{array}$ & $54 \%$ & $61 \%$ & $71 \%$ \\
\hline No necesitas dar crédito de una fuente si es: & $63 \%$ & $71 \%$ & $51 \%$ \\
\hline El plagio es: & $93 \%$ & $98 \%$ & $93 \%$ \\
\hline Para evitar ser acusado de plagio, debo: & $28 \%$ & $42 \%$ & $72 \%$ \\
\hline $\begin{array}{l}\text { Si reproduces el trabajo de otra persona sin su permiso, ¿qué concepto } \\
\text { estarías trasgrediendo? }\end{array}$ & $23 \%$ & $90 \%$ & $75 \%$ \\
\hline En general es considerado aceptado que fotocopies: & $58 \%$ & $26 \%$ & $36 \%$ \\
\hline $\begin{array}{l}\text { Puedes fotocopiar una página de un libro para utilizarla en la redacción de } \\
\text { un ensayo porque: }\end{array}$ & $65 \%$ & $81 \%$ & $68 \%$ \\
\hline Parafrasear es: & $47 \%$ & $57 \%$ & $61 \%$ \\
\hline
\end{tabular}

En la tesis 1, se realizaron las siguientes preguntas, y se obtuvieron los siguientes resultados generales. 
1. En los trabajos académicos ¿utilizas algún estilo de referencia bibliográfica? 79\%, contestó que sí.

2. ¿Cuáles son elementos principales de una referencia bibliográfica? $82 \%$ contestó de forma correcta.

3. ¿Qué norma usa para la redacción de citas y referencias bibliográficas? 62\% los alumnos utilizan APA; un 2\%, Chicago; un 2\%, ISO-690 e ISO-690-2, y 1\% elige Vancouver y MLA, mientras que un 32\% no utiliza ninguna de las anteriores.

4. En un documento la "cita bibliográfica" se describe como: con un 55\% los alumnos eligen información incluida en un texto acerca de una fuente que utilizaste, el 20\% eligió "todas las anteriores", el 19\% respondió a la respuesta correcta "información acerca de una fuente que es incluida al final de una página", un $6 \%$ eligió "un fragmento de un trabajo que has leído.

5. Seleccione un tema de los que se describen a continuación que es de su interés para recibir formación o capacitación. R. un 13\% le gustaría saber usar bibliografía, citas bibliográficas y gestores bibliográfi$\cos$

\section{ANEXO 2}

Compilación de comentarios textuales expresados en todas las tesis y que refieren al tema de organización y uso ético de la información

El copyright es una de las maneras de robarte el trabajo de alguien más.

No al plagio. 


\section{La Infodiversidad y el uso ético del conocimiento...}

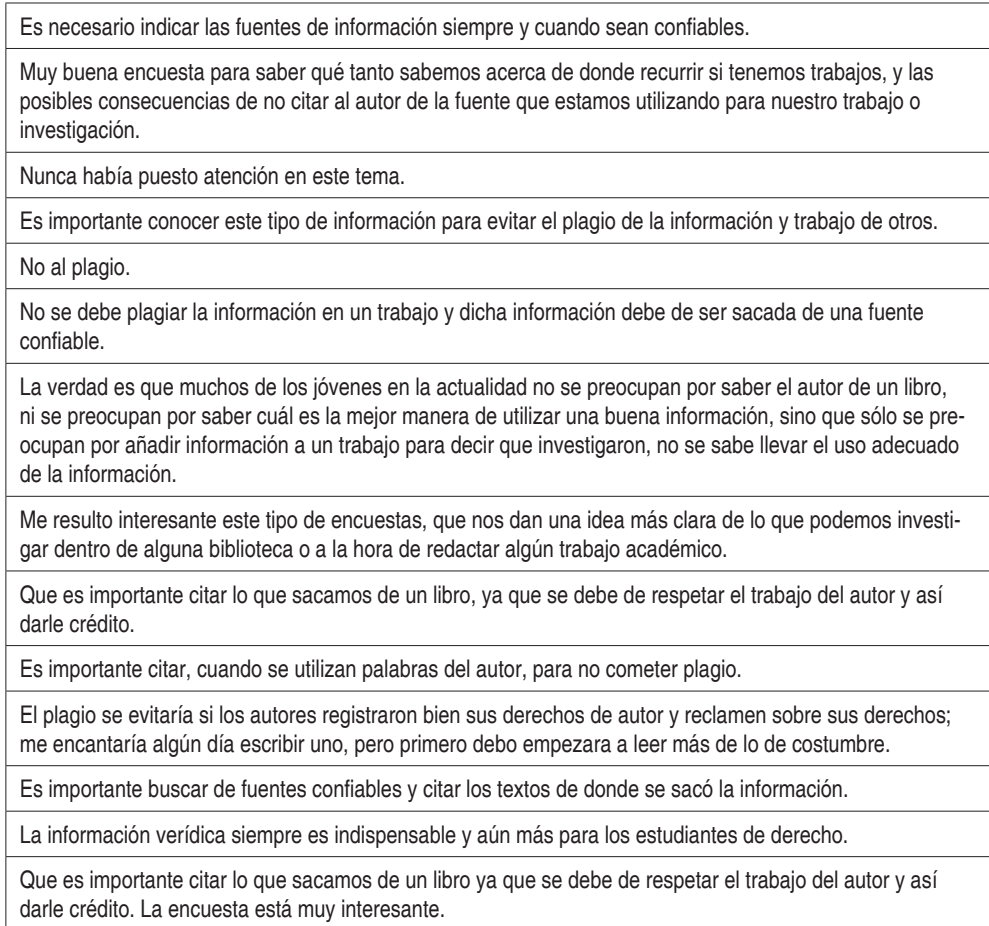




\title{
Estrategias y herramientas tecnológicas para evitar el plagio académico
}

\author{
ANDRÉS FERNÁNDEZ RAMOS
}

Universidad de León, España

INTRODUCCIÓN

$\mathrm{E}$

el ámbito académico se puede considerar plagio a la copia o la inclusión de ideas o fragmentos de otras obras en un trabajo propio sin incluir los créditos correspondientes a la fuente original. Desde un punto de vista ético, se trata de una mala práctica, en la medida en que el autor del plagio pretende cometer un engaño, hacer pasar algo por lo que no es, y supone un menoscabo de los valores que deben imperar en las instituciones dedicadas a la enseñanza y a la investigación, como son la honestidad, integridad, esfuerzo y respeto al trabajo ajeno. Además, tiene repercusiones negativas importantes, puesto que supone un descrédito del autor, de la institución, de la formación que se recibe en la escuela y en la universidad, e incluso de la carrera académica.

Desde un punto de vista legal, se trata de un fraude que puede ser sancionado por parte de las distintas administra- 
La Infodiversidad y el uso ético del conocimiento...

ciones e instituciones a las que se ha defraudado, puesto que se presenta por original una obra que no lo es. Asimismo, puede suponer una violación de los derechos morales del autor de la obra original, que tiene derecho a que su autoría sea reconocida, e incluso patrimoniales, en el caso de obtener algún beneficio económico con el plagio. Según Cavanillas (2008), el plagio afecta a dos grupos de intereses: los intereses del destinatario de la obra, a quien se pretende engañar haciéndola pasar como propia, y los intereses del autor de la obra original y, en su caso, los del titular de los derechos de explotación de la obra, como puede ser el editor.

Aunque el plagio está documentado desde hace mucho tiempo, en los últimos años, sobre todo a partir de la aparición de internet, está acaparando una especial atención por parte de la comunidad académica y de la sociedad en general. Esto es debido no solo al creciente número de casos que salen a la luz en los medios de comunicación, sino también a las investigaciones científicas que se han llevado a cabo para determinar la magnitud del problema y que afectan tanto a profesores e investigadores como a alumnos.

Algunos ejemplos de estos estudios referidos al plagio entre estudiantes serían los siguientes: los resultados que obtuvo McCabe (2005) en una encuesta a más de 70000 alumnos de universidades de Estados Unidos y Canadá mostraron que el $36 \%$ de los encuestados había copiado fragmentos de internet sin citar la fuente y un 38\% había hecho lo mismo con fuentes impresas; Comas-Forgás y otros (2011) encontraron, a partir de una encuesta a 560 alumnos de universidades españolas, que más del 60\% de dichos alumnos habían copiado de internet en sus trabajos académicos sin citar la fuente y un $48 \%$ de fuentes impresas; mientras, Sureda, Comas-Forgás y Oliver (2015) observaron unas tasas de plagio de internet del $81 \%$ y de fuentes impre- 
Estrategias y herramientas tecnológicas para evitar el plagio...

sas del $72.5 \%$ en una encuesta a 2794 estudiantes españoles de secundaria y bachillerato.

En cuanto a investigadores y profesores, Fang, Steen y Casadevall (2012) constataron que más de 200 artículos indizados en Pubmed hasta 2012 fueron retirados por plagio; Honing y Bedi (2012) identificaron una tasa de plagio del $13 \%$ en los trabajos presentados a la Conferencia de la Management Academy en 2009 contenían plagios significativos; y Baždaric y otros (2012) localizaron un 11\% de artículos con plagios significativos entre los enviados a la revista Croatian Medical Journal entre 2009 y 2010.

\section{CAUSAS Y MOTIVACIONES}

Uno de los motivos que más recurrentemente se han esgrimido para explicar la proliferación del plagio, principalmente entre los estudiantes, es la aparición de internet, un espacio virtual en el que hay millones de documentos a los que se accede muy fácilmente y que resultan aún más fáciles de copiar (Ma, Wan y Lu, 2008). En realidad, internet, más que una causa, es un factor que favorece el plagio, puesto que lo hace mucho más sencillo, pero las raíces del plagio son más profundas y deben ser analizadas cuidadosamente para poder abordar el problema de una forma rigurosa. Como señalan Macdonald y Carroll (2006), para resolver el problema del plagio es necesario ir más allá de los síntomas y llegar a conocer sus causas fundamentales.

Las razones que llevan al plagio a estudiantes y a profesores e investigadores son distintas, puesto que unos y otros desarrollan sus trabajos académicos en contextos diferentes, con distinta finalidad y con conocimientos sobre integridad académica muy dispares. 
La Infodiversidad y el uso ético del conocimiento...

La literatura sobre los motivos del plagio entre estudiantes es abundante; en su mayoría se trata de estudios basados en encuestas y entrevistas con los principales actores implicados, reflejo de una preocupación cada vez mayor por conocer las motivaciones para el plagio y encontrar soluciones. Los principales motivos encontrados en los numerosos estudios sobre el tema (Comas-Forgas y Sureda-Negre, 2010, 2016; Devlin y Gray, 2007; Eret y Gokmenoglu, 2010; Eret y Ok, 2014; Park, 2003; Sureda-Negre, Comas-Forgás y Morey, 2009) se pueden agrupar en cuatro grandes temas:

- Carencias formativas en materia de plagio. En muchas ocasiones los estudiantes no tienen claro qué es exactamente el plagio, puesto que no han recibido formación al respecto ni por parte de los profesores ni de la biblioteca. El desconocimiento de las pautas para citar otros trabajos, en especial de los que proceden de internet, ha sido señalado un varios estudios tanto por parte de los estudiantes como de sus profesores. Asumir que los estudiantes cuentan con ese tipo de conocimientos puede ser un grave error, que en ocasiones se da por la creencia de que ya han recibido ese tipo de formación en otras asignaturas, cursos, etcétera. Además, el uso masivo de internet ha dado lugar a que muchos piensen que lo que está en internet es conocimiento de uso común y que está disponible para ser reproducido por quien quiera (Walker, 2010).

- Sensación de impunidad. En muchos casos los estudiantes no creen que el plagio vaya a ser detectado, bien por la dificultad que conlleva encontrarlo o bien por la sensación de que el profesor no va a esforzarse en averiguarlo. Además, al no tener conciencia de la gravedad de la falta, puesto que en muchas ocasiones no han re- 
cibido formación al respecto, y al no existir una política clara por parte de los centros educativos sobre lo que es el plagio y sus posibles consecuencias, minimizan el riesgo de posibles repercusiones negativas.

- Deterioro de valores académicos. Aunque este motivo no ha sido señalado por los estudiantes cuando se les ha encuestado, los profesores y otras autoridades académicas no dudan en señalar que la cultura del mínimo esfuerzo derivada de una crisis del sistema de valores ha repercutido notablemente en el aumento del plagio. La búsqueda de una solución fácil y sencilla a las tareas, independientemente de la validez de las fuentes y la falta de respeto al trabajo ajeno, es algo cada vez más común en todos los niveles educativos (Sureda-Negre y otros, 2015). Además, se han señalado otras causas directas relacionadas con ésta, como una mala gestión del tiempo, la procrastinación y la observación de que es un comportamiento habitual entre los compañeros.

- Volumen y naturaleza de las tareas académicas. El cambio de modelo educativo, que ha pasado de estar basado en el aprendizaje memorístico a otro basado en competencias a desarrollar en diferentes actividades, ha dado lugar al incremento de las tareas a realizar por parte de los estudiantes. Muchos de ellos se sienten desbordados por el volumen de trabajo a realizar y recurren al plagio para aliviar esa carga de trabajo, puesto que en muchas ocasiones las tareas que tienen que realizar se prestan a este tipo de comportamientos. Como muestran GómezEspinosa, Francisco y Moreno-Ger (2016), también la naturaleza de las actividades a realizar, poco creativas y participativas en muchas ocasiones, influyen en la propensión al plagio. 
La Infodiversidad y el uso ético del conocimiento...

En el caso de las motivaciones de los investigadores y profesores para recurrir al plagio, la literatura es mucho menor y se basa principalmente en las reacciones de algunos de ellos cuando se les ha detectado y sancionado. Aunque son muchos menos casos, también es igual o más preocupante, ya que su comportamiento tiene menos justificación, puesto que se asume que ellos sí saben lo que es el plagio y son conscientes de lo que hacen. Las razones esgrimidas por este colectivo para explicar el plagio es la constante presión por publicar, descuidos al elaborar la bibliografía o la ambigüedad de lo que se considera plagio, que en ocasiones no tienen muy claro (Enders y Hoover, 2006). Por otra parte, algunas modalidades de plagio, como el que se produce al copiar ideas redactadas en otros idiomas, dificultan notablemente su detección, lo que puede dar lugar también a cierta sensación de impunidad.

\section{ESTRATEgIAS PARA EVITAR EL PLAGIO}

Para combatir el plagio académico existen diferentes estrategias, orientadas cada una de ellas a combatir el problema poniendo el foco de atención en algunas las diversas causas y motivaciones que hay detrás de esta mala práctica. Estas estrategias son compatibles y complementarias y, de hecho, se considera necesario que se actúe en todos los frentes posibles para que la estrategia sea global y efectiva y dé los frutos esperados. Las principales estrategias que deben utilizarse serían las siguientes: 
Estrategias y herramientas tecnológicas para evitar el plagio...

\section{Formación en ética académica}

La falta de formación en competencias informativas en general, y sobre todo aquellas relacionadas con la ética en el uso de la información, es uno de los motivos más recurrentes que aducen los alumnos en relación a esta práctica. Es por ello que la formación ha sido señalada como una de las acciones más recomendables para acabar, o al menos disminuir, la incidencia del plagio en los trabajos académicos de los alumnos. En este sentido, se han publicado numerosos estudios en los que se aprecia la disminución de esta práctica a partir de cursos formativos sobre estas materias (Belter y Pré, 2009; Dee y Jacob, 2012; Divan, Bowman y Seabourne, 2015; Owens y White, 2013), teniendo la biblioteca un papel fundamental que jugar en dicho tipo de formación (Domínguez-Aroca, 2012; Gibson y Chester-Fangman, 2011).

Para que esta formación sea efectiva deben implicarse profesores y bibliotecarios, y es aconsejable que cada centro educativo establezca un programa de formación para evitar duplicidades o que al final no se imparta porque todos los actores implicados asuman que la formación en esas competencias las impartirá otra persona. Además, hay que tener en cuenta que el plagio académico no solo atañe a estudiantes universitarios, sino que se da en la enseñanza previa y luego se arrastra hasta la educación superior, por lo que debería empezar a impartir formación al respecto en etapas formativas anteriores, como la educación secundaria y el bachillerato (Sureda-Negre y otros, 2015).

\section{Regulación y sanción}

Otro factor que ha sido señalado en la literatura como influyente en el plagio es la carencia en muchas instituciones 
La Infodiversidad y el uso ético del conocimiento...

educativas y científicas de una regulación clara al respecto, así como su desconocimiento por parte de profesores, científicos y alumnos (Gullifer y Tyson, 2014). Es necesario que en las instituciones de enseñanza haya una normativa específica en la que se recoja lo que se entiende por plagio, las sanciones correspondientes en caso de ser detectado y a quien corresponde denunciarlo o sancionarlo (Cavanillas, 2008). En las instituciones donde sí hay políticas claras para los alumnos que cometen plagio, las sanciones van desde reprobar al alumno que haya cometido la falta hasta la expulsión en los casos más extremos.

Además de que exista una reglamentación que recoja y sanciones el plagio académico, es necesario que ésta sea difundida y conocida por la comunidad, creando así un efecto disuasorio que reduciría la sensación de impunidad sobre este tipo de acciones (Levy y Rakovski, 2006). El uso de códigos de honor en los que los estudiantes se comprometen a actuar de acuerdo a una serie de principios y pautas de conducta ética también se ha visto efectivo en la reducción del plagio (Arnold, Martin, Jinks y Bigby, 2007; McCabe, Treviño, y Butterfield, 2002).

En el caso de los trabajos científicos, corresponde a los editores incluir en sus publicaciones información sobre las normas éticas de publicación, pero hay muchas revistas que no muestran una reglamentación clara sobre lo que se considera fraude científico (Bosch, Hernández, Pericas, Doti y Marušic, 2012; Enders y Hoover, 2004). Es por ello que existe una gran variedad de actuaciones cuando se detecta un caso de esta naturaleza. En algunos casos, la sanción es únicamente el rechazo el artículo; en otros, la prohibición de publicar en esa revista, la publicidad del fraude cometido, o la notificación a la institución a la que pertenece el autor del plagio, que puede y debe sancionar estos com- 
Estrategias y herramientas tecnológicas para evitar el plagio...

portamientos mediante sanciones administrativas, multas o la suspensión de empleo. Sería aconsejable en este sentido un mayor esfuerzo por armonizar los criterios y pautas de actuación ante casos de fraude científico entre las diversas editoriales y el desarrollo de un código ético a nivel internacional (Hernández-Ruiz, 2016).

\section{Uso de software específico para su detección}

Otra de las causas atribuidas al plagio es la sensación de impunidad; la creencia de que el plagio no va a ser advertido, debido a la complejidad que tiene detectarlo. Aunque internet permita la copia de documentos de manera muy sencilla, también facilita la labor de rastreo y reconocimiento de textos plagiados, en especial desde la aparición de diversos softwares diseñados para tal fin.

A pesar de la efectividad de dichas herramientas, hay estudios que indican que aún son pocos los profesores que lo utilizan. Por ejemplo, en una encuesta a 560 profesores de secundaria publicada en 2014 se mostraba que menos del 9\% utilizaban alguna herramienta tecnológica para detectar plagio en institutos de secundaria en una región española y en esos casos, salvo 4 profesores, la herramienta era Google (Comas-Forgas, Urbina-Ramírez y Gallardo, 2014). Es por ello necesaria una mayor implicación por parte de las instituciones académicas y de los profesores en el uso de este tipo de software.

Además de utilizar herramientas tecnológicas de detección del plagio, es conveniente publicitar su uso, de forma que sirva también de medida disuasoria, tal y como se pone de manifiesto en algunos estudios que apuntan a una disminución del plagio, tanto a nivel de trabajos de clase como de envíos a revistas científicas, desde que se difundió el uso 
La Infodiversidad y el uso ético del conocimiento...

de este tipo de software (Baker, Thornton y Adams, 2011; Batane, 2010; Ledwith y Rísquez, 2008; Stapleton, 2012).

En el caso de las revistas científicas cada vez es más frecuente su uso y que avisen a los autores de que cuentan con programas para detectarlo. Así, cada vez son más las editoriales que ya lo incluyen en sus revistas, como BMJ, Edorium, Nature o Elsevier (Butler, 2010).

\section{HERRAMIENTAS PARA LA DETECCIÓN DEL PLAGIO}

La detección del plagio es una tarea compleja que puede llevar bastante tiempo, incluso si se utiliza software específico para hacerlo, por lo que en algunos casos puede que sea necesario ser selectivos y centrarse en algunos documentos que pueden levantar nuestras sospechas. Algunos indicios que pueden indicar que ha habido plagio son las incongruencias gramaticales en el texto (una traducción automática mal hecha), incongruencias semánticas, diferencias de estilos a lo largo del texto (vocabulario, puntuación, sintaxis) y las citas o referencias que no tienen correspondencia. En estos casos podemos tener ciertas sospechas, o incluso cierta seguridad, de que se ha cometido plagio; sin embargo, no es suficiente para poder demostrarlo, y es necesario demostrarlo identificando las fuentes que han sido plagiadas.

En el mundo analógico la detección del plagio resulta bastante complicada. Si la fuente que ha sido plagiada no se encuentra en formato digital o no ha sido publicada (por ejemplo, un trabajo de clase de un alumno elaborado hace algunos años y entregada en formato impreso), la única forma de detectarlo es que el lector conozca el texto plagiado o lleve a cabo una investigación exhaustiva en bibliotecas y 
Estrategias y herramientas tecnológicas para evitar el plagio...

archivos. Un factor determinante a la hora de detectar este tipo de plagio es el grado de difusión de la obra, ya que, en principio, cuanta más gente tenga acceso a ella, más probabilidades habrá de que alguien la reconozca. Otro factor es lo conocida que sea la obra plagiada por parte del público al que va dirigida. Es por estos motivos que resulta más fácil detectarlo en las publicaciones científicas, puesto que los posibles lectores están familiarizados con esa literatura o incluso puede que el autor de la obra original sea uno de los lectores. En el caso de los trabajos que presentan los alumnos o en las tesis es un poco más difícil, ya que su difusión es menor y solo unas pocas personas van a leer el texto. En todo caso, se supone que la tendencia a este tipo de plagio cada vez es menor por el grado de dificultad y esfuerzo que requiere: ir a la biblioteca, consultar catálogos, copiar el texto manualmente, etcétera, mientras que copiar de fuentes digitales es mucho más rápido y sencillo.

En el entorno digital el plagio es mucho más fácil, sobre todo si el documento está accesible libremente en internet, pero también es mucho más fácil de detectar, puesto que existen numerosas herramientas tecnológicas que pueden ayudarnos a identificarlos. Estas herramientas, que pueden ser más o menos sofisticadas, están adquiriendo cada vez más popularidad y empiezan a ser cada vez más utilizadas por parte de centros educativos y editoriales.

Sus principales ventajas, además del efecto disuasorio que se ha comentado anteriormente, son la cantidad de tiempo que ahorran, en la mayoría de los casos su facilidad de uso $\mathrm{y}$, dependiendo de la herramienta concreta que usemos, su efectividad. Sin embargo, es necesario señalar que no son infalibles, puesto que también tienen un margen de error amplio y pueden proporcionar casos de falsos negativos y falsos positivos. En todo caso es necesario el veredicto del 
La Infodiversidad y el uso ético del conocimiento...

ser humano para determinar si realmente ha habido plagio o no, ya que estos programas detectan similitudes entre documentos, pero no distinguen entre una cita y un plagio (Patil, 2015). Por otra parte, no son igual de efectivos en todos los casos de plagio; funcionan especialmente bien cuando el plagio es literal, pero no tanto cuando se trata de una paráfrasis o de la traducción de un texto en otro idioma.

\section{Tipología}

En los últimos años han proliferado los productos de software diseñados para ayudar a detectar el plagio, existiendo en la actualidad una gran variedad de ellos con características y prestaciones diferentes. Tal y como se muestra en la Tabla 1, se pueden establecer diferentes clasificaciones de estos programas en función de varios criterios.

Tabla 1.

Tipología de las herramientas de software para detectar plagio

\begin{tabular}{|l|l|l|}
\hline \multicolumn{1}{|c|}{ Criterio } & \multicolumn{2}{c|}{ Modalidades } \\
\hline Coste & Gratuitos & De pago \\
\hline Presentación del producto & Servicio web & Software de escritorio \\
\hline Técnica & $\begin{array}{l}\text { Equiparación de cadenas de caracte- } \\
\text { res (rastreadores) }\end{array}$ & Equiparación + técnicas estadísticas \\
\hline Base de conocimiento & Motor de búsqueda & $\begin{array}{l}\text { Múltiples fuentes (internet, base de } \\
\text { conocimientos propia) }\end{array}$ \\
\hline
\end{tabular}

Fuente: elaboración propia.

El primer criterio que se puede mencionar es el coste del programa. Una gran mayoría de programas son de pago, que suelen ofrecer tarifas institucionales o personales y que pueden cobrar en función del número de textos o palabras a analizar o en función del tiempo de suscripción. Aunque también existen opciones gratuitas, éstas suelen ofrecer 
Estrategias y herramientas tecnológicas para evitar el plagio...

menos prestaciones. También hay software con versión de pago y versión gratuita con menos funcionalidades o por un periodo determinado.

Con respecto a la presentación del producto, existen dos modalidades. La primera es mediante una aplicación que se instala en la propia computadora del cliente, y la otra es a través de una aplicación web a la que se accede mediante una contraseña o mediante el reconocimiento de la IP del equipo.

La técnica utilizada o el conjunto de algoritmos empleados para identificar documentos similares es uno de los criterios más destacados para clasificar este tipo de software. Los softwares más sencillos, denominados rastreadores, únicamente identifican cadenas de caracteres similares, mientras, los más sofisticados utilizan técnicas estadísticas y lingüísticas que permiten detectar ciertas variaciones en el texto. Los primeros son efectivos cuando se trata de detectar plagio por "copia directa”, que es la copia literal de fragmentos de otros textos. Los segundos también sirven para identificar otros casos de plagio más complejos, como la "re-escritura" o la "paráfrasis", que consisten en tomar una idea de otro texto y reformularla con otras palabras.

En cuanto a la base de conocimiento, otro de los criterios más importantes y que marcan la diferencia entre unos productos y otros desde el punto de vista de la efectividad, existen dos grandes grupos de software, los que funcionan como rastreadores en la parte visible de la web y aquellos que además cuentan con una base de datos de recursos propios extraídos de la web profunda y de las aportaciones de los usuarios. A mayor y más apropiada selección de documentos de la base de conocimiento, mayor será la posibilidad de encontrar el documento fuente del plagio. 
La Infodiversidad y el uso ético del conocimiento...

\section{Componentes y funcionamiento}

Aunque existen matices relacionados con las características del tipo de software que hemos visto en el epígrafe anterior, en general cualquier producto creado para ayudarnos a encontrar plagios se basa en tres elementos o componentes fundamentales: una amplia base de conocimiento compuesta por un elevado número de documentos provenientes de la internet visible o de la invisible, un programa que utiliza diferentes algoritmos para comparar el documento a examinar con los documentos almacenados en la base de conocimiento, y una aplicación para mostrar los resultados de la equiparación. Al margen de estos componentes principales, existe una amplia gama de funcionalidades y de servicios de valor añadido que varían en función de cada producto.

El funcionamiento de estos programas consiste en varias etapas consecutivas. La primera es la carga de un texto que se quiere analizar en el programa o la inclusión de un fragmento en una caja de búsqueda; posteriormente se inicia la equiparación del texto o fragmento con los documentos almacenados en la base de conocimiento; y finalmente el programa ofrece unos resultados, de forma inmediata o diferida, en los que se muestran las similitudes. En función de las características del producto se podrá parametrizar o no la forma en que se realizarán las equiparaciones, por ejemplo indicando a partir de cuántas palabras iguales se debe mostrar un documento en los resultados, y se podrá obtener un informe más o menos detallado de las fuentes plagiadas, del porcentaje de similitud, etcétera. En el Gráfico 1 se puede observar de forma sencilla el funcionamiento general de este tipo de programas. 
Estrategias y herramientas tecnológicas para evitar el plagio...

Gráfico 1.

Funcionamiento general de los softwares de detección de plagio

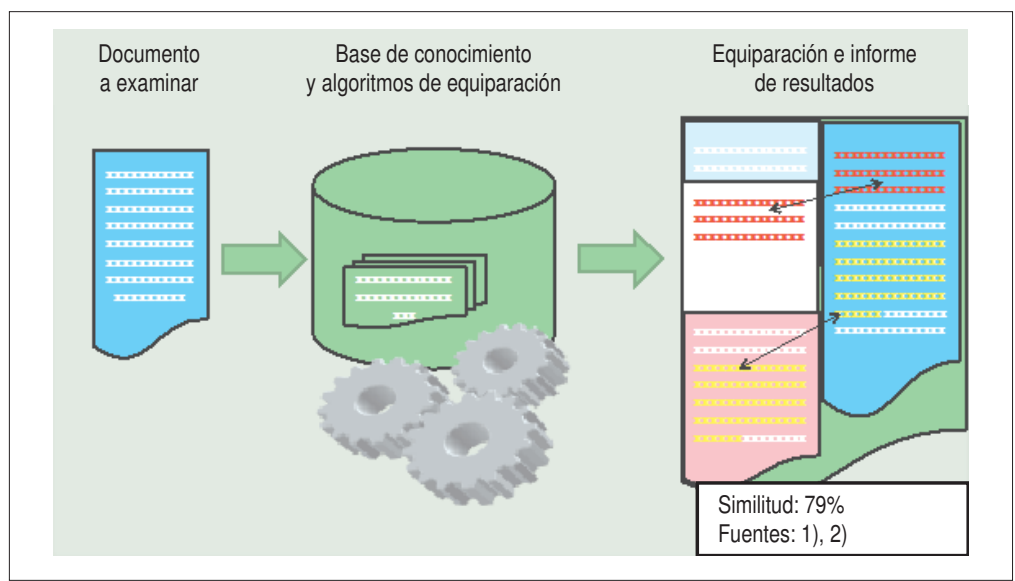

Fuente: elaboración propia.

\section{Algunos ejemplos de software de detección del plagio}

A continuación se describen sucintamente algunos de los softwares más empleados en la detección del plagio:

- Google y Google académico (http://www.google.com y https://scholar.google.es). No son herramientas diseñadas para detectar el plagio sino grandes buscadores, pero se utilizan de forma habitual para localizar fragmentos de texto en otras fuentes. Para ello basta con entrecomillar el "fragmento sospechoso" en la caja de búsqueda y analizar los resultados en busca de textos que contengan esa misma cadena de caracteres.

- Viper (http://www.scanmyessay.com/). Es un programa creado por una empresa de Reino Unido, que se instala en nuestro propio ordenador. Compara un documento subido con otros ubicados en nuestra propia computa- 
La Infodiversidad y el uso ético del conocimiento...

dora y con una base de conocimiento compuesta por 10.000 millones de documentos de internet. Una de sus ventajas es que tiene versión gratuita, aunque limitada, y que permite subir documentos propios. El informe de resultados es bastante completo, aunque cuando encuentra similitudes con un trabajo de otro estudiante solo muestra el porcentaje de similitud, pero no el texto completo del trabajo. Uno de sus mayores inconvenientes es que no detecta paráfrasis. Además de la versión gratuita, cuenta con una versión de pago institucional, que permite a las instituciones subir su propia base de conocimiento (repositorios, trabajos de estudiantes, etcétera).

- Plagscan (http://www.plagscan.com/). Es un servicio web de pago ampliamente utilizado a nivel mundial; según su página web es usado por más de 1000 organizaciones en todos los continentes. Cuenta con una amplia base de conocimiento compuesta por billones de documentos que se actualiza diariamente. Cuenta con potentes algoritmos de equiparación basados en técnicas de computación y estadística. Cuenta con diferentes modelos de suscripción, tanto individuales como para empresas o instituciones académicas.

- Plagaware (http://www.plagaware.com/). Servicio web de pago, que ofrece una versión de prueba gratuita. Cuenta con un sistema de equiparación muy sofisticado, basado en similitudes y no solo en equiparación de cadenas de caracteres, y con una importante base de conocimiento que incluye repositorios y bases de datos además de internet y que se actualiza constantemente. Ofrece diferentes tipos de licencias de uso para instituciones y personas particulares. 
- Turnitin.com (http://turnitin.com/). Es una empresa estadounidense que ofrece una amplia gama de productos para detectar el plagio y guiar a los estudiantes y científicos en el proceso de elaboración de trabajos académicos. Sus productos son utilizados por multitud de instituciones académicas y de editoriales, siendo una de las empresas líderes en el sector. Su software específico para la detección del plagio se llama iThenticate (http://www.ithenticate.com/), que cuenta con una base de conocimiento formada por 49 millones de artículos y 60,000 millones de páginas web. Es un servicio que funciona directamente en la web y cuenta con algoritmos avanzados que van más allá de la equiparación de cadenas de caracteres.

- Compilatio.net (https://www.compilatio.net/es/). Es un software francés que cuenta con dos versiones, una orientada a profesores para detectar el plagio entre los alumnos (Magister) y otra pensada para los alumnos (Studium) que les permite comprobar la originalidad de su trabajo y les ayuda en la elaboración de bibliografías. Cuenta con una base de conocimiento de más de dos millones de páginas web de carácter académico. Tiene una aplicación para moodle y permite que los alumnos carguen los documentos directamente. Funciona muy bien en el caso de copia directa, pero tiene fallas en la detección de paráfrasis. En el informe de resultados ofrece el porcentaje de similitud del documento analizado, todas las fuentes similares, clasificadas por pertinencia, y todos los fragmentos similares con otros documentos. 
La Infodiversidad y el uso ético del conocimiento...

\section{CONCLUSIONES}

El plagio académico es un problema complejo y necesita ser abordado en diferentes niveles: formativo, regulador y supervisor. En el primer nivel es necesario prestar atención a la formación en competencias informativas, haciendo especial hincapié en la educación sobre lo que es plagio, lo que son las citas y las referencias bibliográficas, algo en lo que debe implicarse toda la comunidad académica afectada de forma coordinada. En el segundo nivel, debe haber una normativa clara que recoja lo que se considera plagio, los procedimientos para actuar contra esta mala práctica y las sanciones correspondientes, siendo además necesario que la normativa sea ampliamente difundida y conocida. En el tercer nivel, el de la supervisión y detección del plagio, es necesario que la comunidad académica se implique en su detección y conozca las herramientas que pueden ayudarle a detectarlo. Lo ideal sería que con la formación fuese suficiente, pero lamentablemente también es necesario actuar en los otros dos niveles, tanto por su carácter sancionador de las malas prácticas, como por el efecto disuasorio que tienen.

El plagio es difícil de detectar en algunos casos, como cuando se trata de paráfrasis o de traducciones libres de otros textos, pero muy fácil en otros habiendo voluntad para hacerlo. En gran medida depende de la forma de plagio y de cuáles son las características del texto plagiado. Los programas informáticos para la detección del plagio nos brindan una importante ayuda, tienen un gran potencial y cada vez son más sofisticados, pero debemos tener en cuenta que ninguno es infalible al cien por cien. Además, como ya se mencionó, es necesario que haya políticas institucionales y se motive a los profesores y editores a utilizarlos. Se aconseja en este sentido que sean las instituciones las que 
Estrategias y herramientas tecnológicas para evitar el plagio...

adquieran este tipo de software y no lo dejen al criterio de los profesores. Aunque sea casi imposible detectar todos los casos de plagio, sí que es posible identificarlo en un número muy elevado.

\section{BIBLIOGRAFÍA}

Arnold, R., Martin, B. N., Jinks, M. y Bigby, L. (2007). Is there a relationship between honor codes and academic dishonesty? Journal of College Character, 8(2), 1-20.

Baker, R. K., Thornton, B. y Adams, M. (2011). An evaluation of the effectiveness of Turnitin. com as a tool for reducing plagiarism in graduate student term papers. College Teaching Methods $\mathcal{E}$ Styles Journal (CTMS), 4(9), 1-4.

Batane, T. (2010). Turning to Turnitin to Fight Plagiarism among University Students. Educational Technology \& Society, 13(2), $1-12$.

Baždaric, K., Bilic-Zulle, L., Brumini, G. y Petrovecki, M. (2012). Prevalence of plagiarism in recent submissions to the Croatian Medical Journal. Science and Engineering Ethics, 18(2), 223-239.

Belter, R. y Pré, a Du. (2009). A strategy to reduce plagiarism in an undergraduate course. Teaching of Psychology, 36(4), 257-261.

Bosch, X., Hernández, C., Pericas, J. M., Doti, P. y Marušic, A. (2012). Misconduct Policies in High-Impact Biomedical Journals. PLoS ONE, 7(12), e51928.

Butler, D. (2010). Journals step up plagiarism policing. Nature, 466(July), 167.

Cavanillas, S. (2008). El ciberplagio en la normativa universitaria. Digithum, (10). Disponible en internet en: http://www.uoc. edu/digithum/10/dt/esp/cavanillas.pdf 
La Infodiversidad y el uso ético del conocimiento...

Comas-Forgas, R. y Sureda-Negre, J. (2010). Academic Plagiarism: Explanatory Factors from Students' Perspective. Journal of Academic Ethics, 8(3), 217-232.

Comas-Forgas, R. y Sureda-Negre, J. (2016). Prevalencia y capacidad de reconocimiento del plagio académico entre el alumnado del área de economía. El Profesional de La Información, 25(4), 616-622.

Comas-Forgas, R., Sureda-Negre, J., Casero, A. y Morey, M. (2011). La integridad académica entre el alumnado universitario español. Estudios Pedagógicos (Valdivia), 37(1), 207-225.

Comas-Forgas, R., Urbina-Ramírez, S. y Gallardo, J. M. (2014). Programas de detección de plagio académico: conocimiento y uso por parte del profesorado de eso y consejos para su utilización. Edutec. Revista Electrónica de Tecnología Educativa, (49). Diponible en internet en: http://www.edutec.es/revista/ index.php/edutec-e/article/view/210

Dee, T. S. y Jacob, B. A. (2012). Rational Ignorance in Education A Field Experiment in Student Plagiarism. Journal of Human Resources, 47(2), 397-434.

Devlin, M. y Gray, K. (2007). In their own words: A qualitative study of the reasons Australian university students plagiarise. High Education Research \& Development, 26(2), 181-198.

Divan, A., Bowman, M. y Seabourne, A. (2015). Reducing unintentional plagiarism amongst international students in the biological sciences: An embedded academic writing development programme. Journal of Further and Higher Education, 39(3), 358-378.

Domínguez-Aroca, M.-I. (2012). Lucha contra el plagio desde las bibliotecas universitarias. El Profesional de La Información, 21(5), 498-503.

Enders, W. y Hoover, G. (2006). Plagiarism in the Economics Profession: A Survey. Challenge, 49(5), 92-107. 
Estrategias y herramientas tecnológicas para evitar el plagio...

Enders, W. y Hoover, G. A. (2004). Whose Line Is It? Plagiarism in Economics. Journal of Economic Literature, 42(2), 487-493.

Eret, E. y Gokmenoglu, T. (2010). Plagiarism in higher education: A case study with prospective academicians. Procedia - Social and Behavioral Sciences, 2(2), 3303-3307.

Eret, E., y Ok, A. (2014). Internet plagiarism in higher education: tendencies, triggering factors and reasons among teacher candidates. Assessment \& Evaluation in Higher Education, 39(8), 1002-1016.

Fang, F. C., Steen, R. G. y Casadevall, A. (2012). Misconduct accounts for the majority of retracted scientific publications. Proceedings of the National Academy of Sciences, 109(42), 1702817033.

Gibson, N. S. y Chester-Fangman, C. (2011). The librarian's role in combating plagiarism. Reference Services Review, 39(1), 132150.

Gómez-Espinosa, M., Francisco, V. y Moreno-Ger, P. (2016). El impacto del diseño de actividades en el plagio de Internet en educación superior. Comunicar, 24(48), 39-48.

Gullifer, J. M. y Tyson, G. A. (2014). Who has read the policy on plagiarism? Unpacking students' understanding of plagiarism. Studies in Higher Education, 39(7), 1202-1218.

Hernández-Ruiz, A. (2016). La política editorial antifraude de las revistas científicas españolas e iberoamericanas del JCR en Ciencias Sociales. Comunicar, 48(24), 19-27.

Honig, B. y Bedi, A. (2012). The fox in the hen house: A critical examination of plagiarism among members of the Academy of Management. Academy of Management Learning \& Education, 11(1), 101-123.

Ledwith, A. y Rísquez, A. (2008). Using anti-plagiarism software to promote academic honesty in the context of peer reviewed assignments. Studies in Higher Education, 33(4), 371-384. 
La Infodiversidad y el uso ético del conocimiento...

Levy, E. S. y Rakovski, C. C. (2006). Academic dishonesty: A zero tolerance professor and student registration choices. Research in Higher Education, 47(6), 735-754.

Ma, J. H., Wan, G. y Lu, E. Y. (2008). Digital Cheating and Plagiarism in Schools. Theory Into Practice, 47(3), 197-203.

Macdonald, R. y Carroll, J. (2006). Plagarism - a complex issue requiring a holistic institutional approach. Assessment $\&$ Evaluation in Higher Education, 31(2), 233-245.

McCabe, D. L. (2005). Cheating among college and university students: A North American perspective. International Journal for Educational Integrity, 1(1), 1-11.

McCabe, D. L., Treviño, L. K. y Butterfield, K. D. (2002). Honor codes and other contextual influences on academic integrity: A replication and extension to modified honor code settings. Research in Higher Education, 43(3), 357-378.

Owens, C. y White, F. A. (2013). A 5-year systematic strategy to reduce plagiarism among first-year psychology university students. Australian Journal of Psychology, 65(1), 14-21.

Park, C. (2003). In other (people's) words: Plagiarism by university students - literature and lessons. Assessment and Evaluation in Higher Education, 28(5), 471-488.

Patil, A. V. (2015). Plagiarism Software's Useful to Researchers : Analysis of few Softwares. Asian Journal of Multidisciplinary Studies, 3(12), 86-91.

Stapleton, P. (2012). Gauging the effectiveness of anti-plagiarism software: An empirical study of second language graduate writers. Journal of English for Academic Purposes, 11(2), 125-133.

Sureda-Negre, J., Comas-Forgás, R. y Oliver-Trobat, M. F. (2015). Plagio académico entre alumnado de secundaria y bachillerato : Diferencias en cuanto al género y la procrastinación. Comunicar, 44(21), 103-111. 
Estrategias y herramientas tecnológicas para evitar el plagio...

Sureda-Negre, J., Comas-Forgas, R. y Morey, M. (2009). Las causas del plagio académico entre el alumnado universitario según el profesorado. Revista Iberoamericana de Educación, 50, 197-220.

Walker, J. (2010). Measuring plagiarism: researching what students do, not what they say they do. Studies in Higher Education, 35(1), 41-59. 
La Infodiversidad y el uso ético del conocimiento individual y colectivo. La edición consta de 100 ejemplares. Coordinación editorial, Carlos Ceballos Sosa; revisión especializada, formación editorial y revisión de pruebas, LOGIEM, Análisis y Soluciones. Instituto de Investigaciones Bibliotecológicas y de la Información. Instituto de Investigaciones Bibliotecológicas y de la Información/UNAM. Fue impreso en papel cultural de $90 \mathrm{~g}$. Se terminó de imprimir en el mes de abril de 2017 en AGYS Alevin S. C., Retorno de Amores No. 14, colonia Del Valle, c.p. 03100, delegación Benito Juárez, México, CDMX. 